Nevada

Environmental

Restoration

Project

\title{
Closure Report for Corrective Action Unit 177: Mud Pits and Cellars \\ Nevada Test Site, Nevada
}

Controlled Copy No::

Revision No.: 0

February 2007

Approved for public release; further dissemination unlimited.

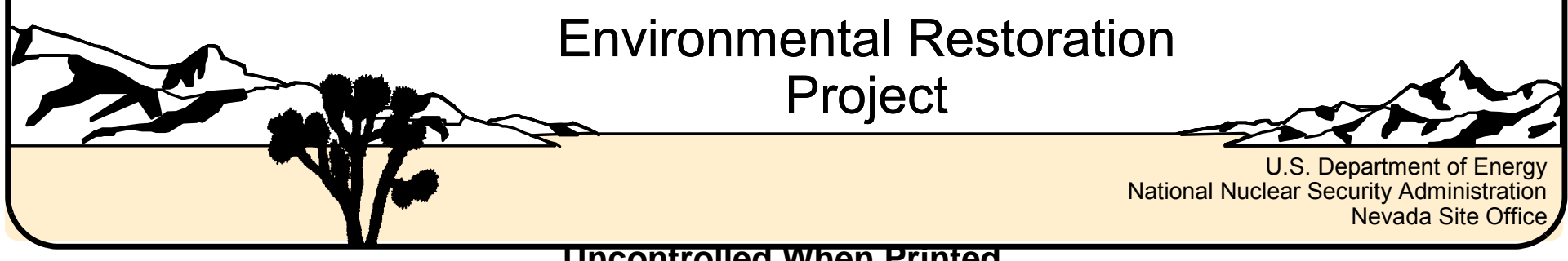


Available for public sale, in paper, from:

U.S. Department of Commerce

National Technical Information Service

5285 Port Royal Road

Springfield, VA 22161

Phone: 800.553.6847

Fax: 703.605.6900

Email: orders@ntis.gov

Online ordering: http://www.ntis.gov/ordering.htm

Available electronically at http://www.osti.gov/bridge

Available for a processing fee to U.S. Department of Energy and its contractors, in paper, from:

\section{U.S. Department of Energy}

Office of Scientific and Technical Information

P.O. Box 62

Oak Ridge, TN 37831-0062

Phone: 865.576.8401

Fax: 865.576.5728

Email: reports@adonis.osti.gov

Reference herein to any specific commercial product, process, or service by trade name, trademark, manufacturer, or otherwise, does not necessarily constitute or imply its endorsement, recommendation, or favoring by the United States Government or any agency thereof or its contractors or subcontractors. 


\section{CLOSURE REPORT FOR CORRECTIVE ACTION UNIT 177: MUD PITS AND CELLARS NEVADA TEST SITE, NEVADA}

U.S. Department of Energy, National Nuclear Security Administration

Nevada Site Office

Las Vegas, Nevada

Controlled Copy No.:

Revision No.: 0

February 2007

Approved for public release; further dissemination unlimited. 


\section{CLOSURE REPORT FOR \\ CORRECTIVE ACTION UNIT 177: \\ MUD PITS AND CELLARS \\ NEVADA TEST SITE, NEVADA}

Approved by: /s/ Peter A. Sanders

Date: 02/14/2007

Peter A. Sanders

Acting Federal Sub-Project Director

Industrial Sites Sub-Project

Approved by: /s/ Kevin J. Cabble

Date: 02/14/2007

Kevin J. Cabble

Acting Federal Project Director

Environmental Restoration Project 


\section{Table of Contents}

List of Figures. . . . . . . . . . . . . . . . . . . . . . .

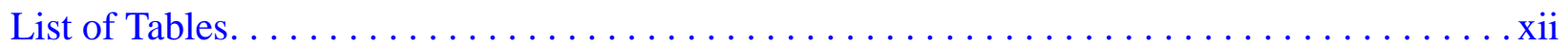

List of Acronyms and Abbreviations . . . . . . . . . . . . . . . . . .

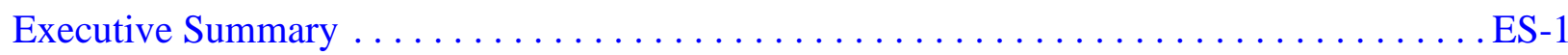

1.0 Introduction. . . . . . . . . . . . . . . . . . . . . . . . . . . 1

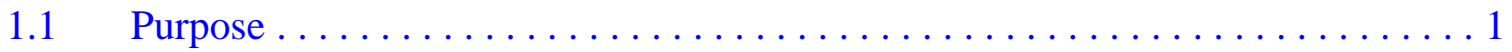

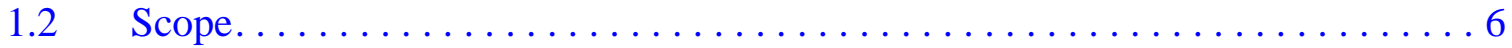

1.3 Document Contents. .......................... 6

1.3.1 Applicable Programmatic Plans and Documents ............. 7

1.3.2 Data Quality Objectives ....................... 8

1.3.3 Data Quality Assessment Summary .................. 8

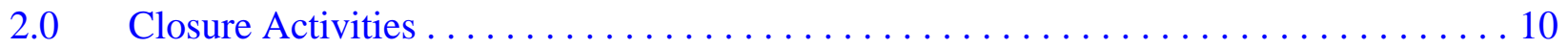

2.1 Description of Corrective Action Activities . . . . . . . . . . . . . 10

2.1.1 CAS 08-23-01, Mud Pit and Cellar ..................... 13

2.1.2 CAS 09-09-41, Unknown \#3 Mud Pit/Disposal Area . . . . . . . . . . . . 13

2.1.3 CAS 09-09-45, U-9bz PS \#1A Mud Pit (1) and Cellar . . . . . . . . . . 13

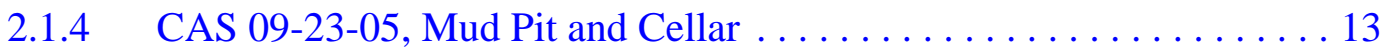

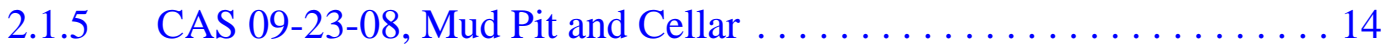

2.1.6 CAS 09-23-09, U-9itsx20 PS \#1A Cellar. . . . . . . . . . . . . . . . . 14

2.1.7 CAS 10-23-02, Mud Pit and Cellar . . . . . . . . . . . . . . 14

2.1.8 CAS 10-23-03, Mud Pit and Cellar . . . . . . . . . . . . . . 15

2.1.9 CAS 19-23-01, Mud Pit and Cellar . ................... 15

2.1.10 CAS 19-23-02, Cellar and Waste Storage Area . . . . . . . . . . . . 15

2.1.11 CAS 19-23-03, Cellar with Casing. . . . . . . . . . . . . . . 16

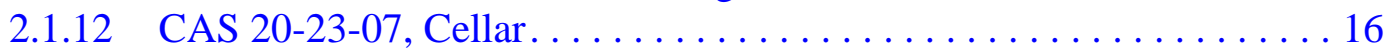

2.2 Deviations from CAU 177 SAFER Plan as Approved................ 16

2.3 Corrective Action Schedule as Completed . . . . . . . . . . . . . 17

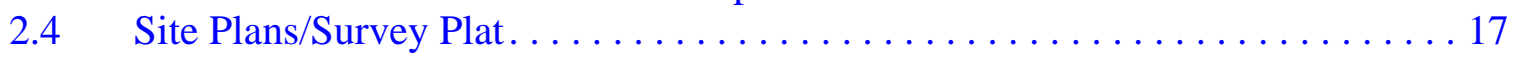

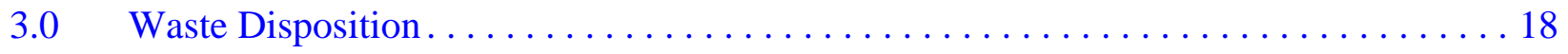

$3.1 \quad$ Waste Streams. . . . . . . . . . . . . . . . . . . . 18

$4.0 \quad$ Closure Verification Results. . . . . . . . . . . . . . . . . . . . . . . 19

$4.1 \quad$ Data Quality Assessment . . . . . . . . . . . . . . . . . . 21

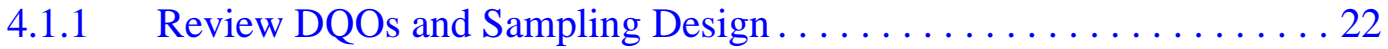

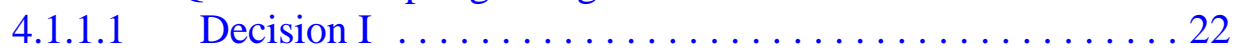

4.1.1.1.1 DQO Provisions To Limit False

Negative Decision Error ............ 23 


\section{Table of Contents (Continued)}

\subsection{DQO Provisions To Limit False}

Positive Decision Error . . . . . . . . . . . . 32

4.1.1.2 Decision II . . . . . . . . . . . . . . . . 32

4.1.1.3 Sampling Design . . . . . . . . . . . . . . . . . 32

4.1.2 Conduct a Preliminary Data Review . . . . . . . . . . . . . . 33

4.1.3 Select the Test and Identify Key Assumptions. . . . . . . . . . . . . . . 33

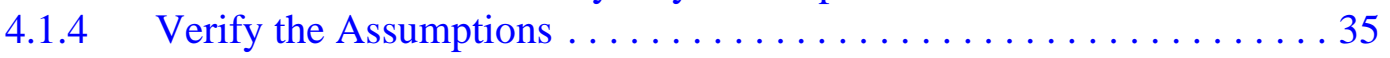

4.1.5 Draw Conclusions from the Data . . . . . . . . . . . . . . . 35

4.1.5.1 Decision Rules for Decision I . . . . . . . . . . 35

4.2 Use Restrictions . . . . . . . . . . . . . . . . . . . . . 36

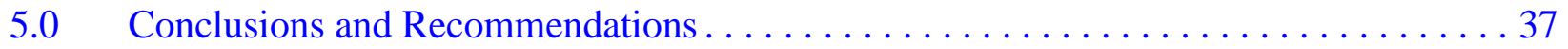

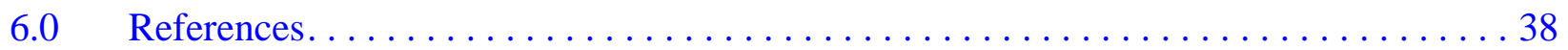

\section{Appendix A - Data Quality Objectives as Developed in the SAFER Plan}

A.1.0 DQOs as Developed in the SAFER Plan $\ldots \ldots \ldots \ldots \ldots \ldots \ldots \ldots \ldots \ldots \ldots$ A-1

A.2.0 Step 1 - State the Problem. .............................. A-2

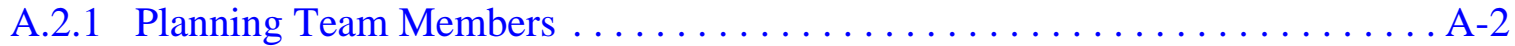

A.2.2 Conceptual Site Model . . . . . . . . . . . . . . . . . . . . . A-3

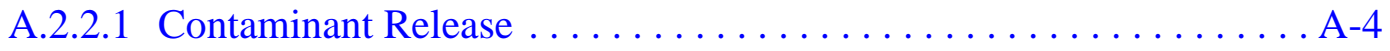

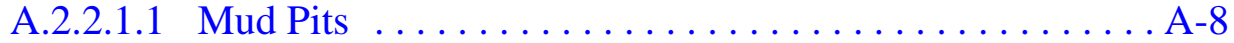

A.2.2.1.2 Cellars ......................... A

A.2.2.2 Potential Contaminants. ....................... A-10

A.2.2.3 Contaminant Characteristics. . . . . . . . . . . . . . . A-12

A.2.2.4 Site Characteristics . . . . . . . . . . . . . . . . . A-12

A.2.2.5 Migration Pathways and Transport Mechanisms . . . . . . . . . . . A-15

A.2.2.6 Exposure Scenarios . . . . . . . . . . . . . . A-16

A.3.0 Step 2 - Identify the Decisions . . . . . . . . . . . . . . . . . A-18

A.3.1 Decision Statements . . . . . . . . . . . . . . . . . A-18

A.3.2 Alternative Actions to the Decisions . . . . . . . . . . . . . . A-18

A.3.2.1 Alternative Actions to Decision I. . . . . . . . . . . . . . . . A-19

A.3.2.2 Alternative Actions to Decision II . . . . . . . . . . . . . . . A-19

A.4.0 Step 3 - Identify the Inputs to the Decision $\ldots \ldots \ldots \ldots \ldots \ldots \ldots \ldots \ldots \ldots \ldots \ldots$

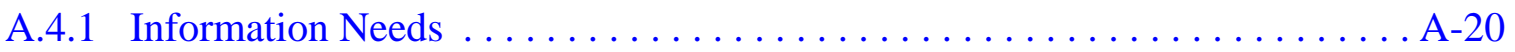

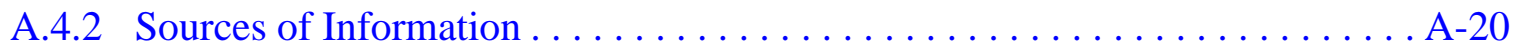

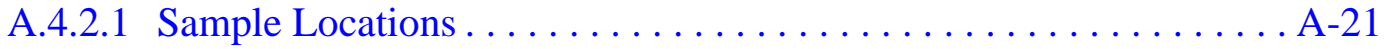




\section{Table of Contents (Continued)}

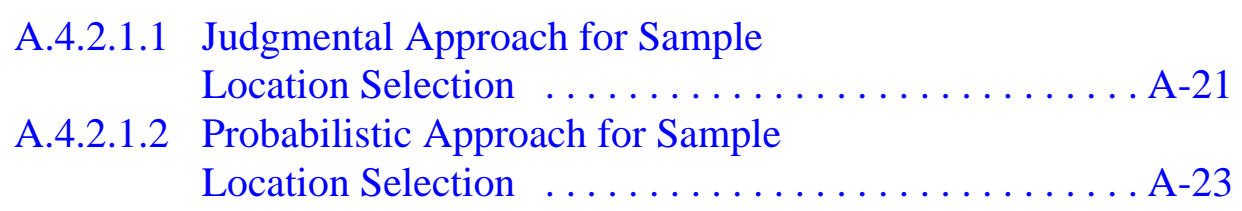

A.4.2.2 Analytical Methods .......................... A-25

A.5.0 Step 4 - Define the Boundaries of the Study $\ldots \ldots \ldots \ldots \ldots \ldots \ldots \ldots \ldots \ldots$ A-27

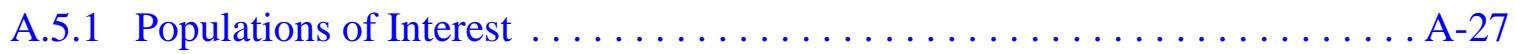

A.5.2 Spatial Boundaries ................................. A-28

A.5.3 Practical Constraints ................................

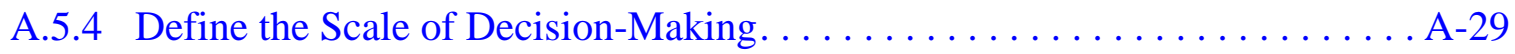

A.6.0 Step 5 - Develop a Decision Rule............................. A-30

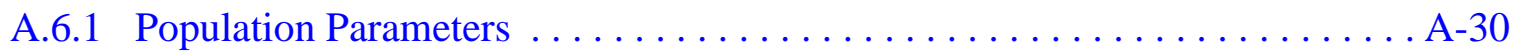

A.6.2 Decision Rules . . . . . . . . . . . . . . . . . . . . . . . . . A-30

A.6.3 Action Levels . ............................. A-31

A.6.4 Measurement and Analysis Sensitivity . . . . . . . . . . . . . . . . A-32

A.7.0 Step 6 - Tolerable Limits on Decision Errors . . . . . . . . . . . . . . . . . . . A-33

A.7.1 False Negative Decision Error $\ldots \ldots \ldots \ldots \ldots \ldots \ldots \ldots \ldots \ldots \ldots$ A-34

A.7.1.1 False Negative Decision Error for Judgmental Sampling . . . . . . . . A-34

A.7.1.2 False Negative Decision Error for Probabilistic Sampling ........ A-36

A.7.2 False Positive Decision Error . . . . . . . . . . . . . . . . . . . A-36

A.8.0 Step 7 - Optimize the Design for Obtaining Data.................. A-38

A.8.1 Mud Pit Sampling Design. ........................... A-39

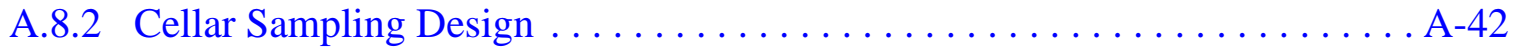

A.9.0 References.................................. A-45

\section{Appendix B - Closure Certification}

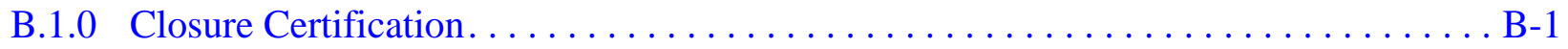

\section{Appendix C - As-Built Documentation}

C.1.0 As-Built Documentation. .............................. C-1

\section{Appendix D - Confirmation Sampling Test Results}

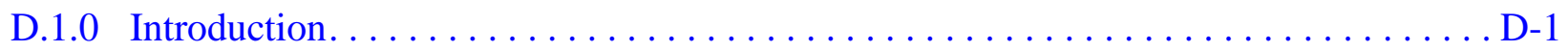




\section{Table of Contents (Continued)}

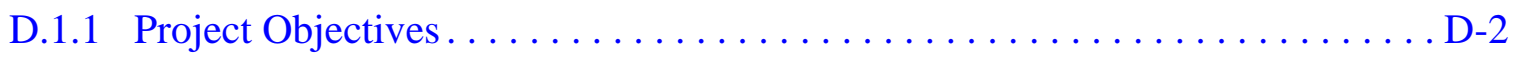

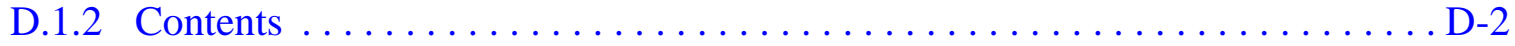

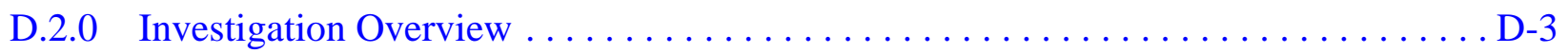

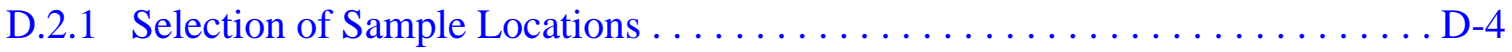

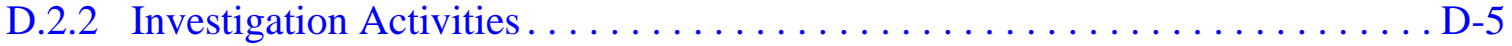

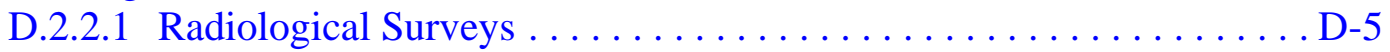

D.2.2.2 Field Screening. . . . . . . . . . . . . . . . . D-6

D.2.2.3 Surface and Subsurface Soil Sampling. . . . . . . . . . . . . . . . D-6

D.2.2.4 Waste Characterization Sampling ...................... D-7

D.2.3 Laboratory Analytical Information. . . . . . . . . . . . . . . . . . D-7

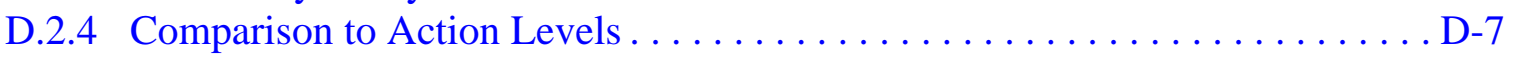

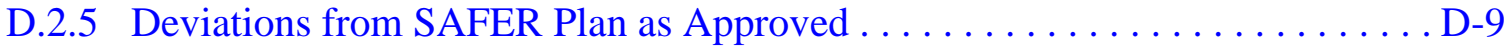

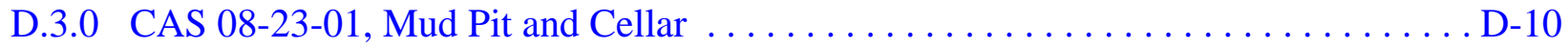

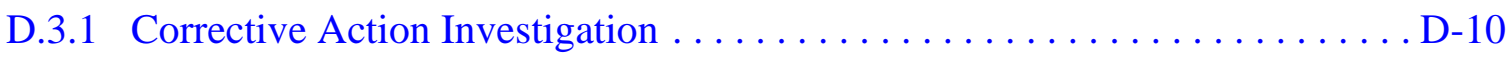

D.3.1.1 Field Screening. . . . . . . . . . . . . . . . . . D-10

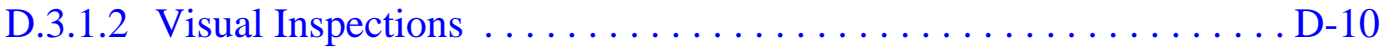

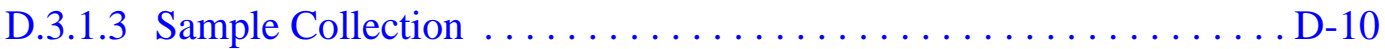

D.3.2 Investigation Results. . . . . . . . . . . . . . . . . . . D-13

D.3.2.1 Volatile Organic Compounds.... . . . . . . . . . . . . . . . D-14

D.3.2.2 Semivolatile Organic Compounds . . . . . . . . . . . . . . . D-14

D.3.2.3 Total Petroleum Hydrocarbons. . . . . . . . . . . . . . . . . . . D-16

D.3.2.4 RCRA Metals and Beryllium . . . . . . . . . . . . . . . D-16

D.3.2.5 Polychlorinated Biphenyls . . . . . . . . . . . . . . . D-17

D.3.2.6 Gamma-Emitting Radionuclides . . . . . . . . . . . . . . . . D-17

D.3.2.7 Plutonium, Strontium-90, and Uranium Isotopes. . . . . . . . . . . . D-19

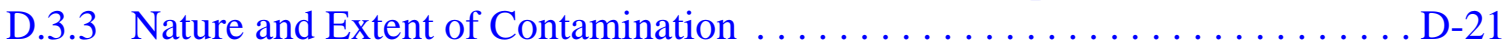

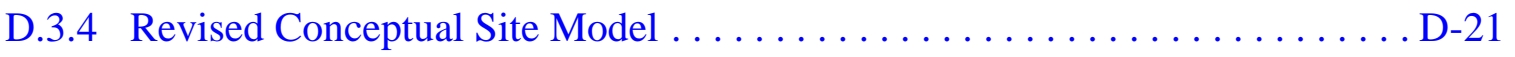

D.4.0 CAS 09-09-41, Unknown \#3 Mud Pit/Disposal Area . . . . . . . . . . . . . . . . . D-22

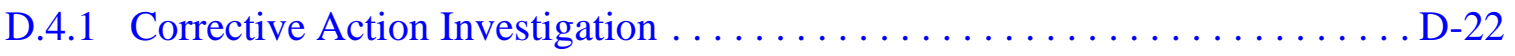

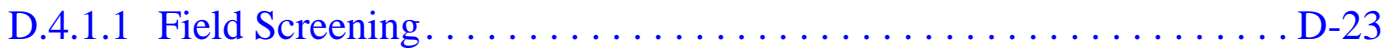

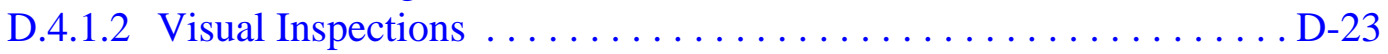

D.4.1.3 Sample Collection ......................... D-23

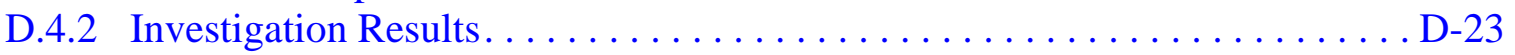

D.4.2.1 Gamma-Emitting Radionuclides . . . . . . . . . . . . . D-25

D.4.2.2 Plutonium, Strontium-90, and Uranium Isotopes. . . . . . . . . . . . D-26

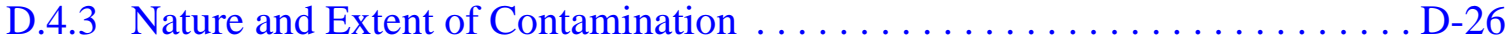

D.4.4 Revised Conceptual Site Model . . . . . . . . . . . . . . . . . . D-29 


\section{Table of Contents (Continued)}

D.5.0 CAS 09-09-45, U-9bz PS \#1A Mud Pit (1) and Cellar ................ D-31

D.5.1 Corrective Action Investigation $\ldots \ldots \ldots \ldots \ldots \ldots \ldots \ldots \ldots \ldots \ldots \ldots \ldots \ldots \ldots \ldots \ldots \ldots$

D.5.1.1 Field Screening. .....................

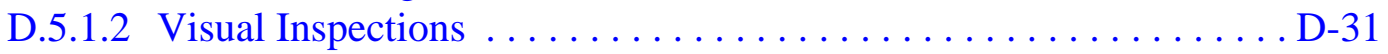

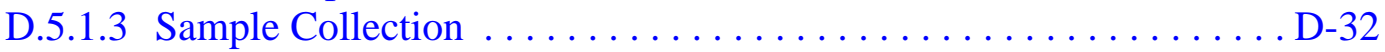

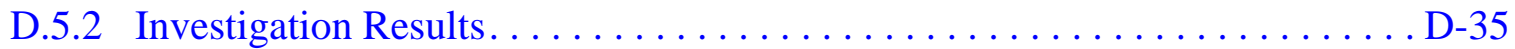

D.5.2.1 Volatile Organic Compounds................... D-36

D.5.2.2 Semivolatile Organic Compounds ................ D-37

D.5.2.3 Total Petroleum Hydrocarbons. . . . . . . . . . . . . . . D-37

D.5.2.4 Polychlorinated Biphenyls ...................... D-37

D.5.2.5 RCRA Metals and Beryllium ................... D-38

D.5.2.6 Gamma-Emitting Radionuclides .................. D-38

D.5.2.7 Plutonium, Strontium-90, and Uranium Isotopes. . . . . . . . . . D-41

D.5.3 Nature and Extent of Contamination ........................ D-43

D.5.4 Revised Conceptual Site Model ............................. D-44

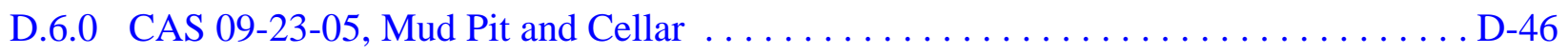

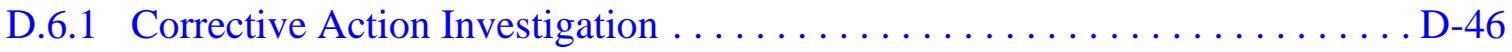

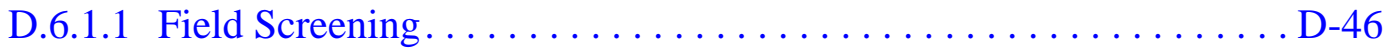

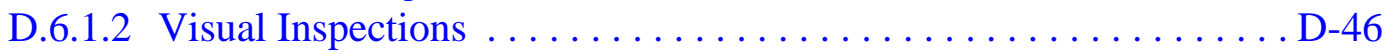

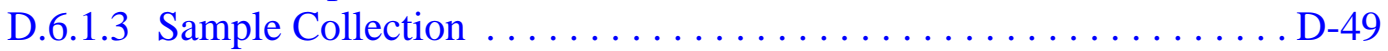

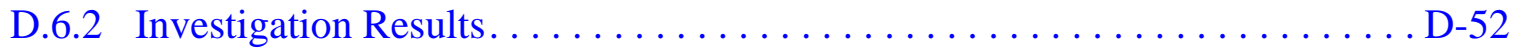

D.6.2.1 Volatile Organic Compounds.................... D-52

D.6.2.2 Semivolatile Organic Compounds ................ D-52

D.6.2.3 Total Petroleum Hydrocarbons. . . . . . . . . . . . . . . D-53

D.6.2.4 Polychlorinated Biphenyls ....................... D-53

D.6.2.5 RCRA Metals and Beryllium ..................... D-54

D.6.2.6 Gamma-Emitting Radionuclides ................ D-54

D.6.2.7 Plutonium, Strontium-90, and Uranium Isotopes. . . . . . . . . D-56

D.6.3 Nature and Extent of Contamination ...................... D-58

D.6.4 Revised Conceptual Site Model . . . . . . . . . . . . . . . . . . . . . . D-58

D.7.0 CAS 09-23-08, Mud Pit and Cellar ......................... D-59

D.7.1 Corrective Action Investigation $\ldots \ldots \ldots \ldots \ldots \ldots \ldots \ldots \ldots \ldots \ldots \ldots \ldots \ldots$

D.7.1.1 Field Screening.............................. D-59

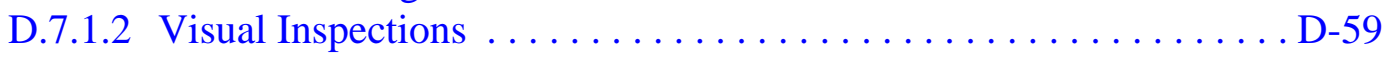

D.7.1.3 Sample Collection .......................... D-60

D.7.2 Investigation Results...............................

D.7.2.1 Volatile Organic Compounds..................... D-63

D.7.2.2 Semivolatile Organic Compounds .................. D-63 


\section{Table of Contents (Continued)}

D.7.2.3 Total Petroleum Hydrocarbons....................... D-63

D.7.2.4 Polychlorinated Biphenyls ......................... D-63

D.7.2.5 RCRA Metals and Beryllium ...................... D-64

D.7.2.6 Gamma-Emitting Radionuclides .................. D-64

D.7.2.7 Plutonium, Strontium-90, and Uranium Isotopes............. D-65

D.7.3 Nature and Extent of Contamination ....................... D-67

D.7.4 Revised Conceptual Site Model .......................... D-67

D.8.0 CAS 09-23-09, U-9itsx20 PS \#1A Cellar....................... D-68

D.8.1 Corrective Action Investigation $\ldots \ldots \ldots \ldots \ldots \ldots \ldots \ldots \ldots \ldots \ldots \ldots \ldots$

D.8.1.1 Field Screening. . . . . . . . . . . . . . . . . . . . 68

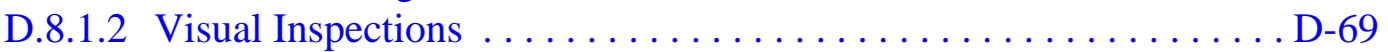

D.8.1.3 Sample Collection .......................... D-69

D.8.2 Investigation Results................................ D-69

D.8.2.1 Volatile Organic Compounds..................... D-71

D.8.2.2 Semivolatile Organic Compounds ................. D-71

D.8.2.3 Total Petroleum Hydrocarbons. . . . . . . . . . . . . . . . . D-71

D.8.2.4 Polychlorinated Biphenyls ....................... D-72

D.8.2.5 RCRA Metals and Beryllium ...................... D

D.8.2.6 Gamma-Emitting Radionuclides ................ D-72

D.8.2.7 Plutonium, Strontium-90, and Uranium Isotopes. . . . . . . . D-73

D.8.3 Nature and Extent of Contamination $\ldots \ldots \ldots \ldots \ldots \ldots \ldots \ldots \ldots \ldots \ldots \ldots \ldots \ldots \ldots \ldots$

D.8.4 Revised Conceptual Site Model ........................... D-74

D.9.0 CAS 10-23-02, Mud Pit and Cellar ........................ D

D.9.1 Corrective Action Investigation $\ldots \ldots \ldots \ldots \ldots \ldots \ldots \ldots \ldots \ldots \ldots \ldots \ldots \ldots \ldots$

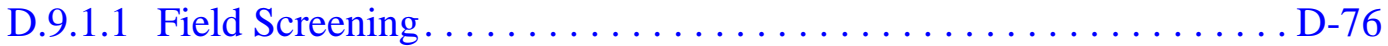

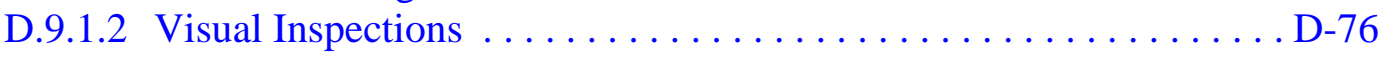

D.9.1.3 Sample Collection .......................... D-76

D.9.2 Investigation Results............................... D-78

D.9.2.1 Volatile Organic Compounds..................... D-79

D.9.2.2 Semivolatile Organic Compounds .................. D-80

D.9.2.3 Total Petroleum Hydrocarbons. . . . . . . . . . . . . . D-80

D.9.2.4 Polychlorinated Biphenyls ....................... D-81

D.9.2.5 RCRA Metals and Beryllium ...................... D-81

D.9.2.6 Gamma-Emitting Radionuclides .................. D-83

D.9.2.7 Plutonium, Strontium-90, and Uranium Isotopes. . . . . . . . . D-83

D.9.3 Nature and Extent of Contamination $\ldots \ldots \ldots \ldots \ldots \ldots \ldots \ldots \ldots \ldots \ldots \ldots \ldots$

D.9.4 Revised Conceptual Site Model ........................ D-83 


\section{Table of Contents (Continued)}

D.10.0 CAS 10-23-03, Mud Pit and Cellar $\ldots \ldots \ldots \ldots \ldots \ldots \ldots \ldots \ldots \ldots \ldots \ldots \ldots \ldots \ldots \ldots$

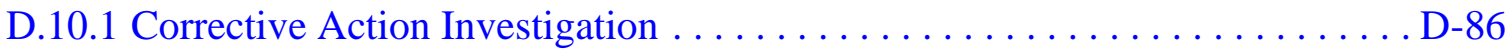

D.10.1.1 Field Screening. . . . . . . . . . . . . . . . . . . .

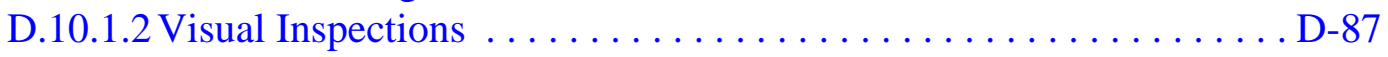

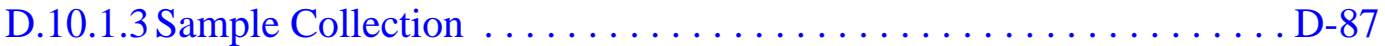

D.10.2 Investigation Results.............................. D-89

D.10.2.1 Volatile Organic Compounds.................. D-90

D.10.2.2 Semivolatile Organic Compounds ................ D-90

D.10.2.3 Total Petroleum Hydrocarbons. . . . . . . . . . . . . . . D-90

D.10.2.4 Polychlorinated Biphenyls ..................... D-90

D.10.2.5 RCRA Metals and Beryllium ................... D-90

D.10.2.6 Gamma-Emitting Radionuclides ................. D-92

D.10.2.7 Plutonium, Strontium-90, and Uranium Isotopes. . . . . . . . . D-92

D.10.3 Nature and Extent of Contamination . . . . . . . . . . . . . . . . D-92

D.10.4 Revised Conceptual Site Model .......................... D-92

D.11.0 CAS 19-23-01, Mud Pit and Cellar .......................... D-95

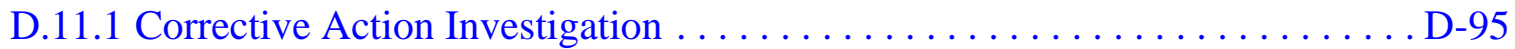

D.11.1.1 Field Screening. .............................

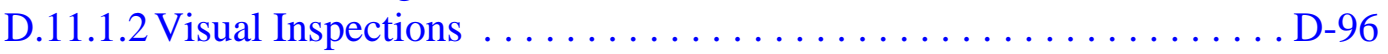

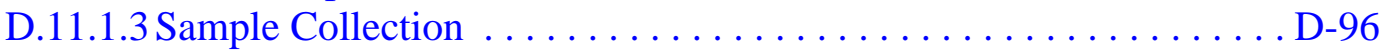

D.11.2 Investigation Results.............................. D-99

D.11.2.1 Volatile Organic Compounds................... D-99

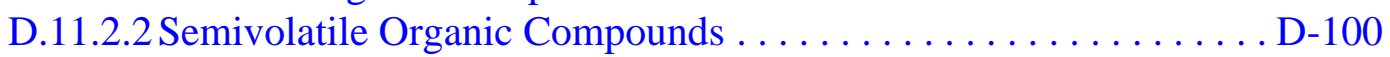

D.11.2.3 Total Petroleum Hydrocarbons. . . . . . . . . . . . . . D-100

D.11.2.4 Polychlorinated Biphenyls ..................... D-101

D.11.2.5 RCRA Metals and Beryllium ................... D-101

D.11.2.6 Gamma-Emitting Radionuclides ................ D-102

D.11.2.7 Plutonium, Strontium-90, and Uranium Isotopes. . . . . . . . D-102

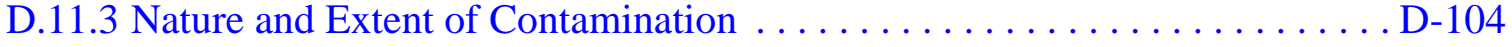

D.11.4 Revised Conceptual Site Model ......................... D-105

D.12.0 CAS 19-23-02, Cellar and Waste Storage Area ...................... D-106

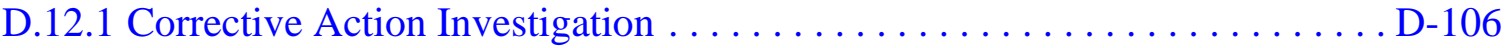

D.12.1.1 Field Screening.......................... D-107

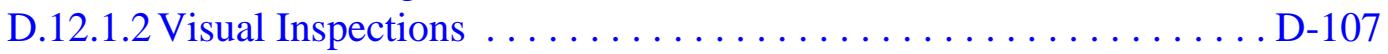

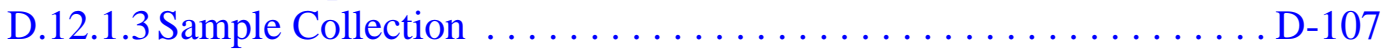

D.12.2 Investigation Results...............................

D.12.2.1 Volatile Organic Compounds..................... D-109

D.12.2.2 Semivolatile Organic Compounds ................ D-110 


\section{Table of Contents (Continued)}

D.12.2.3 Total Petroleum Hydrocarbons. . . . . . . . . . . . . . . . . D-110

D.12.2.4 Polychlorinated Biphenyls . . . . . . . . . . . . . . . . . D-110

D.12.2.5 RCRA Metals and Beryllium . . . . . . . . . . . . . . D-111

D.12.2.6 Gamma-Emitting Radionuclides . . . . . . . . . . . . . . D-111

D.12.2.7 Plutonium, Strontium-90, and Uranium Isotopes. . . . . . . . . . . . D-113

D.12.3 Nature and Extent of Contamination . . . . . . . . . . . . . . . . . D-113

D.12.4 Revised Conceptual Site Model . . . . . . . . . . . . . . . . . . D-114

D.13.0 CAS 19-23-03, Cellar with Casing . . . . . . . . . . . . . . . . . . . D-115

D.13.1 Corrective Action Investigation . . . . . . . . . . . . . . . . D-115

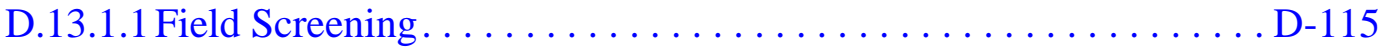

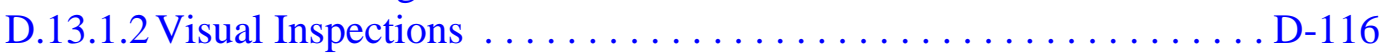

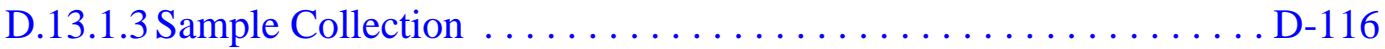

D.13.2 Investigation Results. . . . . . . . . . . . . . . . . . . . . D-116

D.13.2.1 Volatile Organic Compounds. . . . . . . . . . . . . . . . . D-118

D.13.2.2 Semivolatile Organic Compounds . . . . . . . . . . . . . . D-118

D.13.2.3 Total Petroleum Hydrocarbons. . . . . . . . . . . . . . . . . D-118

D.13.2.4 Polychlorinated Biphenyls . . . . . . . . . . . . . . . . D-119

D.13.2.5 RCRA Metals and Beryllium . . . . . . . . . . . . . . D-119

D.13.2.6 Gamma-Emitting Radionuclides . . . . . . . . . . . . . . D-120

D.13.2.7 Plutonium, Strontium-90, and Uranium Isotopes. . . . . . . . . . . D-120

D.13.3 Nature and Extent of Contamination . . . . . . . . . . . . . . . . . D-121

D.13.4 Revised Conceptual Site Model . . . . . . . . . . . . . . . . . D-122

D.14.0 CAS 20-23-07, Cellar . . . . . . . . . . . . . . . . . . . . . . . D-123

D.14.1 Corrective Action Investigation . . . . . . . . . . . . . . . . . D-123

D.14.1.1 Field Screening . . . . . . . . . . . . . . . . . . D-125

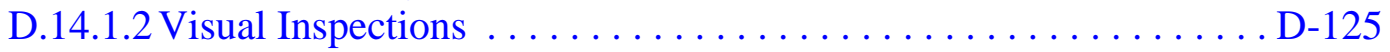

D.14.1.3 Sample Collection . . . . . . . . . . . . . . . . . . . . . D-125

D.14.2 Investigation Results. . . . . . . . . . . . . . . . . . . . D-126

D.14.2.1 Volatile Organic Compounds. . . . . . . . . . . . . . . . . . . D-126

D.14.2.2 Semivolatile Organic Compounds . . . . . . . . . . . . . . D-126

D.14.2.3 Total Petroleum Hydrocarbons. . . . . . . . . . . . . . . . . D-126

D.14.2.4 Polychlorinated Biphenyls . . . . . . . . . . . . . . . . . D-128

D.14.2.5 RCRA Metals and Beryllium .................... D-128

D.14.2.6 Gamma-Emitting Radionuclides . . . . . . . . . . . . . . . . D-129

D.14.2.7 Plutonium, Strontium-90, and Uranium Isotopes. . . . . . . . . . . . D-129

D.14.3 Nature and Extent of Contamination . . . . . . . . . . . . . . . . D -130

D.14.4 Revised Conceptual Site Model . . . . . . . . . . . . . . . . . . . . D-130 


\section{Table of Contents (Continued)}

D.15.0 Waste Disposition ............................. D-131

D.15.1 Investigation-Derived Waste . . . . . . . . . . . . . . . D-131

D.15.2 Waste Streams. . . . . . . . . . . . . . . . . . . D-131

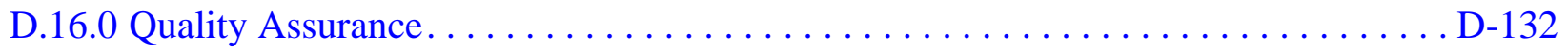

D.16.1 Data Validation. .............................. D-132

D.16.1.1 Tier 1 Evaluation . . . . . . . . . . . . . . . . . . . . D-132

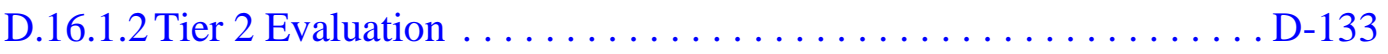

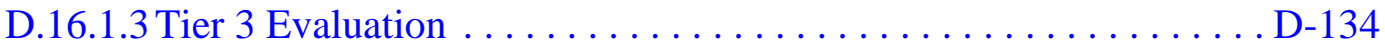

D.16.2 Field Quality Control Samples . . . . . . . . . . . . . . . . D-135

D.16.2.1 Laboratory Quality Control Samples . . . . . . . . . . . . . . . . D-135

D.16.3 Field Nonconformances . . . . . . . . . . . . . . . . . . D-136

D.16.4 Laboratory Nonconformances . . . . . . . . . . . . . . . D-136

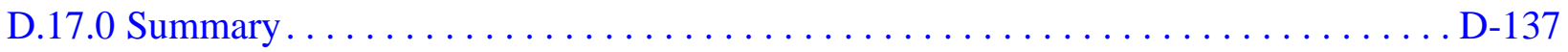

D.18.0 References. . . . . . . . . . . . . . . . . . . . . . . . . . . D-139

\section{Appendix E - Waste Disposition Documentation}

E.1.0 Waste Disposition Documentation $\ldots \ldots \ldots \ldots \ldots \ldots \ldots \ldots \ldots \ldots \ldots \ldots \ldots$.

Appendix F - Modifications to the Post-Closure Plan

F.1.0 Modifications to the Post-Closure Plan $\ldots \ldots \ldots \ldots \ldots \ldots \ldots \ldots \ldots \ldots \ldots$ F-1

\section{Appendix G - Use Restrictions}

G.1.0 Closure Activity Summary $\ldots \ldots \ldots \ldots \ldots \ldots \ldots \ldots \ldots \ldots \ldots \ldots \ldots \ldots \ldots \ldots$

\section{Appendix H - Risk Evaluation}

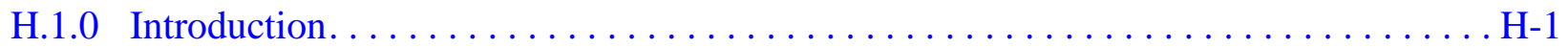

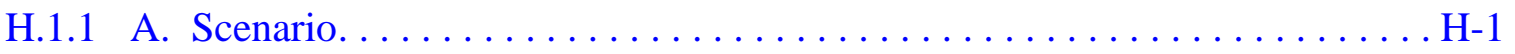

H.1.2 B. Site Assessment. . . . . . . . . . . . . . . . . . . . .

H.1.3 C. Site Classification and Initial Response Action . . . . . . . . . . . . . H-7

H.1.4 D. Development of Tier 1 Look-Up Table of RBSLs . . . . . . . . . . . . . H-7

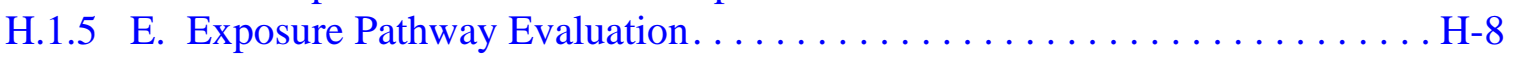

H.1.6 F. Comparison of Site Conditions with Tier 1 RBSLs . . . . . . . . . . H-8

H.1.7 G. Evaluation of Tier 1 Results . . . . . . . . . . . . . . . .

H.1.8 H. Tier 1 Remedial Action Evaluation . . . . . . . . . . . . . . . H-9 


\section{Table of Contents (Continued)}

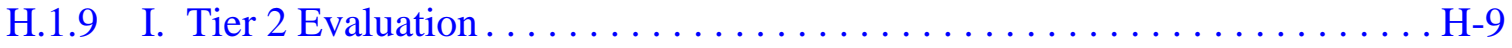

H.1.10 J. Development of Tier 2 Table of SSTLs . . . . . . . . . . . . . H-10

H.1.11 K. Comparison of Site Conditions with Tier 2 Table SSTLs . . . . . . . . . H-11

H.1.12 L. Tier 2 Remedial Action Evaluation. . . . . . . . . . . . . . . . . H-11

H.2.0 Recommendations. . . . . . . . . . . . . . . . . . . . . . . . H-12

H.3.0 References. . . . . . . . . . . . . . . . . . . . . . . . . . . . . . . . . . . . . . H-13

Appendix I - Nevada Division of Environmental Protection Comments 


\section{List of Figures}

Number

Title

Page

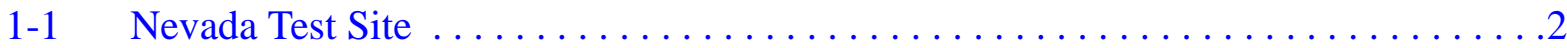

1-2 CAU 177, CAS Location Map................................

A.2-1 Conceptual Site Model for CAU $177 \ldots \ldots \ldots \ldots \ldots \ldots \ldots \ldots \ldots$ A-7

A.8-1 Proposed Sample Locations at Mud Pits ..................... A-41

A.8-2 Proposed Sample Locations at Cellars. . . . . . . . . . . . . . . . . A A-43

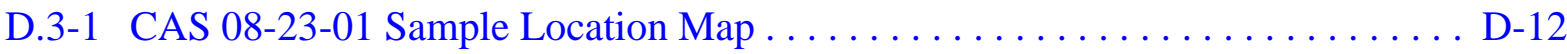

D.3-2 Core Material Showing Interface with Cellar Bottom (Location A12) . . . . . . D D-14

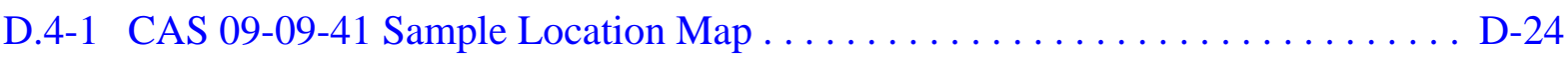

D.4-2 CAU 177 CASs in Relation to the B9a Radiological Plume.............. D-28

D.4-3 CAS 09-09-41 Radiological Walkover Survey ..................... D-30

D.5-1 CAS 09-09-45 Sample Location Map ......................... D-33

D.5-2 Core Material Showing Interface with Cellar Bottom (Location C11) ........ D-34

D.5-3 Core Material Showing Interface with Cellar Bottom (Location C12) . . . . . . D-35

D.5-4 CAS 09-09-45 Radiological Walkover Survey $\ldots \ldots \ldots \ldots \ldots \ldots \ldots \ldots$ D-45

D.6-1 Cellar Before Borehole Plugging Activities $\ldots \ldots \ldots \ldots \ldots \ldots \ldots \ldots$ D-48

D.6-2 Cellar After Borehole Plugging Activities................... D-48

D.6-3 CAS 09-23-05 Sample Location Map ....................... D-50 


\section{List of Figures (Continued)}

Number

Title

Page

D.6-4 Interface with Drilling Mud/Cuttings in Profile $\ldots \ldots \ldots \ldots \ldots \ldots \ldots \ldots$ D-51

D.6-5 Example of Soft Mud Sampled at CAS 09-23-05 Mud Pit ............. D-51

D.7-1 CAS 09-23-08 Sample Location Map ......................... D-61

D.8-1 CAS 09-23-09 Sample Location Map $\ldots \ldots \ldots \ldots \ldots \ldots \ldots \ldots \ldots \ldots \ldots \ldots \ldots$

D.9-1 CAS 10-23-02 Sample Location Map ........................ D-77

D.10-1 CAS 10-23-03 Sample Location Map $\ldots \ldots \ldots \ldots \ldots \ldots \ldots \ldots \ldots \ldots . \ldots \ldots$

D.11-1 CAS 19-23-01 Sample Location Map $\ldots \ldots \ldots \ldots \ldots \ldots \ldots \ldots \ldots \ldots$ D-97

D.12-1 CAS 19-23-02 Sample Location Map $\ldots \ldots \ldots \ldots \ldots \ldots \ldots \ldots \ldots \ldots \ldots . \ldots \ldots$

D.13-1 CAS 19-23-03 Sample Location Map ........................ D-117

D.14-1 CAS 20-23-07 Sample Location Map ........................ D-124

H.1-1 Risk-Based Corrective Action Decision Process .................... H-2 


\section{List of Tables}

Number

Title

Page

2-1 Corrective Action Investigation Activities Conducted at Each CAS

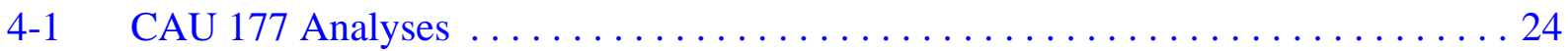

4-2 Analytes Failing Sensitivity Criteria $\ldots \ldots \ldots \ldots \ldots \ldots \ldots \ldots \ldots \ldots \ldots \ldots \ldots \ldots \ldots \ldots \ldots \ldots$

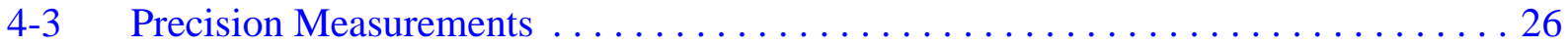

4-4 Accuracy Measurements . . . . . . . . . . . . . . . . . . 27

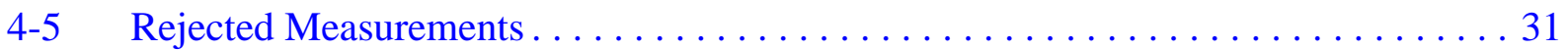

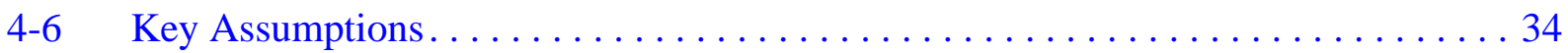

A.2-1 Data Quality Objective Meeting Participants $\ldots \ldots \ldots \ldots \ldots \ldots \ldots \ldots \ldots$ A-2

A.2-2 Conceptual Site Model Description of Elements for All CASs in CAU 177 . . . . A A-5

A.2-3 Analytical Program $\ldots \ldots \ldots \ldots \ldots \ldots \ldots \ldots \ldots \ldots \ldots \ldots \ldots \ldots \ldots \ldots \ldots \ldots \ldots \ldots$

A.2-4 Targeted Analytes for CAU $177 \ldots \ldots \ldots \ldots \ldots \ldots \ldots \ldots \ldots \ldots \ldots \ldots \ldots \ldots \ldots \ldots$

A.2-5 Physical Setting of CAU 177 Corrective Action Sites . . . . . . . . . . . . . A-13

A.2-6 Future Land-Use and Exposure Scenarios. . . . . . . . . . . . . A-17

A.4-1 Parameter Values Established by DQO Participants . . . . . . . . . . . . . A-24

A.4-2 Analytes Reported by Analytical Methods $\ldots \ldots \ldots \ldots \ldots \ldots \ldots \ldots \ldots \ldots$ A-26

A.5-1 Spatial Boundaries of CAU 177 Mud Pits and Cellars . . . . . . . . . . A-28

A.8-1 Summary of Sampling Approach and Data Evaluation for CAU 177 . . . . . . . A-38 


\section{List of Tables (Continued)}

Number

Title

Page

D.2-1 Corrective Action Investigation Activities Conducted at Each CAS .......... D-3

D.2-2 Laboratory Analytical Parameters and Methods, CAU 177 Investigation Samples . . . . . . . . . . . . . . . . . D-8

D.3-1 Samples Collected at CAS 08-23-01, Mud Pit and Cellar. . . . . . . . . . . D-11

D.3-2 Soil Sample Results for Total VOCs Detected Above Minimum Detectable Concentrations at CAS 08-23-01, Mud Pit and Cellar ................ D-15

D.3-3 Soil Sample Results for Total SVOCs Detected Above Minimum Detectable Concentrations at CAS 08-23-01, Mud Pit and Cellar .............. D-15

D.3-4 Soil Sample Results for TPH-DRO Detected Above Minimum Detectable Concentrations at CAS 08-23-01, Mud Pit and Cellar .............. D-16

D.3-5 Soil Sample Results for Metals Detected Above Minimum Detectable Concentrations at CAS 08-23-01, Mud Pit and Cellar .............. D-17

D.3-6 Soil Sample Results for PCBs Detected Above Minimum Detectable Concentrations at CAS 08-23-01, Mud Pit and Cellar .............. D-18

D.3-7 Soil Sample Results for Gamma-Emitting Radionuclides Detected Above Minimum Detectable Concentrations at CAS 08-23-01, Mud Pit and Cellar.... . D-18

D.3-8 Soil Sample Results for Isotopes Detected Above Minimum Detectable Concentrations at CAS 08-23-01, Mud Pit and Cellar ............. D-20

D.4-1 Samples Collected at CAS 09-09-41, Unknown \#3 Mud Pit/Disposal Area..... . . D-22

D.4-2 Soil Sample Results for Gamma-Emitting Radionuclides Detected Above Minimum Detectable Concentrations at CAS 09-09-41, Unknown \#3 Mud Pit/Disposal Area................................. D-25 


\section{List of Tables (Continued)}

Number

Title

Page

D.4-3 Soil Sample Results for Isotopes Detected Above Minimum Detectable Concentrations at CAS 09-09-41, Unknown \#3 Mud Pit/Disposal Area . . . . . . . D-27

D.5-1 Samples Collected at CAS 09-09-45, U-9bz PS \#1A Mud Pit (1) and Cellar. . . . D-32

D.5-2 Soil Sample Results for Total VOCs Detected Above Minimum Detectable Concentrations at CAS 09-09-45, U-9bz PS \#1A Mud Pit (1) and Cellar . . . . . . D-36

D.5-3 Soil Sample Results for Total SVOCs Detected Above Minimum Detectable Concentrations at CAS 09-09-45, U-9bz PS \#1A Mud Pit (1) and Cellar . . . . . . D-37

D.5-4 Soil Sample Results for TPH-DRO Detected Above Minimum Detectable Concentrations at CAS 09-09-45, U-9bz PS \#1A Mud Pit (1) and Cellar . . . . . . D-38

D.5-5 Soil Sample Results for Metals Detected Above Minimum Detectable Concentrations at CAS 09-09-45, U-9bz PS \#1A Mud Pit (1) and Cellar . . . . . . D-39

D.5-6 Soil Sample Results for Gamma-Emitting Radionuclides Detected Above Minimum Detectable Concentrations at CAS 09-09-45, U-9bz PS \#1A

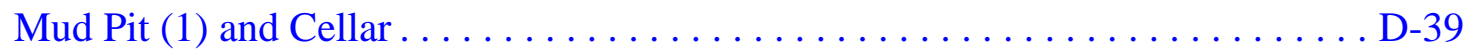

D.5-7 Soil Sample Results for Isotopes Detected Above Minimum Detectable Concentrations at CAS 09-09-45, U-9bz PS \#1A Mud Pit (1) and Cellar . . . . . . D-41

D.6-1 Samples Collected at CAS 09-23-05, Mud Pit and Cellar. . . . . . . . . . . . . . D-47

D.6-2 Soil Sample Results for Total VOCs Detected Above Minimum Detectable Concentrations at CAS 09-23-05, Mud Pit and Cellar ............. D-53

D.6-3 Soil Sample Results for TPH-DRO Detected Above Minimum Reporting Limits at CAS 09-23-05, Mud Pit and Cellar . . . . . . . . . . . . . D-54

D.6-4 Soil Sample Results for Metals Detected Above Minimum Detectable Concentrations at CAS 09-23-05, Mud Pit and Cellar . . . . . . . . . . . D-55 


\section{List of Tables (Continued)}

Number

Title

Page

D.6-5 Soil Sample Results for Gamma-Emitting Radionuclides Detected Above Minimum Detectable Concentrations at CAS 09-23-05, Mud Pit and Cellar . . . . . D-55

D.6-6 Soil Sample Results for Isotopes Detected Above Minimum Detectable Concentrations at CAS 09-23-05, Mud Pit and Cellar . . . . . . . . . . . D-57

D.7-1 Samples Collected at CAS 09-23-08, Mud Pit and Cellar. . . . . . . . . . . . . D-60

D.7-2 Soil Sample Results for Metals Detected Above Minimum Detectable Concentrations at CAS 09-23-08, Mud Pit and Cellar . . . . . . . . . . . D-64

D.7-3 Soil Sample Results for Gamma-Emitting Radionuclides Detected Above Minimum Detectable Concentrations at CAS 09-23-08, Mud Pit and Cellar . . . . D-65

D.7-4 Soil Sample Results for Isotopes Detected Above Minimum Detectable Concentrations at CAS 09-23-08, Mud Pit and Cellar . . . . . . . . . . . . . D-66

D.8-1 Samples Collected at CAS 09-23-09, U-9itsx20 PS \#1A Cellar . . . . . . . . . . . . D-68

D.8-2 Soil Sample Results for TPH-DRO Detected Above Minimum Detectable Concentrations at CAS 09-23-09, U-9itsx20 PS \#1A Cellar. . . . . . . . . . . . D-71

D.8-3 Soil Sample Results for Metals Detected Above Minimum Detectable Concentrations at CAS 09-23-09, U-9itsx20 PS \#1A Cellar. .

D.8-4 Soil Sample Results for Gamma-Emitting Radionuclides Detected Above Minimum Detectable Concentrations at CAS 09-23-09, U-9itsx20 PS \#1A Cellar . . . . . . . . . . . . . . . . . . . . . . D-73

D.8-5 Soil Sample Results for Isotopes Detected Above Minimum Detectable Concentrations at CAS 09-23-09, U-9itsx20 PS \#1A Cellar. . . . . . . . . . . . D-74

D.9-1 Samples Collected at CAS 10-23-02, Mud Pit and Cellar. . . . . . . . . . . . . D-75 


\section{List of Tables (Continued)}

Number

Title

Page

D.9-2 Soil Sample Results for Total VOCs Detected Above Minimum Detectable Concentrations at CAS 10-23-02, Mud Pit and Cellar . . . . . . . . . . . . D-79

D.9-3 Soil Sample Results for TPH-DRO Detected Above Minimum Detectable Concentrations at CAS 10-23-02, Mud Pit and Cellar . . . . . . . . . . . D-81

D.9-4 Soil Sample Results for PCBs Detected Above Minimum Detectable Concentrations at CAS 10-23-02, Mud Pit and Cellar . . . . . . . . . . . . D-82

D.9-5 Soil Sample Results for Metals Detected Above Minimum Detectable Concentrations at CAS 10-23-02, Mud Pit and Cellar . . . . . . . . . . . . D-82

D.9-6 Soil Sample Results for Gamma-Emitting Radionuclides Detected Above Minimum Detectable Concentrations at CAS 10-23-02, Mud Pit and Cellar . . . . D-84

D.9-7 Soil Sample Results for Isotopes Detected Above Minimum Detectable Concentrations at CAS 10-23-02, Mud Pit and Cellar . . . . . . . . . . D-85

D.10-1 Samples Collected at CAS 10-23-03, Mud Pit and Cellar. . . . . . . . . . . . D-86

D.10-2 Soil Sample Results for TPH-DRO Detected Above Minimum Detectable Concentrations at CAS 10-23-03, Mud Pit and Cellar . . . . . . . . . . . D-91

D.10-3 Soil Sample Results for Metals Detected Above Minimum Detectable Concentrations at CAS 10-23-03, Mud Pit and Cellar . . . . . . . . . . . D-91

D.10-4 Soil Sample Results for Gamma-Emitting Radionuclides Detected Above Minimum Detectable Concentrations at CAS 10-23-03, Mud Pit and Cellar . ... . D-93

D.10-5 Soil Sample Results for Isotopes Detected Above Minimum Detectable Concentrations at CAS 10-23-03, Mud Pit and Cellar . . . . . . . . . . . D-94

D.11-1 Samples Collected at CAS 19-23-01, Mud Pit and Cellar. . . . . . . . . . . . D-95 


\section{List of Tables (Continued)}

Number

Title

Page

D.11-2 Soil Sample Results for Total VOCs Detected Above Minimum Detectable

Concentrations at CAS 19-23-01, Mud Pit and Cellar . . . . . . . . . . D-100

D.11-3 Soil Sample Results for TPH-DRO Detected Above Minimum Detectable

Concentrations at CAS 19-23-01, Mud Pit and Cellar . . . . . . . . . . . D-101

D.11-4 Soil Sample Results for Metals Detected Above Minimum Detectable

Concentrations at CAS 19-23-01, Mud Pit and Cellar . . . . . . . . . . . D-102

D.11-5 Soil Sample Results for Gamma-Emitting Radionuclides Detected Above

Minimum Detectable Concentrations at CAS 19-23-01, Mud Pit and Cellar . . . D-103

D.11-6 Soil Sample Results for Isotopic Uranium Detected Above Minimum

Detectable Concentration at CAS 19-23-01, Mud Pit and Cellar . . . . . . . . . . D-104

D.12-1 Samples Collected at CAS 19-23-02, Cellar and Waste Storage Area . . . . . . . D-106

D.12-2 Soil Sample Results for Total VOCs Detected Above Minimum Detectable

Concentrations at CAS 19-23-02, Cellar and Waste Storage Area . . . . . . . . . D-109

D.12-3 Soil Sample Results for Total SVOCs Detected Above Minimum Detectable

Concentrations at CAS 19-23-02, Cellar and Waste Storage Area . . . . . . . . . D-110

D.12-4 Soil Sample Results for TPH-DRO Detected Above Minimum Detectable

Concentrations at CAS 19-23-02, Cellar and Waste Storage Area . . . . . . . . . D-111

D.12-5 Soil Sample Results for Metals Detected Above Minimum Detectable

Concentrations at CAS 19-23-02, Cellar and Waste Storage Area . . . . . . . . . . D-112

D.12-6 Soil Sample Results for Gamma-Emitting Radionuclides Detected Above

Minimum Detectable Concentrations at CAS 19-23-02, Cellar and

Waste Storage Area . . . . . . . . . . . . . . . . . . . . D-112 


\section{List of Tables (Continued)}

Number

Title

Page

D.12-7 Soil Sample Results for Isotopic Uranium Detected Above Minimum

Detectable Concentrations at CAS 19-23-02, Cellar and Waste Storage Area . . D-114

D.13-1 Samples Collected at CAS 19-23-03, Cellar with Casing . .

D-115

D.13-2 Soil Sample Results for Total VOCs Detected Above Minimum Detectable

Concentrations at CAS 19-23-03, Cellar with Casing. . . . . . . . . . . . D-118

D.13-3 Soil Sample Results for TPH-DRO Detected Above Minimum Detectable

Concentrations at CAS 19-23-03, Cellar with Casing. .............. D-119

D.13-4 Soil Sample Results for Metals Detected Above Minimum Detectable

Concentrations at CAS 19-23-03, Cellar with Casing. . . . . . . . . . . . D-120

D.13-5 Soil Sample Results for Gamma-Emitting Radionuclides Detected Above

Minimum Detectable Concentrations at CAS 19-23-03, Cellar with Casing .... D-121

D.13-6 Soil Sample Results for Isotopes Detected Above Minimum Detectable

Concentrations at CAS 19-23-03, Cellar with Casing. . . . . . . . . . . D-121

D.14-1 Samples Collected at CAS 20-23-07, Cellar .................... D-123

D.14-2 Soil Sample Results for Total VOCs Detected Above Minimum Detectable

Concentrations at CAS 20-23-07, Cellar.................... D-127

D.14-3 Soil Sample Results for TPH-DRO Detected Above Minimum Detectable

Concentrations at CAS 20-23-07, Cellar..................... D-127

D.14-4 Soil Sample Results for Metals Detected Above Minimum Detectable

Concentrations at CAS 20-23-07, Cellar..................... D-128

D.14-5 Soil Sample Results for Gamma-Emitting Radionuclides Detected Above

Minimum Detectable Concentrations at CAS 20-23-07, Cellar . . . . . . . . . . D-129 


\section{List of Tables (Continued)}

Number

Title

Page

D.14-6 Soil Sample Results for Isotopic Uranium Detected Above Minimum

Detectable Concentrations at CAS 20-23-07, Cellar . . . . . . . . . . . . . . . . D-130

H.1-1 Maximum Reported Value for Tier 1 Comparison $\ldots \ldots \ldots \ldots \ldots \ldots \ldots \ldots \ldots$. . . .

H.1-2 COPCs Detected Above PALs at CAU $177 \ldots \ldots \ldots \ldots \ldots \ldots \ldots \ldots \ldots$ 


\section{List of Acronyms and Abbreviations}

ASTM

bgs

CAI

CAS

CAU

CLP

COC

COPC

cps

CR

Cs

CSM

DOE

dpm

DQA

DQI

DRO

EPA

$\mathrm{Eu}$

FAL

FD

FFACO

FSL

FSR

$\mathrm{ft}$

GPS
American Society for Testing and Materials

Below ground surface

Corrective Action Investigation

Corrective Action Site

Corrective Action Unit

Contract Laboratory Program

Contaminant of concern

Contaminant of potential concern

Counts per second

Closure Report

Cesium

Conceptual site model

U.S. Department of Energy

Disintegrations per minute

Data quality assessment

Data quality indicator

Diesel-range organics

U.S. Environmental Protection Agency

Europium

Final action level

Field duplicate

Federal Facility Agreement and Consent Order

Field-screening level

Field-screening result

Foot

Global Positioning System 


\section{List of Acronyms and Abbreviations (Continued)}

GRO Gasoline-range organics

HWAA Hazardous waste accumulation area

ID Identification

IDW Investigation-derived waste

in. Inch

LCS Laboratory control sample

MB Method blank

MDC Minimum detectable concentration

$\mathrm{mg} / \mathrm{kg} \quad$ Milligram per kilogram

mi Mile

MS Matrix spike

NAC Nevada Administrative Code

NDEP Nevada Division of Environmental Protection

NIST National Institute for Standards and Technology

NNSA/NSO U.S. Department of Energy, National Nuclear Security Administration Nevada Site Office

NTS Nevada Test Site

NSTec National Security Technologies, LLC

PAL Preliminary action level

PCB Polychlorinated biphenyl

pCi/g Picocuries per gram

PPE Personal protective equipment

PRG Preliminary Remediation Goal

$\mathrm{Pu} \quad$ Plutonium

QA Quality assurance

QAPP Quality Assurance Project Plan

QC Quality control 


\section{List of Acronyms and Abbreviations (Continued)}

\begin{tabular}{|c|c|}
\hline RBCA & Risk-based corrective action \\
\hline RBCSR & Risk-based Closure Strategy Report \\
\hline RBSL & Risk-based screening level \\
\hline RCRA & Resource Conservation and Recovery Act \\
\hline RMA & Radioactive Material Area \\
\hline RPD & Relative percent difference \\
\hline SAFER & Streamlined Approach for Environmental Restoration \\
\hline SCL & Sample collection log \\
\hline SDG & Sample delivery group \\
\hline SNJV & Stoller-Navarro Joint Venture \\
\hline SSTL & Site-specific target level \\
\hline $\mathrm{Sr}$ & Strontium \\
\hline SS & Site Supervisor \\
\hline SVOC & Semivolatile organic compound \\
\hline $\mathrm{TPH}$ & Total petroleum hydrocarbons \\
\hline TTR & Tonopah Test Range \\
\hline $\mathrm{U}$ & Uranium \\
\hline UCL & Upper confidence limit \\
\hline URMA & Underground Radioactive Material Area \\
\hline VOC & Volatile organic compound \\
\hline VSP & Visual Sample Plan \\
\hline$\% \mathrm{R}$ & Percent recovery \\
\hline$\mu g / \mathrm{kg}$ & Micrograms per kilograms \\
\hline$\mu g / m g$ & Micrograms per milligram \\
\hline$\mu \mathrm{R} / \mathrm{hr}$ & Microentgens per hour \\
\hline
\end{tabular}




\section{Executive Summary}

This Closure Report presents information supporting the closure of Corrective Action Unit (CAU) 177: Mud Pits and Cellars, Nevada Test Site, Nevada. This Closure Report complies with the requirements of the Federal Facility Agreement and Consent Order (1996) that was agreed to by the State of Nevada, the U.S. Department of Energy, and the U.S. Department of Defense. The Corrective Action Sites (CASs) within CAU 177 are located within Areas 8, 9, 19, and 20 of the Nevada Test Site. Corrective Action Unit 177 comprises the following CASs:

- 08-23-01, Mud Pit and Cellar

- 09-09-41, Unknown \#3 Mud Pit/Disposal Area

- 09-09-45, U-9bz PS \#1A Mud Pit (1) and Cellar

- 09-23-05, Mud Pit and Cellar

- 09-23-08, Mud Pit and Cellar

- 09-23-09, U-9itsx20 PS \#1A Cellar

- 10-23-02, Mud Pit and Cellar

- 10-23-03, Mud Pit and Cellar

- 19-23-01, Mud Pit and Cellar

- 19-23-02, Cellar and Waste Storage Area

- 19-23-03, Cellar with Casing

- 20-23-07, Cellar

The purpose of this Closure Report is to provide documentation supporting the completed corrective actions and data that confirm the corrective actions implemented for CAU 177 CASs. To achieve this, the following actions were performed:

- Reviewed the current site conditions including the concentration and extent of contamination.

- Implemented any corrective actions necessary to protect human health and the environment.

- Disposed of corrective action and investigation wastes as appropriate.

- Documented Notice of Completion and closure of CAU 177 issued by Nevada Division of Environmental Protection.

From August 7 through August 31, 2006, closure activities were performed as set forth in the Streamlined Approach for Environmental Restoration Plan for CAU 177, Mud Pits and Cellars, Nevada Test Site, Nevada. The purposes of the activities as defined during the data quality objectives process were:

- To determine if contaminants of concern (COCs) are present. 
- If COCs are present, determine their nature and extent, implement appropriate corrective actions, and properly dispose of wastes, as appropriate.

Analytes detected during CAU 177 closure activities were evaluated against final action levels to determine COCs. Assessment of the data generated from closure activities indicates that no COCs are present at any of the CAU 177 CASs. Therefore, no further corrective action is required for all CAU 177 CASs.

The U.S. Department of Energy, National Nuclear Security Administration Nevada Site Office provides the following recommendations for all CAU 177 CASs:

- No further corrective action is required.

- A Notice of Completion to U.S. Department of Energy, National Nuclear Security Administration Nevada Site Office, is requested from the Nevada Division of Environmental Protection for closure.

- Move CAU 177 from Appendix III to Appendix IV of the Federal Facility Agreement and Consent Order. 


\subsection{Introduction}

This Closure Report (CR) presents information supporting closure of Corrective Action Unit (CAU) 177, Mud Pits and Cellars, Nevada Test Site (NTS), Nevada. This complies with the requirements of the Federal Facility Agreement and Consent Order (FFACO) (1996) agreed to by the State of Nevada, U.S. Department of Energy (DOE), and the U.S. Department of Defense. Corrective Action Unit 177 contains Corrective Action Sites (CASs) located in Areas 8, 9, 19, and 20 of the NTS. The NTS is located approximately 65 miles (mi) northwest of Las Vegas, Nevada (Figure 1-1).

Corrective Action Unit 177 is comprised of the 12 CASs that are shown on Figure 1-2 and listed below:

- 08-23-01, Mud Pit and Cellar

- 09-09-41, Unknown \#3 Mud Pit/Disposal Area

- 09-09-45, U-9bz PS \#1A Mud Pit (1) and Cellar

- 09-23-05, Mud Pit and Cellar

- 09-23-08, Mud Pit and Cellar

- 09-23-09, U-9itsx20 PS \#1A Cellar

- 10-23-02, Mud Pit and Cellar

- 10-23-03, Mud Pit and Cellar

- 19-23-01, Mud Pit and Cellar

- 19-23-02, Cellar and Waste Storage Area

- 19-23-03, Cellar with Casing

- 20-23-07, Cellar

\subsection{Purpose}

This CR provides justification for the closure of CAU 177 without further corrective action. This justification is based on process knowledge and the results of the closure activities conducted in accordance with the Streamlined Approach for Environmental Restoration (SAFER) Plan for Corrective Action Unit 177: Mud Pits and Cellars (NNSA/NSO, 2006). The CAU 177 SAFER Plan provides information relating to site history, as well as the scope and planning of the investigation. Therefore, this information will not be repeated in this CR.

Corrective Action Unit 177 consists of three CASs in Area 8, five CASs in Area 9, three CASs in Area 19, and one CAS in Area 20 (described below). All 12 CASs consist of mud pits and/or cellars 


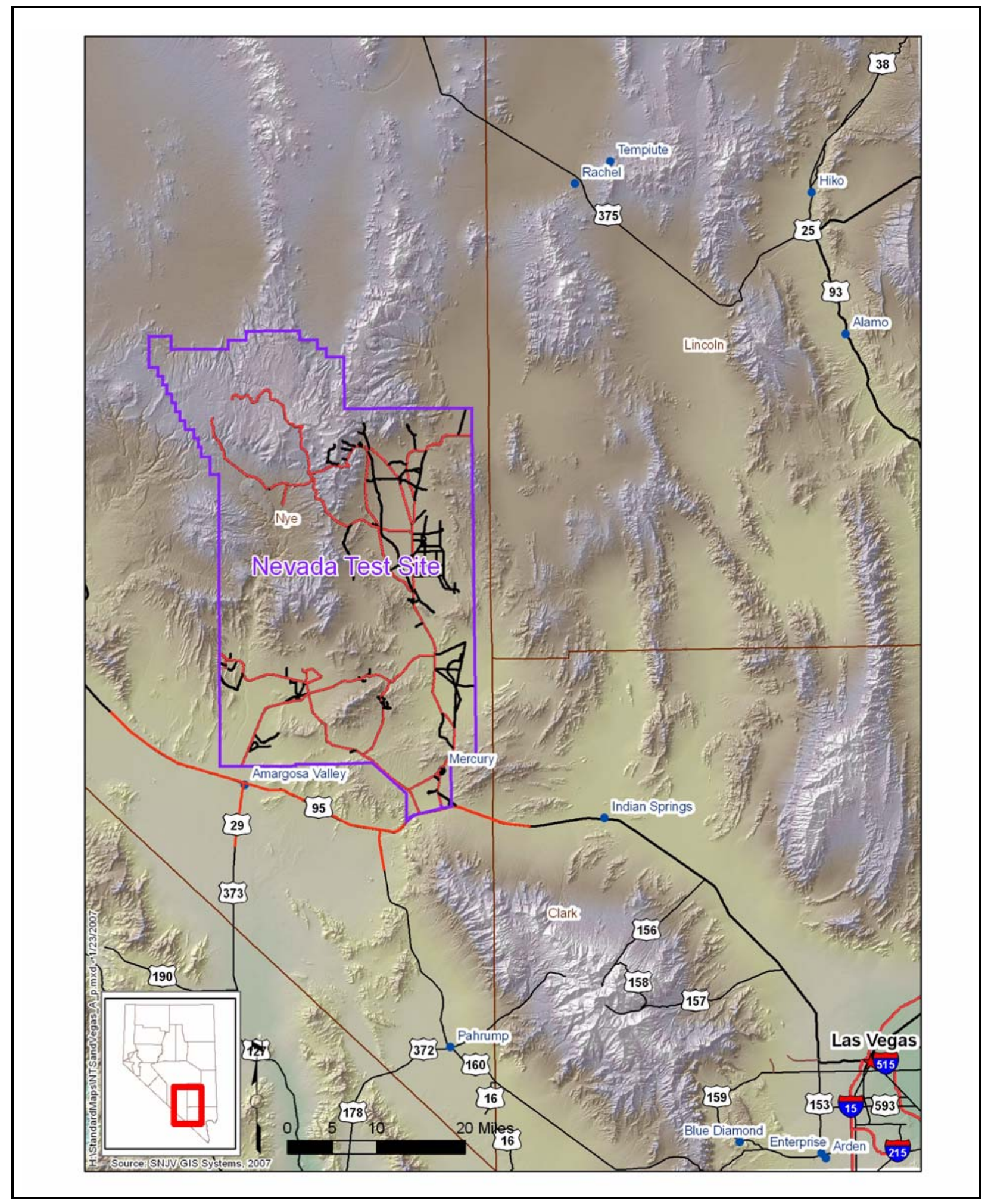

Figure 1-1

Nevada Test Site 


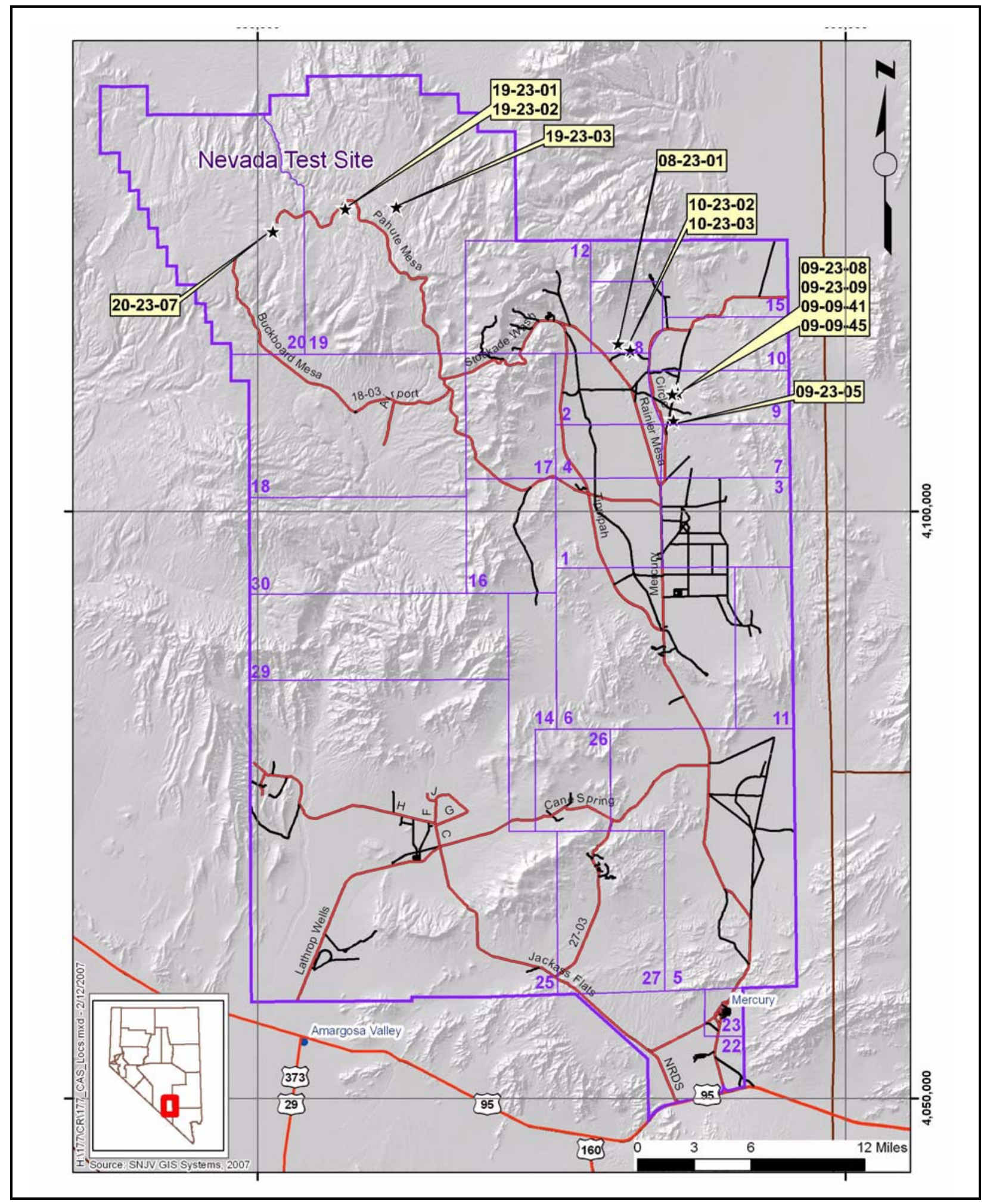

Figure 1-2

CAU 177, CAS Location Map 
constructed and used during drilling activities conducted at the NTS in support of underground nuclear weapons testing. In particular, the mud pits and cellars of 11 CASs were constructed as part of post-test drilling activities, and most are located within underground radioactive material areas (URMAs). The mud pit of CAS 09-09-41 is a disposal-type mud pit and the only one in CAU 177 that is not associated with a borehole.

Corrective Action Site 08-23-01 is within a fenced URMA in Area 8 of the NTS (Figure 1-2) on the north side of 2-07 Road. The CAS components identified for investigation include an open earthen mud pit and a backfilled cellar. Debris present did not interfere with investigation activities and is not considered part of this CAS.

Corrective Action Site 09-09-41 is in Area 9 of the NTS (Figure 1-2) within the posted Area 9 radioactive material area (RMA) on the west side of Old Mercury Highway, slightly north of 9-01 Road. The CAS components identified for investigation include an open earthen mud pit. Debris present did not interfere with investigation activities and is not considered part of this CAS.

Corrective Action Site 09-09-45 is within the posted Area 9 B-9a RMA on the west side of Old Mercury Highway, slightly north of 9-01 Road, in Area 9 of the NTS (Figure 1-2). The CAS components identified for investigation include an open earthen mud pit and a backfilled cellar. Debris present did not interfere with investigation activities and is not considered part of this CAS.

Corrective Action Site 09-23-05 is within a fenced URMA that is located on the east side of Old Mercury Highway in Area 9 (Figure 1-2), approximately 100 feet (ft) west of the U-9ch crater. The CAS components identified for investigation include a backfilled earthen mud pit and a backfilled cellar. Debris present did not interfere with investigation activities and is not considered part of this CAS.

Corrective Action Site 09-23-08 is within a fenced URMA located in Area 9, approximately $100 \mathrm{ft}$ east of Old Mercury Highway (Figure 1-2). The CAS components identified for investigation include a backfilled earthen mud pit and a backfilled cellar. No surface debris has been identified at this CAS. 
Corrective Action Site 09-23-09 is within a fenced URMA that is located on the east side of Old Mercury Highway in Area 9 (Figure 1-2), northeast of the U-9itsx20 crater. The CAS components identified for investigation include a backfilled cellar.

Corrective Action Site 10-23-02 is within a fenced URMA located in Area 8 (Figure 1-2), north of the U-10am3 crater. The CAS components identified for investigation include an open earthen mud pit and two backfilled cellars (“north” cellar and "west” cellar). Debris present did not interfere with investigation activities and is not considered part of this CAS.

Corrective Action Site 10-23-03 is within a fenced URMA located in Area 8 (Figure 1-2), north of the U-10am1 crater. The CAS components identified for investigation include an open earthen mud pit and a backfilled cellar. Debris present did not interfere with investigation activities and is not considered part of this CAS.

Corrective Action Site 19-23-01 is in Area 19 (Figure 1-2, northeast of the U-19ys crater. The CAS components identified for investigation include a backfilled earthen mud pit (not fenced or posted) and a backfilled cellar, which is located in a fenced URMA and has a single Controlled Area posting at the east side.

Corrective Action Site 19-23-02 is in Area 19 (Figure 1-2), several hundred feet northeast of CAS 19-23-01. The CAS components identified for investigation include a backfilled cellar that is not fenced or posted. The location of the cellar is marked by a steel pole at its center that is difficult to see due to the vegetation cover. The area immediately surrounding the metal flag is slightly subsided indicating that the cellar casing may have been removed. There is no debris present at this CAS.

Corrective Action Site 19-23-03 is within a fenced URMA off of Dead Horse Flats Road in Area 19 (Figure 1-2). The CAS components identified for investigation include an open cellar. The floor of the cellar is covered with approximately 4 inches (in.) of soil and contains borehole riser casing that extends several feet above the ground surface. Debris present is not included in the scope of the CAS.

Corrective Action Site 20-23-07 is within a posted Controlled Area approximately 1 mi past the Area 20 Camp off of the east side of Pahute Mesa Road in Area 20 (Figure 1-2). The CAS 
components identified for investigation include an open cellar, which is surrounded by orange construction fencing. The floor of the cellar is covered with approximately 4 in. of soil and contains borehole casing that has been cut off approximately $2 \mathrm{ft}$ above the cellar bottom. Debris present is not included in the scope of the CAS.

\subsection{Scope}

The corrective action of no further action was completed by demonstrating through environmental sample analytical results using probabilistic (mud pits) and judgmental (cellars) sampling that contaminants of concern (COCs) do not exist within the CASs. Activities used to implement this corrective action included the following:

- Performance of field screening

- Collection of surface and subsurface samples

- Collection of quality control (QC) samples

- Justification for no further corrective action

\subsection{Document Contents}

This CR is comprised of the following sections and appendices:

Section 1.0 - Introduction: Summarizes the purpose, scope, and contents of this CR.

Section 2.0 - Closure Activities: Summarizes the closure activities, schedule, and SAFER Plan deviations.

Section 3.0 - Waste Disposition: Discusses the wastes generated that are entered into an approved waste management system.

Section 4.0 - Closure Verification Results: Describes verification activities and results.

Section 5.0 - Conclusions and Recommendations: Recommends no further action for CAU 177 with supporting rationale.

Section 6.0 - References: Provides a list of documents referenced in preparation of this CR. 
Appendix A - Data Quality Objectives as Developed in the SAFER Plan for CAU 177: Provides the data quality objectives (DQOs) as presented in Appendix B of the CAU 177 SAFER Plan.

Appendix B - Closure Certification: This appendix is not applicable to CAU 177 because no closure activities have been completed.

Appendix C - As-Built Documentation: This appendix is not applicable to CAU 177.

Appendix D - Confirmation Sampling Test Results: Provides a description of the sampling activities and presents the analytical data used in evaluating the DQO decisions.

Appendix E - Waste Disposition Documentation: This appendix is not applicable to CAU 177.

Appendix F - Modifications to the Post Closure Plan: This appendix is not applicable to CAU 177.

Appendix G - Use Restrictions: This appendix is not applicable to CAU 177 because no use restrictions are recommended.

Appendix H - Risk Evaluation: Documents the CAU 177 risk assessment results.

Appendix I - Nevada Division of Environmental Protection (NDEP) Comments: Contains responses to NDEP comments on the draft version of this document.

\subsubsection{Applicable Programmatic Plans and Documents}

To ensure adherence to all project objectives, health and safety requirements, and quality control procedures, all closure activities were performed in accordance with the following documents:

- Streamlined Approach for Environmental Restoration Plan for CAU 177, Mud Pits and Cellars (NNSA/NSO, 2006)

- Industrial Sites Quality Assurance Project Plan (QAPP) (NNSA/NV, 2002)

- Federal Facility Agreement and Consent Order (1996), as amended 
- Project Execution Plan (SNJV, 2006)

- Standard operating procedures

\subsubsection{Data Quality Objectives}

This section contains a summary of the DQO process that is presented in Appendix A. The DQOs were developed to identify data needs, clearly define the intended use of environmental data, and design a data collection program to satisfy these purposes.

The problem statement for CAU 177 is: "Existing information on the nature and extent of potential contamination is insufficient to validate the assumptions used to select the corrective actions and to verify that closure objectives were met.” To address this statement, it is required that the following decisions are resolved:

- Decision I: "Is any COC present in environmental media within a mud pit or cellar?" For the judgmental sampling design, any analytical result for a contaminant of potential concern (COPC) above its corresponding final action level (FAL) will result in that COPC being designated as a COC. For the probabilistic sampling design, any significant COPC that has a 95 percent upper confidence limit (UCL) of the average concentration exceeding the FAL will result in that COPC being designated as a COC.

- Decision II: "If a COC is present, is sufficient information available to meet closure objectives?” Sufficient information is defined to include:

- Identifying the volume of media containing any COC, as bounded by analytical sample results in lateral and vertical directions.

- The information needed to characterize wastes for disposal.

The presence of a COC would require a corrective action. A corrective action may also be necessary if there is a potential for wastes that are present at a site to impose COCs into site environmental media if the wastes were to be released.

\subsubsection{Data Quality Assessment Summary}

The data quality assessment (DQA) presented in Section 4.1 includes an evaluation of the data quality indicators (DQIs) to determine the degree of acceptability and usability of the reported data in the decision-making process. The DQO process ensures that the right type, quality, and quantity of data 
will be available to support the resolution of those decisions at an appropriate level of confidence. Using both the DQO and DQA processes help to ensure that DQO decisions are sound and defensible.

The DQA process as presented in Section 4.1 is comprised of the following steps:

- Step 1: Review DQOs and Sampling Design

- Step 2: Conduct a Preliminary Data Review

- Step 3: Select the Test

- Step 4: Verify the Assumptions

- Step 5: Draw Conclusions from the Data

Based on the results of the DQA presented in Section 4.1, the information generated during the investigation supports the conceptual site model (CSM) assumptions and the data collected meet the DQOs and support their intended use in the decision-making process. 


\subsection{Closure Activities}

The following sections summarize the CAU 177 closure activities and deviations, if any, from the original scope of work. Detailed CAS-specific activities (e.g., field screening, visual surveys, sample collection) and the results of confirmation sampling for individual CAU 177 CASs are presented in Appendix D.

\subsection{Description of Corrective Action Activities}

The corrective action activities (i.e., the field investigations that supported the no further action determination) were performed from August 7 through August 31, 2006 (NNSA/NSO, 2006). Table 2-1 lists activities conducted in support of the no further action determination at each CAS. Refer to Appendix D for details of these activities.

Closure verification samples were collected from surface and subsurface soils. Surface soil samples were collected at open mud pits and cellars by hand excavation using a “scoop and trowel” technique. Subsurface soil samples were collected at backfilled mud pits using backhoe operations and at backfilled cellars using rotosonic drilling operations. All surface sample locations were initially field screened for alpha and beta/gamma radiation before the start of sampling. Additional screening was conducted during sample collection to both guide the investigation and serve as a health and safety control to protect the sampling team. Collected samples were shipped to an offsite laboratory to be analyzed for appropriate chemical and radiological parameters.

A combination of judgmental and probabilistic sampling schemes were implemented to select sample locations and evaluate analytical results, as outlined in the CAU 177 SAFER Plan (NNSA/NSO, 2006). Judgmental sampling allows the methodical selection of sample locations that target the populations of interest (defined in the DQOs) rather than non-selective random locations. Probabilistic sampling uses random sample locations in the absence of adequate biasing factors to define site-wide (i.e., mud pit) contamination characteristics. 
Table 2-1

Corrective Action Investigation Activities Conducted at Each CAS

\begin{tabular}{|c|c|c|c|c|c|c|c|c|c|c|c|c|}
\hline \multirow[b]{2}{*}{ Corrective Action Investigation Activities } & \multicolumn{12}{|c|}{ Corrective Action Site } \\
\hline & $\begin{array}{l}\text { 우 } \\
\text { ஸे } \\
\text { ஸे } \\
\text { o. }\end{array}$ & $\begin{array}{l}\text { 구 } \\
\text { o̊ } \\
\text { ó } \\
\text { த் }\end{array}$ & 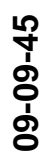 & $\begin{array}{l}\text { م } \\
\text { ஸे } \\
\text { ஸे }\end{array}$ & 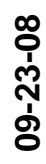 & $\begin{array}{l}\text { \& } \\
\text { ஸे } \\
\text { ஸे } \\
\text { ó }\end{array}$ & 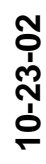 & $\begin{array}{l}\text { O̊ } \\
\text { N̦} \\
\text { ஸे }\end{array}$ & $\begin{array}{l}\text { 오 } \\
\text { ஸे } \\
\text { ஸे }\end{array}$ & $\begin{array}{l}\text { ָे } \\
\text { స் } \\
\text { ஸे }\end{array}$ & 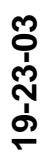 & 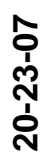 \\
\hline $\begin{array}{l}\text { Inspected and verified the CAS components identified in } \\
\text { the CAU } 177 \text { SAFER Plan. }\end{array}$ & $\mathrm{X}$ & $\mathrm{X}$ & $\mathrm{X}$ & $\mathrm{X}$ & $\mathrm{X}$ & $\mathrm{X}$ & $\mathrm{X}$ & $X$ & $\mathrm{X}$ & $\mathrm{X}$ & $\mathrm{X}$ & $\mathrm{X}$ \\
\hline $\begin{array}{l}\text { Performed underground/overhead utility checklist } \\
\text { inspections. }\end{array}$ & $\mathrm{X}$ & -- & $X$ & $\mathrm{X}$ & $\mathrm{X}$ & $\mathrm{X}$ & $\mathrm{X}$ & $x$ & $\mathrm{X}$ & $x$ & -- & -- \\
\hline $\begin{array}{l}\text { Performed visual surveys and site walkovers to identify } \\
\text { any changes to site conditions. }\end{array}$ & $\mathrm{X}$ & $\mathrm{X}$ & $\mathrm{X}$ & $\mathrm{X}$ & $\mathrm{X}$ & $\mathrm{X}$ & $\mathrm{X}$ & $\mathrm{X}$ & $\mathrm{X}$ & $x$ & $\mathrm{X}$ & $\mathrm{X}$ \\
\hline $\begin{array}{l}\text { Removed accumulated vegetation in order to access } \\
\text { mud pit sample locations. }\end{array}$ & -- & $X$ & $X$ & -- & -- & -- & -- & -- & -- & -- & -- & -- \\
\hline $\begin{array}{l}\text { Identified and staked predetermined GPS sample } \\
\text { locations at mud pits. }\end{array}$ & $X$ & $X$ & $X$ & $\mathrm{X}$ & $\mathrm{X}$ & -- & $\mathrm{X}$ & $\mathrm{X}$ & $\mathrm{X}$ & -- & -- & -- \\
\hline $\begin{array}{l}\text { Assessed orientation of existing or potentially buried } \\
\text { borehole casing at and performed visual surveys to } \\
\text { select biased sample locations at cellars. }\end{array}$ & $\mathrm{X}$ & -- & $\mathrm{X}$ & $\mathrm{X}$ & $\mathrm{X}$ & $\mathrm{X}$ & $\mathrm{X}$ & $X$ & $\mathrm{X}$ & $x$ & $\mathrm{X}$ & $\mathrm{X}$ \\
\hline Collected biased soil samples at cellars. & $\mathrm{X}$ & $\overline{--}$ & $\mathrm{X}$ & $\mathrm{X}$ & $x$ & $x$ & $\mathrm{X}$ & $\mathrm{X}$ & $\mathrm{X}$ & $\mathrm{X}$ & $\mathrm{X}$ & $\mathrm{X}$ \\
\hline Collected randomly located soil samples at mud pits. & $\mathrm{X}$ & $\mathrm{X}$ & $\mathrm{X}$ & $\mathrm{X}$ & $\mathrm{X}$ & -- & $\mathrm{X}$ & $\mathrm{X}$ & $\mathrm{X}$ & -- & -- & -- \\
\hline $\begin{array}{l}\text { Field screened samples for alpha and beta/gamma } \\
\text { radiation using a handheld survey instrument. }\end{array}$ & $\mathrm{X}$ & -- & -- & $X$ & $\mathrm{X}$ & $\mathrm{X}$ & $\mathrm{X}$ & $\mathrm{X}$ & $\mathrm{X}$ & $\mathrm{X}$ & $\mathrm{X}$ & $\mathrm{X}$ \\
\hline $\begin{array}{l}\text { Analyzed samples for gamma radiation using a } \\
\text { high-purity germanium gamma spectrometer } \\
\text { (Building 23-153, Mercury, NV). }\end{array}$ & -- & $\mathrm{X}$ & $\mathrm{X}$ & -- & -- & -- & -- & -- & -- & -- & -- & -- \\
\hline $\begin{array}{l}\text { Collected subsurface soil samples at cellars provided } \\
\text { refusal was not encountered. }\end{array}$ & $X$ & -- & $X$ & $X$ & -- & -- & -- & $x$ & $X$ & $x$ & -- & -- \\
\hline $\begin{array}{l}\text { Submitted select samples for off-site laboratory } \\
\text { analysis. }\end{array}$ & $X$ & $X$ & $X$ & $X$ & $X$ & $X$ & $X$ & $x$ & $X$ & $x$ & $X$ & $X$ \\
\hline
\end{tabular}

CAS $=$ Corrective action site

GPS $=$ Global positioning System

SAFER = Streamlined Approach to Environmental Restoration

-- = Not applicable to CAS 
For the judgmental sampling scheme, individual sample results (rather than average concentrations) are used to compare to FALs. Therefore, statistical methods to generate site characteristics (averages) were not necessary. If accurate previous information is available on the target site of interest, then the sampling may be designed to collect samples only from areas known to have the highest concentration levels on the target site. If the observed concentrations from these samples are below the action level, then a decision can be made that the site does not contain unsafe levels of the contaminant without the samples being truly representative of the entire area (EPA, 2006). The judgmental sampling design was used to determine the existence of contamination at specific locations. Confidence in judgmental sampling scheme decisions was established qualitatively by the validation of the CSM and justification that sampling locations are the most likely locations to contain a COC, if a COC exists.

For the probabilistic sampling scheme, the average contaminant concentrations at the site in question were used to compare to FALs. The averages from sample analytical results for each constituent are an estimation of the true average contaminant concentrations. Because the average contaminant concentrations from samples is only an estimate of the true (unknown) average, it is uncertain how well the sample averages represent the actual averages. To reduce the probability of making a false negative decision error, the 95th percent UCL of the respective sample contaminant concentration averages were used to compare to final action levels, if necessary. Therefore, by definition, there will be a 95 percent probability that the true average concentration is less than the 95th percent UCL of the sample average. As stipulated in Section C.1.2.1 of the CAU 177 SAFER Plan (NNSA/NSO, 2006), UCLs were only calculated for significant COPCs (i.e., COPCs detected in any sample within a CAS at a concentration greater than the PAL). If no COPCs are detected in any sample within a CAS at a concentration that exceeds the PAL, then it will be concluded that no COCs are present. Confidence in probabilistic sampling scheme decisions was established by the validation of the CSM, justification that sampling locations are representative of site conditions, demonstration that a sufficient number of samples were collected, and that contaminant distribution assumptions are valid and appropriate to the statistical test being performed. 


\subsubsection{CAS 08-23-01, Mud Pit and Cellar}

Eleven Decision I surface samples (0 to 12 in. below ground surface [bgs]) were collected from 10 locations within the mud pit. Four Decision I environmental samples were collected from two boreholes located within the cellar. One interface subsurface sample was collected from each of the two boreholes at a depth of 13 to $14 \mathrm{ft}$ bgs and at a depth of 15 to $16 \mathrm{ft}$ bgs. The interface with the cellar bottom was identified at $14 \mathrm{ft}$ bgs, marked by a lithology change from backfilled soil to a potential grout layer (2 to 6 in. thick).

\subsubsection{CAS 09-09-41, Unknown \#3 Mud Pit/Disposal Area}

Eleven Decision I randomly-located surface samples (0 to 12 in. bgs) were collected from 10 locations at the open mud pit. Decision I soil samples collected at CASs 09-09-41 were not screened for alpha and beta/gamma radiation during sample collection activities due to the elevated background readings in the Area 9 RMA.

\subsubsection{CAS 09-09-45, U-9bz PS \#1A Mud Pit (1) and Cellar}

Eleven Decision I randomly-located surface samples (0 to 12 in. bgs) were collected from 10 locations within the mud pit. The mud pit boundary of this CAS was re-established after tumbleweed clearing and new sample locations were generated using the Visual Sample Plan (VSP) model. Four Decision I environmental samples were collected from two boreholes located within the cellar. One interface subsurface sample was collected from each borehole at a depth of 8 to $9 \mathrm{ft}$ bgs and at a depth of 9.5 to $10.5 \mathrm{ft}$ bgs. The interface between backfill material with the cellar bottom was identified at $9 \mathrm{ft}$ bgs, marked by a lithology change from $8.5 \mathrm{ft}$ of pea-gravel with a small interval of sand at the base to a potential grout layer (up to 6 in. thick).

\subsubsection{CAS 09-23-05, Mud Pit and Cellar}

Eleven Decision I randomly-located subsurface soil samples were collected from 10 locations within the estimated boundary of the backfilled mud pit. The trench and soils brought to the surface through backhoe excavation were monitored for lithology changes and the interface with mud/cuttings and/or debris was consistently identified at 5 to $6 \mathrm{ft}$ bgs. Four Decision I environmental samples were collected from two boreholes located within the cellar. One subsurface interface sample was 
collected from each borehole at a depth of 6 to $7 \mathrm{ft}$ bgs (location D12), and 7 to $8 \mathrm{ft}$ bgs (location D11), and deeper subsurface samples were collected at a depth of 8 to $9 \mathrm{ft}$ bgs (location D12) and 9 to $10 \mathrm{ft}$ bgs (location D11). The interface with the cellar bottom was identified at 7 to $8 \mathrm{ft}$ bgs, marked by a lithology change from backfilled soil to a potential grout layer (up to $1 \mathrm{ft}$ thick).

\subsubsection{CAS 09-23-08, Mud Pit and Cellar}

Eleven Decision I randomly-located subsurface soil samples were collected from 10 locations within the estimated boundary of the backfilled mud pit. The trench and soils brought to the surface through backhoe excavation were monitored for lithology changes and the interface with mud/cuttings and/or debris was consistently identified at 3.5 to $5 \mathrm{ft}$ bgs. No obvious interface or debris was identified at the two northern most locations (E09 and E10) indicating that these points may be near the edge of the mud pit. Two environmental samples were collected from two boreholes within the cellar. One subsurface interface sample was collected from each borehole at a depth of 6 to $7 \mathrm{ft}$ bgs, above the interface between backfill material and the cellar bottom. The interface with the cellar bottom was identified at $7 \mathrm{ft}$ bgs, marked by a lithology change from backfilled soil to a layer of potential grout/concrete (at least $1.0 \mathrm{ft}$ thick). Drilling was terminated at $8 \mathrm{ft}$ bgs to avoid creating a migration pathway through the grout/concrete material; therefore, no subsurface samples were collected.

\subsubsection{CAS 09-23-09, U-9itsx20 PS \#1A Cellar}

Three Decision I environmental samples were collected at two borehole locations at a depth of 6 to $7 \mathrm{ft}$ bgs, above the interface between backfill material and the cellar bottom. The interface with the cellar bottom was identified at $7 \mathrm{ft}$ bgs, marked by a lithology change from backfilled soil to a layer of potential concrete (at least $2.0 \mathrm{ft}$ thick). Drilling was terminated at $9 \mathrm{ft}$ bgs to avoid creating a migration pathway through the concrete bottom; therefore, no subsurface samples were collected.

\subsubsection{CAS 10-23-02, Mud Pit and Cellar}

Eleven Decision I randomly-located surface samples were collected from 10 locations within the mud pit. The mud pit boundary of this CAS was re-established and new sample locations were generated using the VSP model because several original locations were in the mud pit berms. One subsurface interface sample was collected at the "west” cellar from each borehole location (G11 and G12) at 6 to $7 \mathrm{ft}$ bgs and one subsurface interface sample was collected at the "north” cellar from each borehole 
location (G13 and G14), also at 6 to $7 \mathrm{ft}$ bgs. The interface with the bottom of both cellars was identified at $8 \mathrm{ft}$ bgs, marked by a lithology change from backfilled soil to a layer of potential concrete. Drilling at both cellars was terminated at $8 \mathrm{ft}$ bgs to avoid creating a migration pathway through the concrete; therefore, no subsurface samples were collected.

\subsubsection{CAS 10-23-03, Mud Pit and Cellar}

Eleven Decision I randomly-located surface samples were collected from 10 locations within the mud pit. Four environmental samples were collected from two boreholes within the cellar. One subsurface interface sample was collected from each borehole at a depth of 11 to $12 \mathrm{ft}$ bgs and at a depth of 13 to $14 \mathrm{ft}$ bgs. The interface with the cellar bottom was identified at $12 \mathrm{ft}$ bgs, marked by a lithology change from backfilled soil to a thin layer (less than $0.5 \mathrm{ft}$ thick) of gray silt suspected to be grout. Plastic debris identified at the interface also supports the interpretation that this boundary is the cellar bottom.

\subsubsection{CAS 19-23-01, Mud Pit and Cellar}

Eleven Decision I randomly-located subsurface samples were collected from 10 locations within the estimated perimeter of the mud pit. The trench walls and soils brought to the surface through backhoe excavation were monitored for lithology changes and the interface between backfill material and drilling mud/cuttings ranged from 3 to 6 ft bgs. Debris (e.g., t-posts, wood, wire/cables, rope) was encountered at several locations just above the identified interface. Four Decision I environmental samples were collected from two boreholes within the cellar. One subsurface interface sample was collected from each borehole at a depth of 11 to $12 \mathrm{ft}$ bgs (location I12) and 12 to $13 \mathrm{ft}$ bgs (location I11) and deeper subsurface samples were collected at 12 to $13 \mathrm{ft}$ bgs (location I12) and 14 to $15 \mathrm{ft}$ bgs (location I11). The interface with the cellar bottom was identified at 12 to $13 \mathrm{ft}$ bgs, marked by a lithology change from backfilled soil to a layer (several inches thick) of potential grout.

\subsubsection{CAS 19-23-02, Cellar and Waste Storage Area}

Five characterization samples were collected during investigation activities at CAS 19-23-02.

Decision I environmental sampling activities included the collection of five biased soil samples from two borehole locations at the backfilled cellar. Two subsurface interface samples were collected from each borehole at a depth of 12 to $13 \mathrm{ft}$ bgs and three deeper subsurface samples (including one field 
duplicate [FD]) were collected at a depth of 14 to $15 \mathrm{ft}$ bgs. The interface with the cellar bottom was identified at $12 \mathrm{ft}$ bgs, marked by a lithology change from pea gravel (backfill) to a fine brown sand that extended to at least $15 \mathrm{ft}$ bgs. String/rope debris identified at the interface also supports the interpretation that this boundary is the cellar bottom.

\subsubsection{CAS 19-23-03, Cellar with Casing}

Three Decision I surface samples were collected from two locations within the open cellar. These locations were spaced equally on the most accessible side of the cellar floor, because no obvious biasing factors were identified. Subsurface samples were not collected due to the presence of a concrete bottom 4 in. beneath the surface soil.

\subsubsection{CAS 20-23-07, Cellar}

Three Decision I surface samples were collected from two locations within the open cellar. Soil and debris (miscellaneous wood, plastic, paper, and metal) at the surface of the cellar floor were screened for radioactivity for protection of worker health and safety and to guide selection of sample locations. During this survey an area of elevated beta radioactivity of approximately 22,000 disintegrations per minute (dpm) (6 times background field-screening level (FSL) of 3,641 dpm, beta) was identified at the southeast quadrant of the cellar floor. This area of elevated radioactivity was used as a biasing factor for selection of sample location L02. Because soil collected at location L02 did not exceed radiological FSLs, it is likely that the elevated beta levels identified at the surface may have been from debris that was not captured in the collected soil. Subsurface samples were not collected due to the presence of a concrete bottom 4 in. beneath the surface soil.

\subsection{Deviations from CAU 177 SAFER Plan as Approved}

To eliminate data validation and project evaluation time on radionuclides not crucial to project needs, the Stoller-Navarro Joint Venture (SNJV) isotopic gamma library listed in Table B.4-2 of the CAU 177 SAFER Plan (NNSA/NSO, 2006) was modified to only include radionuclides of interest (Snelling-Young, 2006). Radionuclides eliminated from the SNJV gamma library, effective July 1, 2006, and Table B.4-2 include aluminum-26, antimony-125, beryllium-7, bismuth-212, bismuth-214, cesium-134, cobalt-58, curium-243, and thorium-227. A radionuclide in a sample that 
is not included in the modified SNJV isotopic gamma library can still be detected and reported, because data validators review the gamma spectrum of each sample for unusual energy peaks.

\subsection{Corrective Action Schedule as Completed}

The corrective action activities for CAU 177 were conducted from August 7 through

August 31, 2006. Post-investigation verification sampling activities were not required.

\subsection{Site Plans/Survey Plat}

Site maps that show the components of each CAS (i.e., mud pit and/or cellar), sample locations, and geospatial coordinates of sample locations and other features of interest are presented for each CAS in Appendix D. 


\subsection{Waste Disposition}

Investigation-derived waste (IDW) generated during the field investigation activities of CAU 177 was segregated to the greatest extent possible, and waste minimization techniques were effectively integrated into the field activities to reduce generated waste. Controls were in place to minimize the use of hazardous materials and the unnecessary generation of hazardous and/or mixed waste. Decontamination activities were planned and executed in a manner that minimized the volume of rinsate generated to amounts that did not require management. No waste characterization samples were collected during the corrective action investigation (CAI).

No drums of waste (hazardous or non-hazardous) were generated during the field investigation and none of the five areas designated for hazardous waste accumulation areas (HWAAs) were established.

\subsection{Waste Streams}

Investigation-derived waste generated during the investigation was segregated into the following waste streams:

- Disposable personal protective equipment (PPE) and sampling equipment

- Decontamination rinsate

Disposable PPE and sampling equipment waste was inspected for gross contamination and radioactivity, managed as sanitary IDW, and disposed of in a designated sanitary industrial waste bin located at Building 23-153 and allocated for disposal at the NTS industrial waste landfill. Although decontamination rinsate was generated, the small volumes evaporated before the rinsate could be transferred for containment or sampled. Office waste and lunch trash was disposed of in designated sanitary waste bins allocated for disposal at the NTS sanitary landfill. 


\subsection{Closure Verification Results}

Closure verification results consist of the analytical results from environmental samples that demonstrate that closure objectives were met. For no further action, verification results demonstrate that COCs do not exist within the CASs.

The CAU 177 SAFER Plan (NNSA/NSO, 2006) identified that the right type, quality, and quantity of data were available to resolve the DQO decision statements. To verify that the dataset obtained as a result of this investigation supports the DQO decisions, a DQA was conducted. Section 4.1 provides a summary of the DQA and Section 4.2 summarizes any land-use restrictions for each CAS.

All CAU 177 sampling locations were accessible and sampling activities at planned locations were not restricted by buildings, storage areas, active operations, or aboveground and underground utilities. The analytical data support no further action as the closure option for all CAU 177 CASs. Four CASs (09-23-08, 09-23-09, 10-23-03, and 19-23-02) had no COPC concentrations in soil samples that were detected above the respective PALs. The following subsections provide a summary of the remaining CAS-specific closure sampling results presented in Appendix D. All of the soil samples collected at CAU 177 cellars that contained total petroleum hydrocarbons (TPH) above the PAL did not contain any of the hazardous constituents of diesel as defined by the American Society for Testing and Materials (ASTM) Method E 1739-95 (ASTM, 1995); therefore, TPH, diesel-range organics (DRO) is not a COC.

\section{CAS 08-23-01, Mud Pit and Cellar; CAS 09-23-05, Mud Pit and Cellar; CAS 19-23-01 Mud Pit and Cellar; CAS 19-23-03, Cellar with Casing; CAS 20-23-07, Cellar}

Total petroleum hydrocarbons were detected above the PAL in soil collected from the cellars of these CASs; however, the Tier 2 evaluation determined that none of the hazardous constituents of diesel were detected above PALs, so TPH-DRO is not a COC for these CASs. No COCs were identified at these CASs and the analytical data support no further action. 


\section{CAS 09-09-41, Unknown \#3 Mud Pit/Disposal Area and CAS 09-09-45, U-9bz PS \#1A} Mud Pit (1) and Cellar

The europium (Eu)-152 detected in concentrations above the PAL in soils samples collected at CASs 09-09-41 and 09-09-45, and the plutonium (Pu)-239 detected above the PAL at the mud pit of CAS 09-09-45, are not considered COCs, because their presence is assumed to be sourced from the adjacent Soils Project CASs 09-99-01 and 09-23-14, which consist of soils containing elevated radioactivity (see Sections D.4.3 and D.5.3); not from a release associated with these CASs. The analytical data obtained as a result of the investigation of these CASs, along with the radiological data presented in Sections D.4.3 and D.5.3, support no further action for this CAS. No COCs were identified at these CASs.

\section{CAS 10-23-02, Mud Pit and Cellar}

Total petroleum hydrocarbons were detected above the PAL in soil collected from the "west" cellar; however, the Tier 2 evaluation determined that none of the hazardous constituents of diesel were detected above PALs, so TPH-DRO is not a COC. Aroclor 1254 was detected above the PAL in a soil sample collected at the "west" cellar, but did not exceed the Tier 2 risk-based corrective action (RBCA) criteria of being present at a reasonable point of exposure. Therefore, it is not considered a COC. No COCs were identified at this CAS, and the analytical data support no further action for this CAS. Justification that Aroclor 1254 is not present at a reasonable point of exposure includes the following:

- Aroclor 1254 contamination is at depth and covered by $8 \mathrm{ft}$ of backfilled soil. A receptor would only be exposed to contamination if the buried soils were to be excavated.

- Migration of contaminants is limited laterally by the presence of a metal corrugated metal casing.

- Migration of contaminants is limited vertically by the presence of a concrete cellar bottom.

- The presence of a borehole will prevent future use of the cellar component of the CAS and serves in part as a use restriction. According to the National Security Technologies, LLC (NSTec) Borehole Management Project (Gustafson, 2006), the borehole (U-10am \#3 PS \#1A) associated with the west cellar is on the current list of plugback candidates; however, no plugback work has been scheduled. Because plugback activities would only involve excavating soil to the depth of the riser casing (typically 3 to $4 \mathrm{ft}$ above the cellar floor), the 
soil interval sampled as part of this investigation is not expected to be disturbed; therefore, there is little potential for future exposure. To assure that the soil containing Aroclor 1254 will not be disturbed, the Borehole Management Project will be informed of the results of the investigation at CAS 10-23-02.

- The CAS is currently located within a fenced area that is posted as an URMA.

\subsection{Data Quality Assessment}

The DQA process is the scientific evaluation of the actual investigation results to determine whether the DQO criteria established in the CAU 177 SAFER Plan (NNSA/NSO, 2006) were met and whether DQO decisions can be resolved at the desired level of confidence. The DQO process ensures that the right type, quality, and quantity of data will be available to support the resolution of those decisions at an appropriate level of confidence. Using both the DQO and DQA processes helps to ensure that DQO decisions are sound and defensible.

The DQA involves five steps that begin with a review of the DQOs and end with an answer to the DQO decisions. The five steps are summarized briefly as follows:

Step 1: Review DQOs and Sampling Design - Review the DQO process to provide context for analyzing the data. State the primary statistical hypotheses, confirm the limits on decision errors for committing false negative (Type I) or false positive (Type II) decision errors, and review any special features, potential problems, or any deviations to the sampling design.

Step 2: Conduct a Preliminary Data Review - A preliminary data review should be performed by reviewing quality assurance (QA) reports and inspecting the data both numerically and graphically, validating and verifying the data to ensure that the measurement systems performed in accordance with the criteria specified, and using the validated dataset to determine whether the quality of the data is satisfactory.

Step 3: Select the Test - Select the test based on the population of interest, population parameter, and the hypotheses. Identify the key underlying assumptions that could cause a change in one of the DQO decisions. 
Step 4: Verify the Assumptions - Perform tests of assumptions. If data are missing or censored, determine the impact on DQO decision error.

Step 5: Draw Conclusions from the Data - Perform the calculations required for the test.

\subsubsection{Review DQOs and Sampling Design}

This section contains a review of the DQO process presented in Appendix A. The DQO decisions are presented with the DQO provisions to limit false negative or false positive decision errors. Special features, potential problems, or any deviations to the sampling design are also presented.

\subsubsection{Decision I}

The Decision I statement as presented in the CAU 177 SAFER Plan: "Is any COC present in environmental media within a mud pit or cellar?”

\section{Decision I Rules:}

- If the population parameter of any COPC in a target population for a cellar exceeds the corresponding FAL, then that COPC is identified as a COC, and Decision II samples will be collected.

- If the population parameter of any COPC in a target population for a mud pit exceeds the corresponding FAL, then that COPC is identified as a COC, and it will be determined that the residual mud is contaminated and bounded by the Decision I sampling and the berm of the mud pit. Because contamination is expected to be bound within the matrix of the drilling mud, further evaluation (i.e., Decision II sampling) is not necessary.

- If a COC is detected, then the Decision II statement must be resolved.

- If COCs are not identified, then the decision will be that no further corrective action is necessary.

Population Parameter: For judgmental sampling results, the population parameter is the maximum observed sample result from each individual sample. For probabilistic sampling results, the population parameter is the 95 percent UCL of the sample population average concentration of each contaminant from all analytical samples collected at a single mud pit. 


\subsection{DQO Provisions To Limit False Negative Decision Error}

A false negative decision error (where consequences are more severe) was controlled by meeting the following criteria:

1. Having a high degree of confidence that locations selected will identify COCs if present anywhere within the CAS (for probabilistic sampling at mud pits, determining the appropriate population distributions and ensuring a sufficient sample size was collected).

2. Having a high degree of confidence that analyses conducted will be sufficient to detect any COCs present in the samples.

3. Having a high degree of confidence that the dataset is of sufficient quality and completeness.

\section{Criterion 1:}

The following methods were used to select sample locations.

1. Mud pit sample locations were predetermined using the VSP software, in which 10 locations were identified within the mud pit perimeter using a triangular grid pattern and a randomly selected start location. Because no significant COPCs were detected, UCLs were not calculated, and it was determined that a sufficient number of samples were collected.

2. Cellar sample locations were distributed equally on each side of the borehole casing or distributed equally on the side of the cellar that was accessible for the appropriate sample collection method (i.e., rotosonic drilling at backfilled cellars or hand scoop at open cellars)

3. Sample locations at backfilled cellars and mud pits associated with the presence of debris, staining, and lithology changes (i.e., identification of subsurface interfaces) were selected by visual observation.

4. Sample locations associated with radiological field-screening results (FSRs) were selected by screening the area using a handheld NE Technology Electra.

5. Sample locations associated with professional judgement based on acceptable knowledge were selected by:

- Source and location of release

- Chemical nature and fate properties

- Physical transport pathways and properties

- Transport drivers 


\section{Criterion 2:}

All samples were analyzed using the chemical and radiological methods listed in Table 7-2 and Table 7-3 of the CAU 177 SAFER Plan (NNSA/NSO 2006). Samples collected at mud pits were submitted for radiological analyses and samples collected at cellars were submitted for chemical and radiological analyses. Table 4-1 provides a reconciliation of samples analyzed to the planned analytical program.

Table 4-1

CAU 177 Analyses

\begin{tabular}{|c|c|c|c|c|c|c|c|c|c|c|}
\hline \multirow[b]{2}{*}{ CAS } & \multicolumn{10}{|c|}{ Analytes } \\
\hline & 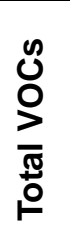 & $\begin{array}{l}0 \\
0 \\
0 \\
\frac{\pi}{\pi} \\
0 \\
0\end{array}$ & 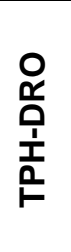 & $\begin{array}{l}0 \\
\frac{1}{0} \\
\frac{1}{1} \\
\frac{1}{0} \\
r\end{array}$ & 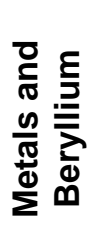 & 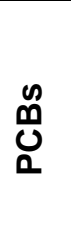 & 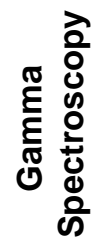 & 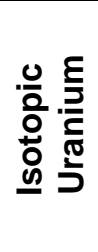 & 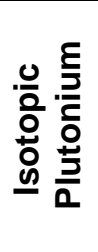 & 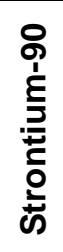 \\
\hline 08-23-01 & RS & RS & RS & $\overline{R S}$ & $\overline{\mathrm{RS}}$ & RS & $\overline{\mathrm{RS}}$ & $\overline{\mathrm{RS}}$ & $\overline{\mathrm{RS}}$ & $\overline{\mathrm{RS}}$ \\
\hline $09-09-41$ & RS & RS & RS & $\mathrm{RS}$ & $\overline{\mathrm{RS}}$ & RS & $\overline{R S}$ & RS & RS & $\overline{\mathrm{RS}}$ \\
\hline $09-09-45$ & -- & -- & -- & -- & -- & -- & $\overline{R S}$ & RS & RS & $\overline{\mathrm{RS}}$ \\
\hline $09-23-05$ & RS & RS & RS & $\mathrm{RS}$ & $\overline{R S}$ & RS & $\overline{R S}$ & RS & RS & $\overline{\mathrm{RS}}$ \\
\hline $09-23-08$ & RS & RS & RS & $\mathrm{RS}$ & $\overline{R S}$ & RS & $\overline{R S}$ & RS & RS & $\overline{R S}$ \\
\hline 09-23-09 & RS & RS & RS & $\mathrm{RS}$ & RS & RS & RS & RS & RS & $\mathrm{RS}$ \\
\hline $10-23-02$ & RS & RS & RS & RS & RS & RS & RS & RS & RS & RS \\
\hline $10-23-03$ & RS & RS & RS & $\mathrm{RS}$ & RS & RS & RS & RS & RS & $\mathrm{RS}$ \\
\hline 19-23-01 & RS & RS & RS & $\mathrm{RS}$ & RS & $\mathrm{RS}$ & RS & RS & RS & $\mathrm{RS}$ \\
\hline $19-23-02$ & RS & RS & RS & $\mathrm{RS}$ & RS & RS & RS & RS & RS & $\mathrm{RS}$ \\
\hline $19-23-03$ & RS & RS & RS & RS & $\overline{R S}$ & RS & RS & RS & $\overline{R S}$ & $\mathrm{RS}$ \\
\hline $20-23-07$ & $\mathrm{RS}$ & $\mathrm{RS}$ & $\mathrm{RS}$ & $\mathrm{RS}$ & $\mathrm{RS}$ & $\mathrm{RS}$ & RS & $\mathrm{RS}$ & $\mathrm{RS}$ & $\mathrm{RS}$ \\
\hline
\end{tabular}

DRO $=$ Diesel-range organics

$\mathrm{GRO}=$ Gasoline-range organics

RS = Required and submitted

$\mathrm{PCB}=$ Polychlorinated biphenyl

-- = Not required or submitted

SVOC $=$ Semivolatile organic compound

$\mathrm{TPH}=$ Total petroleum hydrocarbons

VOC $=$ Volatile organic compound

Sample results were assessed against the acceptance criterion for the DQI of sensitivity as defined in the Industrial Sites QAPP (NNSA/NV, 2002). The sensitivity acceptance criterion defined in the CAU 177 SAFER Plan (NNSA/NSO 2006) is that analytical detection limits will be less than the corresponding action level. This criterion was not achieved for the analytical results listed in Table 4-2. Results not meeting the sensitivity acceptance criterion were not used in making DQO 
Table 4-2

Analytes Failing Sensitivity Criteria

\begin{tabular}{|c|c|c|c|c|}
\hline $\begin{array}{c}\text { Sample } \\
\text { Number }\end{array}$ & Parameter & $\begin{array}{c}\text { Result } \\
(\mu \mathbf{g} / \mathbf{k g})\end{array}$ & $\begin{array}{c}\text { Minimum } \\
\text { Detection } \\
\text { Concentration } \\
(\mu \mathbf{g} / \mathbf{k g})\end{array}$ & $\begin{array}{c}\text { Final Action Level } \\
(\mu \mathbf{g} / \mathbf{k g})\end{array}$ \\
\hline \hline 177K001 & N-Nitroso-Di-N-Propylamine & 3,800 & 760 & 250 \\
\hline 177K002 & N-Nitroso-Di-N-Propylamine & 3,780 & 757 & 250 \\
\hline 177K003 & N-Nitroso-Di-N-Propylamine & 3,850 & 770 & 250 \\
\hline 177L001 & N-Nitroso-Di-N-Propylamine & 3,490 & 698 & 250 \\
\hline 177L002 & N-Nitroso-Di-N-Propylamine & 3,540 & 708 & 250 \\
\hline 177L003 & N-Nitroso-Di-N-Propylamine & 3,430 & 685 & 250 \\
\hline
\end{tabular}

$\mu \mathrm{g} / \mathrm{kg}=$ Micrograms per kilogram

decisions and are therefore considered rejected data. The impact on DQO decisions is addressed in the assessment of completeness.

\section{Criterion 3:}

To satisfy the third criterion, the entire dataset, as well as individual sample results, were assessed against the acceptance criteria for the DQIs of precision, accuracy, comparability, completeness, and representativeness, as defined in the Industrial Sites QAPP (NNSA/NV, 2002). The DQI acceptance criteria are presented in Table 7-1 of the CAU 177 SAFER Plan (NNSA/NSO, 2006). As presented in Tables 4-3 and 4-4, these criteria were met for each the DQIs.

\section{$\underline{\text { Precision }}$}

The duplicate precision is evaluated using the relative percent difference (RPD) or normalized difference. For the purpose of determining the data precision of chemical analyses, the RPD between duplicate analyses was calculated. For radionuclides, the RPD was not calculated unless both the sample and its duplicate had concentrations of the target radionuclide exceeding five times their minimum detectable concentration (MDC). Otherwise radionuclide, duplicate results were evaluated using the normalized difference. Table 4-3 provides the chemical and radiological precision analysis results for all constituents that were qualified for precision. The only chemical analytes qualified for 
Table 4-3

Precision Measurements

\begin{tabular}{|c|c|c|c|c|}
\hline Parameter & User Test Panel & $\begin{array}{c}\text { Number of } \\
\text { Analytes } \\
\text { Qualified }\end{array}$ & $\begin{array}{c}\text { Number of } \\
\text { Measurements } \\
\text { Performed }\end{array}$ & $\begin{array}{c}\text { Percent } \\
\text { within } \\
\text { criteria }\end{array}$ \\
\hline \hline Barium & $6010 B^{\mathrm{a}}$ & 20 & 40 & 50 \\
\hline Lead & $6010 \mathrm{~B}^{\mathrm{a}}$ & 16 & 40 & 60 \\
\hline Strontium-90 & HASL-300 $^{\mathrm{b}}$ & 2 & 127 & 98.4 \\
\hline Plutonium-239/240 & ASTM C 1001-00 & 3 & 127 & 97.6 \\
\hline Cesium-137 & HASL-300 & 19 & 127 & 85 \\
\hline
\end{tabular}

ASTM = American Society for Testing Materials

HASL = Health and Safety Laboratory

${ }^{a}$ Test Methods for Evaluating Solid Waste Physical/Chemical Methods, 3rd Edition, Parts 1-4, (SW-846) CD-ROM, Washington, DC (EPA, 1996)

${ }^{\mathrm{b}}$ The Procedures Manual of the Environmental Measurements Laboratory, HASL-300 (DOE, 1997)

' Standard Test Method for Radiochemical Determination of Plutonium in Soil by Alpha Spectroscopy (ASTM, 2000)

precision were barium and lead. The only radionuclides qualified for precision were strontium (Sr)-90, Pu-239/240, and cesium (Cs)-137.

As shown in Table 4-3, the precision rate for Sr-90, Pu-239/240, and Cs-137 were above the CAU 177 SAFER Plan acceptance criterion of 80 percent. The precision rate for barium and lead are 50 and 60 percent, respectively. There is no potential for a false negative DQO decision error, because the highest reported values for barium and lead are orders of magnitude lower than their respective PALs. Therefore, the lack of qualification of the precision results from the analysis of samples for barium and lead did not affect any decision. As the precision rate for all other constituents exceed the acceptance criteria for precision, the dataset is determined to be acceptable for the DQI of precision.

\section{Accuracy}

To determine data accuracy of sample analyses, environmental soil samples were evaluated and incorporated into the accuracy calculation. The results qualified for accuracy were associated with surrogate or matrix spike (MS) recoveries that were outside control limits and could potentially be reported at concentrations lower or higher than actual concentrations. Table 4-4 provides the chemical accuracy analysis results for all constituents qualified for accuracy. Accuracy rates are 
above the CAU 177 SAFER Plan criterion of 80 percent, except for DRO (77.5 percent); arsenic, beryllium, cadmium, chromium, selenium, and silver (45 percent); barium (25 percent); and lead (20 percent). There were no radiological data that qualified for accuracy.

Nine DRO results that qualified for accuracy were above the PAL (100 milligrams per kilogram $[\mathrm{mg} / \mathrm{kg}]$ ); however, all of the hazardous constituents of diesel passed the accuracy criteria, and the Tier 2 evaluation indicated that none of the hazardous constituents are present above PALs; therefore, TPH-DRO is not a COC. For the remaining analytes that qualified for accuracy (arsenic, beryllium, cadmium, chromium, selenium, silver, barium, and lead), results were associated with either an MS recovery that exceeded the upper limits, or an MS recovery that was below the limits. This would indicate that the associated samples may have been reported at concentrations that were either higher or lower than the actual concentrations. Because the highest reported concentration of each qualifying analyte was orders of magnitude lower than the respective PAL, the results that were qualified for reasons of accuracy can be confidently used to support DQO decisions. Therefore, the dataset is determined to be acceptable for the DQI of accuracy.

Table 4-4 Accuracy Measurements (Page 1 of 4 )

\begin{tabular}{|c|c|c|c|c|}
\hline Parameter & $\begin{array}{c}\text { User Test } \\
\text { Panel }^{\mathrm{a}}\end{array}$ & $\begin{array}{c}\text { Number of } \\
\text { Analytes } \\
\text { Qualified }\end{array}$ & $\begin{array}{l}\text { Number of } \\
\text { Measurements } \\
\text { Performed }\end{array}$ & $\begin{array}{c}\text { Percent } \\
\text { within } \\
\text { Criteria }\end{array}$ \\
\hline 2,3,4,6-Tetrachlorophenol & $8270 \mathrm{C}$ & 1 & 41 & 97.6 \\
\hline 2,4,5-Trichlorophenol & $8270 \mathrm{C}$ & 1 & 41 & 97.6 \\
\hline 2,4,6-Trichlorophenol & $8270 \mathrm{C}$ & 1 & 41 & 97.6 \\
\hline 2,4-Dimethylphenol & $8270 \mathrm{C}$ & 1 & 41 & 97.6 \\
\hline 2-Chlorophenol & $8270 \mathrm{C}$ & 1 & 41 & 97.6 \\
\hline 2-Nitrophenol & $8270 \mathrm{C}$ & 1 & 41 & 97.6 \\
\hline 4-Nitrophenol & $8270 \mathrm{C}$ & 1 & 41 & 97.6 \\
\hline Benzoic Acid & $8270 \mathrm{C}$ & 1 & 41 & 97.6 \\
\hline Phenol & $8270 \mathrm{C}$ & 1 & 41 & 97.6 \\
\hline Pentachlorophenol & $8270 \mathrm{C}$ & 2 & 41 & 95.1 \\
\hline 1,1,1,2-Tetrachloroethane & $8260 B$ & 2 & 40 & 95 \\
\hline 1,1,2,2-Tetrachloroethane & $8260 B$ & 2 & 40 & 95 \\
\hline 1,1,2-Trichloroethane & $8260 B$ & 2 & 40 & 95 \\
\hline 1,1-Dichloroethane & $8260 B$ & 2 & 40 & 95 \\
\hline
\end{tabular}


Table 4-4

Accuracy Measurements

(Page 2 of 4)

\begin{tabular}{|c|c|c|c|c|}
\hline Parameter & $\begin{array}{c}\text { User Test } \\
\text { Panel }^{\mathrm{a}}\end{array}$ & $\begin{array}{l}\text { Number of } \\
\text { Analytes } \\
\text { Qualified }\end{array}$ & $\begin{array}{l}\text { Number of } \\
\text { Measurements } \\
\text { Performed }\end{array}$ & $\begin{array}{l}\text { Percent } \\
\text { within } \\
\text { Criteria }\end{array}$ \\
\hline 1,1-Dichloroethylene & $8260 B$ & 2 & 40 & 95 \\
\hline 1,2,4-Trichlorobenzene & $8260 B$ & 2 & 40 & 95 \\
\hline 1,2-Dibromo-3-Chloropropane & $8260 B$ & 2 & 40 & 95 \\
\hline 1,2-Dichlorobenzene & $8260 B$ & 2 & 40 & 95 \\
\hline 1,2-Dichloroethane & $8260 \mathrm{~B}$ & 2 & 40 & 95 \\
\hline 1,2-Dichloropropane & $8260 B$ & 2 & 40 & 95 \\
\hline 1,3,5-Trimethylbenzene & $8260 B$ & 2 & 40 & 95 \\
\hline 1,3-Dichlorobenzene & $8260 B$ & 2 & 40 & 95 \\
\hline 1,4-Dichlorobenzene & $8260 \mathrm{~B}$ & 2 & 40 & 95 \\
\hline 1,4-Dioxane & $8260 B$ & 2 & 40 & 95 \\
\hline 2-Butanone & $8260 \mathrm{~B}$ & 2 & 40 & 95 \\
\hline 2-Chloro-1,3-Butadiene & $8260 B$ & 2 & 40 & 95 \\
\hline 2-Chlorotoluene & $8260 B$ & 2 & 40 & 95 \\
\hline 2-Hexanone & $8260 \mathrm{~B}$ & 2 & 40 & 95 \\
\hline 4-Isopropyltoluene & $8260 B$ & 2 & 40 & 95 \\
\hline 4-Methyl-2-Pentanone & $8260 \mathrm{~B}$ & 2 & 40 & 95 \\
\hline Acetone & $8260 B$ & 2 & 40 & 95 \\
\hline Acetonitrile & $8260 \mathrm{~B}$ & 2 & 40 & 95 \\
\hline Allyl Chloride & $8260 B$ & 2 & 40 & 95 \\
\hline Benzene & $8260 B$ & 2 & 40 & 95 \\
\hline Bromodichloromethane & $8260 B$ & 2 & 40 & 95 \\
\hline Bromoform & $8260 B$ & 2 & 40 & 95 \\
\hline Bromomethane & $8260 B$ & 2 & 40 & 95 \\
\hline Carbon Disulfide & $8260 B$ & 2 & 40 & 95 \\
\hline Carbon Tetrachloride & 8260B & 2 & 40 & 95 \\
\hline Chlorobenzene & $8260 \mathrm{~B}$ & 2 & 40 & 95 \\
\hline Chloroethane & $8260 B$ & 2 & 40 & 95 \\
\hline Chloromethane & $8260 B$ & 2 & 40 & 95 \\
\hline Cis-1,2-Dichloroethylene & $8260 \mathrm{~B}$ & 2 & 40 & 95 \\
\hline Dibromochloromethane & $8260 \mathrm{~B}$ & 2 & 40 & 95 \\
\hline Dichlorodifluoromethane & $8260 B$ & 2 & 40 & 95 \\
\hline
\end{tabular}


Table 4-4

Accuracy Measurements

(Page 3 of 4)

\begin{tabular}{|c|c|c|c|c|}
\hline Parameter & $\begin{array}{c}\text { User Test } \\
\text { Panel }^{\mathrm{a}}\end{array}$ & $\begin{array}{c}\text { Number of } \\
\text { Analytes } \\
\text { Qualified }\end{array}$ & $\begin{array}{c}\text { Number of } \\
\text { Measurements } \\
\text { Performed }\end{array}$ & $\begin{array}{c}\text { Percent } \\
\text { within } \\
\text { Criteria }\end{array}$ \\
\hline Ethyl Methacrylate & $8260 B$ & 2 & 40 & 95 \\
\hline Ethylbenzene & $8260 B$ & 2 & 40 & 95 \\
\hline Isobutyl Alcohol & $8260 \mathrm{~B}$ & 2 & 40 & 95 \\
\hline Isopropylbenzene & $8260 B$ & 2 & 40 & 95 \\
\hline Methacrylonitrile & $8260 \mathrm{~B}$ & 2 & 40 & 95 \\
\hline Methyl Methacrylate & $8260 B$ & 2 & 40 & 95 \\
\hline Methylene Chloride & $8260 \mathrm{~B}$ & 2 & 40 & 95 \\
\hline N-Butylbenzene & $8260 B$ & 2 & 40 & 95 \\
\hline N-Propylbenzene & $8260 B$ & 2 & 40 & 95 \\
\hline Sec-Butylbenzene & $8260 B$ & 2 & 40 & 95 \\
\hline Tert-Butylbenzene & $8260 B$ & 2 & 40 & 95 \\
\hline Tetrachloroethylene & $8260 B$ & 2 & 40 & 95 \\
\hline Trichloroethylene & 8260B & 2 & 40 & 95 \\
\hline Trichlorofluoromethane & $8260 B$ & 2 & 40 & 95 \\
\hline Vinyl Acetate & $8260 B$ & 2 & 40 & 95 \\
\hline Vinyl Chloride & $8260 B$ & 2 & 40 & 95 \\
\hline Xylenes (Total) & $8260 B$ & 2 & 40 & 95 \\
\hline 1,2,4-Trimethylbenzene & $8260 B$ & 3 & 40 & 92.5 \\
\hline Chloroform & $8260 B$ & 3 & 40 & 92.5 \\
\hline Styrene & $8260 B$ & 3 & 40 & 92.5 \\
\hline 1,1,1-Trichloroethane & $8260 B$ & 5 & 40 & 87.5 \\
\hline Toluene & $8260 \mathrm{~B}$ & 5 & 40 & 87.5 \\
\hline Mercury & $7471 \mathrm{~A}$ & 8 & 40 & 80 \\
\hline Diesel-Range Organics & 8015B & 9 & 40 & 77.5 \\
\hline Arsenic & $6010 \mathrm{~B}$ & 22 & 40 & 45 \\
\hline Beryllium & $6010 \mathrm{~B}$ & 22 & 40 & 45 \\
\hline Cadmium & $6010 B$ & 22 & 40 & 45 \\
\hline Chromium & $6010 B$ & 22 & 40 & 45 \\
\hline Selenium & $6010 B$ & 22 & 40 & 45 \\
\hline Silver & 6010B & 22 & 40 & 45 \\
\hline Barium & $6010 B$ & 30 & 40 & 25 \\
\hline
\end{tabular}


Table 4-4

\section{Accuracy Measurements}

(Page 4 of 4)

\begin{tabular}{|c|c|c|c|c|}
\hline Parameter & $\begin{array}{c}\text { User Test } \\
\text { Panel }^{\mathrm{a}}\end{array}$ & $\begin{array}{c}\text { Number of } \\
\text { Analytes } \\
\text { Qualified }\end{array}$ & $\begin{array}{c}\text { Number of } \\
\text { Measurements } \\
\text { Performed }\end{array}$ & $\begin{array}{c}\text { Percent } \\
\text { within } \\
\text { Criteria }\end{array}$ \\
\hline \hline Lead & $6010 \mathrm{~B}$ & 32 & 40 & 20 \\
\hline
\end{tabular}

aU.S. Environmental Protection Agency, SW-846 Test Methods (EPA, 1996)

\section{$\underline{\text { Representativeness }}$}

The DQO process (Appendix A) was used to address sampling and analytical requirements for CAU 177. During this process, appropriate locations were selected that enabled collected samples to be representative of the population parameters identified in the DQO (the most likely locations to contain contamination and locations that bound COCs). The sampling locations identified in the Criterion 1 discussion meet this criterion. Therefore, the analytical data acquired during the CAU 177 CAI are considered representative of the population parameters.

\section{Comparability}

Field sampling, as described in the CAU 177 SAFER Plan (NNSA/NSO, 2006), was performed and documented in accordance with approved procedures that are in conformance with standard industry practices. Analytical methods and procedures approved by DOE were used to analyze, report, and validate the data, and are in conformance with applicable methods used in industry and government practices. Therefore, project datasets are considered comparable to other datasets generated using standard industry procedures, thereby meeting DQO requirements.

\section{Completeness}

The CAU 177 SAFER Plan defines acceptable criteria for completeness to be 80 percent of CAS-specific non-target analytes identified having valid results and 100 percent of critical (target) analytes having valid results (NNSA/NSO, 2006). Additionally, the dataset must be sufficiently complete to be able to make the DQO decisions. Target analytes for CAU 177 are identified as radionuclides Eu-152 and Pu-239/240. 
Rejected data (either qualified as rejected or data that failed the criterion of sensitivity) were not used in the resolution of DQO decisions and are not counted toward meeting the completeness acceptance criterion. The N-Nitroso-Di-N-Propylamine failed the criterion for sensitivity in specific samples (Table 4-2) and analytes that were qualified as rejected data due to analytical quality issues are listed in Table 4-5. All data for all analyses were within the acceptable criteria of 80 percent for CAS-specific COPC analytes and 100 percent for CAS-specific target analytes Eu-152 and Pu-239, as identified in the CAU 177 SAFER Plan (NNSA/NSO, 2006).

Table 4-5

\section{Rejected Measurements}

\begin{tabular}{|c|c|c|c|c|c|}
\hline Parameter & $\begin{array}{c}\text { CAS } \\
\text { Number }\end{array}$ & User Test Panel & $\begin{array}{c}\text { Number of } \\
\text { Analytes } \\
\text { Qualified }\end{array}$ & $\begin{array}{l}\text { Number of } \\
\text { Measurements } \\
\text { Performed }\end{array}$ & $\begin{array}{c}\text { Percent } \\
\text { within } \\
\text { Criteria }\end{array}$ \\
\hline Europium-154 & $15585-10-1$ & HASL300 ${ }^{a}$ & 2 & 127 & 98.4 \\
\hline Uranium-238 & $7440-61-1$ & HASL300 & 2 & 127 & 98.4 \\
\hline 2,3,4,6-Tetrachlorophenol & $58-90-2$ & $8270 \mathrm{C}^{\mathrm{b}}$ & 1 & 41 & 97.6 \\
\hline 2,4,5-Trichlorophenol & $95-95-4$ & $8270 C^{b}$ & 1 & 41 & 97.6 \\
\hline 2,4,6-Trichlorophenol & $88-06-2$ & $8270 C^{b}$ & 1 & 41 & 97.6 \\
\hline 2,4-Dimethylphenol & $105-67-9$ & $8270 C^{b}$ & 1 & 41 & 97.6 \\
\hline 2-Chlorophenol & $95-57-8$ & $8270 \mathrm{C}^{b}$ & 1 & 41 & 97.6 \\
\hline 2-Nitrophenol & $88-75-5$ & $8270 C^{b}$ & 1 & 41 & 97.6 \\
\hline 4-Nitrophenol & $100-02-7$ & $8270 C^{b}$ & 1 & 41 & 97.6 \\
\hline Benzoic acid & $65-85-0$ & $8270 C^{b}$ & 1 & 41 & 97.6 \\
\hline Pentachlorophenol & $87-86-5$ & $8270 C^{b}$ & 1 & 41 & 97.6 \\
\hline Phenol & $108-95-2$ & $8270 C^{b}$ & 1 & 41 & 97.6 \\
\hline Lead & $7439-92-1$ & $6010 B^{b}$ & 1 & 40 & 97.5 \\
\hline
\end{tabular}

${ }^{a}$ The Procedures Manual of the Environmental Measurements Laboratory, HASL-300 (DOE, 1997)

${ }^{\mathrm{b}}$ Test Methods for Evaluating Solid Waste Physical/Chemical Methods, 3rd Edition, Parts 1-4, (SW-846) CD-ROM, Washington, DC (EPA, 1996) 


\subsection{DQO Provisions To Limit False Positive Decision Error}

The false positive decision error was controlled by assessing the potential for false positive analytical results. Quality assurance/QC samples such as field blanks, trip blanks, and method blanks were used to determine whether a false positive analytical result may have occurred. The evaluation of false positives resulted in the qualification of three environmental samples results of toluene for field blank contamination and one environmental sample result of Aroclor 1254 for method blank contamination.

Proper decontamination of sampling equipment and the use of certified clean sampling equipment and containers minimized the potential for cross contamination that could lead to a false positive analytical result.

\subsubsection{Decision II}

The Decision II as presented in the CAU 177 SAFER Plan (NNSA/NSO, 2006): "If a COC is present, is sufficient information available to meet closure objectives?”

Analytical results, as presented in Appendix D, indicate that no COCs are present that are associated with a release from any CAU 177 CAS; therefore, the Decision II statement does not need to be resolved.

\subsubsection{Sampling Design}

The CAU 177 SAFER Plan (NNSA/NSO, 2006) made the following commitments for sampling:

1. Probabilistic sampling will be conducted at the mud pit component of each CAS, in which 10 samples per mud pit will be collected from the residual drilling mud, defined as 0 to 12 in. bgs for open mud pits, or 0 to $12 \mathrm{in.} \mathrm{below} \mathrm{the} \mathrm{cover} \mathrm{material/mud} \mathrm{interface} \mathrm{or} \mathrm{at} \mathrm{the}$ expected depth of mud for backfilled mud pits. Samples collected at mud pits will be analyzed for radiological constituents. Additional biased samples may be collected in areas of obvious spills or staining at the mud pits.

Result: All random sample locations designated by the VSP software were collected as planned and analyzed for the appropriate COPCs. An interface with residual mud was consistently identified at the backfilled mud pits. The layout of sample locations was regenerated at two mud pits where several sample locations were on the berms, rather than the bottom of the pit. No additional biased samples were collected at the mud pits. 
2. Judgmental sampling will be conducted at the cellar component of each CAS. Two samples will be collected at the base of open cellars and at the first 12 in. of soil directly beneath cover material using drilling operations at backfilled cellars. Deeper subsurface samples would be collected, where possible, to provide potential Decision II information on vertical migration of contaminants. Actual sample locations within the cellar would be dependent on the presence and orientation of borehole casing. Samples collected at cellars would be analyzed for chemical and radiological constituents.

Result: Judgmental samples were collected as planned and analyzed for the appropriate COPCs. An interface with the cellar bottom was consistently identified at backfilled cellars and many cellars contained a concrete bottom. Samples were collected at each cellar (open and backfilled) and deeper subsurface samples were collected where refusal was not encountered.

\subsubsection{Conduct a Preliminary Data Review}

A preliminary data review was conducted by reviewing QA reports and inspecting the data. The contract analytical laboratories generate a QA non-conformance report when data quality does not meet contractual requirements. All data received from the analytical laboratories met contractual requirements, and a QA non-conformance report was not generated. Data were validated and verified to ensure that the measurement systems performed in accordance with the criteria specified. The validated dataset quality was found to be satisfactory.

\subsubsection{Select the Test and Identify Key Assumptions}

The test for making DQO Decision I for the judgmental sampling design was the comparison of the maximum analyte result from each CAS to the corresponding FAL. The probabilistic sampling design was the comparison of the 95 percent UCL of the average concentration of each significant COPC to the FAL. The test for making DQO Decision II was not necessary as there were no COCs identified at any of the CASs. The key CSM assumptions that could impact a DQO decision are listed in Table 4-6. 


\section{Table 4-6}

\section{Key Assumptions}

\section{(Page 1 of 2)}

\begin{tabular}{|c|c|}
\hline Exposure Scenario & $\begin{array}{l}\text { Site workers are only exposed to contaminants of concern (COCs) through oral ingestion, } \\
\text { inhalation, external exposure to radiation, or dermal contact (by absorption) of COCs } \\
\text { absorbed onto the soils. } \\
\text { Exposure to contamination is limited to industrial site workers, construction/remediation } \\
\text { workers, visitors, and military personnel conducting training. } \\
\text { The investigation results did not reveal any potential exposures other than those identified } \\
\text { in the conceptual site model (CSM). }\end{array}$ \\
\hline Affected Media & $\begin{array}{l}\text { Mud Pit: Residual mud contained in the boundaries of the constructed mud pit. Underlying } \\
\text { soils are not expected to have been affected due to the properties of drilling mud. } \\
\text { Cellar: Surface and shallow subsurface soils within the cellar. } \\
\text { Groundwater contamination is not a concern. Contaminants migrating to regional aquifers } \\
\text { are not considered. } \\
\text { The investigation results did not reveal any affected media other than those identified in the } \\
\text { CSM. }\end{array}$ \\
\hline $\begin{array}{c}\text { Location of } \\
\text { Contamination/ } \\
\text { Release Points }\end{array}$ & $\begin{array}{l}\text { Mud Pit: Residual drilling mud contained within the boundaries of the mud pit walls/berms, } \\
\text { or at drilling mud spills adjacent to the mud pit. If a backfilled mud pit, the mud would be } \\
\text { located directly beneath the cover material (typically } 4-5 \mathrm{ft} \text { bgs) } \\
\text { Cellar: Surface and shallow subsurface soils at the base of the cellar } \\
\text { (typically 10-12ft bgs) contained within the boundaries of the corrugated metal casing } \\
\text { (typically } 10 \mathrm{ft} \text { in diameter) and a concrete bottom, if present. } \\
\text { The investigation results did not reveal any locations of contamination or release points } \\
\text { other than those identified in the CSM. }\end{array}$ \\
\hline Transport Mechanisms & $\begin{array}{l}\text { Infiltration and percolation of precipitation through affected media serves as the major } \\
\text { driving force for contamination to migrate vertically. However, due to the low precipitation } \\
\text { and high evaporation rates of the arid environment, this mechanism is limited and is not } \\
\text { considered to be significant in regard transport of contaminants to groundwater. } \\
\text { Lateral transportation of some contaminants may occur as a result of surface water runoff or } \\
\text { overflow of surface water accumulated in the mud pits or cellars; however, this is unlikely to } \\
\text { occur. } \\
\text { Evaporation of volatile components may release contaminants to the air. } \\
\text { Wind blowing over open mud pits and cellars may re-suspend contaminated surface soil } \\
\text { particles. } \\
\text { The investigation results did not reveal any transport mechanisms other than those } \\
\text { identified in the CSMs. }\end{array}$ \\
\hline Preferential Pathways & n results did not reveal any preferential pathways. \\
\hline
\end{tabular}

\section{Uncontrolled When Printed}


Table 4-6

Key Assumptions

(Page 2 of 2)

\begin{tabular}{|c|l|}
\hline $\begin{array}{c}\text { Lateral and Vertical } \\
\text { Extent of Contamination }\end{array}$ & $\begin{array}{l}\text { Mud Pits: The lateral extent of contamination is expected to be limited to the walls/berms } \\
\text { of the mud pit unless there is a breach that would allow for overland transport. Any } \\
\text { contamination within a mud pit is expected to be bound within the residual mud and is not } \\
\text { expected to migrate vertically into the underlying soil. } \\
\text { Cellar: The lateral extent of contamination in cellars will be limited by the metal casing that } \\
\text { surrounds the cellar cavity. The vertical extent of potential contamination in the affected } \\
\text { media of a cellar is not expected to infiltrate more than a few inches below the base of the } \\
\text { cellar, if at all. } \\
\text { The investigation results did not reveal any lateral and vertical extent of contamination other } \\
\text { than those identified in the CSM. }\end{array}$ \\
\hline Groundwater Impacts & $\begin{array}{l}\text { None; the investigation results did not reveal groundwater impacts other than those } \\
\text { identified in the CSM, and migration to groundwater is not a concern. }\end{array}$ \\
\hline $\begin{array}{c}\text { Future Land Use } \\
\text { Objective Assumptions }\end{array}$ & Non-residential \\
\hline
\end{tabular}

\subsubsection{Verify the Assumptions}

The results of the investigation support the key assumptions identified in the CAU 177 DQOs and

Table 4-6. All data collected during the CAI support the CSM and do not necessitate revisions to the CSM.

\subsubsection{Draw Conclusions from the Data}

This section resolves the two DQO decisions for each of the CAU 177 CASs.

\subsubsection{Decision Rules for Decision I}

\section{Decision Rules:}

- If the population parameter of any COPC in a target population for a cellar exceeds the corresponding FAL, then that COPC is identified as a COC, and Decision II samples will be collected.

- If the population parameter of any COPC in a target population for a mud pit exceeds the corresponding FAL, then that COPC is identified as a COC, and it will be determined that the residual mud is contaminated and bounded by the Decision I sampling and the berm of the 
mud pit. Because contamination is expected to be bound within the matrix of the drilling mud, further evaluation is not necessary.

- If a COC is detected, then the Decision II statement must be resolved.

- If COCs are not identified, then the decision will be no further action.

Result: Because no COCs were identified at any CAS, no further action is recommended as the corrective action alternative and the Decision II statement does not need to be resolved.

\subsection{Use Restrictions}

Analytes detected in soil during the corrective action activities at each CAS were evaluated against FALs, and it was determined that no COCs were present. Therefore, no further action is recommended at the CASs of CAU 177 and no use restrictions are necessary. 


\subsection{Conclusions and Recommendations}

Based on the closure activities results, no further closure activities are necessary for CAU 177.

The U.S. Department of Energy, National Nuclear Security Administration Nevada Site Office (NNSA/NSO) provides the following recommendations:

- A Notice of Completion is requested from the Nevada Department of Environmental Protection (NDEP) for the closure of CAU 177.

- Move CAU 177 from Appendix III to Appendix IV of the FFACO. 


\subsection{References}

ASTM, see American Society for Testing and Materials.

American Society for Testing and Materials. 1995. Standard Guide for Risk-Based Corrective Action Applied at Petroleum Release Sites, Method E 1739-95 (Reapproved 2002). Philadelphia, PA.

American Society for Testing and Materials. 2000. Standard Test Method for Radiochemical Determination of Plutonium in Soil by Alpha Spectroscopy, C 1001-2000. Philadelphia, PA.

DOE, see U.S. Department of Energy.

EPA, see U.S. Environmental Protection Agency.

FFACO, see Federal Facility Agreement and Consent Order.

Federal Facility Agreement and Consent Order. 1996 (as amended). Agreed to by the State of Nevada, the U.S. Department of Energy, and the U.S. Department of Defense.

Gustafson, D., National Security Technologies, LLC. 2006. Email to N. Nastanski (SNJV) concerning CAU 177 Boreholes, 6 February. Las Vegas, NV.

NNSA/NSO, see U.S. Department of Energy, National Nuclear Security Administration Nevada Site Office.

NNSA/NV, see U.S. Department of Energy, National Nuclear Security Administration Nevada Operations Office.

SNJV, see Stoller-Navarro Joint Venture.

SNJV GIS Systems, see Stoller-Navarro Joint Venture Geographic Information Systems.

Snelling-Young, J.K., Stoller-Navarro Joint Venture. 2006. Memorandum to S.L. Alderson, et al., entitled, “New Default Stoller-Navarro Joint Venture (SNJV) Isotopic Gamma Library,” 5 July. Las Vegas, NV.

Stoller-Navarro Joint Venture. 2006. Project Execution Plan, Rev. 1. Las Vegas, NV.

Stoller-Navarro Joint Venture Geographic Information Systems. 2007. ESRI ArcGIS Software.

U.S. Department of Energy. 1997. The Procedures Manual of the Environmental Measurements Laboratory Procedures Manual, HASL-300, 28th Edition, Vol. 1. New York, NY. 
U.S. Department of Energy, National Nuclear Security Administration Nevada Operations Office. 2002. Industrial Sites Quality Assurance Project Plan, Nevada Test Site, Nevada, Rev. 3, DOE/NV--372. Las Vegas, NV.

U.S. Department of Energy, National Nuclear Security Administration Nevada Site Office. 2006. Streamlined Approach for Environmental Restoration (SAFER) Plan for Corrective Action Unit 177: Mud Pits and Cellars, Nevada Test Site, Nevada, Rev. 0, DOE/NV--1126. Las Vegas, NV.

U.S. Environmental Protection Agency. 1996. Test Methods for Evaluating Solid Waste, Physical/Chemical Methods, SW-846, 3rd Edition, CD-ROM PB97-501928GEI. Washington, DC.

U.S. Environmental Protection Agency. 2006. Data Quality Objectives Process for Hazardous Waste Site Investigations, EPA QA/G-4HW, EPA/600/R-00/007. Washington, DC: Office of Environmental Information. 


\section{Appendix A}

\section{Data Quality Objectives as Developed in the SAFER Plan}




\section{A.1.0 DQOs as Developed in the SAFER Plan}

The DQO process is a seven-step systematic planning process based on the scientific method that was used to plan data collection activities and define performance criteria for the CAU 177, Mud Pits and Cellars, field investigation. The DQOs are designed to ensure that data collected will provide sufficient and reliable information to determine the appropriate corrective actions, verify the adequacy of existing information, provide sufficient data to implement the corrective actions, and verify that closure was achieved.

The seven steps of the DQO process presented in Sections A.2.0 through A.8.0 were developed in accordance with EPA Guidance for the Data Quality Objectives Process (EPA QA/G-4) (EPA, 2000b) and EPA Guidance for Quality Assurance Project Plans (EPA QA/G-5) (EPA, 2002b). The DQO process presented herein is based on the EPA Quality System Document for DQOs entitled Data Quality Objectives Process for Hazardous Waste Site Investigations (EPA QA/G-4HW) (EPA, 2000a) and the CAS-specific information presented in Section A.2.0.

In general, the procedures used in the DQO process provide:

- A scientific basis to make inferences about a site (or portion of a site) based on environmental data or process knowledge.

- A basis to define decision performance criteria and assess the achieved decision quality of the data collection design.

- Criteria to know when site investigators should stop data collection (i.e., once sufficient information is available to support decisions).

- A basis to demonstrate an acceptable level of confidence in the sampling approach to generate the appropriate quantity and quality of information necessary to minimize the potential to make decision errors. 


\section{A.2.0 Step 1 - State the Problem}

The problem statement for CAU 177 is: "Existing information on the nature and extent of potential contamination is insufficient to validate the assumptions used to select the corrective action alternatives of no further action or closure in place, or to verify that closure objectives were met."

\section{A.2.1 Planning Team Members}

The DQO planning team consists of representatives from NDEP, NNSA/NSO, SNJV, and NSTec. The primary decision-makers are representatives of NDEP and NNSA/NSO. Table A.2-1 lists the representatives in attendance at the February 21, 2006, DQO meeting.

Table A.2-1

Data Quality Objective Meeting Participants

\begin{tabular}{|c|c|}
\hline Organization & Department/Project Team Function \\
\hline NDEP & NDEP Representative \\
\hline NNSA/NSO & $\begin{array}{l}\text { Environmental Restoration Project Federal Industrial Sites } \\
\text { Sub-Project Task Manager }\end{array}$ \\
\hline NSTec & Environmental Restoration Deputy Project Manager \\
\hline NSTEC & Environmental Restoration Field Support Manager \\
\hline SNJV & Industrial Sites Project Manager \\
\hline SNJV & Industrial Sites Technical Coordinator \\
\hline SNJV & Industrial Sites (CAU 177) Task Co-leads (2) \\
\hline SNJV & Federal Facility Agreement and Consent Order Representative \\
\hline SNJV & Quality Assurance Representative \\
\hline SNJV & Analytical Services Chemical Data Validator \\
\hline SNJV & Analytical Services Radiological Data Validator \\
\hline SNJV & Health and Safety Group Representative \\
\hline SNJV & Environmental Compliance and Waste Management Representative \\
\hline SNJV & Radiation Services Health Physicist \\
\hline
\end{tabular}

NDEP = Nevada Division of Environmental Protection

NNSA/NSO = U.S. Department of Energy, National Security Administration Nevada Site Office

NSTec = National Security Technologies, LLC

SNJV = Stoller-Navarro Joint Venture 


\section{A.2.2 Conceptual Site Model}

The CSM is used to organize and communicate information about site characteristics. It reflects the best interpretation of available information at any point in time. The CSM is a primary vehicle for communicating assumptions about release mechanisms, potential migration pathways, or specific constraints. It provides a summary of how and where contaminants are expected to move, and what impacts such movement may have. It is the basis for assessing how contaminants could reach receptors both in the present and future. The CSM describes the most probable scenario for current conditions at each site and defines the assumptions that are the basis for identifying appropriate sampling strategy and data collection methods. Accurate CSMs are important as they serve as the basis for all subsequent inputs and decisions throughout the DQO process.

The CSM was developed for CAU 177 using information from the physical setting, potential contaminant sources, release information, historical background information, knowledge from similar sites, and physical and chemical properties of the potentially affected media and COPCs.

The CSM represents contamination of the surrounding environment due to migration of contaminants that either are currently, or were formerly, present at each of the CASs. Migration of contaminants to areas not presently impacted can occur through infiltration and percolation of contaminants into the soil profile, lateral transportation (overland flow) of some contaminants as a result of surface water runoff or overflow of accumulated surface water in mud pits or cellars, or wind-borne re-suspension of contaminated surface particles.

The CSM consists of:

- Potential contaminant releases, including media subsequently affected.

- Release mechanisms (the conditions associated with the release).

- Potential contaminant source characteristics, including contaminants suspected to be present.

- Site characteristics, including physical and meteorological information.

- Migration pathways and transport mechanisms that describe the potential for migration and where the contamination may be transported. 
- The locations of points of exposure where individuals or populations may come in contact with a COC associated with a CAS.

- Routes of exposure.

If additional elements are identified during the investigation that are outside the scope of this CSM, the situation will be reviewed and a recommendation will be made on how to proceed. In such cases, NDEP and NNSA/NSO will be notified and offered the opportunity to comment on and concur with the recommendation.

The applicability of this CSM to the mud pits and cellars is summarized in Table A.2-2 and discussed below. Table A.2-2 provides information on CSM elements that will be used throughout the remaining steps of the DQO process. Figure A.2-1 represents site conditions applicable to the CSM.

\section{A.2.2.1 Contaminant Release}

The mud pits and cellars of CAU 177 are suspected to contain radiologically contaminated media generated by activities associated with nuclear testing. With the exception of two mud pits from which preliminary sample results indicate radiological contamination, the only indication of radiological contamination at the other CASs is the posting or former posting of URMA signage.

There have been no inorganic or organic COPCs identified for NTS mud pits based on the conclusions of the Mud Pit Risk-Based Closure Strategy Report (RBCSR) (NNSA/NSO, 2004) and the available documentation from the investigation of CAUs 530-535, Mud Pits. Results of the RBCSR have eliminated volatile organic compounds (VOCs), semivolatile organic compounds (SVOCs), polychlorinated biphenyls (PCBs), and metals as COPCs from NTS mud pits based on the conclusion that there is no analytical or process knowledge to suggest these constituents are present at significant concentrations in residual mud. Although the risk assessment concluded that TPH does not pose an unacceptable risk to human health or the environment, it was the most frequently detected contaminant in residual mud. To be conservative, it was determined that the investigation of CAUs 530-535 would further evaluate the risk posed by TPH-DRO, the only COPC, and would verify the closure strategy of no further action for NTS mud pits. It was determined that sampling 52 of the 268 CASs would be an acceptable number to represent the entire population of mud pits (NNSA/NSO, 2005). Sampling results from this investigation have verified that TPH-DRO does not 
Table A.2-2

Conceptual Site Model Description of Elements for All CASs in CAU 177

(Page 1 of 2)

\begin{tabular}{|c|c|}
\hline CAS Description & Mud Pits and Cellars \\
\hline CAU Status & Sites are inactive and abandoned \\
\hline Future Land Use & Nuclear and High Explosives Test Zone (DOE/NV, 1998b) \\
\hline $\begin{array}{c}\text { Sources of } \\
\text { Potential Soil } \\
\text { Contamination }\end{array}$ & $\begin{array}{l}\text { Mud Pit: Primary source for radiological contamination is a release of drilling mud associated with } \\
\text { post-test drilling activities subsequent to underground nuclear testing. Other contributors to } \\
\text { contamination may include a release of radiological effluents from an underground test, or fallout } \\
\text { from an atmospheric test. Organic or inorganic contamination is not expected at mud pits. } \\
\text { Cellar: Primary source for chemical contamination is a direct release of drill rig fluids (hydraulic } \\
\text { fluid, oils, greases, diesel fuel). Other contributors may include the decontamination of drilling } \\
\text { equipment over the cellar cavity, or discarding of potentially hazardous drilling materials. The } \\
\text { primary source for radiological contamination is an accidental release of contaminated drilling mud } \\
\text { via spills or leaks from drilling hoses or tubing. Other contributors may include a release of } \\
\text { radiological effluents from an underground test or fallout from an atmospheric test. }\end{array}$ \\
\hline $\begin{array}{l}\text { Location of } \\
\text { Contamination/ } \\
\text { Release Point }\end{array}$ & $\begin{array}{l}\text { Mud Pit: Residual drilling mud contained within the boundaries of the mud pit walls/berms, or at } \\
\text { drilling mud spills adjacent to the mud pit. If a backfilled mud pit, the mud would be located directly } \\
\text { beneath the cover material (typically } 4-5 \mathrm{ft} \text { bgs). } \\
\text { Cellar: Surface and shallow subsurface soils at the base of the cellar (typically } 10-12 \mathrm{ft} \text { bgs) } \\
\text { contained within the boundaries of the corrugated metal casing (typically } 10 \mathrm{ft} \text { in diameter). }\end{array}$ \\
\hline Amount Released & Unknown \\
\hline Affected Media & $\begin{array}{l}\text { Mud Pit: Residual mud contained in the boundaries of the mud pit. Underlying soils are not } \\
\text { expected to have been affected due to properties of drilling mud. } \\
\text { Cellar: Surface and shallow subsurface soil at the base of the cellar. }\end{array}$ \\
\hline $\begin{array}{c}\text { Potential } \\
\text { Contaminants }\end{array}$ & $\begin{array}{l}\text { Mud Pit: Limited to radionuclides (gamma-emitters, isotopic uranium, plutonium, and } \\
\text { strontium-90). } \\
\text { Cellar: Contaminants include VOCs, SVOCs, PCBs, metals, TPH, and radionuclides } \\
\text { (gamma-emitters, isotopic uranium, plutonium, and strontium-90). }\end{array}$ \\
\hline $\begin{array}{c}\text { Transport } \\
\text { Mechanisms }\end{array}$ & $\begin{array}{l}\text { - Infiltration and percolation of precipitation through affected media serves as the major driving } \\
\text { force for contamination to migrate vertically. Due to the low precipitation and high evaporation } \\
\text { rates of the arid environment, percolation of infiltrated precipitation is limited and is not } \\
\text { considered a significant mechanism regarding the transport of contaminants to groundwater. } \\
\text { - Lateral transportation of some contaminants may occur as a result of surface water runoff or } \\
\text { overflow of surface water accumulated in the mud pits and cellars. } \\
\text { - Evaporation of volatile components may release contaminants to the air. } \\
\text { - Wind blowing over open mud pits and cellars may resuspend contaminated surface soil } \\
\text { particles. }\end{array}$ \\
\hline
\end{tabular}


Table A.2-2

Conceptual Site Model Description of Elements for All CASs in CAU 177

(Page 2 of 2)

\begin{tabular}{|c|c|}
\hline CAS Description & Mud Pits and Cellars \\
\hline $\begin{array}{l}\text { Migration } \\
\text { Pathways }\end{array}$ & $\begin{array}{l}\text { - Vertical migration of contaminants through the affected media in mud pits and cellars is } \\
\text { considered insignificant due to the arid climate of the Nevada Test Site. Cover material for } \\
\text { backfilled mud pits and cellars could also significantly prevent percolation of precipitation as a } \\
\text { driving force. Also, vertical migration of contaminants through drilling mud into the underlying } \\
\text { soil is not expected due to the physical properties of the drilling mud. } \\
\text { - Without a breach in the berms of a mud pit, or a large rainfall event that would cause } \\
\text { overtopping of the mud pit or cellar, potential lateral migration, or overland flow is considered to } \\
\text { be limited. } \\
\text { Evaporation as a migration pathway would only be applicable to open cellars; however, this } \\
\text { pathway is considered insignificant because the volatile components of TPH are expected to } \\
\text { have weathered away. Contaminants of potential concern for mud pits do not include vapor } \\
\text { phases. Previous sampling has eliminated VOCs as COPCs for mud pits. } \\
\text { Wind transport of resuspended particles is considered an insignificant pathway because the } \\
\text { affected media in mud pits and cellars is protected by berms and } 10-12 \mathrm{ft} \text { bgs metal casing, } \\
\text { respectively. A release of contaminants to the air is not considered a complete migration } \\
\text { pathway for mud pits and cellars that have been backfilled because the affected media is } \\
\text { covered. }\end{array}$ \\
\hline $\begin{array}{l}\text { Lateral and } \\
\text { Vertical Extent of } \\
\text { Contamination }\end{array}$ & $\begin{array}{l}\text { - The lateral extent of contamination in mud pits is expected to be limited to the walls/berms of the } \\
\text { mud pit unless there is a noticeable breach that would allow for overland transport. The lateral } \\
\text { extent of contamination in cellars is expected to be limited by the metal casing that surrounds } \\
\text { the cellar cavity. } \\
\text { - The vertical extent of potential contamination in the affected media of a cellar is not expected to } \\
\text { infiltrate more than a few inches below the base of cellar, if at all. Contamination at a mud pit is } \\
\text { expected to be bound within the residual mud and would not be expected to migrate vertically } \\
\text { downward into the underlying soil. Groundwater contamination is not expected because depth } \\
\text { to groundwater varies between } 500 \text { to } 2,800 \mathrm{ft} \text { bgs and averages approximately } 800 \mathrm{ft} \text { bgs } \\
\text { (USGS/DOE, 2005). }\end{array}$ \\
\hline $\begin{array}{l}\text { Exposure } \\
\text { Scenario }\end{array}$ & $\begin{array}{l}\text { - The exposure scenario for all CASs is the Occasional Use Area Scenario, which assumes } \\
\text { occasional work activities at a site. This scenario addresses exposure to industrial workers who } \\
\text { are not assigned to the area as a regular work site but may occasionally use the site. This } \\
\text { scenario assumes that this is an area where the worker does not regularly visit but may } \\
\text { occasionally use for short-term activities. The criteria for this exposure scenario is that it is a } \\
\text { remote area with no active improvements (NNSA/NSO, 2006) and the future land use } \\
\text { designation is for outdoor tests and/or military training exercises, categorized as the Nuclear and } \\
\text { High Explosives Test Zone (DOE/NV, 1998b). } \\
\text { - A site worker under the Occasional Use Area Scenario is assumed to be on the site for an } \\
\text { equivalent of } 80 \text { hours (or } 10 \text { days) per year, for } 5 \text { years (NNSA/NSO, 2006) }\end{array}$ \\
\hline
\end{tabular}

bgs $=$ Below ground surface COPC $=$ Contaminant of potential concern $\mathrm{ft}=$ Foot

$\mathrm{PCB}=$ Polychlorinated biphenyl
SVOC $=$ Semivolatile organic compound

$\mathrm{TPH}=$ Total petroleum hydrocarbons

VOC $=$ Volatile organic compound 


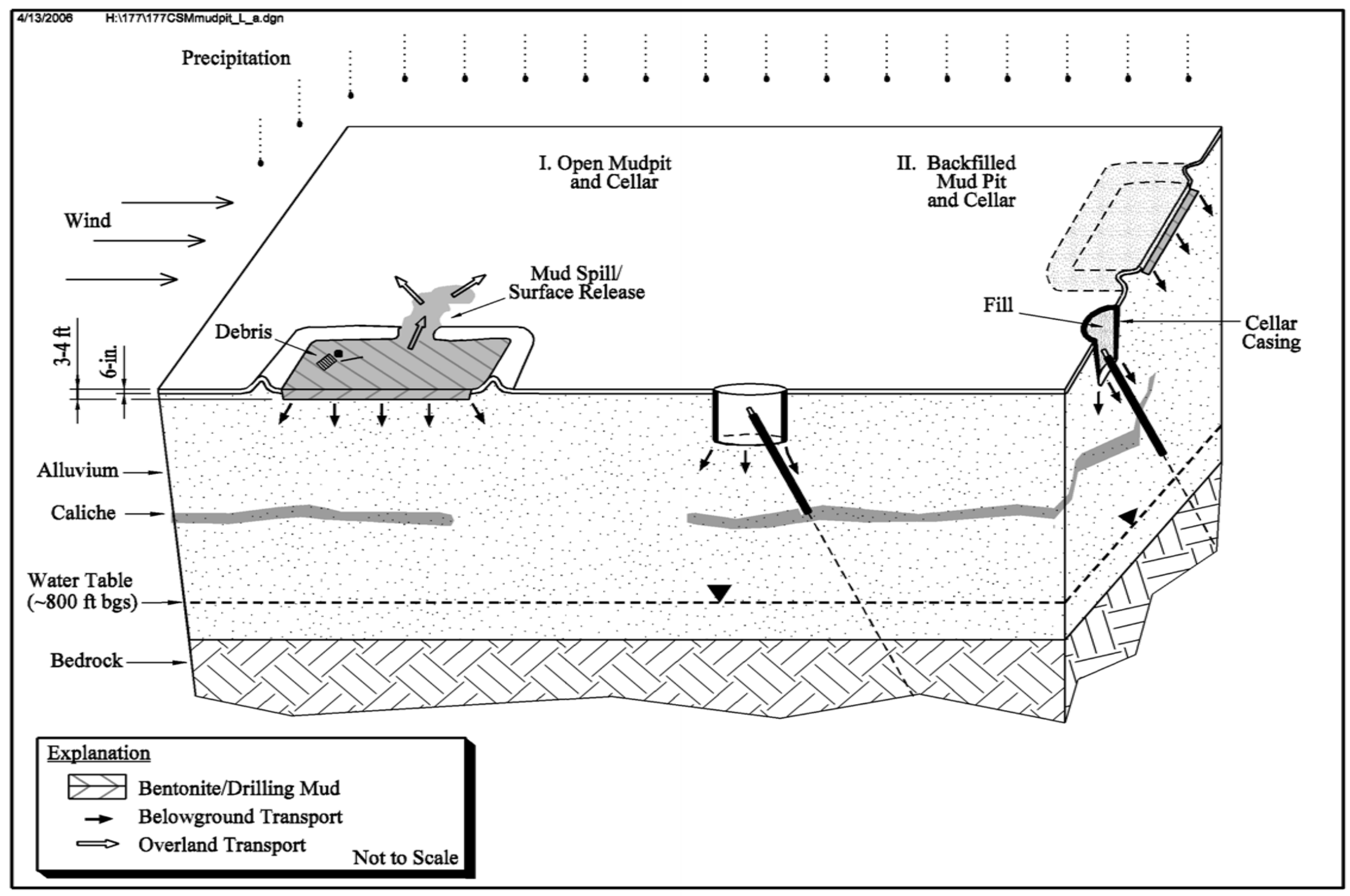

Figure A.2-1

Conceptual Site Model for CAU 177 
pose an unacceptable risk to human health or the environment; therefore, it is eliminated as a COPC for CAU 177 mud pits.

Because complete information regarding activities performed at the CAU 177 cellars is not available, chemical constituents will be included as COPCs in addition to radionuclides in order to fully characterize cellars and to reduce the uncertainty. As a result, this investigation will provide preliminary data for characterizing other identified cellars that may be included in future corrective action investigations.

The process associated with potential contamination at a mud pit is not the same process that may have contributed to contamination at a cellar. Therefore, the following sections will address the release of contaminants associated with each feature separately.

\section{A.2.1.1 Mud Pits}

The primary source of potential radiological contamination is the release of drilling mud that may have been in contact with radioactive rock and circulated from the borehole to the mud pit during post-test drilling. Process knowledge indicates that bentonite clay is a major ingredient in drilling mud (IMANA, 2004). In general, clay minerals have high porosity, low permeability, and the property of expanding several times its original volume when saturated with water. This clay-water mixture has a viscosity several times that of water, making it useful as a drilling fluid (DOE/NV, 1998a). Based on the unique properties of bentonite and its prominent occurrence in drilling mud, it is believed that its use would help retard the migration of COPCs present in the mud. Furthermore, the layer of residual drilling mud contained within the mud pit is expected to act as a barrier to prevent the downward migration of contaminants into underlying native soil. The document Evaluation of Potential Hydrocarbon Transport at the UC-4 Emplacement Hole, Central Nevada Test Area (DOE/NV, 1998a) reports data that support the conclusion that contamination within drilling mud does not migrate significantly based on TPH release experiments.

The locations for a release of drilling mud are at the base of the excavated mud pit, or at drilling mud spills adjacent to the pits. The media affected by a release is typically the surface and shallow subsurface soil; however, due to the binding properties of bentonite, contamination is expected to be bound within the mud with no migration to the native soil adjacent to the floor and walls of the mud 
pits. Contamination, if any, is expected to be evenly dispersed and present at relatively uniform concentrations because the mud was homogenized as it was circulated. This suggests that surface samples of the residual mud would be representative of the mud throughout the depth of the mud pit. Contamination unrelated to the mud pit process may be localized beneath potentially hazardous discarded drilling materials, if present.

\section{A.2.2.1.2 Cellars}

A release of radiological or chemical contaminants to media within a cellar is not expected based on cellar processes; however, contamination, if any, can be attributed to accidental spills and leaks or materials discarded during drilling activities.

The primary source of a release of radionuclides is suspected to be from radiologically contaminated drilling mud that either spilled or leaked into the cellar cavity as a result of careless activities or a failure of the circulation system. Typically, a release of drilling mud to the cellar would not occur because the drilling mud was recirculated from the borehole to the mud pit through a closed system. Although unlikely, another potential contributor of radiological contamination is a release of radiological effluents from underground tests through a vent or fissure, or fallout from an atmospheric test. The primary source of a chemical contaminant release is suspected to be from drill rig fluids such as hydraulic fluid, oils, greases, and potentially diesel fuel that was directly introduced to the cellar cavity through either spills or leaks, decontamination of drilling equipment over the cellar cavity, or discarded drilling materials. The organic components of these materials would show up in the analyses as VOCs, SVOCs, PCB, and TPH. If TPH is detected, the source may be either from drilling fluid known to contain diesel fuel as an additive (DOE/NV, 2001; NNSA/NSO, 2004), or from fluids associated with the drill rig as described above.

A release of either radiological or chemical contamination is expected to be located at the base of the cellar (typically 10 to $12 \mathrm{ft}$ bgs) and contained within the boundaries of the corrugated metal casing (typically $10 \mathrm{ft}$ in diameter). The affected media is expected to be the surface and shallow subsurface soil at the cellar bottom. Soil outside of the 10- to 12-ft deep cellar casing is not expected to have been impacted because the casing acts as a barrier to contaminant migration. In the event of a release immediately adjacent to the cellar, the concrete foundation that surrounds the cellar casing would provide a barrier to contaminants migrating into the underlying soil. Contamination, if present, is 
expected to be contiguous to the respective release locations described for cellars and is expected to decrease with horizontal and vertical distance from the source.

Groundwater contamination is not considered a likely scenario at any CAS based on the depth to groundwater in Areas 8, 9, 19, and 20. Data from nearest wells indicate that groundwater levels are approximately 2,000 ft bgs for Area 8 CASs, may range from approximately 500 to 2,000 ft bgs for Area 9 CASs, and may range from 2,100 to 2,800 ft bgs for Area 19 and 20 CASs (USGS/DOE, 2005). Surface migration is not expected to be significant because the engineered structure of a mud pit and cellar would limit surface migration to within the physical barriers (i.e, mud pit berms and cellar casing).

\section{A.2.2.2 Potential Contaminants}

The COPCs for CAU 177 are defined as the analytes reported from the analyses identified in Table A.2-3. The analyses to be conducted are not CAS specific, but rather are dependent on whether a release is associated with the mud pit process or the cellar process because the targeted analytes vary for each of these processes. The list of COPCs is applicable to Decision I environmental samples from each mud pit and cellar, and is intended to encompass all of the contaminants that could potentially be present. These contaminants were identified during the planning process through the review of site history, process knowledge, personal interviews, past investigation efforts (where available), and inferred activities associated with the mud pit and cellar processes. Because complete information regarding activities performed at the cellars of CAU 177 is not available, contaminants commonly detected at other similar NTS sites were included in the contaminant list to reduce the uncertainty.

Some COPCs are identified as targeted analytes, which are those contaminants for which evidence and/or process information suggests that they are reasonably suspected to be present at a given CAS. The targeted analytes are required to meet a more stringent completeness criteria than other COPCs thus providing greater protection against a decision error (Section A.7.0). For this investigation, Eu-152 and Pu-239 have been identified as targeted analytes based on sampling results from a previous investigation of CAS 09-09-41 and CAS 09-09-45 (SNJV, Date Unknown). Europium-152 (CASs 09-09-41 and 09-09-45) and Pu-239 (CAS 09-09-45) were detected at concentrations that exceeded PALs in both surface ( 0 to 3 in.) and near surface (3 to 6 in.) soil samples, which 
Table A.2-3

Analytical Programa

\begin{tabular}{|c|c|c|}
\hline Analyses $^{b}$ & Mud Pits & Cellars \\
\hline \multicolumn{3}{|c|}{ Organic COPCs } \\
\hline Total Petroleum Hydrocarbons-Diesel-Range Organics & --- & $\mathrm{X}$ \\
\hline Total Petroleum Hydrocarbons-Gasoline-Range Organics & --- & $x$ \\
\hline Polychlorinated Biphenyls & --- & $x$ \\
\hline Semivolatile Organic Compounds ${ }^{c}$ & --- & $x$ \\
\hline Volatile Organic Compounds ${ }^{c}$ & --- & $x$ \\
\hline \multicolumn{3}{|c|}{ Inorganic COPCs } \\
\hline Total Resource Conservation and Recovery Act Metals ${ }^{c}$ & --- & $\mathrm{X}$ \\
\hline Total Beryllium & --- & $\mathrm{X}$ \\
\hline \multicolumn{3}{|c|}{ Radionuclide COPCs } \\
\hline Gamma Emitters & $\mathrm{X}$ & $\mathrm{X}$ \\
\hline Isotopic Uranium & $x$ & $x$ \\
\hline Isotopic Plutonium & $x$ & $x$ \\
\hline Strontium-90 & $x$ & $x$ \\
\hline
\end{tabular}

${ }^{\text {a }}$ The COPCs are the analytes reported from the analytical methods listed.

' If the volume of material is limited, prioritization of the analyses will be necessary.

'May also include Toxicity Characteristic Leaching Procedure analytes if sample is collected for waste management purposes.

COPC $=$ Contaminant of potential concern

$X=$ Required analytical method

--- = Analyses will not be performed at this feature.

demonstrates that contamination cannot be attributed solely to fallout from atmospheric testing. In addition to these radionuclides, any Decision II COC will also be treated as a targeted analyte. Targeted analytes for mud pits and cellars are identified in Table A.2-4. 
Table A.2-4

Targeted Analytes for CAU 177

\begin{tabular}{|c|c|c|}
\hline Feature & Chemical Targeted Analyte(s) & Radiological Targeted Analyte(s) $^{\mathbf{a}}$ \\
\hline \hline Mud Pit & None & Europium-152, Plutonium-239 \\
\hline Cellar & None & Europium-152, Plutonium-239 \\
\hline
\end{tabular}

${ }^{2}$ The evidence for radiological target analytes at mud pits and cellars is from previous sampling results of CAS 09-09-41 and CAS 09-09-45. See Sections 2.3.3 and 2.4.3 of the CAU 177 SAFER Plan.

Source: SNJV, Date Unknown

\section{A.2.2.3 Contaminant Characteristics}

Contaminant characteristics include, but are not limited to: solubility, density, and adsorption potential. In general, contaminants with large particle size, low solubility, high affinity for media, and/or high density can be expected to be found relatively close to release points. Contaminants with small particle size, high solubility, low affinity for media, and/or low density are found further from release points or in low areas where evaporation of ponding will concentrate dissolved contaminants.

\section{A.2.2.4 Site Characteristics}

Site characteristics are the physical, topographical, and meteorological attributes and properties. Table A.2-5 lists the physical setting of the CAU 177 CASs; whether it contains a mud pit, a cellar, or both; and whether that feature has been backfilled or left open. The practice of backfilling these features appears to be arbitrary and should only impact sampling logistics, hazard controls, and potentially migration pathways. In general, the mud pits and cellars are expected to have similar characteristics, because they were all constructed within the surface and shallow subsurface soil of the NTS using comparable mud pit and cellar processes. All but one of the CAU 177 mud pits are post-test pits associated with a borehole (i.e., cellar) and thus, construction and drilling procedures were similar. The only variations between the post-test mud pits and the one disposal-type mud pit (CAS 09-09-41) is that the latter is larger in size and is not associated with a borehole.

Mud pit dimensions are listed in Table A.2-5; however, only the depth of the mud pit is of interest because it is an indicator of the depth at which mud would be expected to be encountered if the mud pit is backfilled. Residual drilling mud is expected to be present in all mud pits, but the amount 
Table A.2-5

Physical Setting of CAU 177 Corrective Action Sites

\begin{tabular}{|c|c|c|c|c|c|c|c|c|c|c|c|c|}
\hline CAS & 08-23-01 & 09-23-05 & $09-23-08$ & 09-23-09 & $10-23-02$ & $10-23-03$ & $19-23-01$ & $19-23-03$ & 09-09-41 & $09-09-45$ & 19-23-02 & 20-23-07 \\
\hline Mud Pit & $\mathrm{O}$ & $\mathrm{BF}$ & $\mathrm{BF}$ & --- & $\mathrm{O}$ & $\mathrm{O}$ & $\mathrm{BF}$ & --- & $\mathrm{O}$ & $\mathrm{O}$ & --- & --- \\
\hline Cellar & BF & BF & BF & $\mathrm{BF}$ & $\mathrm{BF}(2)$ & BF & BF & $\mathrm{O}$ & --- & BF & BF & $\mathrm{O}$ \\
\hline $\begin{array}{c}\text { Mud Pit } \\
\text { Dimensions (ft) }\end{array}$ & $100 \times 40 \times 6$ & $45 \times 43$ & $65 \times 35$ & N/A & $41 \times 21 \times 5$ & $42 \times 17 \times 5$ & $90 \times 30$ & N/A & $100 \times 50 \times 12$ & $80 \times 25 \times 4$ & N/A & N/A \\
\hline $\begin{array}{c}\text { Cellar } \\
\text { Dimensions (ft) }\end{array}$ & \multicolumn{12}{|c|}{$\sim 10 \mathrm{ft}$ in diameter, $10-12 \mathrm{ft}$ deep } \\
\hline RAD Postings & \multicolumn{8}{|c|}{ URMA } & \multicolumn{2}{|c|}{ RMA } & \multicolumn{2}{|c|}{ Postings Removed } \\
\hline Fence & $\sqrt{ }$ & $\sqrt{ }$ & $\sqrt{ }$ & $\sqrt{ }$ & $\sqrt{ }$ & $\sqrt{ }$ & $\sqrt{ }$ & $\sqrt{ }$ & & & & $\sqrt{ }$ \\
\hline Associated Test & $\begin{array}{l}\text { Cyathus } \\
1970\end{array}$ & $\begin{array}{l}\text { Cathay } \\
1971\end{array}$ & $\begin{array}{c}\text { Haplopappus } \\
1972\end{array}$ & $\begin{array}{c}\text { Hod-B (Red) } \\
1970\end{array}$ & $\begin{array}{c}\text { Tun-C,D } \\
1969\end{array}$ & $\begin{array}{l}\text { Tun-A } \\
1969\end{array}$ & $\begin{array}{l}\text { Panir } \\
1978\end{array}$ & $\begin{array}{l}\text { Tierra } \\
1984\end{array}$ & N/A & $\begin{array}{l}\text { Biggin } \\
1969\end{array}$ & $\begin{array}{l}\text { Amarillo } \\
1989\end{array}$ & $\begin{array}{l}\text { Bullion } \\
1990\end{array}$ \\
\hline Test Release & & & & & $\sqrt{ }$ & $\sqrt{ }$ & & $\sqrt{ }$ & $\mathrm{N} / \mathrm{A}$ & & & \\
\hline
\end{tabular}

$\mathrm{ft}=$ Foot

N/A = Not applicable

RMA = Radioactive material area

URMA = Underground radioactive material area

--- = No feature with this CAS

$\sim$ Approximately
$\mathrm{BF}=$ Backfilled

$\mathrm{O}=$ Open

Test Release $=$ Either a post-test or associated test release occurred that may have contributed fallout Backfilled MPs $=3$

Backfilled Cellars $=10$

Open MPs = 5

Open Cellars $=2$

Total $=8$

Total $=12$ 
remaining may vary. Soil that was excavated during construction of a mud pit was typically used to form earthen berms that surround the pit and act as a protective barrier.

The cellar dimensions reported in Table A.2-5 include the typical cellar diameter and its depth bgs based on visual observations from open cellars. The cellar cavities are expected to have been excavated to a depth of 10 to $12 \mathrm{ft}$ bgs, which is an indicator of the depth at which potentially impacted soil would be encountered if the cellar is backfilled. The cellars are lined with at least 10 to $12 \mathrm{ft}$ of corrugated metal casing that is typically $10 \mathrm{ft}$ in diameter and is set in a 14- by 14 - by $1-\mathrm{ft}$ concrete foundation at the ground surface. Soil is observed at the base of the open cellars of CAU 177; however, it has been documented in previous cellar investigations that a concrete floor may be beneath this layer of soil (NNSA/NSO, 2003a and b).

It is common at CAU 177 that most CASs are located within posted radiological areas. With the exception of CASs 09-09-41 and 09-09-45, which are located in the larger RMA in Area 9, all other CASs were posted as URMAs by the NSTec RadCon organization (Table A.2-5). Since originally posted, CASs 19-23-02 and 20-23-07 have had URMA postings removed, but the reason is uncertain. It is speculated that URMAs were fenced and posted based on process knowledge that the mud pits and cellars were associated with the post-test borehole that extended into the underground area potentially affected by the associated nuclear test (Table A.2-5). The rationale for posting the area may have been that the borehole allowed for a pathway to media that was potentially radioactive. The fences and postings that delineate existing URMAs are the responsibility of the NSTec RadCon organization and not the NNSA/NSO Environmental Restoration Project.

The boreholes within the cellars are under the control of the Borehole Management Project and are not included in the scope of the CAS. The current primary objective of this program is to plug and abandon NTS legacy boreholes for which there is no future use. The boreholes associated with six CASs (08-23-01, 09-09-45, 09-23-08, 09-23-09, 19-23-01, and 19-23-02) in CAU 177 have already been plugged. The boreholes associated with four CASs (09-23-05, 10-23-02, 10-23-03, and 19-23-03) are currently on the list of plugback candidates. One of two boreholes associated with CAS 10-23-02 and the borehole associated with CAS 20-23-07 are not currently scheduled for plugback activities. 
The amount of infiltration at any specific NTS mud pit is expected to be minimal based on the physical properties of bentonite as well as the low precipitation and high evapotranspiration rates common at the NTS.

\section{A.2.2.5 Migration Pathways and Transport Mechanisms}

An important element of the CSM is the expected fate and transport of contaminants (i.e., how contaminants migrate through media and where they can be expected in the environment). Fate and transport of contaminants are presented in the CSM as the migration pathways and transport mechanism that could potentially move the contaminants vertically and laterally throughout the various media. The pathways include air, surface water, and groundwater, and are the routes through which possible contamination could migrate from the site(s) to locations where a receptor might receive an exposure. Fate and transport are influenced by physical and chemical characteristics of the contaminants and media described in Sections A.2.2.3 and A.2.2.4. Given the characteristics of both the contaminants and the bentonite drilling mud, contaminant migration is expected to be limited.

Infiltration and percolation of precipitation serves as a driving force for the downward vertical migration of contaminants through the mud or underlying soil in the mud pits and cellars. The annual potential evapotranspiration at the Area 5 Radiological Waste Management Site has been estimated at 62.6 in. (Shott et al., 1997), but the annual precipitation for this region is between 3.5 and 6 in. (Winograd and Thordarson, 1975). Therefore, percolation of infiltrated precipitation at the NTS does not provide a significant mechanism for vertical migration of contaminants to groundwater (DOE/NV, 1992; NNSA/NSO, 2004). Cover material, depending on its thickness, for backfilled mud pits and cellars could significantly diminish infiltration and percolation of precipitation as a driving force for vertical migration of contaminants in the affected media. Additionally, if present, the concrete floor of a cellar would limit infiltration.

Lateral migration of contaminants through impacted media is expected to be limited to within the physical boundaries of the mud pits and cellars, identified as the walls/berms and metal casing, respectively. Lateral migration may occur as a result of overland flow or erosion and is dependent on the integrity of the mud pit berms and the depth to the base of the excavated cellar. Without a breach in the berm or a large rainfall event that would cause overtopping of the berm, lateral migration through media contained in or surrounding mud pits is expected to be insignificant. Similarly, 
without a large rainfall event that would cause the cellar cavity to fill with water and overflow, lateral migration through media contained in or surrounding cellars is not expected. Lateral migration of contaminants through the soil from beneath the cellar casing (i.e., 10 to $12 \mathrm{ft}$ bgs) is possible; however, vertical migration would dominate due to infiltration of precipitation through the soil. Also, where applicable, the process of backfilling mud pits and cellars following the completion of drilling activities, or plugback activities, would further limit the potential of lateral migration due to lack of a driving force.

Releases to the air may result from re-suspension of contaminated surface soil particles with wind movement, or evaporation of the volatile components of TPH in regards to the cellars. Wind could potentially suspend surface soil particles and carry them beyond the boundaries of the mud pits and cellars. However, the mud pits were typically constructed by excavating native soils and creating a protective berm that surrounds the mud pits and reduces the potential for wind to disturb the mud pit surface. Similarly, the soil at the base of open cellars is protected by the metal casing located approximately 10 to $12 \mathrm{ft}$ bgs and, therefore, reduces the potential for wind disturbance. With regard to the open cellars, given that they have been weathered for many years, it is unlikely that evaporation of TPH components is a significant migration pathway. A release of contaminants to the air is not considered an active transport mechanism for mud pits and cellars that have been backfilled, because the overlying fill would prevent the re-suspension of impacted media. Overall, airborne migration of contaminants is considered a minor transport mechanism for CAU 177.

\section{A.2.2.6 Exposure Scenarios}

Human receptors may be exposed to COPCs through oral ingestion, inhalation, or dermal contact (absorption) of drilling mud, soil, or debris due to inadvertent disturbance of these materials, or through irradiation by radioactive materials. The exposure of workers and visitors to site contaminants is very dependent upon the activities of the exposed individual at the site. Based on the future land use as identified in the Nevada Test Site Resource Management Plan (DOE/NV, 1998b), the areas in which all CAU 177 CASs are located are restricted to industrial uses.

The appropriate exposure scenarios for all CAU 177 CASs is the Occasional Use Area, due to each site being in a remote area with no active improvements and the future land use designation is for outdoor tests and/or military training exercises. There is still the possibility, however, that site 
workers could occupy these locations on an occasional and temporary basis such as a military exercise (NNSA/NSO, 2006). Investigation decisions will be based on the future land-use and exposure scenarios for CAU 177 provided in Table A.2-6.

Table A.2-6

Future Land-Use and Exposure Scenarios

\begin{tabular}{|c|c|c|}
\hline $\begin{array}{c}\text { Corrective } \\
\text { Action Sites }\end{array}$ & Future Land-Use Zone & Exposure Scenario \\
\hline All & $\begin{array}{l}\text { Nuclear and High Explosives Test } \\
\text { This area is designated within the } \\
\text { Nuclear Test Zone for additional } \\
\text { underground nuclear weapons tests } \\
\text { and outdoor high-explosive tests. This } \\
\text { zone includes compatible defense and } \\
\text { nondefense research, development, } \\
\text { and testing activities }\end{array}$ & $\begin{array}{l}\text { Occasional Use Area } \\
\text { This exposure scenario assumes exposure to industrial } \\
\text { workers who are not assigned to the area as a regular } \\
\text { worksite but may occasionally use the site for intermittent } \\
\text { or short-term activities. } \\
\text { A site worker under this scenario is assumed to be on the } \\
\text { site for } 8 \text { hours per day, } 10 \text { days per year, for } 5 \text { years. }\end{array}$ \\
\hline
\end{tabular}

Source: DOE/NV, 1998b; NNSA/NSO, 2006 


\section{A.3.0 Step 2 - Identify the Decisions}

Step 2 of the DQO process identifies the decision statements and defines appropriate alternative actions that may be taken, depending on the answer to the decision statements.

\section{A.3.1 Decision Statements}

The Decision I statement is: "Is any COC present in environmental media within a mud pit or cellar?” For judgmental sampling design, any analytical result for a COPC above the FAL will result in that COPC being designated as a COC. For a probabilistic sampling design, any COPC that has a 95 percent UCL of the average concentration exceeding the FAL will result in that COPC being designated as a COC. If a COC is detected, then Decision II must be resolved.

The Decision II statement is: "If a COC is present, is sufficient information available to meet closure objectives?” Sufficient information is defined to include:

- Identifying the volume of media containing any COC, as bounded by analytical sample results in lateral and vertical directions

- Characterizing IDW for disposal

- Determining potential remediation waste types

- Evaluating the feasibility of potential closure options

If sufficient information is not available to meet closure objectives, then site conditions will be re-evaluated and additional samples will be collected (as long as the scope of the investigation is not exceeded and any CSM assumption has not been shown to be incorrect).

\section{A.3.2 Alternative Actions to the Decisions}

In this section, the actions that may be taken to solve the problem statement are identified depending on the possible outcomes of the investigation. 


\section{A.3.2.1 Alternative Actions to Decision I}

If no COC associated with a release from the CAS is detected, then mud pit and/or cellar will be closed via the no further action alternative. If a COC associated with a release from the CAS is detected, then the extent of COC contamination will be determined and additional information required to confirm that closure objectives were met will be collected.

\section{A.3.2.2 Alternative Actions to Decision II}

If sufficient information is available to define the extent of COC contamination then a closure strategy of closure in place with administrative controls will be implemented and further assessment of the CAS is not required. If sufficient information is not available to define the extent of COC contamination and confirm that closure objectives were met, then additional samples will be collected. 


\section{A.4.0 Step 3 - Identify the Inputs to the Decision}

This step identifies the information needed, determines information sources, and identifies sampling and analysis methods that allow reliable comparisons of analytical results with FALs.

\section{A.4.1 Information Needs}

To resolve Decision I (determine whether a COC is present at a given CAS), samples need to be collected and analyzed following these two criteria: (1) samples must be either (a) be collected in areas most likely to contain a COC (judgmental sampling) or (b) properly represent contamination at the CAS (probabilistic sampling); and (2) the analytical suite selected must be sufficient to identify any COCs present in the samples.

To resolve Decision II (determine whether sufficient information is available to meet closure objectives at each CAS), samples will be collected and analyzed to meet the following criteria:

- Collection in areas contiguous to the contamination but where concentrations are below FALs.

- Waste or environmental media must provide sufficient information to characterize the IDW for disposal.

- Analytical suites selected must be sufficient to detect contaminants at concentrations equal to or less than their corresponding FALs.

\section{A.4.2 Sources of Information}

Information to satisfy Decision I and Decision II will be generated by collecting environmental samples using grab sampling, backhoe excavation, drilling, or other appropriate sampling methods. These samples will be submitted to analytical laboratories meeting the quality criteria stipulated in the Industrial Sites QAPP (NNSA/NV, 2002). Only validated data from analytical laboratories will be used to support DQO decisions. Sample collection and handling activities will follow standard procedures. 


\section{A.4.2.1 Sample Locations}

Design of the sampling approaches for the CAU 177 CASs must ensure that the data collected are sufficient for supporting the selection of the corrective action alternatives (EPA, 2002a). To meet this objective, the samples collected from each site should be either from locations that most likely contain a COC, if present (judgmental), or properly represent any contamination that is present within the CAS (probabilistic).

A judgmental sampling approach will be implemented for all cellars and for mud pits if unexpected biasing factors are identified. Biasing factors (including FSRs) will be used to select the most appropriate samples from a particular location for submittal to the analytical laboratory.Biasing factors to be used for selection of sampling locations are listed in Section A.2.2.1.1. Sample locations may be modified based on site conditions, obvious debris or staining of soils, FSRs, or professional judgment if the modified locations meet the DQO decision needs and criteria stipulated. As biasing factors are identified and used for selection of sampling locations, they will be recorded in the appropriate field documents.

A probabilistic sampling approach will be implemented for the mud pits. Sample locations at mud pits are specified by the process presented in Appendix C, which reviews the methodology and computational approach for probabilistic sampling and lists the sample size and locations as calculated by the VSP software program (PNNL, 2005).

The implementation of the judgmental and probabilistic sampling approaches for CAU 177 are summarized in the following sections.

\section{A.4.2.1.1 Judgmental Approach for Sample Location Selection}

Decision I sample locations at cellars and where applicable at mud pits, will be determined based upon the likelihood of the soil containing a COC, if present. These locations will be selected based on field-screening techniques, biasing factors, the CSM, and existing information. Analytical suites for Decision I samples will include all COPCs identified in Tables A.2-3 and A.2-4.

Field-screening techniques may be used to select appropriate sampling locations by providing semi-quantitative data that can be used to comparatively select samples to be submitted for laboratory 
analyses from several screening locations. Field screening may also be used for health and safety monitoring and to assist in health and safety decision-making. The following field-screening methods may be used to select analytical samples at CAU 177:

- Walkover surface area radiological surveys - A vehicle-mounted or handheld radiological survey instrument over approximately 100 percent of the CAS boundaries, as permitted by terrain and field conditions to detect hot spots of radiological contamination.

- Alpha and Beta/Gamma Radiation - A handheld radiological survey instrument, or equivalent instrument or method, may be used at these CASs.

- Gamma-Emitting Radionuclides - A handheld dose rate instrument.

Biasing factors may also be used to select samples to be submitted for laboratory analyses based on existing site information and site conditions discovered during the investigation. The following biasing factors will be considered in selecting locations for analytical samples at CAU 177:

- Documented process knowledge on source and location of release.

- Stains: Any spot or area on the soil surface that may indicate the presence of a potentially hazardous liquid release. Typically, stains indicate an organic liquid such as an oil has reached the soil, and may have spread out vertically and horizontally.

- Elevated radiation: Any location identified during radiological surveys that had alpha/beta/gamma levels significantly higher than surrounding background soil.

- Geophysical anomalies: Any location identified during geophysical surveys that had results indicating subsurface materials exist and are not consistent with the natural surroundings or process knowledge (e.g., buried concrete or metal, surface metallic objects).

- Drums, containers, equipment or debris: Materials of interest that may have been used at, or added to, a location, and that may have contained or come in contact with hazardous or radioactive substances at some point during their use.

- Lithology: Locations where variations in lithology (soil or rock) indicate that different conditions or materials exist.

- Preselected areas based on process knowledge of the site: Locations for which evidence such as historical photographs, experience from previous investigations, or interviewee input exists that a release of hazardous or radioactive substances may have occurred. 
- Preselected areas based on process knowledge of the contaminant(s): Locations that may reasonably have received contamination, selected on the basis of the chemical and/or physical properties of the suspected contaminant(s) in that environmental setting.

- Previous sample results: Locations that may reasonably have been contaminated based upon the results of previous field investigations.

- Other biasing factors: Factors not previously defined for the investigation, but become evident once the investigation of the site is under way.

Decision II sample step-out locations will be selected based on the CSM, biasing factors, and existing data. Analytical suites will include those parameters that exceeded FALs (i.e., COCs) in previous samples. Biasing factors to support Decision II sample locations include Decision I biasing factors plus available analytical results.

\section{A.4.2.1.2 Probabilistic Approach for Sample Location Selection}

Decision I sample locations at mud pits will be selected using a probabilistic approach. Several parameters must be agreed to by the decision-makers before estimating the required number of samples to be collected and the sampling locations. These parameters include:

- The form of the probability-based sampling design (e.g., simple random vs. systematic/grid).

- A confidence level that a Type 1 error (false negative) will not occur.

- A confidence level that a Type 2 error (false positive) will not occur.

- The width of the "Gray Region" (the range of values below the action level for which it cannot be determined that a COC does not exist at the site).

- An estimated sampling standard deviation (e.g., professional judgment of the expected standard deviation of the sample results) (PNNL, 2005).

- Estimations, if any, for the distribution of the data (e.g., normal, lognormal, or gamma).

By consensus of the DQO meeting participants and agreed to by the decision-makers, the values in Table A.4-1 were established for the probabilistic sampling.

For analytical non-detections (non-detects), a proxy method of using one-half the actual detection limit values will be followed (EPA, 2004). 
Table A.4-1

Parameter Values Established by DQO Participants

\begin{tabular}{|c|c|c|c|}
\hline Parameter & Description & $\begin{array}{l}\text { DQO Decision for } \\
\text { Estimating } \\
\text { Sample Size }\end{array}$ & $\begin{array}{l}\text { May Change, or Be } \\
\text { Recalculated, Based } \\
\text { on Actual Data? }\end{array}$ \\
\hline $\begin{array}{l}\text { Sampling Design } \\
\text { Type }\end{array}$ & $\begin{array}{l}\text { Probabilistic sampling approaches include } \\
\text { Simple Random, Stratified, Systematic and } \\
\text { Grid, Ranked Set, Adaptive Cluster, and } \\
\text { Composite }\end{array}$ & $\begin{array}{l}\text { Employ a systematic } \\
\text { random design. }\end{array}$ & $\begin{array}{l}\text { No, unless decision is } \\
\text { made to use data } \\
\text { collected to stratify the } \\
\text { site. }\end{array}$ \\
\hline $\begin{array}{l}\text { False Negative } \\
\text { Error }\end{array}$ & $\begin{array}{l}\text { Error generated from deciding that a COC is } \\
\text { not present when it actually is. }\end{array}$ & $\begin{array}{l}\text { UCL established at } \\
95 \text { percent. }\end{array}$ & No \\
\hline $\begin{array}{l}\text { False Positive } \\
\text { Error }\end{array}$ & $\begin{array}{l}\text { Error generated from deciding that a COC is } \\
\text { present when it actually is not. }\end{array}$ & Established at $80 \%$. & No \\
\hline $\begin{array}{l}\text { Gray Region } \\
\text { Width }\end{array}$ & $\begin{array}{l}\text { Region of a Decision Performance Goal } \\
\text { Diagram where the sample data tend toward } \\
\text { rejecting the baseline condition, but the } \\
\text { evidence (data statistics) is not sufficient to be } \\
\text { overwhelming. Wider Gray Regions yield } \\
\text { smaller sample sizes. Determined with } \\
\text { professional judgment and cost/benefit } \\
\text { evaluation. }\end{array}$ & $\begin{array}{l}\text { Initially established to } \\
\text { be one-half the } \\
\text { action level. }\end{array}$ & $\begin{array}{l}\text { No, unless decision is } \\
\text { made to use data } \\
\text { collected to stratify the } \\
\text { site. Gray Region used } \\
\text { for sampling design } \\
\text { purposes only. }\end{array}$ \\
\hline Action Level & $\begin{array}{l}\text { For sampling design purposes, the action } \\
\text { level is the numerical value which, when } \\
\text { exceeded, declares the site to be } \\
\text { contaminated. }\end{array}$ & $\begin{array}{l}\text { Established to be } \\
\text { two times the mean } \\
\text { (average) of the } \\
\text { background } \\
\text { radiological readings } \\
\text { at each site } \\
\text { (Appendix C). }\end{array}$ & $\begin{array}{l}\text { Final action levels for } \\
\text { COCs are used during } \\
\text { this determination. }\end{array}$ \\
\hline $\begin{array}{l}\text { Estimated } \\
\text { Variability }\end{array}$ & $\begin{array}{l}\text { Estimate of standard deviation expected from } \\
\text { the set of samples collected. Value for the } \\
\text { standard deviation impacts the minimum } \\
\text { required sample size. }\end{array}$ & $\begin{array}{l}\text { Established to be the } \\
\text { variability of data } \\
\text { from site radiological } \\
\text { surveys. }\end{array}$ & $\begin{array}{l}\text { Yes, variability will be } \\
\text { calculated and additional } \\
\text { samples will be collected, } \\
\text { if necessary. }\end{array}$ \\
\hline Data Distribution & $\begin{array}{l}\text { Distribution of the actual data typically follows } \\
\text { a pattern, such as a bell-shaped curve, a } \\
\text { log-normal curve, or skewed towards one } \\
\text { direction, such as a gamma distribution. } \\
\text { Distribution of actual data impacts the } \\
\text { determination of the } 95 \text { percent UCL. }\end{array}$ & $\begin{array}{l}\text { Use non-parametric } \\
\text { statistical tests. }\end{array}$ & $\begin{array}{l}\text { Yes, use best-fit } \\
\text { distributions. }\end{array}$ \\
\hline
\end{tabular}

Source: Summary of CAU 177 DQO meeting; EPA, 2000a and c; PNNL, 2005

$\mathrm{COC}=$ Contaminant of concern

$\mathrm{DQO}=$ Data quality objective

$\mathrm{UCL}=$ Upper confidence limit 
Individual mud pit probabilistic sampling and analysis designs are discussed in Section A.8.0. Appendix C provides the methodology and computational approach for probabilistic sampling and lists the sample size and locations as calculated by the VSP software program (PNNL, 2005).

\section{A.4.2.2 Analytical Methods}

Analytical methods are available to provide the data needed to resolve the decision statements. The analytical methods and laboratory requirements (e.g., detection limits, precision, and accuracy) are specified in Sections 7.2.1 and 7.2.2 of the CAU 177 SAFER Plan. Table A.4-2 lists the analytes reported by the various analytical methods that are considered to be COPCs. 
Table A.4-2

Analytes Reported by Analytical Methods

\begin{tabular}{|c|c|c|c|c|c|c|}
\hline \multicolumn{2}{|c|}{ VOC } & SVOC & TPH & PCB & Metals & Radionuclides \\
\hline $\begin{array}{l}\text { 1,1,1-Trichloroethane } \\
\text { 1,1,1,2-Tetrachloroethane } \\
\text { 1,1,2,2-Tetrachloroethane } \\
\text { 1,1,2-Trichloroethane } \\
\text { 1,1-Dichloroethane } \\
\text { 1,1-Dichloroethene } \\
\text { cis-1,2-Dichloroethene } \\
\text { 1,2-Dichloroethane } \\
\text { 1,2-Dichloropropane } \\
\text { 1,2,4-Trichlorobenzene } \\
\text { 1,2,4-Trimethylbenzene } \\
\text { 1,2-Dibromo-3-chloropropane } \\
\text { 1,3,5-Trimethylbenzene } \\
\text { 1,4-Dioxane } \\
\text { 2-Butanone } \\
\text { 2-Chlorotoluene } \\
\text { 2-Hexanone } \\
\text { 4-Methyl-2-pentanone } \\
\text { Acetone } \\
\text { Acetonitrile } \\
\text { Allyl chloride } \\
\text { Benzene } \\
\text { Bromodichloromethane } \\
\text { Bromoform } \\
\text { Bromomethane } \\
\text { Carbon disulfide } \\
\text { Carbon tetrachloride } \\
\text { Chlorobenzene } \\
\text { Chloroethane } \\
\text { Chloroform } \\
\text { Chloromethane } \\
\text { Chloroprene } \\
\text { Dibromochloromethane } \\
\text { Dichlorodifluoromethane } \\
\text { Ethyl methacrylate } \\
\text { Ethylbenzene } \\
\text { Isobutyl alcohol } \\
\text { Isopropylbenzene } \\
\text { m-Dichlorobenzene (1,3) } \\
\text { Methacrylonitrile } \\
\text { Methyl methacrylate }\end{array}$ & $\begin{array}{l}\text { Methylene chloride } \\
\text { N-Butylbenzene } \\
\text { N-Propylbenzene } \\
\text { o-Dichlorobenzene }(1,2) \\
\text { p-Dichlorobenzene }(1,4) \\
\text { p-isopropyltoluene } \\
\text { sec-Butylbenzene } \\
\text { Styrene } \\
\text { tert-Butylbenzene } \\
\text { Tetrachloroethene } \\
\text { Toluene } \\
\text { Total Xylenes } \\
\text { Trichloroethene } \\
\text { Trichlorofluoromethane } \\
\text { Vinyl acetate } \\
\text { Vinyl chloride }\end{array}$ & $\begin{array}{l}\text { 2,3,4,6-Tetrachlorophenol } \\
\text { 2,4-Dimethylphenol } \\
\text { 2,4-Dinitrotoluene } \\
\text { 2,4,5-Trichlorophenol } \\
\text { 2,4,6-Trichlorophenol } \\
\text { 2-Chlorophenol } \\
\text { 2-Methylnaphthalene } \\
\text { 2-Methylphenol } \\
\text { 2-Nitrophenol } \\
\text { 3-Methylphenol } \\
\text { 4-Chloroaniline } \\
\text { 4-Methylphenol } \\
\text { 4--Nitrophenol } \\
\text { Acenaphthene } \\
\text { Acenaphthylene } \\
\text { Aniline } \\
\text { Anthracene } \\
\text { Benzo(a)anthracene } \\
\text { Benzo(a)pyrene } \\
\text { Benzo(b)fluoranthene } \\
\text { Benzo(g,h,i)perylene } \\
\text { Benzo(k)fluoranthene } \\
\text { Benzoic Acid } \\
\text { Benzyl Alcohol } \\
\text { Bis(2-ethylhexyl) phthalate } \\
\text { Butyl benzyl phthalate } \\
\text { Carbazole } \\
\text { Chrysene } \\
\text { Dibenzo(a,h)anthracene } \\
\text { Dibenzofuran } \\
\text { Diethyl phthalate } \\
\text { Dimethyl phthalate } \\
\text { Di-n-butyl phthalate } \\
\text { Di-n-octyl phthalate } \\
\text { Fluoranthene } \\
\text { Fluorene } \\
\text { Hexachlorobenzene } \\
\text { Hexachlorobutadiene } \\
\text { Hexachloroethane } \\
\text { Indeno(1,2,3-cd)pyrene } \\
\text { Naphthalene } \\
\text { Nitrobenzene } \\
\text { N-Nitroso-di-n-propylamine } \\
\text { Pentachlorophenol } \\
\text { Phenanthrene } \\
\text { Phenol } \\
\text { Pyrene } \\
\text { Pyridine } \\
\text { (a) }\end{array}$ & $\begin{array}{l}\text { TPH } \\
\text { (Diesel-Range Organics } \\
\text { and } \\
\text { Gasoline-Range Organics) }\end{array}$ & $\begin{array}{l}\text { Aroclor } 1016 \\
\text { Aroclor } 1221 \\
\text { Aroclor } 1232 \\
\text { Aroclor } 1242 \\
\text { Aroclor } 1248 \\
\text { Aroclor } 1254 \\
\text { Aroclor } 1260 \\
\text { Aroclor } 1268\end{array}$ & $\begin{array}{l}\text { Arsenic } \\
\text { Barium } \\
\text { Beryllium } \\
\text { Cadmium } \\
\text { Chromium } \\
\text { Lead } \\
\text { Mercury } \\
\text { Selenium } \\
\text { Silver }\end{array}$ & $\begin{array}{l}\text { Plutonium-238 } \\
\text { Plutonium-239/240 } \\
\text { Strontium-90 } \\
\text { Uranium-234 } \\
\text { Uranium-235 } \\
\text { Uranium-238 } \\
\text { Other parameters: } \\
\text { Gamma-emitting radionuclides } \\
\text { including: } \\
\text { Actinium-228 } \\
\text { Aluminum-26 } \\
\text { Americium-241 } \\
\text { Antimony-125 } \\
\text { Beryllium-7 } \\
\text { Bismuth-212 } \\
\text { Bismuth-214 } \\
\text { Cesium-134 } \\
\text { Cesium-137 } \\
\text { Cobalt-58 } \\
\text { Cobalt-60 } \\
\text { Curium-243 } \\
\text { Europium-152 } \\
\text { Europium-154 } \\
\text { Europium-155 } \\
\text { Lead-212 } \\
\text { Lead-214 } \\
\text { Niobium-94 } \\
\text { Potassium-40 } \\
\text { Thallium-208 } \\
\text { Thorium-227 } \\
\text { Thorium-234 } \\
\text { Uranium-235 }\end{array}$ \\
\hline
\end{tabular}




\section{A.5.0 Step 4 - Define the Boundaries of the Study}

The purpose of this step is to define the population of interest and spatial boundaries, determine practical constraints on data collection, and define the scale of decision-making.

\section{A.5.1 Populations of Interest}

The population of interest to resolve Decision I ("Is any COC present in environmental media within a mud pit or cellar?”) is either any location within the site that is contaminated with any contaminant above a FAL (judgmental sampling), or locations representative of site contamination (probabilistic sampling). The populations of interest to resolve Decision II ("If a COC is present, is sufficient information available to meet closure objectives?”) are:

- Each one of a set of locations bounding contamination in lateral and vertical directions.

- Environmental media that must be characterized for disposal or IDW.

- Potential remediation waste.

- Environmental media where natural attenuation or biodegradation or construction/evaluation of barriers is considered.

Regardless of the sampling design, the population of interest for this investigation is surface soil defined as either the residual drilling fluid contained in a mud pit or potentially impacted soil at the base of a cellar. For uncovered mud pits and cellars, the surface soil is defined as 0 to 12 in. in depth. For backfilled mud pits and cellars, the soil to be sampled resides within the first 12 in. directly below the fill material.

Following the approved risk-based approach, soil samples from the surface of the residual drilling fluid are considered sufficient to adequately characterize the risk posed by the mud pits. A review of data from previous mud pit investigations conducted under the complex process has demonstrated that TPH-DRO concentrations in surface soils are representative of the TPH-DRO concentrations throughout the depth of the residual drilling fluid (NNSA/NSO, 2004). The same process would apply to radiological constituents suspected to be present in the residual drilling fluid in the mud pits of CAU 177. In addition, considering the proposed industrial future land uses, the surface soil is the 
primary exposure point for future workers. Thus, samples collected from subsurface soils would yield no additional information.

\section{A.5.2 Spatial Boundaries}

Spatial boundaries are the maximum lateral and vertical extent of expected contamination at each mud pit and cellar, as shown in Table A.5-1. Contamination found beyond these boundaries may indicate a flaw in the CSM and may require re-evaluation of the CSM before the investigation could continue. Each CAS is considered geographically independent and intrusive activities are not intended to extend into the boundaries of neighboring CASs.

Table A.5-1

Spatial Boundaries of CAU 177 Mud Pits and Cellars

\begin{tabular}{||c|l|}
\hline \multicolumn{1}{|c|}{ Feature } & \multicolumn{1}{|c|}{ Spatial Boundaries } \\
\hline \hline Mud Pit & $\begin{array}{l}\text { The lateral boundaries are the walls/berms of each mud pit plus a } \\
50 \text {-foot lateral buffer. The vertical boundary is the depth of } \\
\text { residual drilling mud in the mud pit, typically 1-3 feet. }\end{array}$ \\
\hline Cellar & $\begin{array}{l}\text { The lateral boundary is the corrugated metal casing that lines } \\
\text { each cellar, typically 10 feet in diameter. The vertical boundary is } \\
\text { defined as 15 feet below the base of the cellar. }\end{array}$ \\
\hline
\end{tabular}

\section{A.5.3 Practical Constraints}

Investigation of these CASs may be impacted by physical constraints and activities at the NTS. General practical constraints include weather, rough terrain, and access restrictions. Access restrictions include scheduling conflicts on the NTS with other entities, areas posted as contamination areas requiring appropriate work controls, or areas requiring authorized access, and physical barriers (e.g., fences).

Specific constraints that may temporarily delay sampling include potential restricted access to Area 19 and 20 CASs during winter months due to snow cover; obtaining a confined space permit (if needed) to enter open cellars; restricted access to mud pits and open cellars due to ponding of water following inclement weather; and military exercises, which would restrict access.

Identified constraints that may limit intrusive sampling include buried debris, the orientation and presence of drill stemming that remains in the cellar/borehole, a concrete bottom in the cellar, 
underground utilities, overhead power lines, and underlying geology (i.e., caliche, bedrock). Underground utilities surveys will be conducted at each CAS before starting investigation activities to determine whether utilities exist, and, if so, determining the limit of spatial boundaries for intrusive activities.

\section{A.5.4 Define the Scale of Decision-Making}

The scale of decision-making for resolving Decision I and Decision II statements is defined as the individual mud pit or cellar, which allows for individual mud pits and cellars within a CAS to be closed independently. For Decision I, any COC detected at any location within a cellar will cause the determination that the media contained by that feature is contaminated and needs further evaluation. Any COC identified in a mud pit will cause the determination that the residual mud is contaminated. Because contamination is expected to be bound within the matrix of the drilling mud, further evaluation is not necessary.

For resolving the Decision II statement, the scale of decision-making for a cellar is defined as a contiguous area contaminated with any COC likely originating from the cellar. Resolution of Decision II requires this contiguous area to be bounded laterally and vertically. For mud pits, because contaminants are bound within the matrix of the drilling mud, the maximum lateral extent would be defined as the walls/berms of the mud pit, and the vertical extent would be the depth of the residual drilling mud. 


\section{A.6.0 Step 5 - Develop a Decision Rule}

This step develops a decision rule (“If..., then...”) statement that defines the conditions under which possible alternative actions will be chosen. In this step, we specify parameters that characterize the population of interest, specify the FALs, confirm that detection limits are sensitive enough to detect FALs, and present decision rules.

\section{A.6.1 Population Parameters}

For judgmental sampling results, the population parameter is the maximum observed concentration of each contaminant from each individual analytical sample. Each sample result will be compared to the FALs to determine the appropriate resolution to Decision I and Decision II. For Decision I, a single sample result for any contaminant exceeding a FAL would cause a determination that a COC is present within the CAS.

For probabilistic sampling results, the population parameter is the 95 percent UCL of the sample population average concentration of each contaminant from all analytical samples from an individual contaminant release. The population parameter will be compared to the corresponding FALs to determine the appropriate resolution to Decision I and Decision II. For Decision I, a 95 percent UCL of the average concentration for any contaminant exceeding a FAL would cause a determination that a COC is present within the CAS.

The Decision II population parameter is an individual analytical result from a bounding sample. For Decision II, a single bounding sample result for any contaminant exceeding a FAL would cause a determination that the contamination is not bounded.

\section{A.6.2 Decision Rules}

The decision rules applicable to both Decision I and Decision II are:

- If COC contamination is inconsistent with the CSM, or extends beyond the spatial boundaries identified in Section A.5.2, then work will be suspended and the investigation strategy will be reconsidered. For a cellar, if a COC is present; is consistent with the CSM, and within spatial boundaries, then the decision will be to continue sampling to define the extent. For a mud pit, 
if the characteristic concentration of a contaminant exceeds the action level, then the mud pit will be considered contaminated and closure alternatives will be evaluated.

The decision rules for Decision I are:

- If the population parameter of any COPC in the Decision I population of interest (defined in Step 4) for a cellar exceeds the corresponding FAL, then that analyte is identified as a COC, and Decision II samples will be collected, if necessary, to define the extent of COC contamination. If the population parameter of any COPC in the Decision I population of interest (defined in Step 4) for a mud pit exceeds the corresponding FAL, then that analyte is identified as a COC, and it will be determined that the residual mud is contaminated and bounded by the Decision I random sampling and the berm of the mud pit. If all COPC concentrations are less than the corresponding action levels in both mud pits and cellars, then the decision will be no further action.

The decision rules for Decision II are:

- If the population parameter (the maximum observed concentration of any COC) in the Decision II population of interest (defined in Step 4) for a cellar exceeds the corresponding FAL, then additional samples will be collected to complete the Decision II evaluation. If all bounding COC concentrations are less than the corresponding FALs, then the decision will be that the extent of contamination has been defined in the corresponding lateral and/or vertical direction.

- If valid analytical results are available for the waste characterization samples defined in Section A.8.0, then the decision will be that sufficient information exists to characterize the IDW for disposal, determine potential remediation waste types, and to confirm that closure objectives were met.

\section{A.6.3 Action Levels}

The PALs presented in this section are to be used for site screening purposes. They are not necessarily intended to be used as cleanup action levels or FALs. However, they are useful in screening out contaminants that are not present in sufficient concentrations to warrant further evaluation and, therefore, streamline the consideration of remedial alternatives. The RBCA process used to establish FALs is described in the Industrial Sites Project Establishment of Final Action Levels (NNSA/NSO, 2006). This process conforms with NAC Section 445A.227, which lists the requirements for sites with soil contamination (NAC, 2006a). For the evaluation of corrective actions, NAC Section 445A.22705 (NAC, 2006b) requires the use of ASTM Method E 1739-95 (ASTM, 1995) to "conduct an evaluation of the site, based on the risk it poses to public health and the 
environment, to determine the necessary remediation standards (i.e., FALs) or to establish that corrective action is not necessary."

This RBCA process defines three tiers (or levels) of evaluation involving increasingly sophisticated analyses:

- Tier 1 - Sample results from source areas (highest concentrations) are compared to action levels based on generic (non-site-specific) conditions (i.e., the PALs established in the SAFER Plan). The FALs may then be established as the Tier 1 action levels, or the FALs may be calculated using a Tier 2 evaluation.

- $\quad$ Tier 2 - Conducted by calculating Tier 2 site-specific target levels (SSTLs) using site-specific information as inputs to the same or similar methodology used to calculate Tier 1 action levels. The Tier 2 SSTLs are then compared to individual sample results from reasonable points of exposure (as opposed to the source areas as is done in Tier 1) on a point-by-point basis. Total TPH concentrations will not be used for risk-based decisions under Tier 2 or Tier 3. Rather, the individual chemicals of concern will be compared to the SSTLs.

- $\quad$ Tier 3 - Conducted by calculating Tier 3 SSTLs on the basis of more sophisticated risk analyses using methodologies described in ASTM Method E 1739-95 that consider site-, pathway-, and receptor-specific parameters.

The comparison of laboratory results to FALs and the evaluation of potential corrective actions will be included in the investigation report. The FALs will be defined (along with the basis for definition) in the investigation report.

\section{A.6.4 Measurement and Analysis Sensitivity}

The measurement and analysis methods specified in Sections 7.2.1 and 7.2.2 of the CAU 177 SAFER Plan and in the Industrial Sites QAPP (NNSA/NV, 2002) are capable of measuring analyte concentrations at or below the corresponding FALs for each COPC. See Section 7.2 of the CAU 177 SAFER Plan for details. 


\section{A.7.0 Step 6 - Tolerable Limits on Decision Errors}

The purpose of this step is to specify performance criteria for the decision rule. Setting tolerable limits on decision errors requires the planning team to weigh the relative effects of a threat to human health and the environment, expenditure of resources, and consequences of an incorrect decision.

For judgmental sampling designs, Section 7.1 of the EPA QA/G-4HW (EPA, 2000a) guidance states that quantitative statements about data quality will be limited to measurement error. Measurement error is influenced by imperfections in the measurement and analysis system. Random and systematic measurement errors are introduced in the measurement process during physical sample collection, sample handling, sample preparation, sample analysis, and data reduction. If measurement errors are not controlled, they may lead to errors in making the DQO decisions.

Limits on decision errors for probabilistic sampling designs are quantitatively set and measurable. Hypothesis, therefore, can be tested to ascertain whether a site is contaminated, to what degree it is contaminated, and what additional impacts common to contaminated sites might have occurred. The use of a probabilistic design provides the ability to optimize resources while meeting DQOs.

This section provides an assessment of the possible outcomes of DQO decisions and the impact of those outcomes if the decisions are in error.

The baseline condition (i.e., null hypothesis) and alternative condition for Decision I are:

- Baseline condition - A COC is present.

- Alternative condition - A COC is not present.

The baseline condition (i.e., null hypothesis) and alternative condition for Decision II are as follows:

- $\quad$ Baseline condition - The extent of a COC has not been defined.

- Alternative condition - The extent of a COC has been defined.

Decisions and/or criteria have false negative or false positive errors associated with determination. The impact of these decision errors and the methods that will be used to control these errors are 
discussed in the following subsections. In general terms, confidence in DQO decisions based on judgmental sampling results will be established qualitatively by:

- Development and concurrence of CSM(s) (based on process knowledge) by stakeholder participants during the DQO process.

- Testing the validity of $\operatorname{CSM}(\mathrm{s})$ based on investigation results.

- Evaluating the quality of the data based on DQI parameters.

\section{A.7.1 False Negative Decision Error}

The false negative decision error would mean deciding that a COC is not present when it actually is (Decision I), or deciding that the extent of a COC has been defined when it has not (Decision II). In both cases, the potential consequence is an increased risk to human health and environment.

\section{A.7.1.1 False Negative Decision Error for Judgmental Sampling}

The false negative decision error (where consequences are more severe) for judgmental sampling designs is controlled by meeting these criteria:

1. For Decision I, having a high degree of confidence that the judgmental sample locations selected will identify COCs if present anywhere within the CAS. For Decision II, having a high degree of confidence that the sample locations selected will identify the extent of COCs.

2. Having a high degree of confidence that analyses conducted will be sufficient to detect any COCs present in the samples.

3. Having a high degree of confidence that the dataset is of sufficient quality and completeness.

To satisfy the first criterion, Decision I samples must be collected from areas most likely to be contaminated by COCs (supplemented by random samples where appropriate). Decision II samples must be collected in areas that represent the lateral and vertical extent of contamination (above action levels). The following characteristics must be considered to control decision errors for the first criterion:

- Source and location of release

- Chemical nature and fate properties 
- Physical transport pathways and properties

- Hydrologic drivers

These characteristics were considered during the development of the CSM and the selection of sampling locations. The field-screening methods and biasing factors in Section A.4.2.1.1 will be used to further ensure that appropriate sampling locations are selected to meet these criteria. Radiological survey instruments and field-screening equipment will be calibrated and checked in accordance with the manufacturer's instructions and approved procedures. The investigation report will present an assessment on the DQI of representativeness (i.e., samples were collected from those locations that best represent populations of interest as defined in Section A.5.1).

To satisfy the second criterion, Decision I samples will be analyzed for the chemical and radiological parameters listed in Section 4.1 of the CAU 177 SAFER Plan. Decision II samples will be analyzed for those chemical and radiological parameters that identified unbounded COCs. The DQI of sensitivity will be assessed for all analytical results to ensure that all sample analyses had measurement sensitivities (detection limits) that were less than or equal to the corresponding FALs. If this criterion is not achieved, the affected data will be assessed (for usability and potential impacts on meeting site characterization objectives) in the investigation report.

To satisfy the third criterion, the entire dataset, as well as individual sample results, will be assessed against the DQIs of precision, accuracy, comparability, and completeness as defined in the Industrial Sites QAPP (NNSA/NV, 2002) and in Section 7.2 of the CAU 177 SAFER Plan. The DQIs of precision and accuracy will be used to assess overall analytical method performance as well as to assess the need to potentially “flag” (qualify) individual analyte results when corresponding QC sample results are not within the established control limits for precision and accuracy. Data qualified as estimated for reasons of precision or accuracy may be considered to meet the analyte performance criteria based on an assessment of the data. The DQI of completeness will be assessed to ensure that all data needs identified in the DQO have been met. The DQI of comparability will be assessed to ensure that all analytical methods used are equivalent to standard U.S. Environmental Protection Agency (EPA) methods so that results will be comparable to regulatory action levels that have been established using those procedures. Strict adherence to established procedures and QA/QC protocol protects against false negatives. 
To provide information for the assessment of the DQIs of precision and accuracy, the following QC samples will be collected as required by the Industrial Sites QAPP (NNSA/NV, 2002):

- Field duplicates (minimum of 1 per matrix per 20 environmental samples)

- Laboratory QC samples (minimum of 1 per matrix per 20 environmental samples or 1 per CAS per matrix, if less than 20 collected)

\section{A.7.1.2 False Negative Decision Error for Probabilistic Sampling}

Control of the false negative decision error under a probabilistic sampling design is quantitatively established through the selection of the false negative error rate (PNNL, 2005). The false negative error rate for all CASs was established by the DQO meeting participants at 0.05 (or 5 percent probability). The false negative error rate is contingent upon:

- Population distribution

- Sample size

- Actual population variability

- Measurement error

Control of the false negative decision error, therefore, for probabilistic sampling designs is accomplished by:

- Determining the appropriate population distribution(s).

- Ensuring a sufficient sample size.

- Having a high degree of confidence that analyses will be sufficient to detect any COCs present.

\section{A.7.2 False Positive Decision Error}

The false positive decision error would mean deciding that a COC is present when it is not, or a COC is unbounded when it is not, resulting in increased costs for unnecessary sampling and analysis and potentially for unnecessary corrective actions.

False positive results are typically attributed to laboratory and/or sampling/handling errors that could cause cross contamination. To control against cross contamination, decontamination of sampling equipment will be conducted according to established and approved procedures and only clean sample containers will be used. To determine whether a false positive analytical result may have 
occurred, the following QC samples will be collected as required by the Industrial Sites QAPP (NNSA/NV, 2002):

- Trip blanks (1 per sample cooler containing VOC environmental samples)

- Equipment rinsate blanks (1 per sampling event for each type of decontamination procedure)

- Source blanks (1 per lot of source material that contacts sampled media)

- Field duplicates (1 per 20 environmental samples or 1 per CAS per matrix, if less than 20 collected)

- Field blanks (1 per 20 environmental samples or 1 per day)

- Laboratory QC samples (1 per 20 environmental samples or 1 per CAS per matrix, if less than 20 collected)

For probabilistic sampling, false positive decision error was established by the DQO meeting participants at 0.20 (or 20 percent probability). This decision error will also be controlled by implementing the controls listed in Section A.7.1 for probabilistic sampling designs. 


\section{A.8.0 Step 7 - Optimize the Design for Obtaining Data}

This section provides the general approach for obtaining the information necessary to resolve Decision I and Decision II. Section A.8.1 provides the probabilistic sampling approach that will be implemented to select sample locations and evaluate analytical results at all mud pits. Section A.8.2 provides the judgmental sampling approach that will be implemented to select sample locations and evaluate analytical results at all cellars. Judgmental sampling allows the methodical selection of sample locations that target the populations of interest (defined in Step 4). Even in the absence of biasing factors, the sampling planned is considered judgmental because of the limited spatial boundaries of each cellar. A summary of the sampling approach and data evaluation for each CAS is presented in Table A.8-1.

Table A.8-1

Summary of Sampling Approach and Data Evaluation for CAU 177

\begin{tabular}{|c|c|c|c|}
\hline $\begin{array}{c}\text { Feature with } \\
\text { Applicable CASs }\end{array}$ & Description & Decision I Parameters & Evaluation of Data \\
\hline $\begin{array}{c}\text { Mud Pit } \\
\text { (08-23-01, 09-09-41, } \\
09-09-45,09-23-05 \\
09-23-08,10-23-02 \\
10-23-03,19-23-01)\end{array}$ & $\begin{array}{l}\text { Probabilistic Sampling } \\
\text { Approach }\end{array}$ & $\begin{array}{l}\text { - Initial number of locations: } \\
10 \text { random } \\
\text { - Soil profile depth(s): } \\
\text { Surface (0-12 in. or first } \\
12 \text { in. below cover material } \\
\text { if backfilled) }\end{array}$ & $\begin{array}{l}95 \text { percent UCL of the } \\
\text { mean concentration of } \\
\text { each constituent that } \\
\text { exceeds the PAL will be } \\
\text { compared to the FAL. }\end{array}$ \\
\hline $\begin{array}{c}\text { Cellar } \\
\text { (08-23-01, 09-09-45, } \\
\text { 09-23-05, 09-23-08, } \\
\text { 09-23-09, 10-23-02, } \\
\text { 10-23-03, 19-23-01, } \\
\text { 19-23-02, 19-23-03, } \\
20-23-07)\end{array}$ & $\begin{array}{l}\text { Judgmental Sampling } \\
\text { Approach }\end{array}$ & $\begin{array}{l}\text { - Initial number of locations: } \\
2 \text { equally distributed } \\
\text { locations } \\
\text { - Soil profile depth(s): } \\
\text { Surface (0-12 in. or first } 12 \\
\text { in. below cover material if } \\
\text { backfilled) at biasing factor } \\
\text { or distributed at the } \\
\text { accessible area of the } \\
\text { cellar in the absence of } \\
\text { biasing factors. }\end{array}$ & $\begin{array}{c}\text { Point-by-point } \\
\text { comparison of each } \\
\text { analytical result to the } \\
\text { FAL. }\end{array}$ \\
\hline
\end{tabular}

$\mathrm{FAL}=$ Final action level

$\mathrm{PAL}=$ Preliminary action level

UCL = Upper confidence limit

Statistical methods that generate site characteristics will be used at all mud pits. The information collected from probabilistic sampling will allow for establishing radiological contaminant concentrations that represent the mud pit as a whole. Because individual sample results, rather than an average (mean) concentration, will be used to compare to action levels at the cellars undergoing 
judgmental sampling, statistical methods to generate site characteristics will not be used. Section 0.4.4 of the EPA Data Quality Objectives Process for Hazardous Waste Site Investigations (EPA QA/G-4HW) (EPA, 2000a) guidance states that the use of statistical methods may not be warranted by program guidelines or site-specific sampling objectives. The need for statistical methods is dependent upon the decisions being made. Section 7.1 of the EPA QA/G-4HW guidance states that a nonprobabilistic (judgmental) sampling design is developed when there is sufficient information on the contamination sources and history to develop a valid CSM and to select specific sampling locations. This design is used to confirm the existence of contamination at specific locations and provide information (such as extent of contamination) about specific areas of the site.

Sample locations will be selected to satisfy the DQI of representativeness in that samples collected from selected locations will best represent the populations of interest as defined in Section A.5.1. To meet this criterion for probabilistic sites, randomly selected sample locations will be chosen, with locations specified by the VSP software as outlined in Section A.4.2.1.2 and Appendix C. If a sample cannot be collected from a particular location, or the location is not representative of the site, the location will be replaced by another randomly-determined location. To meet the DQI criterion for

judgmentally sampled sites, a biased sampling strategy will be used for Decision I to target areas with the highest potential for contamination, if it is present in the cellar. Sample locations will be determined based on process knowledge, previously acquired data, or the field screening and biasing factors listed in Section A.4.2.1.1. If biasing factors are present in soils below locations where Decision I samples were removed, additional Decision I soil samples will be collected at depth intervals selected by the Site Supervisor (SS) based on biasing factors to a depth where the biasing factors are no longer present. The SS has the discretion to modify the sample locations at judgmentally sampled CASs, but only if the modified locations meet the decision needs and criteria stipulated in this DQO.

\section{A.8.1 Mud Pit Sampling Design}

The mud pits are being investigated based on the potential for radiological contamination of the residual drilling mud contained within the mud pit. A total of 10 samples per mud pit will be collected from the residual drilling mud, or 0 to 12 in. below cover material, or at the expected depth of mud for backfilled mud pits. This number has been estimated to sufficiently satisfy the criteria of 
establishing the 95 percent UCL of the average COPC concentration and to meet the parameter values listed in Table A.4-1. Appendix C reviews the methodology and computational approach of the VSP software program for determining the sample size and locations for probabilistic sampling (PNNL, 2005). The samples will be configured in a triangular pattern to ensure that all areas of the pit are represented. The initial sample location will be randomly chosen and will serve as the basis for the triangular grid that is established by VSP. Figure A.8-1 shows the predetermined layout of surface sample locations to be collected at a mud pit.

Samples to be collected at open mud pits will be obtained through hand scoop, backhoe excavation, or other appropriate method. Samples to be collected at backfilled mud pits will be obtained through backhoe excavation or other appropriate method. For backfilled mud pits, the cover material/residual mud interface is expected to be easily recognized and encountered at a depth bgs typical of other NTS excavated mud pits (4 to $5 \mathrm{ft}$ bgs based on observations from previous mud pit investigations). Although the cover material/residual mud interface was well recognized at most previously investigated backfilled mud pits, the transition between these layers may not be distinguishable for reasons such as (a) the mud pit was not used or only partially used and (b) because boundaries of backfilled mud pits are approximated; some unbiased samples may be located in the former mud pit berm. The following, therefore, lists a procedure for obtaining samples from residual mud:

- Soil will be monitored for lithology changes during excavation to identify the cover material/residual mud interface.

- If the interface is recognizable, then a sample will be collected from the first 12 in. of mud/cuttings directly below the interface.

- If the interface is not recognizable, then a sample will be collected at the depth where the residual mud is expected to be located based on the observations from other mud pits.

- If the interface has not been identified and a layer of caliche is encountered, then a sample will be collected directly above the caliche.

In addition to the 10 unbiased samples to be collected from each mud pit, additional biased samples may be collected in areas of obvious spills or staining located either within or adjacent to the mud pit. The SS has the discretion to modify the sample locations or order additional biased samples to be collected, but only if the new locations meet the decision needs and criteria stipulated in this DQO. The SS will use professional judgment to determine whether biasing factors (e.g., stains, elevated 


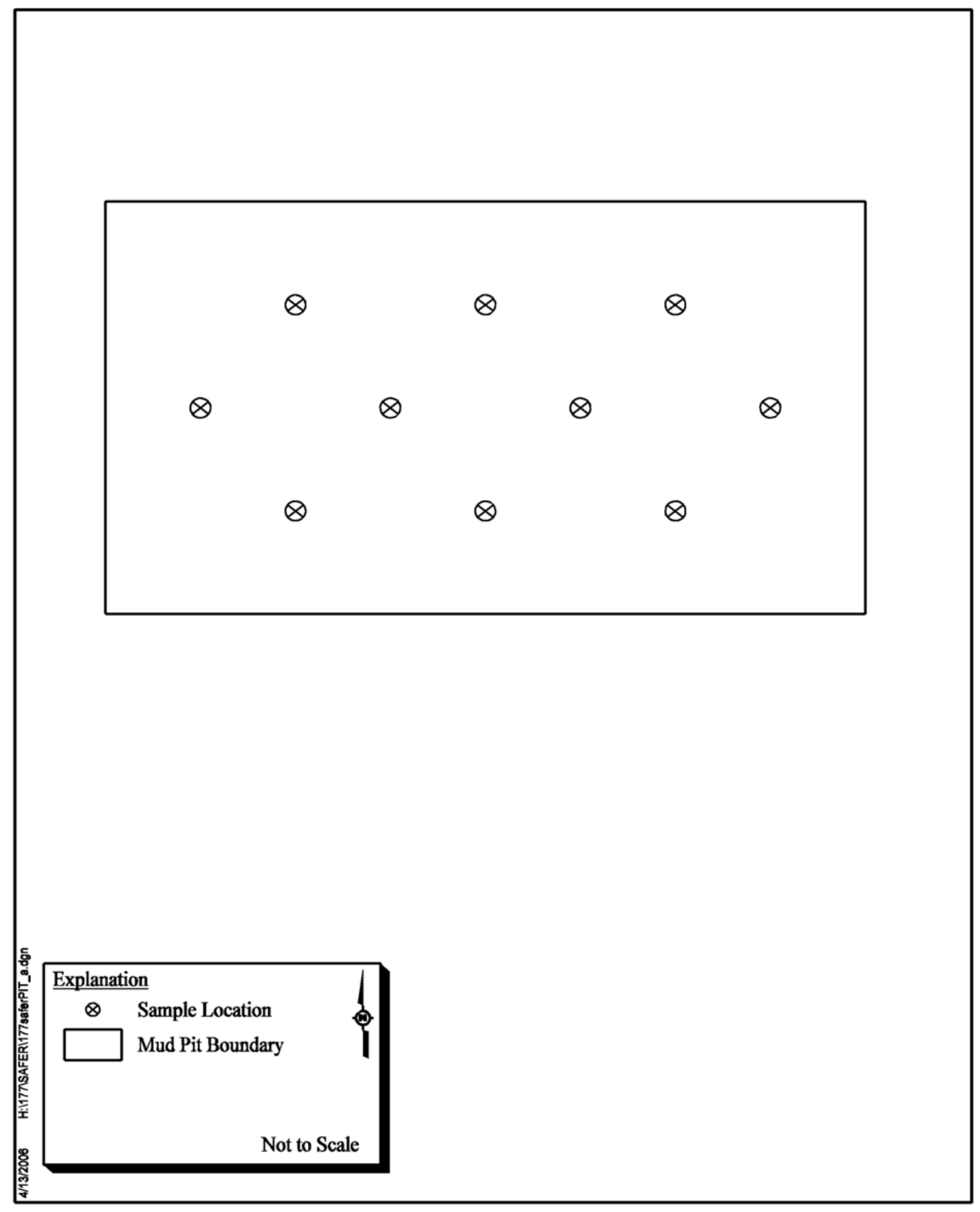

Figure A.8-1

Proposed Sample Locations at Mud Pits 
screening levels) are found during Decision I sampling that might indicate the need to take subsurface Decision II samples.

\section{A.8.2 Cellar Sampling Design}

The cellars are being investigated based on the potential for chemical and radioactive contamination of surface soil at the cellar base. Judgmental samples will be collected from surface soil at the base of an open cellar, or at the first 12 in. of soil directly beneath the cover material for a backfilled cellar based on biasing factors.

During the DQO process, it was agreed that a minimum of four samples (two surface and two subsurface) would be sufficient to determine whether contamination exists. The subsurface samples will be collected during Decision I sampling, to avoid complications with accessing cellar samples at a later time, but may also provide potential Decision II information on vertical migration of contaminants, if any. The locations of the surface samples will be restricted to within the boundaries of the cellar casing, because contamination is not expected to have migrated laterally outside of this boundary. The presence and orientation (i.e., direction and angle of installation) of drill stemming left within the cellar cavity may laterally and vertically restrict access to surface and subsurface sample locations. The common post-test drilling situation was to drill at an angle to access the zone of rock affected by the test associated with post-test drilling (LLNL, 1984). Based on this process, it is possible to determine the direction at which the drill stemming trends below the ground surface. Sample locations may therefore vary and will depend on the following criteria:

- For open cellars, which are confirmed to have drill stemming left in place, surface samples locations, if accessible, will be selected based on biasing factors (defined in Section A.4.2.1.1). In the expected absence of obvious biasing factors, planned sample locations will be either equally distributed on each side of the drill stemming if the entire cellar area is accessible (Figure A.8-2, item [a]), or equally distributed on the side of the cellar that will be accessible for the appropriate sample collection method (Figure A.8-2, item [b]).

- For backfilled cellars, biasing factors are not expected to be apparent. Locations, therefore, will be selected based on the proposed method for open cellars that lack biasing factors. It will be assumed that drill stemming has been left in place for backfilled cellars to avoid contact with the stemming during excavation and sample collection. Access restrictions related to the presence of drill stemming will also be considered for selecting sample locations in backfilled cellars. 
(a)

\section{Plan View}

Full Access

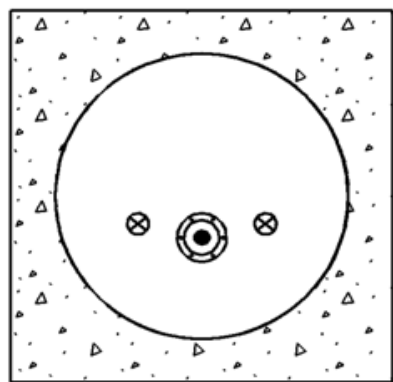

(b)

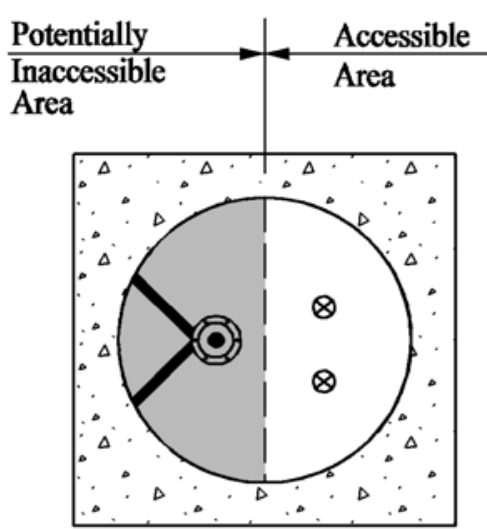

点

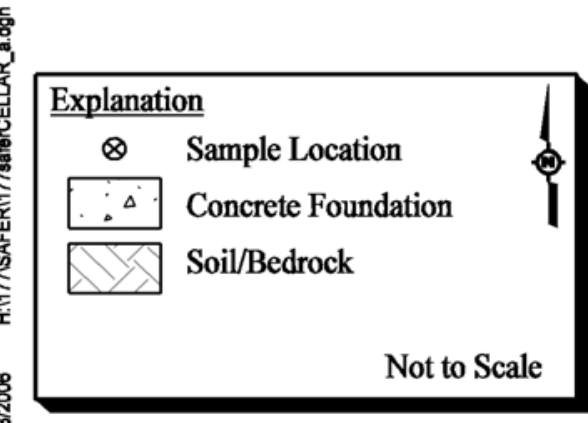

\section{Cross-Section View}

Full Access

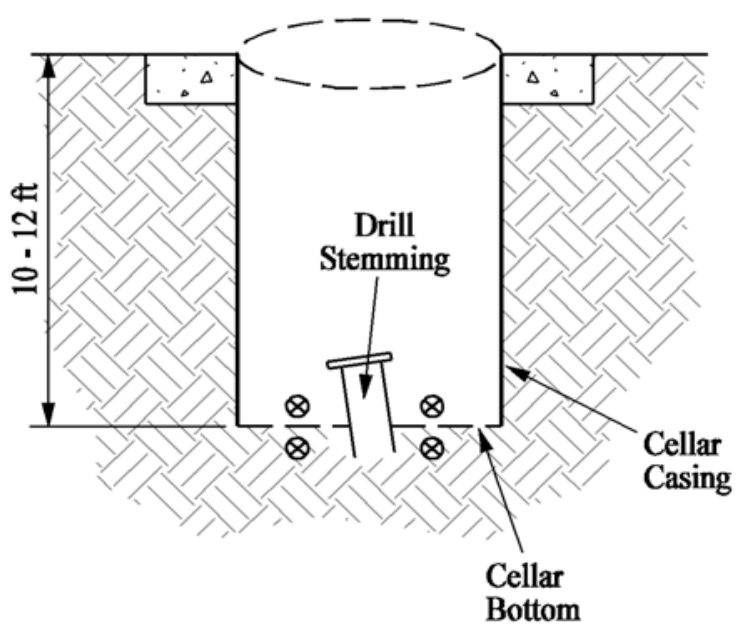

Cross-Section View

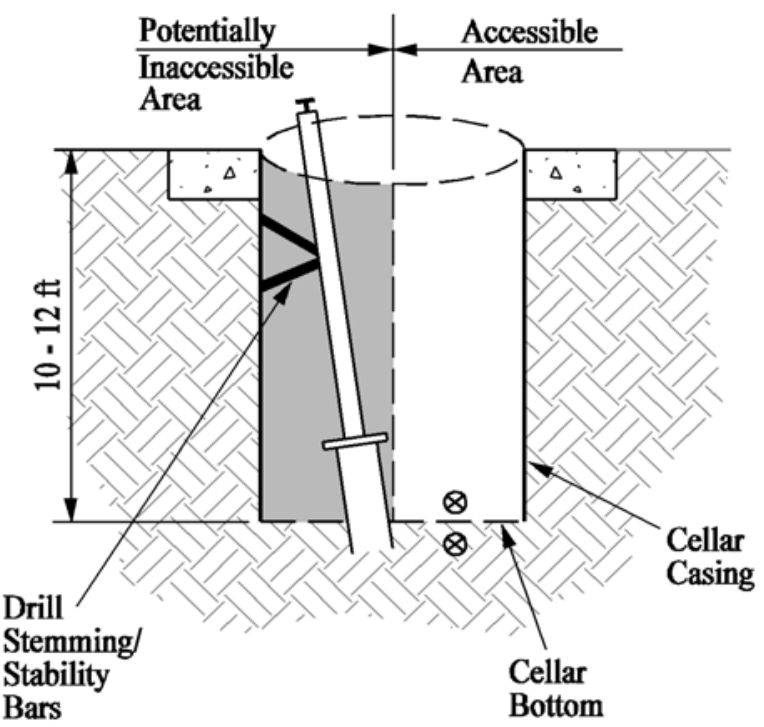

Figure A.8-2

Proposed Sample Locations at Cellars 
Samples will be obtained through either excavation, use of a drill rig, or other appropriate method. Open cellars may be sampled by personnel from the Borehole Management Project for efficiency, because this program has the necessary documentation to enter the cellars. For backfilled cellars, the cover material/surface soil interface is expected to be encountered near a depth of 10 to $12 \mathrm{ft}$ bgs (Figure A.8-2) based on the assumption that this is the typical depth to the base of a cellar as determined from visual observations at the open cellars of CAU 177. However, this transition horizon between cover material and the underlying surface soil may not be distinguishable. The following lists a procedure similar to the mud pits for obtaining samples from the potentially impacted subsurface soil:

- Soil will be monitored for lithology changes during excavation to determine the cover material/surface soil interface.

- If the interface is recognizable, then a sample will be collected from the first $12 \mathrm{in}$. of soil directly below the interface.

- If the interface is not recognizable, then a sample will be collected at the depth where the potentially impacted surface soil is expected to be located (i.e., 10 to $12 \mathrm{ft}$ bgs) based on the observations from open cellars.

- If the interface has not been identified and a layer of caliche, or a cement bottom is encountered, then a sample will be collected directly above that layer.

The SS has the discretion to modify the sample locations or order additional biased samples to be collected, but only if the new locations meet the decision needs and criteria stipulated in this DQO. The SS will use professional judgment to determine whether biasing factors (e.g., stains, elevated screening levels) are found during Decision I sampling that might indicate the need to take subsurface Decision II samples. Decision II step-out samples will only be collected in the vertical direction, because the lateral migration is restricted to the inside of the cellar casing. If a concrete bottom is encountered, then Decision II step-out samples in the vertical direction may not be collected. The SS will determine whether Decision II sampling is appropriate. 


\section{A.9.0 References}

ASTM, see American Society for Testing and Materials.

American Society for Testing and Materials. 1995. Standard Guide for Risk-Based Corrective Action Applied at Petroleum Release Sites, ASTM E 1739-95 (Reapproved 2002). Philadelphia, PA.

DOE/NV, see U.S. Department of Energy, Nevada Operations Office.

EPA, see U.S. Environmental Protection Agency.

Gustafson, D., National Security Technologies, LLC. 2006. Email to N. Nastanski (SNJV) concerning CAU 177 Boreholes, 6 February. Las Vegas, NV.

IMANA, see Industrial Minerals Association - North America.

Industrial Minerals Association - North America. 2004. Bentonite. As accessed at www.ima-na.org/about_industrial_minerals/bentonite.asp on 3 February 2006. Calverton, MD.

LLNL, see Lawrence Livermore National Laboratory.

Lawrence Livermore National Laboratory. 1984. Postshot Drilling Handbook, January. Livermore, CA.

NAC, see Nevada Administrative Code.

NNSA/NV, see U.S. Department of Energy, National Nuclear Security Administration Nevada Operations Office.

NNSA/NSO, see U.S. Department of Energy, National Nuclear Security Administration Nevada Site Office

Nevada Administrative Code. 2006a. NAC 445A.227, “Contamination of Soil: Order by Director for Corrective Action; Factors To Be Considered in Determining Whether Corrective Action Required.” Carson City, NV.

Nevada Administrative Code. 2006b. NAC 445A.22705, “Contamination of Soil: Evaluation of Site by Owner or Operator; Review of Evaluation by Division.” Carson City, NV.

PNNL, see Pacific Northwest National Laboratory.

Pacific Northwest National Laboratory. 2005. Visual Sample Plan Version 4.0 User’s Guide. September. PNNL-14002. Richland, WA. 
SNJV, see Stoller-Navarro Joint Venture.

Stoller-Navarro Joint Venture. Date Unknown. Whitepaper: Assessment of NTS Mud Pit CASs in CAUs 530, 531, 532, 533, 534, and 535 That Are Potentially Contaminated with Radionuclides. 7 July. Las Vegas, NV.

Shott, G.J., V. Yucel, M.J. Sully, L.E. Barker, S.E. Rawlinson, and B.A. Moore. 1997. Performance Assessment/Composite Analysis for the Area 3 Radioactive Waste Management Site at the Nevada Test Site, Nye County, Nevada, Rev. 2.0. Las Vegas, NV.

USGS/DOE, see U.S. Geological Survey and U.S. Department of Energy.

U.S. Department of Energy, National Nuclear Security Administration Nevada Operations Office. 2002. Industrial Sites Quality Assurance Project Plan, Nevada Test Site, Nevada, Rev. 3, DOE/NV--372. Las Vegas, NV.

U.S. Department of Energy, National Nuclear Security Administration Nevada Site Office. 2003a. Closure Report for Corrective Action Unit 355: Area 2 Cellars/Mud Pits, Nevada Test Site, Nevada, DOE/NV--934-Rev. 0, November. Las Vegas, NV.

U.S. Department of Energy, National Nuclear Security Administration Nevada Site Office. 2003b. Draft Closure Report for Corrective Action Unit 358: Area 18, 19, 20 Cellars/Mud Pits, Nevada Test Site, Nevada, November. Las Vegas, NV.

U.S. Department of Energy, National Nuclear Security Administration Nevada Site Office. 2004. Mud Pit Risk-Based Closure Strategy Report, Nevada Test Site, Nevada, DOE/NV--991. Las Vegas, NV.

U.S. Department of Energy, National Nuclear Security Administration Nevada Site Office. 2005. Streamlined Approach for Environmental Restoration Plan for Corrective Action Units 530, 531, 532, 533, 534, and 535, Nevada Test Site Mud Pits, Nevada Test Site, Nevada, DOE/NV--1057. July. Las Vegas, NV.

U.S. Department of Energy, National Nuclear Security Administration Nevada Site Office. 2006. Industrial Sites Project Establishment of Final Action Levels. February. Las Vegas, NV.

U.S. Department of Energy, Nevada Operations Office. 1992. Remedial Investigation and Feasibility Study for the Plutonium Contaminated Soils at Nevada Test Site, Nellis Air Force Range and Tonopah Test Range. April. Las Vegas, NV.

U.S. Department of Energy, Nevada Operations Office. 1998a. Evaluation of Potential Hydrocarbon Transport at the UC-4 Emplacement Hole, Central Nevada Test Area, DOE/NV-11508-43. Prepared by B.F. Lyles, G.Pohll, D.Sloop, C. Papelis. Las Vegas, NV. 
U.S. Department of Energy, Nevada Operations Office. 1998b. Nevada Test Site Resource Management Plan, DOE/NV-518. Las Vegas, NV.

U.S. Department of Energy, Nevada Operations Office. 2001. Mud Pit Strategy, Nevada Test Site, Nevada, DOE/NV-684. Las Vegas, NV.

U.S. Environmental Protection Agency. 2000a. Data Quality Objectives Process for Hazardous Waste Site Investigations. EPA QA/G-4HW. Washington, DC.

U.S. Environmental Protection Agency. 2000b. Guidance for the Data Quality Objective Process, EPA QA/G4. Washington, DC.

U.S. Environmental Protection Agency. 2000c. Multi-Agency Radiation Survey and Site Investigation Manual (MARSSIM). EPA 402-R-97-016, Rev. 1. Washington, DC.

U.S. Environmental Protection Agency. 2002a. Guidance on Choosing a Sampling Design for Environmental Data Collection. EPA QA/G-5S.Washington, DC.

U.S. Environmental Protection Agency. 2002b. Guidance for Quality Assurance Project Plans. EPA QA/G-5. Washington, DC.

U.S. Environmental Protection Agency. 2004. ProUCL Version 3.0 User Guide. EPA/600/R04/079. Washington, DC.

U.S. Geological Survey and U.S. Department of Energy. 2005. "USGS/USDOE Cooperative Studies in Nevada Periodic Water Levels -- Nevada Test Site Map.” As accessed at http://nevada.usgs.gov/doe_nv/doe_nv/ntsmap.htm on 2 February 2006.

Winograd, I.J., and W. Thordarson. 1975. Hydrology and Hydrochemical Framework, South-Central Great Basin, Nevada-California, with Special Reference to the Nevada Test Site, USGS Professional Paper 712-C. Denver, CO. 


\section{Appendix B}

\section{Closure Certification}




\section{B.1.0 Closure Certification}

This appendix is not applicable to CAU 177 because no closure activities were completed. 


\section{Appendix C}

\section{As-Built Documentation}




\section{C.1.0 As-Built Documentation}

This section is not applicable to CAU 177. 


\section{Appendix D}

\section{Confirmation Sampling Test Results}




\section{D.1.0 Introduction}

This appendix presents the CAI activities and analytical results for CAU 177. Corrective Action Unit 177 is located in Areas 8, 9, 19, and 20 of the NTS (Figure 1-1) and comprised of 12 CASs listed below:

- 08-23-01, Mud Pit and Cellar

- 09-09-41, Unknown \#3 Mud Pit/Disposal Area

- 09-09-45, U-9bz PS \#1A Mud Pit (1) and Cellar

- 09-23-05, Mud Pit and Cellar

- 09-23-08, Mud Pit and Cellar

- 09-23-09, U-9itsx20 PS \#1A Cellar

- 10-23-02, Mud Pit and Cellar

- 10-23-03, Mud Pit and Cellar

- 19-23-01, Mud Pit and Cellar

- 19-23-02, Cellar and Waste Storage Area

- 19-23-03, Cellar with Casing

- 20-23-07, Cellar

Corrective Action Unit 177 consists of three CASs in Area 8, five CASs in Area 9, three CASs in Area 19, and one CAS in Area 20. All 12 CASs consist of mud pits and/or cellars constructed and used during drilling activities conducted at the NTS in support of the underground nuclear weapons testing. In particular, the mud pits and cellars of 11 CASs were constructed as part of post-test drilling activities, and most are located within URMAs. It is speculated that the URMAs were posted, based on process knowledge that the mud pits and cellars were associated with the post-test borehole that extended into the underground area, potentially affected by the associated nuclear test. The rationale for posting the area may have been that the borehole allowed for a pathway to potentially radioactive media. The mud pit of CAS 09-09-41 is a disposal-type mud pit and the only one in this CAU that is not associated with a borehole.

The CAI was conducted in accordance with the CAU 177 SAFER Plan as developed under the FFACO (1996). Additional information regarding the history of each site, planning, and the scope of the investigation is presented in the CAU 177 SAFER Plan (NNSA/NSO, 2006b). 


\section{D.1.1 Project Objectives}

The primary objective of the investigation was to provide sufficient information to validate the assumptions used to select the appropriate corrective actions and to verify that closure objectives were met for each for each CAS component (i.e., mud pit or cellar). This objective was achieved by determining the presence of COCs and the vertical and lateral extent of the COCs, if present.

The selection of soil and/or waste characterization sample locations was based on site conditions, and the strategy developed during the DQO process (Appendix A) as presented in the CAU 177 SAFER Plan (NNSA/NSO, 2006b). The sampling strategy involved a probabilistic sampling plan at the mud pits and a judgmental sampling plan at the cellars.

\section{D.1.2 Contents}

This appendix contains information and data in sufficient detail to justify that no further corrective action is required for CAU 177. The contents of this appendix are as follows:

- Section D.1.0 describes the investigation background, objectives, and content.

- Section D.2.0 provides an investigation overview.

- Sections D.3.0 through D.14.0 provide CAS-specific information regarding the field activities, sampling methods, and laboratory analytical results from investigation sampling.

- Section D.15.0 summarizes waste management activities.

- Section D.16.0 discusses the QA/QC procedures followed and results of the QA/QC activities.

- Section D.17.0 provides a summary of the investigation results.

- Section D.18.0 lists the cited references.

The complete field documentation and laboratory data, including Field Activity Daily Logs, sample collection logs (SCLs), analysis request/chain-of-custody forms, soil sample descriptions, laboratory certificates of analyses, analytical results, and surveillance results are retained in project files as hard copy files or electronic media. 


\section{D.2.0 Investigation Overview}

Field investigation and sampling activities for the CAU 177 CAI were conducted from August 7 through August 31, 2006. Table D.2-1 lists the CAI activities that were conducted at each of the CASs.

Table D.2-1

Corrective Action Investigation Activities Conducted at Each CAS

\begin{tabular}{|c|c|c|c|c|c|c|c|c|c|c|c|c|}
\hline \multirow[b]{2}{*}{ Corrective Action Investigation Activities } & \multicolumn{12}{|c|}{ Corrective Action Site } \\
\hline & $\begin{array}{l}\text { 헝 } \\
\text { ஸे } \\
\text { ஸ் }\end{array}$ & $\begin{array}{l}\text { ㅁ } \\
\text { ó } \\
\text { 이 } \\
\text { த் }\end{array}$ & 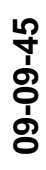 & $\begin{array}{l}\text { م } \\
\text { ஸे } \\
\text { ஸे }\end{array}$ & $\begin{array}{l}\infty \\
\text { o } \\
\text { ஸे } \\
\text { ஸे }\end{array}$ & $\begin{array}{l}\text { o } \\
\text { ஸ் } \\
\text { ஸे }\end{array}$ & 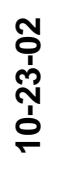 & 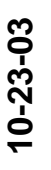 & 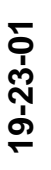 & $\begin{array}{l}\text { ㅇ } \\
\text { ஸे } \\
\stackrel{\text { N }}{\text { ô }}\end{array}$ & 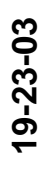 & $\begin{array}{l}\text { ô } \\
\text { Nூ } \\
\text { No } \\
\text { N }\end{array}$ \\
\hline $\begin{array}{l}\text { Inspected and verified the CAS components identified in } \\
\text { the CAU } 177 \text { SAFER Plan. }\end{array}$ & $x$ & $x$ & $x$ & $x$ & $X$ & $X$ & $X$ & $X$ & $X$ & $x$ & $x$ & $x$ \\
\hline $\begin{array}{l}\text { Performed underground/overhead utility checklist } \\
\text { inspections. }\end{array}$ & $x$ & -- & $x$ & $x$ & $x$ & $X$ & $X$ & $x$ & $x$ & $x$ & -- & -- \\
\hline $\begin{array}{l}\text { Performed visual surveys and site walkovers to identify } \\
\text { any changes to site conditions. }\end{array}$ & $x$ & $x$ & $x$ & $x$ & $\mathrm{X}$ & $\mathrm{X}$ & $X$ & $x$ & $x$ & $x$ & $x$ & $x$ \\
\hline $\begin{array}{l}\text { Removed accumulated vegetation to access mud pit } \\
\text { sample locations. }\end{array}$ & -- & $x$ & $x$ & -- & -- & -- & -- & -- & -- & -- & -- & -- \\
\hline $\begin{array}{l}\text { Identified and staked pre-determined GPS sample } \\
\text { locations at mud pits. }\end{array}$ & $x$ & $x$ & $x$ & $x$ & $X$ & -- & $X$ & $x$ & $x$ & -- & -- & -- \\
\hline $\begin{array}{l}\text { Assessed orientation of existing or potentially buried } \\
\text { borehole casing at and performed visual surveys to } \\
\text { select biased sample locations at cellars. }\end{array}$ & $x$ & -- & $x$ & $x$ & $x$ & $X$ & $X$ & $x$ & $x$ & $x$ & $\mathrm{X}$ & $X$ \\
\hline Collected biased soil samples at cellars. & $\mathrm{X}$ & -- & $\mathrm{X}$ & $\mathrm{X}$ & $\mathrm{X}$ & $\mathrm{X}$ & $\mathrm{X}$ & $\mathrm{X}$ & $\mathrm{x}$ & $\mathrm{X}$ & $x$ & $\mathrm{X}$ \\
\hline Collected randomly located soil samples at mud pits. & $\mathrm{X}$ & $\mathrm{X}$ & $\mathrm{X}$ & $\mathrm{X}$ & $\mathrm{X}$ & -- & $\mathrm{X}$ & $\mathrm{X}$ & $\mathrm{x}$ & -- & -- & -- \\
\hline $\begin{array}{l}\text { Field screened samples for alpha and beta/gamma } \\
\text { radiation using a handheld survey instrument. }\end{array}$ & $\mathrm{X}$ & -- & -- & $\mathrm{X}$ & $\mathrm{X}$ & $X$ & $\mathrm{X}$ & $\mathrm{X}$ & $\mathrm{X}$ & $x$ & $\mathrm{X}$ & $X$ \\
\hline $\begin{array}{l}\text { Analyzed samples for gamma radiation using a } \\
\text { high-purity germanium gamma spectrometer } \\
\text { (Building 23-153, Mercury, NV). }\end{array}$ & -- & $\mathrm{X}$ & $\mathrm{X}$ & -- & -- & -- & -- & -- & -- & -- & -- & -- \\
\hline $\begin{array}{l}\text { Collected subsurface soil samples at cellars provided } \\
\text { refusal was not encountered. }\end{array}$ & $\mathrm{X}$ & -- & $\mathrm{X}$ & $\mathrm{X}$ & -- & -- & -- & $x$ & $x$ & $\mathrm{X}$ & -- & -- \\
\hline Submitted select samples for offsite laboratory analysis. & $\mathrm{X}$ & $\mathrm{X}$ & $X$ & $x$ & $x$ & $X$ & $X$ & $x$ & $x$ & $x$ & $x$ & $x$ \\
\hline
\end{tabular}

GPS = Global Positioning System

SAFER = Streamlined Approach for Environmental Restoration

-- = Not applicable 
The investigation and sampling program was managed in accordance with the requirements set forth in the CAU 177 SAFER Plan. Field activities were performed in compliance with safety documents that are consistent with the DOE Integrated Safety Management System. Samples were collected and documented following approved protocols and procedures. Quality control samples (e.g., field blanks, equipment rinsate blanks, trip blanks, and duplicate samples) were collected as required by the Industrial Sites QAPP (NNSA/NV, 2002) and the CAU 177 SAFER Plan (NNSA/NSO, 2006b). During field activities, waste minimization practices were followed according to approved procedures, including segregation of waste by waste stream.

Weather conditions were monitored and at the site varied from sunny to intermittent cloudiness, light to strong winds, and moderate to high temperatures; therefore, weather did not cause delays in site operations.

Sections D.2.1 through D.2.4 provide the investigation methodology and laboratory analytical information.

\section{D.2.1 Selection of Sample Locations}

The sampling locations selected for the CAU 177 investigation were based primarily on information obtained during site visits and process knowledge regarding post-test drilling and the construction of mud pits and cellars. The planned probabilistic and judgmental sampling plans that were applied to the mud pits and cellars, respectively, are discussed in the CAU 177 SAFER Plan (NNSA/NSO, 2006b). The 10 random sample locations that were identified before sampling efforts using the VSP model (PNNL, 2005) were staked at each mud pit using a Global Positioning System (GPS). These locations were configured in a triangular grid pattern with the location of the initial sample randomly chosen. The inner boundary of two mud pits (CASs 09-09-45 and 10-23-02) were resurveyed because multiple sample locations were in the berms rather than the bottom of the mud pit. There were no biasing factors identified at any mud pit that required additional biased sample collection

Selection of biased sample locations at the cellars followed the approach provided in the CAU 177 SAFER Plan. Sample locations at each cellar (open or backfilled) were either equally spaced on each side of the borehole casing, or equally spaced on the accessible side of the cellar. At backfield cellars, 
two subsurface samples will be collected at each borehole; one at the identified interface and a sample 1 to $2 \mathrm{ft}$ below the interface if a cellar bottom is not present. The presence of borehole casing was assumed and its orientation was assessed at each backfilled cellar location. If refusal was encountered due to the presence of borehole casing or other resistant subsurface debris, then the sample location was shifted slightly from the planned location. One surface sample location at CAS 20-23-07 was selected based on an identified area of elevated radioactivity; no other obvious biasing factors were identified at open or backfilled cellars. The actual sample locations at backfilled cellars were surveyed with a GPS instrument; however, the geographic coordinates at some CASs are not considered to be accurate, because the 1 meter accuracy of the instrument is greater than the submeter spatial distance between sample locations. Therefore, the geographic coordinates are not reported for all cellars on the CAS figures in Sections D.3.0 through D.14.0, but the relative geospatial relationship between sample locations is shown, as originally recorded on the SCLs.

\section{D.2.2 Investigation Activities}

The field investigation activities conducted at CAU 177 were based on activities discussed in the CAU 177 SAFER Plan (NNSA/NSO, 2006b). The technical approach consisted of the activities listed in Table D.2-1. The investigation strategy allowed for the nature and extent of contamination associated with each CAS to be established. The following sections describe the specific investigation activities that took place at CAU 177.

\section{D.2.2.1 Radiological Surveys}

Radiological walkover surveys were conducted at each CAS before to investigation activities using a handheld plastic scintillation detector in conjunction with a GPS receiver and datalogger. To conduct radiological static surveys to detect alpha and beta/gamma radiation, a handheld instrument was held within an inch over the sample for one minute. To support unrestricted release determinations per the NV/YMP RadCon Manual (NNSA/NSO, 2004), radiological surveys were performed at the appropriate CASs using a NE Technology Electra with dual-alpha and beta/gamma radiation scintillation probe. Swipe samples were also collected for identification of removable contamination but was not detected on any swipe samples collected during the field investigation. 


\section{D.2.2.2 Field Screening}

Field-screening activities for alpha and beta/gamma radiation, and for gamma-emitting radionuclides were performed as specified in the CAU 177 SAFER Plan. All sample locations were initially field screened for alpha and beta/gamma radiation before the start of sampling. Additional screening was conducted during sample collection both to guide the investigation and serve as a health and safety control measure.

Site-specific FSLs for alpha and beta/gamma radiation were defined as the mean background activity level plus two times the standard deviation of readings from 10 background locations selected near each CAS. With the exception of samples at CAS 09-23-08 that slightly exceeded FSLs for beta (attributed to naturally occurring radon in the soil), no other samples had FSRs that exceeded FSLs. Environmental samples collected at CASs 09-09-41 and 09-09-45 were not screened during sample collection activities due to the elevated background readings in the Area 9 RMA. Instead, these samples were screened for gamma-emitting radionuclides using a high-purity germanium gamma spectrometer (located in Building 23-153) and the FSLs were compared to the PALs established in the CAU 177 SAFER Plan (NNSA/NSO, 2006b) for sample shipping purposes. None of the gamma-spectroscopy results required samples to be shipped as radioactive material.

The CAS-specific sections of this document identify the CASs where field screening was conducted and report if the FSLs were used to aid in the selection of sample locations. Field-screening results are recorded on SCLs that are retained in project files.

\section{D.2.2.3 Surface and Subsurface Soil Sampling}

Surface soil samples were collected using scoop and trowel (surface hand-grab sampling), and subsurface soil samples were collected using a backhoe (backfilled mud pits) and a sonic drill rig (backfilled cellars). All VOC and TPH-gasoline-range organics (GRO) sample containers were filled with soil directly from the sample location. Additional soil was transferred into an aluminium pan, homogenized, and field screened for alpha and beta/gamma radiation. Sample containers for all other analyses were then filled with the homogenized soil. Excess soil was returned to its original location and the disposable sampling equipment was appropriately discarded (based on field-screening). 


\section{D.2.2.4 Waste Characterization Sampling}

No waste characterization samples were collected during the investigation. The waste streams generated included disposable PPE, disposable sampling equipment, and decontamination rinse water. Decontamination rinsate was generated in small volumes that evaporated before the rinsate could be transferred for containment or sampled.

\section{D.2.3 Laboratory Analytical Information}

Chemical and radiological analyses were performed by General Engineering Laboratories, LLC, Charleston, South Carolina. The analytical suites and laboratory analytical methods used to analyze investigation samples are listed in Table D.2-2. Analytical results are reported in this appendix, if detected above the MDCs. The complete laboratory data packages are available in the project files.

Validated analytical data for CAU 177 investigation samples have been compiled and evaluated to confirm the presence and define the extent of contamination, if present. The analytical results for each CAS are presented in Sections D.3.0 through D.14.0.

The analytical parameters are CAS-specific and were selected through the application of site process knowledge according to the EPA’s Guidance for the Data Quality Objectives Process (EPA, 2006).

\section{D.2.4 Comparison to Action Levels}

A COC is defined as any contaminant present in environmental media exceeding a FAL. A COC may also be defined as a contaminant that, in combination with other like contaminants, is determined to jointly pose an unacceptable risk based on a multiple constituent analysis (NNSA/NSO, 2006a).

If COCs are present, a corrective action must be considered for the CAS. The FALs for the CAU 177 investigation are defined for each CAS in Appendix H. Results that are equal to or greater than FALs are identified by bold text in the CAS-specific results tables (Sections D.3.0 through D.14.0). 
Table D.2-2

\section{Laboratory Analytical Parameters and Methods, CAU 177 Investigation Samples ${ }^{a}$}

\begin{tabular}{|c|c|}
\hline Analytical Parameter & Analytical Method \\
\hline \multicolumn{2}{|c|}{ Organic and Inorganic Analyses } \\
\hline Volatile organic compounds & Water and Soil - SW-846 8260B \\
\hline Semivolatile organic compounds & Water and Soil - SW-846 8270C \\
\hline Total petroleum hydrocarbons-gasoline-range organics & Water and Soil - SW-846 8015B (modified) ${ }^{b}$ \\
\hline Total petroleum hydrocarbons-diesel-range organics & Water and Soil - SW-846 8015B (modified) ${ }^{b}$ \\
\hline RCRA metals ${ }^{c}$, plus beryllium & $\begin{array}{l}\text { Water - SW-846 6010B/6020 }, 7470 A^{b} \\
\text { Soil - SW-846 6010B/6020b } 7471 A^{b}\end{array}$ \\
\hline Polychlorinated biphenyls & Water and Soil - SW-846 $8082^{\mathrm{b}}$ \\
\hline \multicolumn{2}{|c|}{ Radiological Analyses } \\
\hline Gamma spectroscopy & $\begin{array}{l}\text { Water - EPA } 901.1^{\mathrm{d}, \mathrm{e}} \\
\text { Soil - HASL-300 }\end{array}$ \\
\hline Isotopic uranium & $\begin{array}{l}\text { Water - ASTM D 3972-02 } \\
\text { Soil - ASTM C 1000-02 }\end{array}$ \\
\hline Isotopic plutonium & $\begin{array}{l}\text { Water - ASTM D 3865-02i } \\
\text { Soil - ASTM C 1001-00' }\end{array}$ \\
\hline Strontium-90 & $\begin{array}{l}\text { Water - ASTM D 5811-00k } \\
\text { Soil - HASL-300 }\end{array}$ \\
\hline
\end{tabular}

anvestigation samples include both environmental and associated quality control samples

bEPA Test Methods for Evaluating Solid Waste, Physical/Chemical Methods, 3rd Edition, Parts 1-4, SW-846 CD ROM (EPA, 1996)

'Arsenic, barium, cadmium, chromium, lead, mercury, selenium, and silver

${ }^{\mathrm{d}}$ Or laboratory equivalent

ePrescribed Methods for Measurement of Radioactivity in Drinking Water

${ }^{\mathrm{f}}$ The Procedures Manual of the Environmental Measurements Laboratory, Health and Safety Laboratory (HASL)-300

${ }^{9}$ Standard Test Method for Isotopic Uranium in Water by Radiochemistry (ASTM, 2002a)

hStandard Test Method for Radiochemical Determination of Uranium Isotopes in Soil by Alpha Spectrometry (ASTM, 2002c)

iStandard Test Method for Isotopic Plutonium in Water by Radiochemistry (ASTM, 2002b)

'Standard Test Method for Radiochemical Determination of Plutonium in Soil by Alpha Spectrometry (ASTM, 2000a)

kStandard Test Method for Strontium-90 in Water (ASTM, 2000b)

ASTM = American Society for Testing and Materials

$E P A=$ U.S. Environmental Protection Agency

HASL = Health and Safety Laboratory

RCRA $=$ Resource Conservation and Recovery Act 


\section{D.2.5 Deviations from SAFER Plan as Approved}

To eliminate data validation and project evaluation time on radionuclides that are not crucial to project needs, the SNJV isotopic gamma library listed in Table B.4-2 of the CAU 177 SAFER Plan (NNSA/NSO, 2006b) was modified to only include radionuclides of interest (Snelling-Young, 2006). Radionuclides eliminated from the SNJV gamma library, effective July 1, 2006, and Table B.4-2 include: aluminum-26, antimony-125, beryllium-7, bismuth-212, bismuth-214, cesium-134, cobalt-58, curium-243, and thorium-227. A radionuclide in a sample that is not included in the modified SNJV isotopic gamma library may still be detected and reported because data validators review the gamma spectrum of each sample for unusual energy peaks. 


\section{D.3.0 CAS 08-23-01, Mud Pit and Cellar}

Corrective Action Site 08-23-01 is located within a fenced URMA on the north side of 2-07 Road in Area 8 of the NTS (Figure 1-1). The CAS components identified for investigation include an open earthen mud pit and a backfilled cellar.

\section{D.3.1 Corrective Action Investigation}

Fifteen characterization samples were collected during investigation activities at CAS 08-23-01. Ten samples and one FD were collected at the mud pit, and four samples were collected at the cellar. The sample identification (IDs), locations, types, and analyses are listed in Table D.3-1. The specific CAI activities conducted to satisfy the CAU 177 SAFER Plan requirements at this CAS are described in the following sections.

\section{D.3.1.1 Field Screening}

Investigation samples were screened for total alpha and beta/gamma radiation. The FSRs were compared to FSLs and no exceedences were identified.

\section{D.3.1.2 Visual Inspections}

No spills, staining, disturbances of soil, or other indications of potential contamination were identified during the inspection of CAS 08-23-01 and site conditions were unchanged from previous field visits. The backfilled cellar was inspected to identify exposures of the cellar casing for sample location selection and drilling purposes.

\section{D.3.1.3 Sample Collection}

Decision I environmental sampling activities included the collection of random surface samples at the open mud pit and biased subsurface soil samples at the cellar (Figure D.3-1).

Eleven Decision I surface samples including one FD (0 to 12 in. bgs) were collected from 10 locations (A01 through A10) within the mud pit. Collected soil consisted primarily of a medium to coarse sand with well sorted small to medium sized gravel (consistent with drill cuttings). Dry gray mud was identified in the soil collected only at location A03. 
Table D.3-1

Samples Collected at CAS 08-23-01, Mud Pit and Cellar

\begin{tabular}{|c|c|c|c|c|c|}
\hline $\begin{array}{c}\text { Sample } \\
\text { Location }\end{array}$ & $\begin{array}{l}\text { Sample } \\
\text { Number }\end{array}$ & $\begin{array}{l}\text { Depth } \\
\text { (ft bgs) }\end{array}$ & Matrix & Purpose & Analyses \\
\hline \multicolumn{6}{|c|}{ Mud Pit Samples } \\
\hline A01 & $177 \mathrm{A003}$ & $0.0-1.0$ & Soil & Environmental & Set 1 \\
\hline $\mathrm{A} 02$ & $177 \mathrm{~A} 006$ & $0.0-1.0$ & Soil & Environmental & Set 1 \\
\hline A03 & $177 \mathrm{~A} 007$ & $0.0-1.0$ & Soil & Environmental & Set 1 \\
\hline A04 & 177A008 & $0.0-1.0$ & Soil & Environmental & Set 1 \\
\hline A05 & 177A009 & $0.0-1.0$ & Soil & Environmental & Set 1 \\
\hline A06 & $177 \mathrm{~A} 010$ & $0.0-1.0$ & Soil & Environmental & Set 1 \\
\hline $\mathrm{A} 07$ & $177 \mathrm{~A} 011$ & $0.0-1.0$ & Soil & Environmental & Set 1 \\
\hline A08 & $177 \mathrm{~A} 012$ & $0.0-1.0$ & Soil & Environmental & Set 1 \\
\hline A09 & $177 \mathrm{~A} 013$ & $0.0-1.0$ & Soil & Environmental & Set 1 \\
\hline \multirow{2}{*}{ A10 } & 177A014 & $0.0-1.0$ & Soil & Environmental & Set 1 \\
\hline & $177 \mathrm{~A} 015$ & $0.0-1.0$ & Soil & Field Duplicate of \#177A014 & Set 1 \\
\hline \multicolumn{6}{|c|}{ Cellar Samples } \\
\hline \multirow{2}{*}{ A11 } & 177A001 & $13.0-14.0$ & Soil & Environmental, Full Lab QC & Set 2 \\
\hline & 177A002 & $15.0-16.0$ & Soil & Environmental & Set 2 \\
\hline \multirow{2}{*}{ A12 } & 177A004 & $13.0-14.0$ & Soil & Environmental & Set 2 \\
\hline & 177A005 & $15.0-16.0$ & Soil & Environmental & Set 2 \\
\hline \multicolumn{6}{|c|}{ QC Samples } \\
\hline $\mathrm{N} / \mathrm{A}$ & 177A301 & $\mathrm{N} / \mathrm{A}$ & Water & Trip Blank & VOCs \\
\hline $\mathrm{N} / \mathrm{A}$ & 177A302 & $\mathrm{N} / \mathrm{A}$ & Water & Field Blank & Set 2 \\
\hline N/A & 177A303 & $\mathrm{N} / \mathrm{A}$ & Water & Source Blank & Set 2 \\
\hline
\end{tabular}

Set 1 = Gamma Spectroscopy, Isotopic Uranium, Isotopic Plutonium, Strontium-90

Set 2 = VOCs, SVOCs, RCRA Metals, Beryllium, TPH-DRO, TPH-GRO, PCBs, Gamma Spectroscopy, Isotopic Uranium, Isotopic Plutonium, Strontium-90

DRO $=$ Diesel-range organics $\mathrm{ft}$ bgs $=$ Feet below ground surface $\mathrm{GRO}=$ Gasoline-range organics N/A = Not applicable

PCB $=$ Polychlorinated biphenyl
$\mathrm{QC}=$ Quality control

RCRA = Resource Conservation and Recovery Act

SVOC $=$ Semivolatile organic compound

$\mathrm{TPH}=$ Total petroleum hydrocarbons

VOC $=$ Volatile organic compound 


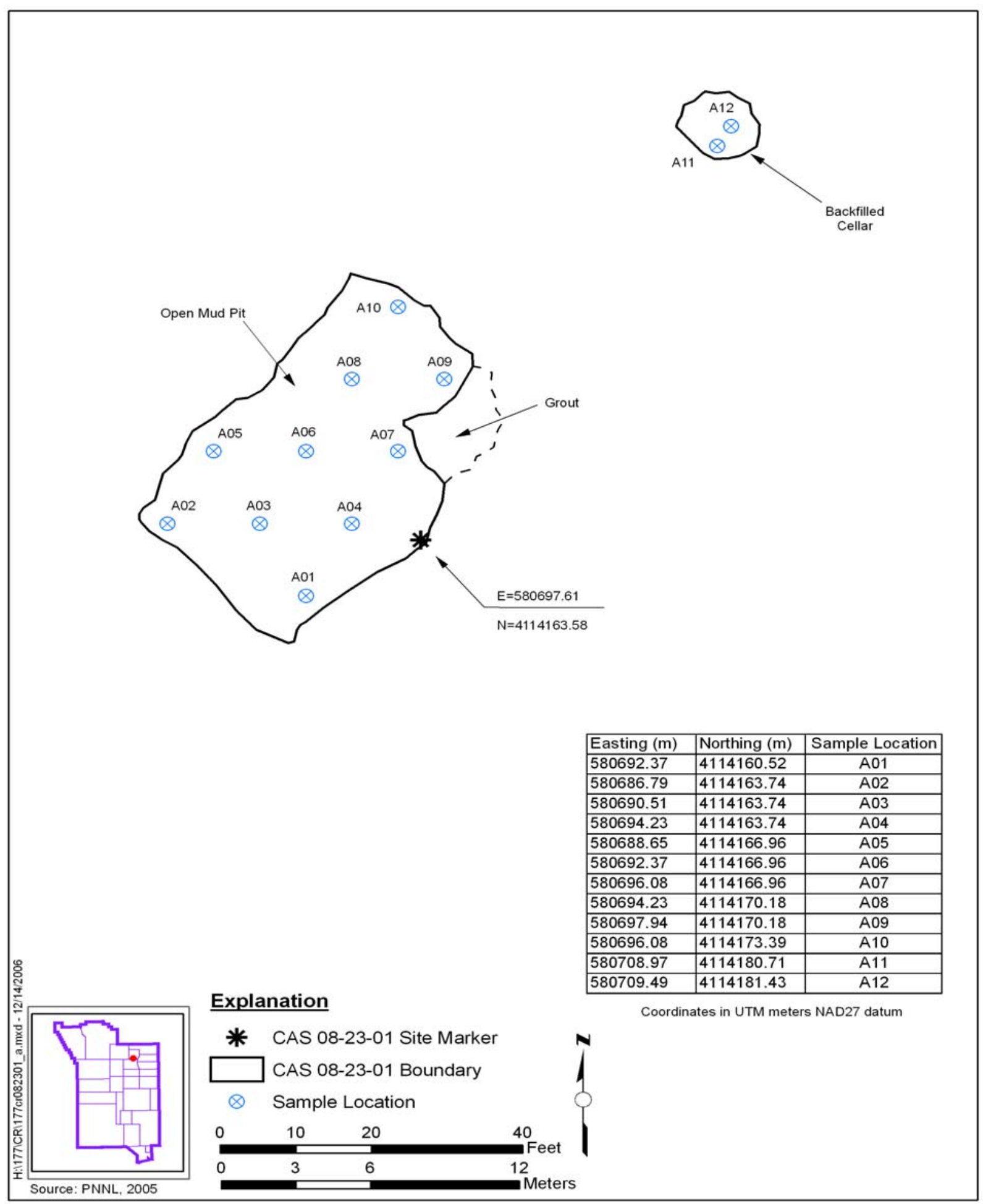

Figure D.3-1

CAS 08-23-01 Sample Location Map 
Four Decision I environmental samples were collected at the cellar. One subsurface sample was collected from each borehole (A11 and A12, Figure D.3-2) at the cellar bottom interface. Two deeper subsurface samples were collected from the same boreholes to obtain information regarding the vertical extent of potentially released contamination. Each borehole was drilled to a depth of $18 \mathrm{ft}$ bgs. Core material was monitored during drilling and the interface with the cellar bottom was identified at $14 \mathrm{ft} \mathrm{bgs;} \mathrm{marked} \mathrm{by} \mathrm{a} \mathrm{lithology} \mathrm{change} \mathrm{from} \mathrm{backfilled} \mathrm{soil} \mathrm{to} \mathrm{a} \mathrm{potential} \mathrm{grout} \mathrm{layer}$ (2 to 6 in. thick) (Figure D.3-2). Two samples were collected directly above the grout layer at 13 to $14 \mathrm{ft}$ bgs, and two samples were collected below the grout interface at 15 to $16 \mathrm{ft}$ bgs.

\section{D.3.2 Investigation Results}

The following sections provide analytical results from the samples collected to complete investigation activities as outlined in the CAU 177 SAFER Plan (NNSA/NSO, 2006b). Investigation samples were analyzed for the SAFER-specified COPCs for cellars, which included VOCs, SVOCs, TPH-DRO and -GRO, Resource Conversation and Recovery Act (RCRA) metals, gamma-emitting radionuclides, isotopic uranium (U), isotopic Pu, and Sr-90; and mud pits, which included only the radiological analytes. Beryllium and PCBs were added parameters to the cellar suite, because these contaminants are a common concern at the NTS. Table D.3-1 lists the sample-specific analytical suite for CAS 08-23-01. Analytical results from the soil samples with concentrations exceeding MDCs are summarized in the following sections.

For the judgmental samples at the cellar component of CASs, an evaluation was conducted on all contaminants detected above MDCs by comparing individual concentration or activity results against the FALs to determine if a constituent is a COC. The FALs were established as the corresponding PALs concentrations or activities if the contaminant concentrations were below respective PALs.

For the probabilistic samples at the mud pit, any COPC that has a 95 percent UCL of the average concentration exceeding the FAL will result in that COPC being designated as a COC. As stipulated in Section C.1.2.1 of the CAU 177 SAFER Plan, UCLs were only calculated for a COPC if it was detected in any sample within any CAS at a concentration equal to or exceeding the PAL. If COPCs were not detected in any mud pit sample at a concentration exceeding the PAL, then it will be concluded that no COCs are present. 


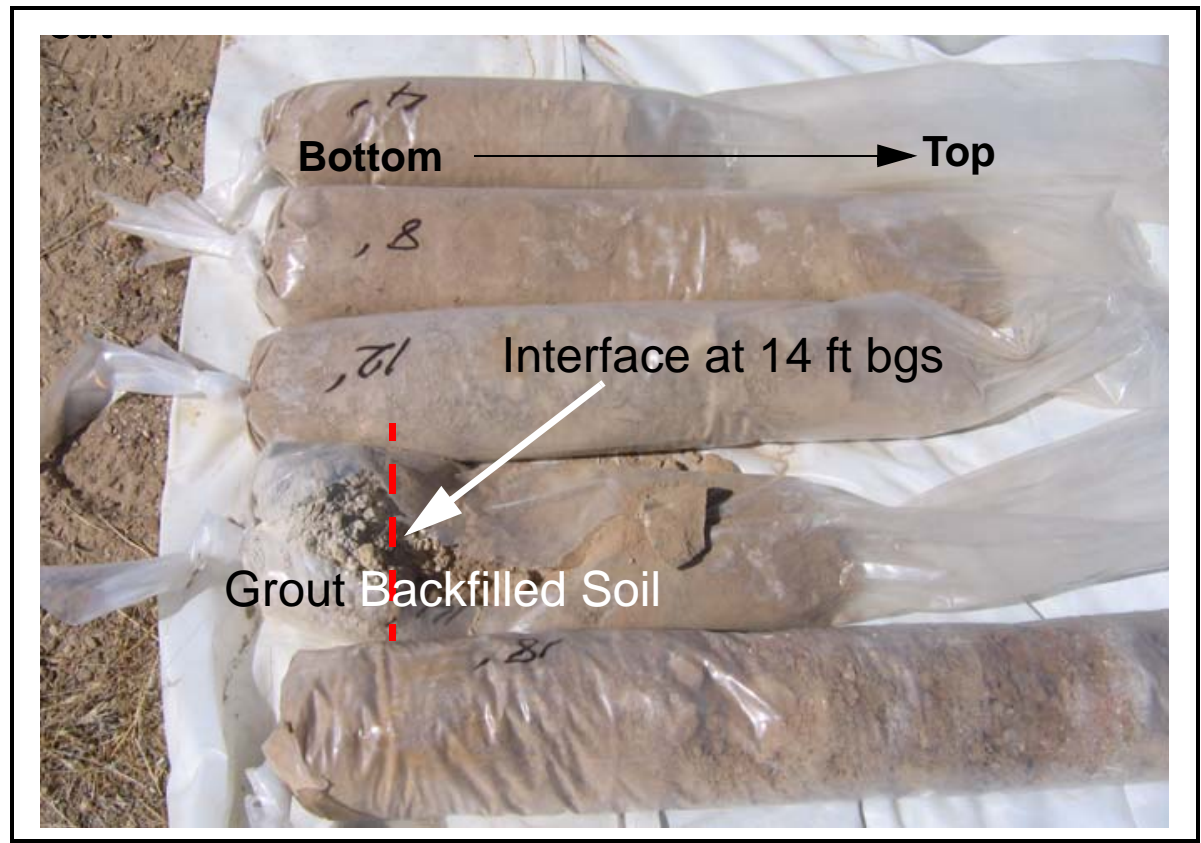

Figure D.3-2

Core Material Showing Interface with Cellar Bottom (Location A12)

\section{D.3.2.1 Volatile Organic Compounds}

Analytical results for VOCs in soil samples collected from the cellar that were detected above MDCs are presented in Table D.3-2. No VOCs were detected at concentrations exceeding PALs; therefore, the FALs were established as the corresponding PALs.

\section{D.3.2.2 Semivolatile Organic Compounds}

Analytical results for SVOCs in soil samples collected from the cellar that were detected above MDCs are presented in Table D.3-3. No SVOCs were detected at concentrations exceeding PALs; therefore, the FALs were established as the corresponding PALs. 
Table D.3-2

Soil Sample Results for Total VOCs Detected Above Minimum Detectable Concentrations at CAS 08-23-01, Mud Pit and Cellar

\begin{tabular}{|c|c|c|c|c|c|c|c|}
\hline \multirow[b]{2}{*}{$\begin{array}{l}\text { Sample } \\
\text { Location }\end{array}$} & \multirow[b]{2}{*}{$\begin{array}{l}\text { Sample } \\
\text { Number }\end{array}$} & \multirow[b]{2}{*}{$\begin{array}{l}\text { Depth } \\
\text { (ft bgs) }\end{array}$} & \multicolumn{5}{|c|}{ Contaminants of Potential Concern $(\mu \mathrm{g} / \mathrm{kg})$} \\
\hline & & & 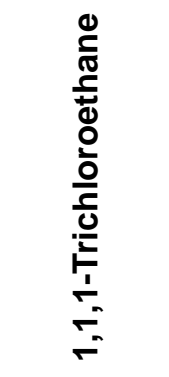 & 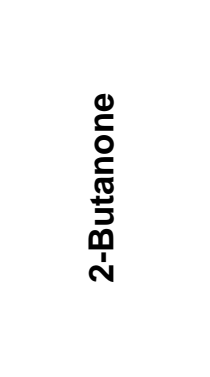 & 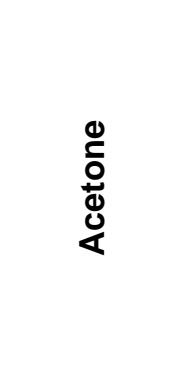 & $\begin{array}{l}\xi \\
\frac{\xi}{0} \\
\frac{0}{0} \\
\frac{0}{\sigma} \\
\end{array}$ & 离 \\
\hline \multicolumn{3}{|c|}{ Final Action Levels ${ }^{a}$} & $1,200,000$ & $110,000,000$ & $54,000,000$ & 470 & $1,700,000$ \\
\hline \multicolumn{8}{|c|}{ Cellar Samples } \\
\hline \multirow{2}{*}{ A11 } & 177A001 & $13.0-14.0$ & $0.363(\mathrm{~J})$ & -- & 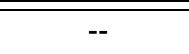 & $0.248(\mathrm{~J})$ & $\overline{---}$ \\
\hline & 177A002 & $15.0-16.0$ & $0.471(\mathrm{~J})$ & $1.9(\mathrm{~J})$ & $5.26(\mathrm{~J})$ & $0.294(\mathrm{~J})$ & $0.412(\mathrm{~J})$ \\
\hline A12 & 177A004 & $13.0-14.0$ & $0.856(\mathrm{~J})$ & -- & -- & $0.42(\mathrm{~J})$ & -- \\
\hline
\end{tabular}

${ }^{a}$ Based on U.S. Environmental Protection Agency, Region 9 Preliminary Remediation Goals (PRGs) (EPA, 2004).

$\mathrm{ft}$ bgs $=$ Feet below ground surface $\mu \mathrm{g} / \mathrm{kg}=$ Micrograms per kilogram

-- = Not detected above minimum detectable concentrations.

$\mathrm{J}=$ Estimated value

Table D.3-3

Soil Sample Results for Total SVOCs Detected Above Minimum Detectable Concentrations at CAS 08-23-01, Mud Pit and Cellar

\begin{tabular}{|c|c|c|c|c|}
\hline \multirow{2}{*}{$\begin{array}{c}\text { Sample } \\
\text { Location }\end{array}$} & \multirow{2}{*}{$\begin{array}{l}\text { Sample } \\
\text { Number }\end{array}$} & \multirow{2}{*}{$\begin{array}{c}\text { Depth } \\
\text { (ft bgs) }\end{array}$} & \multicolumn{2}{|c|}{ Contaminants of Potential Concern $(\mu \mathrm{g} / \mathrm{kg})$} \\
\hline & & & Bis(2-Ethylhexyl)Phthalate & Fluoranthene \\
\hline \multicolumn{3}{|c|}{ Final Action Levels ${ }^{a}$} & 120,000 & $22,000,000$ \\
\hline \multicolumn{5}{|c|}{ Cellar Samples } \\
\hline \multirow{2}{*}{ A11 } & 177A001 & $13.0-14.0$ & $95.4(\mathrm{~J})$ & -- \\
\hline & 177A002 & $15.0-16.0$ & $71.8(\mathrm{~J})$ & $39.4(\mathrm{~J})$ \\
\hline A12 & 177A004 & $13.0-14.0$ & $101(\mathrm{~J})$ & $\overline{--}$ \\
\hline
\end{tabular}

aBased on U.S. Environmental Protection Agency, Region 9 Preliminary Remediation Goals (PRGs) (EPA, 2004).

$\mathrm{ft}$ bgs = Feet below ground surface $\mu \mathrm{g} / \mathrm{kg}=$ Micrograms per kilogram

-- = Not detected above minimum detectable concentrations.

$\mathrm{J}=$ Estimated value 


\section{D.3.2.3 Total Petroleum Hydrocarbons}

The TPH-DRO analytical results for soil samples collected from the cellar that were detected above MDCs are presented in Table D.3-4. One subsurface sample (13 to $14 \mathrm{ft}$ bgs) collected above the interface with the cellar bottom exceeded the PAL of $100 \mathrm{mg} / \mathrm{kg}$ for TPH-DRO. The TPH-DRO was moved on to a Tier 2 evaluation and FALs were established for the hazardous constituents of TPH-DRO at the corresponding PAL activities. Concentrations of the hazardous constituents of TPH-DRO did not exceed FALs; therefore, TPH-DRO is not considered a COC. Concentrations of TPH-GRO were not detected above the respective laboratory MDCs at this CAS.

Table D.3-4

Soil Sample Results for TPH-DRO Detected Above Minimum Detectable Concentrations at CAS 08-23-01, Mud Pit and Cellar

\begin{tabular}{|c|c|c|c|}
\hline \multirow{2}{*}{$\begin{array}{l}\text { Sample } \\
\text { Location }\end{array}$} & \multirow{2}{*}{$\begin{array}{l}\text { Sample } \\
\text { Number }\end{array}$} & \multirow{2}{*}{$\begin{array}{l}\text { Depth } \\
\text { (ft bgs) }\end{array}$} & Contaminants of Potential Concern (mg/kg) \\
\hline & & & Diesel-Range Organics \\
\hline \multicolumn{3}{|c|}{ Preliminary Action Levels ${ }^{a}$} & 100 \\
\hline \multicolumn{4}{|c|}{ Cellar Samples } \\
\hline \multirow{2}{*}{ A11 } & 177A001 & $13.0-14.0$ & 81 \\
\hline & 177A002 & $15.0-16.0$ & 14.6 \\
\hline \multirow{2}{*}{ A12 } & 177A004 & $13.0-14.0$ & 153 \\
\hline & 177A005 & $15.0-16.0$ & 12.6 \\
\hline
\end{tabular}

"Based on Nevada Administrative Code, "Contamination of Soil: Establishment of Action Levels" (NAC, 2006).

$\mathrm{ft}$ bgs $=$ Feet below ground surface $\mathrm{mg} / \mathrm{kg}=$ Milligrams per kilogram

\section{D.3.2.4 RCRA Metals and Beryllium}

Analytical results for RCRA metals and beryllium in soil samples collected from the cellar that were detected above MDCs are presented in Table D.3-5. None of the metals were detected at concentrations exceeding the respective PALs; therefore, the FALs were established as the corresponding PALs. 
Table D.3-5

Soil Sample Results for Metals Detected Above Minimum Detectable Concentrations at CAS 08-23-01, Mud Pit and Cellar

\begin{tabular}{|c|c|c|c|c|c|c|c|c|c|c|c|}
\hline \multirow{2}{*}{ 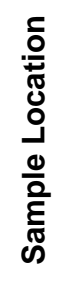 } & \multirow{2}{*}{ 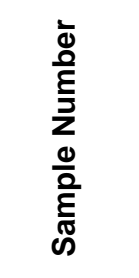 } & \multirow[b]{2}{*}{ 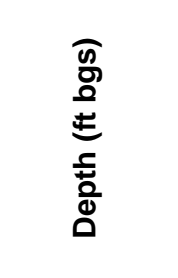 } & \multicolumn{9}{|c|}{ Contaminants of Potential Concern (mg/kg) } \\
\hline & & & 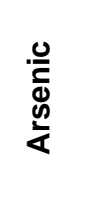 & $\frac{\xi}{\underline{D}}$ & 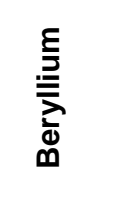 & 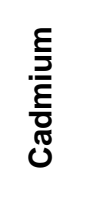 & 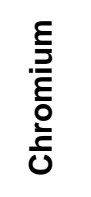 & 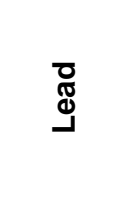 & $\begin{array}{l}\frac{\lambda}{J} \\
\frac{0}{0} \\
\sum\end{array}$ & $\frac{\frac{E}{D}}{\frac{D}{\frac{\omega}{U}}}$ & $\frac{\grave{D}}{\bar{c}}$ \\
\hline \multicolumn{3}{|c|}{ Final Action Levels } & $23^{a}$ & $67,000^{b}$ & $1,900^{b}$ & $450^{b}$ & $450^{b}$ & $800^{b}$ & $310^{b}$ & $5,100^{b}$ & $5,100^{b}$ \\
\hline \multicolumn{12}{|c|}{ Cellar Samples } \\
\hline \multirow{2}{*}{ A11 } & 177A001 & $13.0-14.0$ & 5.7 & $148(\mathrm{~J}+)$ & 0.91 & 0.22 & 17.9 & $54.9(\mathrm{~J}-)$ & $0.066(\mathrm{~J}-)$ & 1.4 & 0.24 \\
\hline & 177A002 & $15.0-16.0$ & 7.6 & $293(\mathrm{~J}+)$ & 1.1 & 0.19 & 17.2 & $31.7(\mathrm{~J}-)$ & $0.02(\mathrm{~J}-)$ & 0.61 & 0.13 \\
\hline \multirow{2}{*}{ A12 } & 177A004 & $13.0-14.0$ & 13.7 & $675(\mathrm{~J}+)$ & 0.72 & 0.32 & 13.8 & $381(\mathrm{~J}-)$ & $0.021(\mathrm{~J}-)$ & -- & -- \\
\hline & 177A005 & $15.0-16.0$ & 9.9 & $214(\mathrm{~J}+)$ & 1.3 & 0.18 & 19.7 & $10.2(\mathrm{~J}-)$ & $0.029(\mathrm{~J}-)$ & 1.4 & -- \\
\hline
\end{tabular}

aBased on the background concentrations for metals. Background is considered the mean plus two times the standard deviation for sediment samples collected by the Nevada Bureau of Mines and Geology throughout the Nevada Test and Training Range (NBMG, 1998; Moore, 1999).

${ }^{\mathrm{b}}$ Based on U.S. Environmental Protection Agency, Region 9 Preliminary Remediation Goals (PRGs) (EPA, 2004)

$\mathrm{ft}$ bgs = Feet below ground surface

$\mathrm{mg} / \mathrm{kg}=$ Milligrams per kilogram

-- = Not detected above minimum detectable concentrations.

$\mathrm{J}+=$ The result is an estimated quantity, but may be biased high.

$\mathrm{J}-=$ The result is an estimated quantity, but may be biased low.

\section{D.3.2.5 Polychlorinated Biphenyls}

Analytical results for PCBs in soil samples collected from the cellar that were detected above MDCs are presented in Table D.3-6. Polychlorinated biphenyl concentrations did not exceed the respective PALs; therefore, the FALs were established as the corresponding PALs.

\section{D.3.2.6 Gamma-Emitting Radionuclides}

Analytical results for gamma-emitting radionuclides in soil samples from the mud pit and cellar that were detected above MDCs are presented in Table D.3-7. Because no gamma-emitting radionuclide COPCs were detected in any mud pit sample at a concentration greater than the PAL, UCLs were not calculated, and it is determined that no COCs exist. Because no gamma-emitting radionuclide COPCs in cellar samples exceeded the respective PALs, the FALs were established at the corresponding PAL activities. 
Table D.3-6

Soil Sample Results for PCBs Detected Above Minimum

Detectable Concentrations at CAS 08-23-01, Mud Pit and Cellar

\begin{tabular}{||c|c|c|c||}
\hline \multirow{2}{*}{$\begin{array}{c}\text { Sample } \\
\text { Location }\end{array}$} & $\begin{array}{c}\text { Sample } \\
\text { Number }\end{array}$ & $\begin{array}{c}\text { Depth } \\
\text { (ft bgs) }\end{array}$ & Contaminants of Potential Concern $(\mu \mathrm{g} / \mathrm{kg})$ \\
\cline { 3 - 4 } & & Aroclor 1260 \\
\hline \hline \multicolumn{3}{|c|}{ Final Action Levels ${ }^{\mathrm{a}}$} & $\mathbf{7 4 0}$ \\
\hline \hline \multicolumn{3}{|c|}{ Cellar Samples } \\
\hline A11 & $177 \mathrm{A001}$ & $13.0-14.0$ & $1.86(\mathrm{~J})$ \\
\hline A12 & $177 \mathrm{~A} 004$ & $13.0-14.0$ & $1.8(\mathrm{~J})$ \\
\hline
\end{tabular}

aBased on U.S. Environmental Protection Agency, Region 9 Preliminary Remediation Goals (PRGs) (EPA, 2004).

$\mathrm{ft}$ bgs $=$ Feet below ground surface

$\mu \mathrm{g} / \mathrm{kg}=$ Micrograms per kilogram

$\mathrm{J}=$ Estimated value

Table D.3-7

Soil Sample Results for Gamma-Emitting Radionuclides Detected Above Minimum Detectable Concentrations at CAS 08-23-01, Mud Pit and Cellar

(Page 1 of 2)

\begin{tabular}{|c|c|c|c|c|c|c|c|}
\hline \multirow[b]{2}{*}{$\begin{array}{c}\text { Sample } \\
\text { Location }\end{array}$} & \multirow[b]{2}{*}{$\begin{array}{l}\text { Sample } \\
\text { Number }\end{array}$} & \multirow[b]{2}{*}{$\begin{array}{c}\text { Depth } \\
\text { (ft bgs) }\end{array}$} & \multicolumn{5}{|c|}{ Contaminants of Potential Concern (pCi/g) } \\
\hline & & & 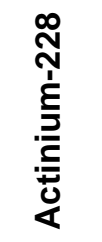 & 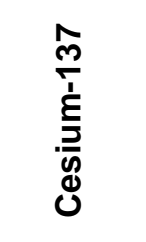 & 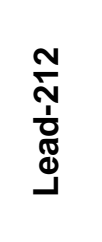 & 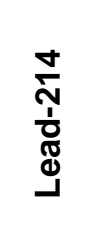 & 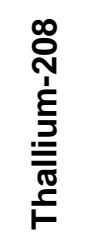 \\
\hline \multicolumn{3}{|c|}{ Final Action Levels } & $5^{a}$ & $12.2^{b}$ & $5^{a}$ & $5^{a}$ & $5^{a}$ \\
\hline \multicolumn{8}{|c|}{ Mud Pit Samples } \\
\hline $\mathrm{A} 01$ & 177A003 & $0.0-1.0$ & 1.28 & $0.451(\mathrm{~J})$ & 1.04 & 0.768 & 0.357 \\
\hline $\mathrm{A} 02$ & 177A006 & $0.0-1.0$ & 0.932 & $0.249(\mathrm{~J})$ & 0.671 & 0.6 & 0.274 \\
\hline A03 & 177A007 & $0.0-1.0$ & 1.44 & $1.49(\mathrm{~J})$ & 1.27 & 1.09 & 0.429 \\
\hline A04 & 177A008 & $0.0-1.0$ & 1.58 & $0.666(\mathrm{~J})$ & 1.47 & 1.23 & 0.498 \\
\hline A05 & 177A009 & $0.0-1.0$ & 1.34 & -- & 1.51 & 0.974 & 0.392 \\
\hline A06 & 177A010 & $0.0-1.0$ & 1.21 & $0.533(\mathrm{~J})$ & 1.32 & 1 & 0.379 \\
\hline $\mathrm{A} 07$ & $177 \mathrm{~A} 011$ & $0.0-1.0$ & 1.47 & $0.718(\mathrm{~J})$ & 1.04 & 1.05 & 0.499 \\
\hline A08 & 177A012 & $0.0-1.0$ & 1.25 & -- & 1.16 & 0.873 & 0.539 \\
\hline A09 & 177A013 & $0.0-1.0$ & 1.23 & $0.639(\mathrm{~J})$ & 1.26 & 0.809 & 0.361 \\
\hline
\end{tabular}


Table D.3-7

Soil Sample Results for Gamma-Emitting Radionuclides Detected Above Minimum Detectable Concentrations at CAS 08-23-01, Mud Pit and Cellar (Page 2 of 2)

\begin{tabular}{|c|c|c|c|c|c|c|c|}
\hline \multirow[b]{2}{*}{$\begin{array}{l}\text { Sample } \\
\text { Location }\end{array}$} & \multirow[b]{2}{*}{$\begin{array}{l}\text { Sample } \\
\text { Number }\end{array}$} & \multirow[b]{2}{*}{$\begin{array}{l}\text { Depth } \\
\text { (ft bgs) }\end{array}$} & \multicolumn{5}{|c|}{ Contaminants of Potential Concern (pCi/g) } \\
\hline & & & 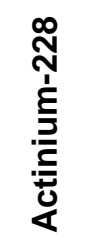 & 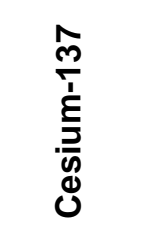 & 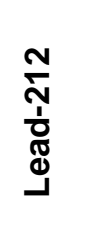 & 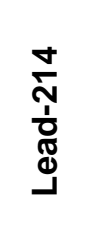 & 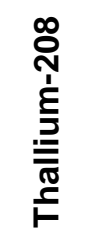 \\
\hline \multicolumn{3}{|c|}{ Final Action Levels } & $5^{a}$ & $12.2^{b}$ & $5^{a}$ & $5^{a}$ & $5^{a}$ \\
\hline \multicolumn{8}{|c|}{ Mud Pit Samples } \\
\hline \multirow{2}{*}{ A10 } & $177 \mathrm{~A} 014$ & $0.0-1.0$ & 1.73 & $0.224(\mathrm{~J})$ & 1.35 & 0.839 & 0.52 \\
\hline & 177A015 & $0.0-1.0$ & 0.984 & $0.179(\mathrm{~J})$ & 1.33 & 0.833 & 0.489 \\
\hline \multicolumn{8}{|c|}{ Cellar Samples } \\
\hline \multirow{2}{*}{ A11 } & $177 \mathrm{A001}$ & $13.0-14.0$ & 1.44 & $0.764(\mathrm{~J})$ & 1.38 & 1.2 & 0.512 \\
\hline & 177A002 & $15.0-16.0$ & 1.68 & $0.465(\mathrm{~J})$ & 1.81 & 1.14 & 0.652 \\
\hline \multirow{2}{*}{ A12 } & 177A004 & $13.0-14.0$ & 1.3 & $1.13(\mathrm{~J})$ & 1.27 & 0.981 & 0.37 \\
\hline & 177A005 & $15.0-16.0$ & 1.65 & $0.148(\mathrm{~J})$ & 1.43 & 1.11 & 0.625 \\
\hline
\end{tabular}

aTaken from the generic guidelines for residual concentrations of actinium-228, bismuth-214, lead-212, lead-214, thallium-208, and thorium-232, as found in Chapter IV of U.S. Department of Energy Order 5400.5, Change 2, Radiation Protection of the Public and Environment (DOE, 1993).

${ }^{\mathrm{b}}$ Taken from the construction, commercial, industrial land-use scenario in Table 2.1 of the National Council on Radiation Protection and Measurement Report No. 129, Recommended Screening Limits for Contaminated Surface Soil and Review Factors Relevant to Site-Specific Studies (NCRP, 1999). The values provided in this source document were scaled to a 25-millirem-per-year dose.

\section{$\mathrm{ft}$ bgs $=$ Feet below ground surface}

$\mathrm{pCi} / \mathrm{g}=$ Picocuries per gram

$\mathrm{J}=$ Estimated value

-- = Not detected above minimum detectable concentrations.

\section{D.3.2.7 Plutonium, Strontium-90, and Uranium Isotopes}

Isotopic $\mathrm{Pu}$ and isotopic $\mathrm{U}$ analytical results for soil samples from the mud pit and cellar that were detected above MDCs are presented in Table D.3-8. Because no Pu, U, or Sr-90 isotope COPCs were detected in any mud pit sample at a concentration greater than the PAL, UCLs were not calculated, and it is determined that no COCs exist. Because no Pu, U, or Sr-90 isotope COPCs were detected in any cellar sample at a concentration equal to or exceeding the PAL, the FALs were established as the corresponding PAL activities. 
Table D.3-8

Soil Sample Results for Isotopes Detected Above Minimum Detectable Concentrations at CAS 08-23-01, Mud Pit and Cellar

\begin{tabular}{|c|c|c|c|c|c|c|}
\hline \multirow[b]{2}{*}{$\begin{array}{l}\text { Sample } \\
\text { Location }\end{array}$} & \multirow[b]{2}{*}{$\begin{array}{l}\text { Sample } \\
\text { Number }\end{array}$} & \multirow[b]{2}{*}{$\begin{array}{l}\text { Depth } \\
\text { (ft bgs) }\end{array}$} & \multicolumn{4}{|c|}{ Contaminants of Potential Concern (pCi/g) } \\
\hline & & & 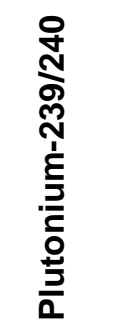 & 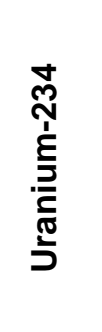 & 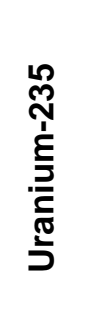 & 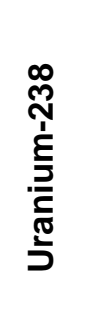 \\
\hline \multicolumn{3}{|c|}{ Final Action Levels ${ }^{a}$} & 12.7 & 143 & 17.6 & 105 \\
\hline \multicolumn{7}{|c|}{ Mud Pit Samples } \\
\hline A01 & 177A003 & $0.0-1.0$ & -- & 0.717 & -- & 0.613 \\
\hline $\mathrm{A} 02$ & 177A006 & $0.0-1.0$ & -- & 0.593 & -- & 0.62 \\
\hline A03 & 177A007 & $0.0-1.0$ & -- & 1.08 & -- & 0.858 \\
\hline A04 & 177A008 & $0.0-1.0$ & -- & 0.912 & -- & 0.996 \\
\hline A05 & 177A009 & $0.0-1.0$ & -- & 0.782 & -- & 0.907 \\
\hline A06 & $177 \mathrm{~A} 010$ & $0.0-1.0$ & -- & 0.745 & -- & 0.77 \\
\hline $\mathrm{A} 07$ & 177A011 & $0.0-1.0$ & -- & 0.803 & 0.116 & 1.12 \\
\hline A08 & $177 \mathrm{~A} 012$ & $0.0-1.0$ & -- & 0.74 & -- & 0.736 \\
\hline A09 & 177A013 & $0.0-1.0$ & -- & 0.701 & -- & 0.719 \\
\hline \multirow{2}{*}{ A10 } & $177 \mathrm{~A} 014$ & $0.0-1.0$ & -- & 0.622 & -- & 0.678 \\
\hline & 177A015 & $0.0-1.0$ & 0.0935 & 0.619 & -- & 0.777 \\
\hline \multicolumn{7}{|c|}{ Cellar Samples } \\
\hline \multirow{2}{*}{ A11 } & 177A001 & $13.0-14.0$ & -- & 0.937 & -- & 0.822 \\
\hline & 177A002 & $15.0-16.0$ & -- & 0.85 & -- & 0.858 \\
\hline \multirow{2}{*}{ A12 } & 177A004 & $13.0-14.0$ & 0.0448 & 0.663 & -- & 0.733 \\
\hline & 177A005 & $15.0-16.0$ & -- & 0.989 & -- & 0.987 \\
\hline
\end{tabular}

aTaken from the construction, commercial, industrial land-use scenario in Table 2.1 of the National Council on Radiation Protection and Measurement Report No. 129, Recommended Screening Limits for Contaminated Surface Soil and Review Factors Relevant to Site-Specific Studies (NCRP, 1999). The values provided in this source document were scaled to a 25-millirem-per-year dose.

$\mathrm{ft}$ bgs $=$ Feet below ground surface $\mathrm{pCi} / \mathrm{g}=$ Picocuries per gram

-- = Not detected above minimum detectable concentrations. 


\section{D.3.3 Nature and Extent of Contamination}

Based on the analytical results, no COCs were identified in the environmental soils samples collected at CAS 08-23-01.

\section{D.3.4 Revised Conceptual Site Model}

The CAU 177 SAFER Plan requirements were met at this CAS, and no revisions were necessary to the CSM. 


\section{D.4.0 CAS 09-09-41, Unknown \#3 Mud Pit/Disposal Area}

Corrective Action Site 09-09-41 is located within a posted RMA on the west side of Old Mercury Highway, slightly north of 9-01 Road in Area 9 of the NTS (Figure 1-1). The CAS components identified for investigation include an open mud pit.

\section{D.4.1 Corrective Action Investigation}

Eleven characterization samples including one FD were collected during investigation activities at CAS 09-09-41. The sample IDs, locations, types, and analyses are listed in Table D.4-1. The specific CAI activities conducted to satisfy the CAU 177 SAFER Plan requirements at this CAS are described in the following sections.

Table D.4-1

Samples Collected at CAS 09-09-41, Unknown \#3 Mud Pit/Disposal Area

\begin{tabular}{|c|c|c|c|c|c|}
\hline $\begin{array}{c}\text { Sample } \\
\text { Location }\end{array}$ & $\begin{array}{l}\text { Sample } \\
\text { Number }\end{array}$ & $\begin{array}{l}\text { Depth } \\
\text { (ft bgs) }\end{array}$ & Matrix & Purpose & Analyses \\
\hline \multicolumn{6}{|c|}{ Mud Pit Samples } \\
\hline B01 & 177B001 & $0.0-1.0$ & Soil & Environmental & Set 1 \\
\hline B02 & 177B002 & $0.0-1.0$ & Soil & Environmental & Set 1 \\
\hline B03 & 177B003 & $0.0-1.0$ & Soil & Environmental & Set 1 \\
\hline B04 & 177B004 & $0.0-1.0$ & Soil & Environmental, Full Lab QC & Set 1 \\
\hline \multirow{2}{*}{ B05 } & 177B005 & $0.0-1.0$ & Soil & Environmental & Set 1 \\
\hline & 177B006 & $0.0-1.0$ & Soil & Field Duplicate of \#177B005 & Set 1 \\
\hline B06 & 177B007 & $0.0-1.0$ & Soil & Environmental & Set 1 \\
\hline B07 & 177B008 & $0.0-1.0$ & Soil & Environmental & Set 1 \\
\hline B08 & 177B009 & $0.0-1.0$ & Soil & Environmental & Set 1 \\
\hline B09 & 177B010 & $0.0-1.0$ & Soil & Environmental & Set 1 \\
\hline B10 & 177B011 & $0.0-1.0$ & Soil & Environmental & Set 1 \\
\hline \multicolumn{6}{|c|}{ QC Samples } \\
\hline $\mathrm{N} / \mathrm{A}$ & 177B301 & $\mathrm{N} / \mathrm{A}$ & Water & Field Blank & Set 1 \\
\hline
\end{tabular}

Set 1 = Gamma Spectroscopy, Isotopic Uranium, Isotopic Plutonium, Strontium-90

$\mathrm{ft}$ bgs $=$ Feet below ground surface

$\mathrm{N} / \mathrm{A}=$ Not applicable

$\mathrm{QC}=$ Quality control 


\section{D.4.1.1 Field Screening}

Decision I soil samples collected at CAS 09-09-41 were not screened for alpha and beta/gamma radiation during sample collection activities due to the elevated background readings in the RMA. Instead, these samples were screened for gamma-emitting radionuclides using a high-purity germanium gamma spectrometer (located in Building 23-153), and the FSLs were used to ensure compliance with shipping requirements.

\section{D.4.1.2 Visual Inspections}

No spills, staining, disturbances of soil, or other indications of potential contamination were identified during the inspection of CAS 09-09-41, and site conditions were unchanged from previous field visits.

\section{D.4.1.3 Sample Collection}

Decision I environmental sampling activities included the collection of random surface samples at the open mud pit (Figure D.4-1). Eleven Decision I surface (0 to 12 in. bgs) samples including 1 FD were collected from 10 locations (B01 through B10) within the mud pit. All soil samples consisted of a silty sand with gravel; no mud was identified. Location B10 was on the berm of the mud pit, but all other sample points were located at the bottom of the pit.

\section{D.4.2 Investigation Results}

The following sections provide analytical results from the samples collected to complete investigation activities as outlined in the CAU 177 SAFER Plan (NNSA/NSO, 2006b). Investigation samples were analyzed for the SAFER-specified COPCs for mud pits, which included gamma-emitting radionuclides and isotopic $\mathrm{U}$, isotopic $\mathrm{Pu}$, and Sr-90. Table D.4-1 lists the sample-specific analytical suite for CAS 09-09-41. Analytical results from the soil samples with concentrations exceeding MDCs are summarized in the following sections. 


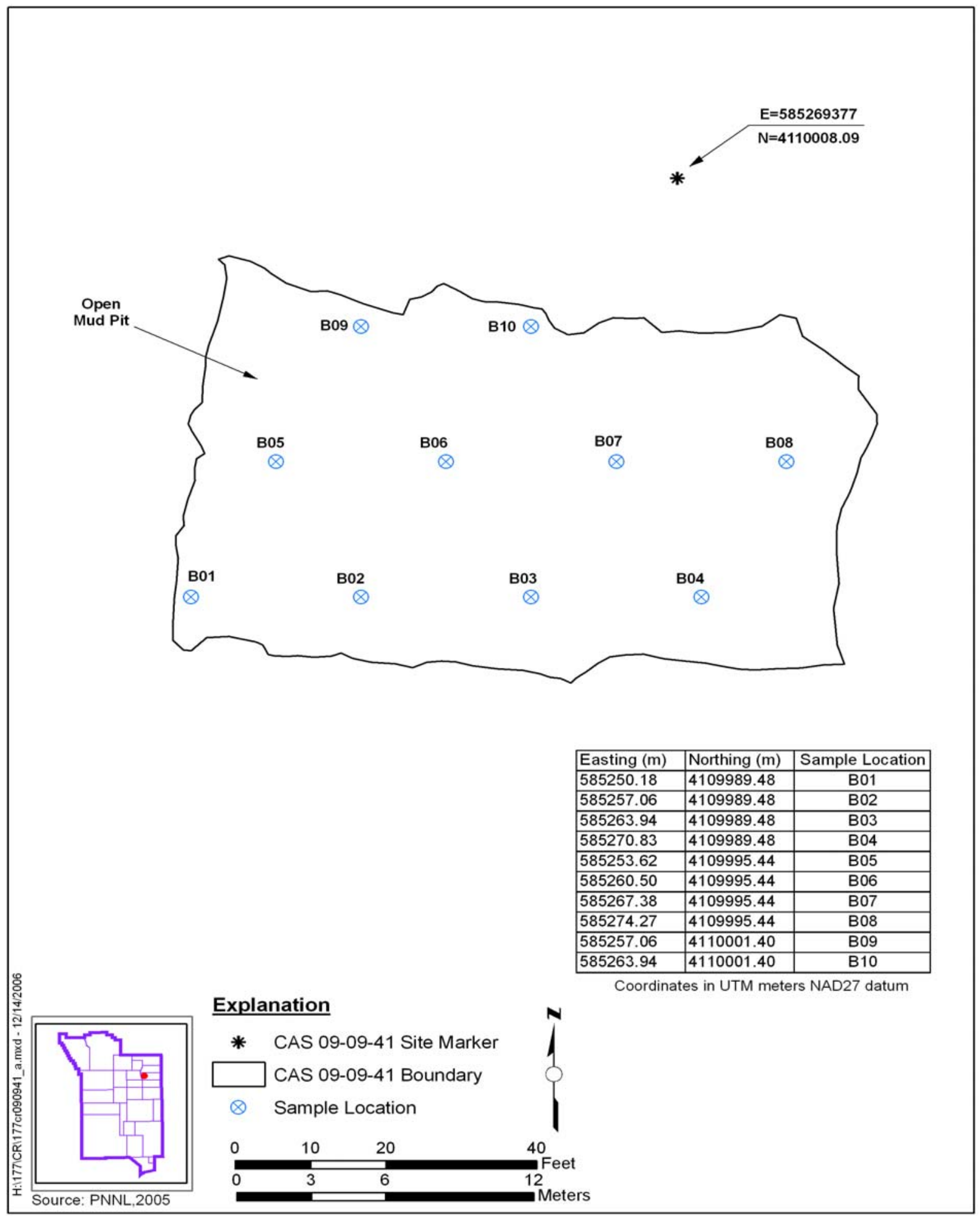

Figure D.4-1

CAS 09-09-41 Sample Location Map 
For the probabilistic samples at the mud pit, any COPC that has a 95 percent UCL of the average concentration exceeding the FAL will result in that COPC designated as a COC. As stipulated in Section C.1.2.1 of the CAU 177 SAFER Plan, UCLs were calculated for a COPC only if it was detected in sample within CAS at a concentration equal to or exceeding the PAL. If COPCs were not detected in any mud pit sample, at a concentration that exceeded the PAL, then it will be concluded that no COCs are present.

\section{D.4.2.1 Gamma-Emitting Radionuclides}

The analytical results for gamma-emitting radionuclides in soil samples that were detected above MDCs are presented in Table D.4-2. The radionuclide Eu-152 was detected at concentrations that exceeded the PAL (5.7 picocuries per gram [pCi/g]) in six surface samples (177B001, 177B005, 177B006, 177B008, 177B010, 177B011) from five locations within the mud pit. However, the presence of Eu-152 is considered to be associated with the adjacent Soils Project CASs 09-99-01 and 09-23-14 and not a release from this CAS (Section D.4.3); therefore, the FALs were established at the corresponding PALs.

Table D.4-2

\section{Soil Sample Results for Gamma-Emitting Radionuclides Detected Above Minimum Detectable Concentrations at CAS 09-09-41, Unknown \#3 Mud Pit/Disposal Area}

(Page 1 of 2)

\begin{tabular}{|c|c|c|c|c|c|c|c|c|c|c|c|}
\hline \multirow[b]{2}{*}{ 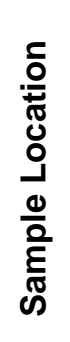 } & \multirow[b]{2}{*}{ 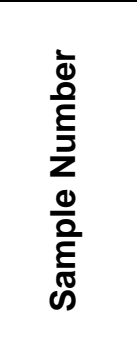 } & \multirow[b]{2}{*}{ 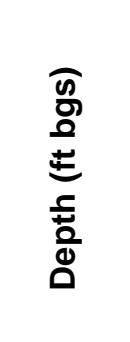 } & \multicolumn{9}{|c|}{ Contaminants of Potential Concern (pCi/g) } \\
\hline & & & 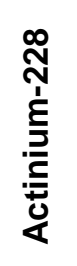 & 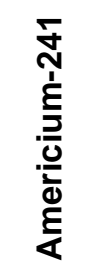 & 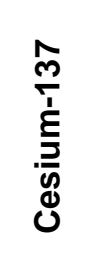 & $\begin{array}{l}0 \\
0 \\
\stackrel{1}{\pi} \\
\frac{0}{0} \\
0 \\
0\end{array}$ & 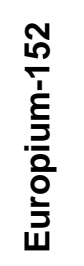 & 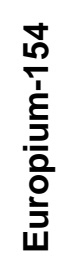 & 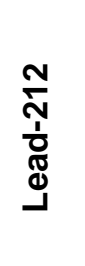 & 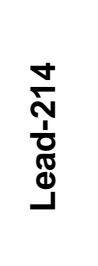 & 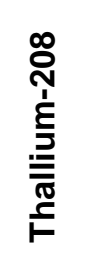 \\
\hline \multicolumn{3}{|c|}{ Final Action Levels } & $5^{a}$ & $12.7^{b}$ & $12.2^{\mathrm{b}}$ & $2.7^{b}$ & $5.7^{\mathrm{b}}$ & $5.4^{b}$ & $5^{a}$ & $5^{a}$ & $5^{a}$ \\
\hline \multicolumn{12}{|c|}{ Mud Pit Samples } \\
\hline B01 & 177B001 & $0.0-1.0$ & 1.12 & 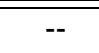 & 0.221 & 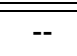 & 17.4 & 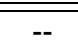 & 1.19 & 0.934 & 0.468 \\
\hline B02 & 177B002 & $0.0-1.0$ & 1.27 & -- & -- & -- & 2.41 & -- & 1.39 & 0.986 & 0.428 \\
\hline B03 & 177B003 & $0.0-1.0$ & 1.4 & -- & -- & -- & 2.91 & -- & 1.49 & 0.991 & 0.548 \\
\hline B04 & 177B004 & $0.0-1.0$ & 1.26 & -- & -- & -- & 3.06 & -- & 1.33 & 1.01 & 0.447 \\
\hline \multirow{2}{*}{ B05 } & 177B005 & $0.0-1.0$ & 1.29 & -- & 0.174 & -- & 11.8 & -- & 1.27 & 0.884 & 0.362 \\
\hline & 177B006 & $0.0-1.0$ & 1.3 & -- & 0.28 & -- & 12.9 & -- & 1.24 & 0.82 & 0.356 \\
\hline
\end{tabular}


Table D.4-2

Soil Sample Results for Gamma-Emitting Radionuclides Detected Above Minimum Detectable Concentrations at CAS 09-09-41, Unknown \#3 Mud Pit/Disposal Area (Page 2 of 2)

\begin{tabular}{|c|c|c|c|c|c|c|c|c|c|c|c|}
\hline \multirow[b]{2}{*}{ 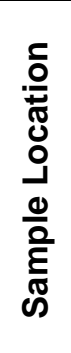 } & \multirow[b]{2}{*}{ 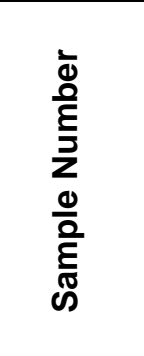 } & \multirow[b]{2}{*}{$\begin{array}{l}0 \\
0 \\
0 \\
\pm \\
\pm \\
5 \\
\vdots \\
0 \\
0\end{array}$} & \multicolumn{9}{|c|}{ Contaminants of Potential Concern (pCi/g) } \\
\hline & & & 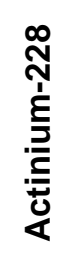 & 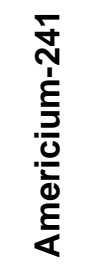 & 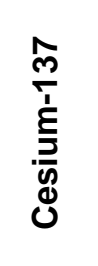 & $\begin{array}{l}8 \\
\stackrel{1}{\pi} \\
\frac{1}{\pi} \\
\frac{0}{0}\end{array}$ & 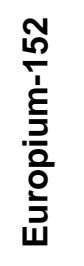 & 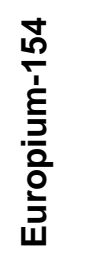 & 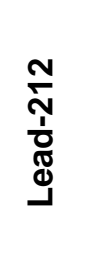 & 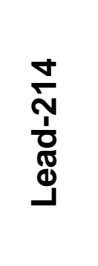 & 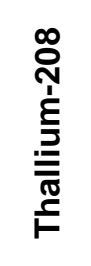 \\
\hline \multicolumn{3}{|c|}{ Final Action Levels } & $5^{\mathrm{a}}$ & $12.7^{b}$ & $12.2^{b}$ & $2.7^{b}$ & $5.7^{\mathrm{b}}$ & $5.4^{\mathrm{b}}$ & $5^{a}$ & $5^{a}$ & $5^{a}$ \\
\hline B06 & 177B007 & $0.0-1.0$ & 1.37 & -- & -- & -- & 4.08 & -- & 1.33 & 1.01 & 0.421 \\
\hline B07 & 177B008 & $0.0-1.0$ & 1.61 & -- & 0.415 & -- & 7.47 & -- & 1.24 & 0.831 & 0.402 \\
\hline B08 & 177B009 & $0.0-1.0$ & 1.22 & 0.609 & 0.781 & 0.314 & 23 & 1.09 & 1.31 & 1.05 & 0.492 \\
\hline B09 & 177B010 & $0.0-1.0$ & 1.2 & $\overline{--}$ & 0.257 & -- & 5.98 & -- & 1.45 & 0.826 & 0.537 \\
\hline B10 & 177B011 & $0.0-1.0$ & -- & -- & 0.725 & 0.635 & 53.1 & 1.81 & 1.26 & 0.999 & 0.478 \\
\hline
\end{tabular}

aTaken from the generic guidelines for residual concentrations of actinium-228, bismuth-214, lead-212, lead-214, thallium-208, and thorium-232, as found in Chapter IV of U.S. Department of Energy Order 5400.5, Change 2, Radiation Protection of the Public and Environment (DOE, 1993).

${ }^{\mathrm{b}}$ Taken from the construction, commercial, industrial land-use scenario in Table 2.1 of the National Council on Radiation Protection and Measurement Report No. 129, Recommended Screening Limits for Contaminated Surface Soil and Review Factors Relevant to Site-Specific Studies (NCRP, 1999). The values provided in this source document were scaled to a 25-millirem-per-year dose.

$\mathrm{ft}$ bgs $=$ Feet below ground surface

$\mathrm{pCi} / \mathrm{g}=$ Picocuries per gram

$--=$ Not detected above minimum detectable concentrations.

\section{D.4.2.2 Plutonium, Strontium-90, and Uranium Isotopes}

Isotopic Pu and isotopic $\mathrm{U}$ analytical results for soil samples that were detected above MDCs are presented in Table D.4-3. Because no Pu, U, or Sr-90 isotope COPCs were detected in any mud pit sample at a concentration equal to or exceeding the PAL, the FALs were established at the corresponding PALs.

\section{D.4.3 Nature and Extent of Contamination}

To determine if the Eu-152 was from a source other than a release from the CAS, the location of the site was overlain on a map that displays the results of a 1994 fly-over radiation survey (Figure D.4-2). The color-coded contours depict a plume of elevated radioactivity measured as man-made exposure rate (gamma ray) in microroentgens per hour ( $\mu \mathrm{R} / \mathrm{hr}$ ). This plume is associated with the B9a location 
and eight atmospheric nuclear tests, all conducted in adjacent locations, and resulted in residual fission and soil activation products in the soil. The source of the radiological activity is attributed to the presence of trinity glass from atmospheric testing and other radioactivity that is dispersed throughout the area (DOE/NV, 2000). Corrective Action Site 09-09-41 is located near the center of the plume in the area of highest activity (80 to $240 \mu \mathrm{R} / \mathrm{hr}$ ) and within a posted RMA boundary that has been established as a result of the eight atmospheric (balloon) tests conducted from June 1957 to October 1958 at the B-9a location. The atmospheric releases associated with these tests are listed in the FFACO as CASs 09-99-01 and 09-23-14 and will be evaluated under the Soils Project.

Table D.4-3

Soil Sample Results for Isotopes Detected Above Minimum Detectable Concentrations at CAS 09-09-41, Unknown \#3 Mud Pit/Disposal Area

\begin{tabular}{|c|c|c|c|c|c|c|}
\hline \multirow{2}{*}{$\begin{array}{c}\text { Sample } \\
\text { Location }\end{array}$} & \multirow{2}{*}{$\begin{array}{l}\text { Sample } \\
\text { Number }\end{array}$} & \multirow{2}{*}{$\begin{array}{l}\text { Depth } \\
\text { (ft bgs) }\end{array}$} & \multicolumn{4}{|c|}{ Contaminants of Potential Concern (pCi/g) } \\
\hline & & & Plutonium-239/240 & Strontium-90 & Uranium-234 & Uranium-238 \\
\hline \multicolumn{3}{|c|}{ Final Action Levels ${ }^{a}$} & 12.7 & 838 & 143 & 105 \\
\hline \multicolumn{7}{|c|}{ Mud Pit Samples } \\
\hline B01 & 177B001 & $0.0-1.0$ & 0.245 & -- & 0.874 & 0.92 \\
\hline B02 & 177B002 & $0.0-1.0$ & -- & -- & 1.09 & 0.948 \\
\hline B03 & 177B003 & $0.0-1.0$ & -- & -- & 0.756 & 0.692 \\
\hline B04 & 177B004 & $0.0-1.0$ & -- & -- & 0.812 & 0.921 \\
\hline \multirow{2}{*}{ B05 } & 177B005 & $0.0-1.0$ & 0.191 & -- & 0.792 & 0.832 \\
\hline & 177B006 & $0.0-1.0$ & 0.226 & -- & 1.07 & 0.995 \\
\hline B06 & 177B007 & $0.0-1.0$ & 0.152 & -- & 0.826 & 0.782 \\
\hline B07 & 177B008 & $0.0-1.0$ & 0.175 & -- & 0.838 & 1 \\
\hline B08 & 177B009 & $0.0-1.0$ & $1.25(\mathrm{~J})$ & 0.677 & 1.01 & 0.957 \\
\hline B09 & 177B010 & $0.0-1.0$ & 0.158 & -- & 0.915 & 0.958 \\
\hline B10 & 177B011 & $0.0-1.0$ & 0.2 & -- & 0.738 & 0.688 \\
\hline
\end{tabular}

aTaken from the construction, commercial, industrial land-use scenario in Table 2.1 of the National Council on Radiation Protection and Measurement Report No. 129, Recommended Screening Limits for Contaminated Surface Soil and Review Factors Relevant to Site-Specific Studies (NCRP, 1999). The values provided in this source document were scaled to a 25-millirem-per-year dose.

$\mathrm{ft}$ bgs $=$ Feet below ground surface $\mathrm{pCi} / \mathrm{g}=$ Picocuries per gram

$\mathrm{J}=$ Estimated value.

-- = Not detected above minimum detectable concentrations. 


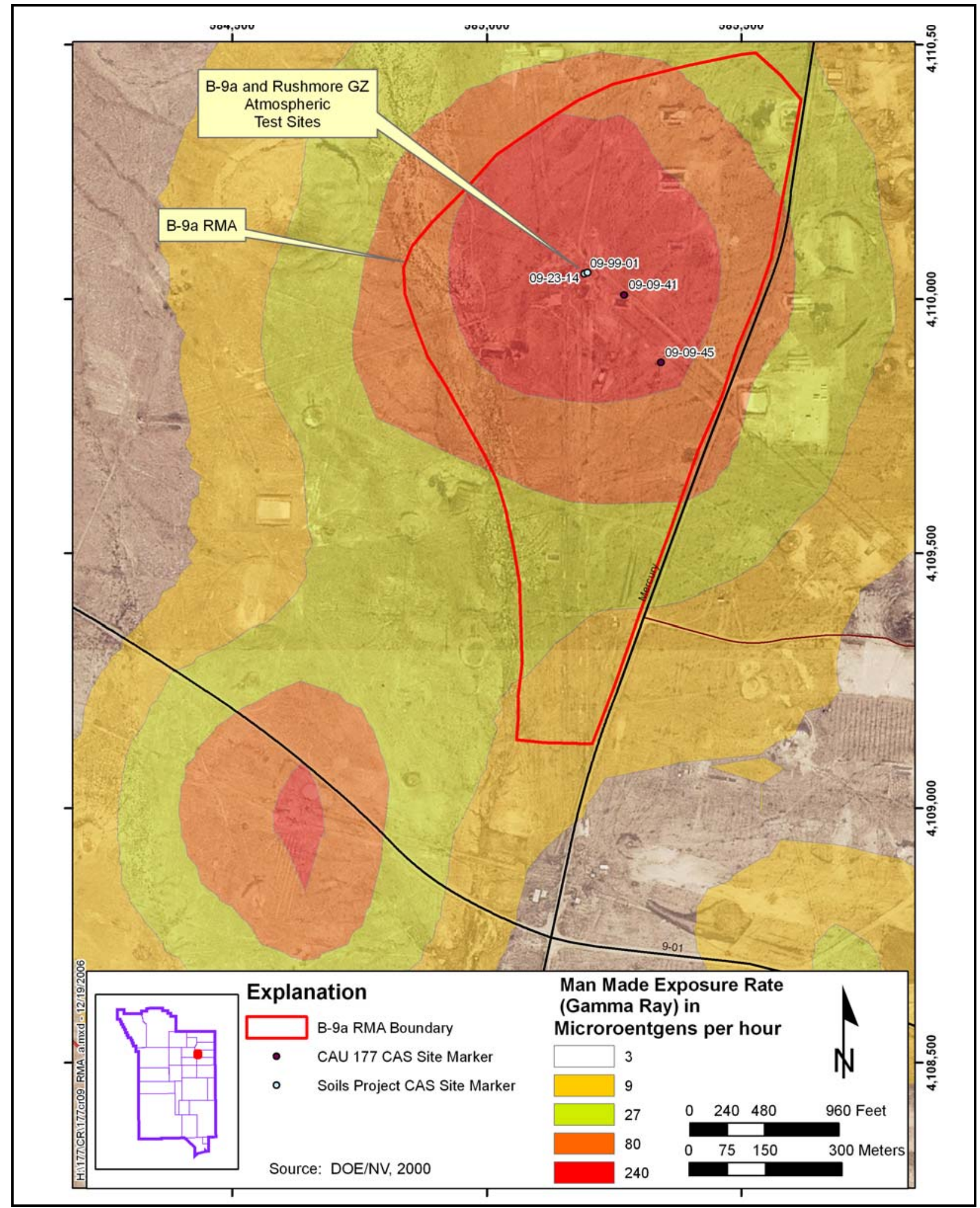

Figure D.4-2

CAU 177 CASs in Relation to the B9a Radiological Plume 
The results of a site-specific radiological land area survey (SNJV, 2006) at CAS 09-09-41

(Figure D.4-3) were compared to identify areas of elevated radioactivity within the mud pit. The color-coded contours shown in Figure D.4-3 depict the radiological data in counts per second (cps) with blue and green colors representing lower activities. Radiological activities at CAS 09-09-41 are lowest within the mud pit and become increasingly higher as distance increases into the surrounding native soil. This is expected, because the mud pit represents a disturbed area where native soil was excavated during construction. Areas shown in dark red are outside of the mud pit berms and represent elevated activities (2,400 to 2,700 cps) that are at least 20 times higher than the mean undisturbed background of 123 cps (measured outside the RMA) (SNJV, 2006).

Based on the association of Eu-152 with atmospheric testing, the location of CAS 09-09-41, near the center of the radiological plume and close proximity to the B-9a and Rushmore ground zeros, and the relatively low activities at the mud pit, in contrast to the elevated levels of radioactivity immediately outside of this feature, the presence of Eu-152 presence is attributed to the background level of radioactivity known to be present in the area as defined by the B-9a RMA and radiological plume. Therefore, Eu-152 contamination is not considered to be attributed to a release from CAS 09-09-41 (i.e., not considered a COC) and will be addressed under the evaluation of Soils Project CASs 09-99-01 and 09-23-14 in CAU 105.

\section{D.4.4 Revised Conceptual Site Model}

The CAU 177 SAFER Plan requirements were met at this CAS, and no revisions were necessary to the CSM. 


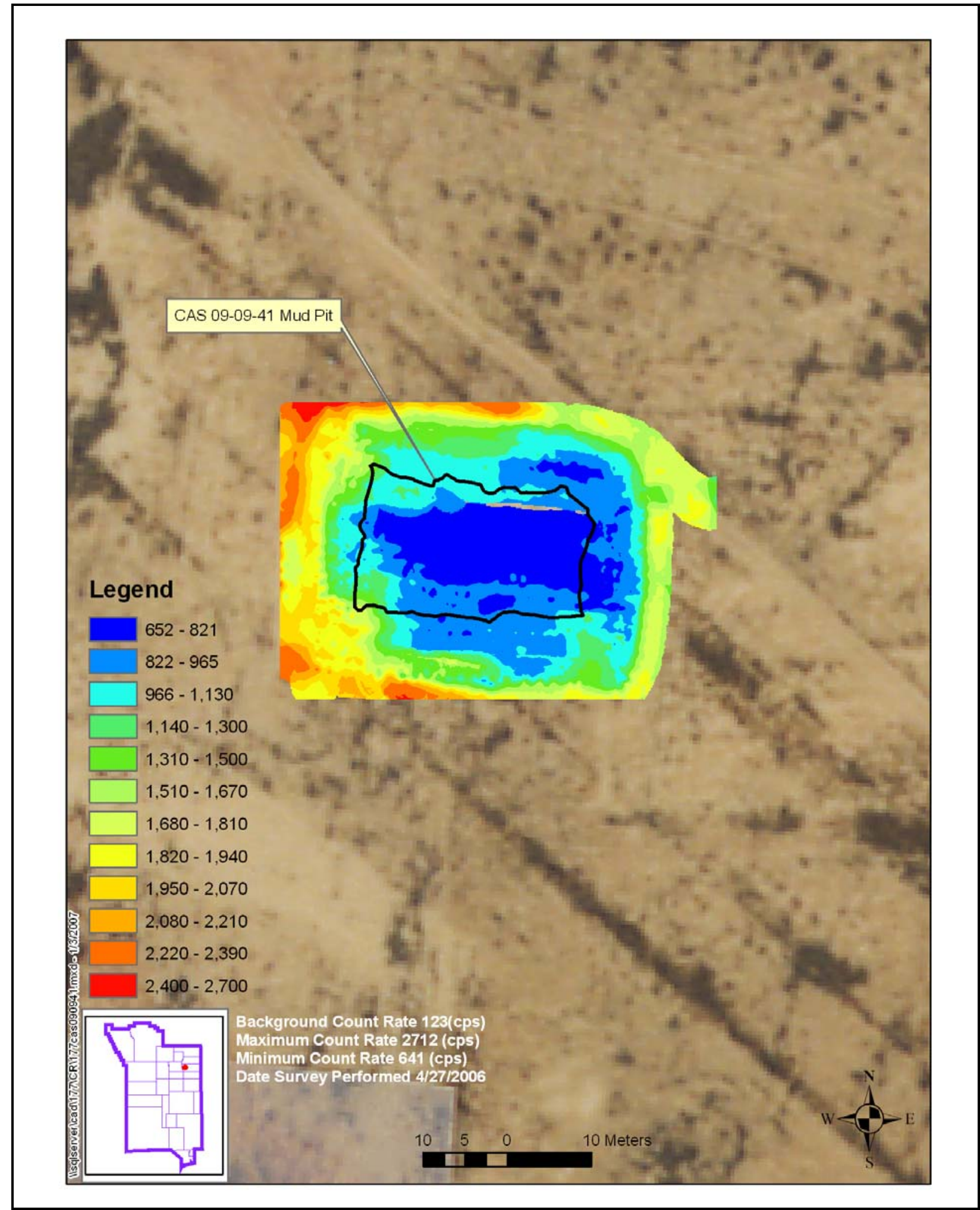

Figure D.4-3

CAS 09-09-41 Radiological Walkover Survey 


\section{D.5.0 CAS 09-09-45, U-9bz PS \#1A Mud Pit (1) and Cellar}

Corrective Action Site 09-09-45 is located within a posted RMA on the west side of Old Mercury Highway, slightly north of 9-01 Road, in Area 9 of the NTS (Figure 1-1). The CAS components identified for investigation include an open mud pit and a backfilled cellar. Accumulated tumbleweeds in the mud pit were removed before sampling activities.

\section{D.5.1 Corrective Action Investigation}

Fifteen characterization samples were collected during investigation activities at CAS 09-09-45. Ten samples and one FD were collected at the mud pit, and four samples were collected at the cellar. The sample IDs, locations, types, and analyses are listed in Table D.5-1. The specific CAI activities conducted to satisfy the CAU 177 SAFER Plan requirements at this CAS are described in the following sections.

\section{D.5.1.1 Field Screening}

Decision I soil samples collected at CAS 09-09-45 were not screened for alpha and beta/gamma radiation during sample collection activities due to the elevated background readings in the RMA. Instead, these samples were screened for gamma-emitting radionuclides using a gamma spectrometer (located in Building 23-153) and the FSLs were used to ensure compliance with shipping requirements.

\section{D.5.1.2 Visual Inspections}

No spills, staining, disturbances of soil, or other indications of potential contamination were identified during the inspection of CAS 09-09-45 and site conditions were unchanged from previous field visits. The base of the mud pit was inspected for evidence of spills and/or staining after tumbleweed removal and before staking sample locations. The backfilled cellar was inspected to assess the orientation of exposed borehole riser casing for sample location selection and drilling purposes. 
Table D.5-1

Samples Collected at CAS 09-09-45, U-9bz PS \#1A Mud Pit (1) and Cellar

\begin{tabular}{|c|c|c|c|c|c|}
\hline $\begin{array}{l}\text { Sample } \\
\text { Location }\end{array}$ & $\begin{array}{l}\text { Sample } \\
\text { Number }\end{array}$ & $\begin{array}{c}\text { Depth } \\
\text { (ft bgs) }\end{array}$ & Matrix & Purpose & Analyses \\
\hline \multicolumn{6}{|c|}{ Mud Pit Samples } \\
\hline \multirow{2}{*}{$\mathrm{C} 01$} & $177 \mathrm{C006}$ & $0.0-1.0$ & Soil & Environmental & Set 1 \\
\hline & $177 \mathrm{C007}$ & $0.0-1.0$ & Soil & Field Duplicate of \#177C006 & Set 1 \\
\hline $\mathrm{CO2}$ & $177 \mathrm{C005}$ & $0.0-1.0$ & Soil & Environmental & Set 1 \\
\hline $\mathrm{CO3}$ & $177 C 009$ & $0.0-1.0$ & Soil & Environmental & Set 1 \\
\hline $\mathrm{CO4}$ & $177 \mathrm{C008}$ & $0.0-1.0$ & Soil & Environmental & Set 1 \\
\hline $\mathrm{CO5}$ & $177 C 010$ & $0.0-1.0$ & Soil & Environmental & Set 1 \\
\hline $\mathrm{C06}$ & $177 \mathrm{C011}$ & $0.0-1.0$ & Soil & Environmental & Set 1 \\
\hline $\mathrm{C07}$ & $177 \mathrm{C} 012$ & $0.0-1.0$ & Soil & Environmental & Set 1 \\
\hline $\mathrm{C08}$ & $177 \mathrm{C} 013$ & $0.0-1.0$ & Soil & Environmental & Set 1 \\
\hline C09 & $177 \mathrm{C} 014$ & $0.0-1.0$ & Soil & Environmental & Set 1 \\
\hline C10 & $177 \mathrm{C} 015$ & $0.0-1.0$ & Soil & Environmental & Set 1 \\
\hline \multicolumn{6}{|c|}{ Cellar Samples } \\
\hline \multirow{2}{*}{ C11 } & $177 \mathrm{C001}$ & $8.0-9.0$ & $\overline{\text { Soil }}$ & Environmental & Set 2 \\
\hline & $177 \mathrm{C002}$ & $9.5-10.5$ & Soil & Environmental, Full Lab QC & Set 2 \\
\hline \multirow{2}{*}{ C12 } & $177 \mathrm{C003}$ & $8.0-9.0$ & Soil & Environmental & Set 2 \\
\hline & $177 \mathrm{C004}$ & $9.5-10.5$ & Soil & Environmental & Set 2 \\
\hline \multicolumn{6}{|c|}{ QC Samples } \\
\hline $\mathrm{N} / \mathrm{A}$ & 177C301 & $\mathrm{N} / \mathrm{A}$ & Water & Trip Blank & VOCs \\
\hline $\mathrm{N} / \mathrm{A}$ & 177 C302 & N/A & Water & Equipment Rinsate (Core Barrels) & Set 2 \\
\hline
\end{tabular}

Set 1 = Gamma Spectroscopy, Isotopic Uranium, Isotopic Plutonium, Strontium-90

Set 2 = VOCs, SVOCs, RCRA Metals, Beryllium, TPH-DRO, TPH-GRO, PCBs, Gamma Spectroscopy, Isotopic Uranium, Isotopic Plutonium, Strontium-90

DRO = Diesel-range organics

$\mathrm{ft}$ bgs $=$ Feet below ground surface

$\mathrm{GRO}=$ Gasoline-range organics

N/A = Not applicable

$\mathrm{PCB}=$ Polychlorinated biphenyl
$\mathrm{QC}=$ Quality control

$\mathrm{RCRA}=$ Resource Conservation and Recovery Act

SVOC $=$ Semivolatile organic compound

$\mathrm{TPH}=$ Total petroleum hydrocarbons

VOC $=$ Volatile organic compound

\section{D.5.1.3 Sample Collection}

Decision I environmental sampling activities included the collection of random surface samples at the open mud pit and biased subsurface soil samples at the backfilled cellar (Figure D.5-1). 


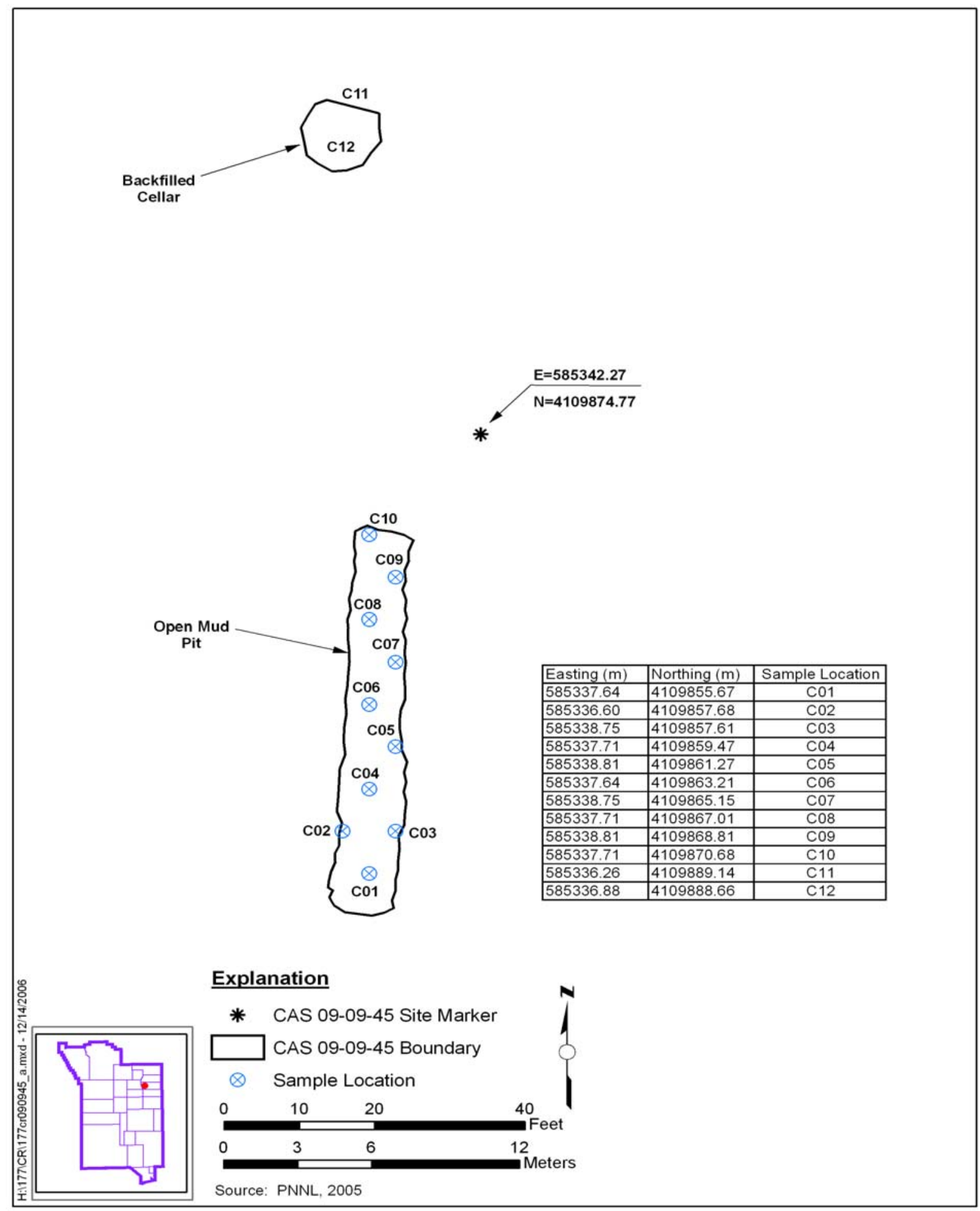

Figure D.5-1

CAS 09-09-45 Sample Location Map 
Eleven Decision I surface samples including 1 FD (0 to 12 in. bgs) were collected from 10 locations (C01 through C10) within the mud pit. The mud pit boundary of this CAS was re-established after tumbleweed clearing and new sample locations were generated using the VSP model. Samples collected at locations C09 and C10 (near the edge of the mud pit) consisted of a silty-sand and; location C02 (on the berm), sand; and all others, primarily moist or dry mud.

Four Decision I environmental samples were collected at the cellar. One subsurface sample was collected from each borehole (locations C11 and C12) at the interface with the cellar bottom. Two deeper subsurface samples were collected from the same boreholes to obtain information regarding the vertical extent of potentially released contamination. Each borehole was drilled to a depth of $11 \mathrm{ft}$ bgs. Core material was monitored during drilling and the interface between backfill material with the cellar bottom was identified at $9 \mathrm{ft}$ bgs, marked by a lithology change from $8.5 \mathrm{ft}$ of pea-gravel with a small interval of sand at the base to a potential grout layer (up to 6 in. thick) (Figures D.5-2 and D.5-3). The grout was underlain by slightly moist, fine sand with gravel, which was determined to represent native soil. The shallower subsurface samples were collected directly above the grout layer (8 to $9 \mathrm{ft}$ bgs) and the deeper subsurface samples were collected below the grout interface (9.5 to 10.5 ft bgs).

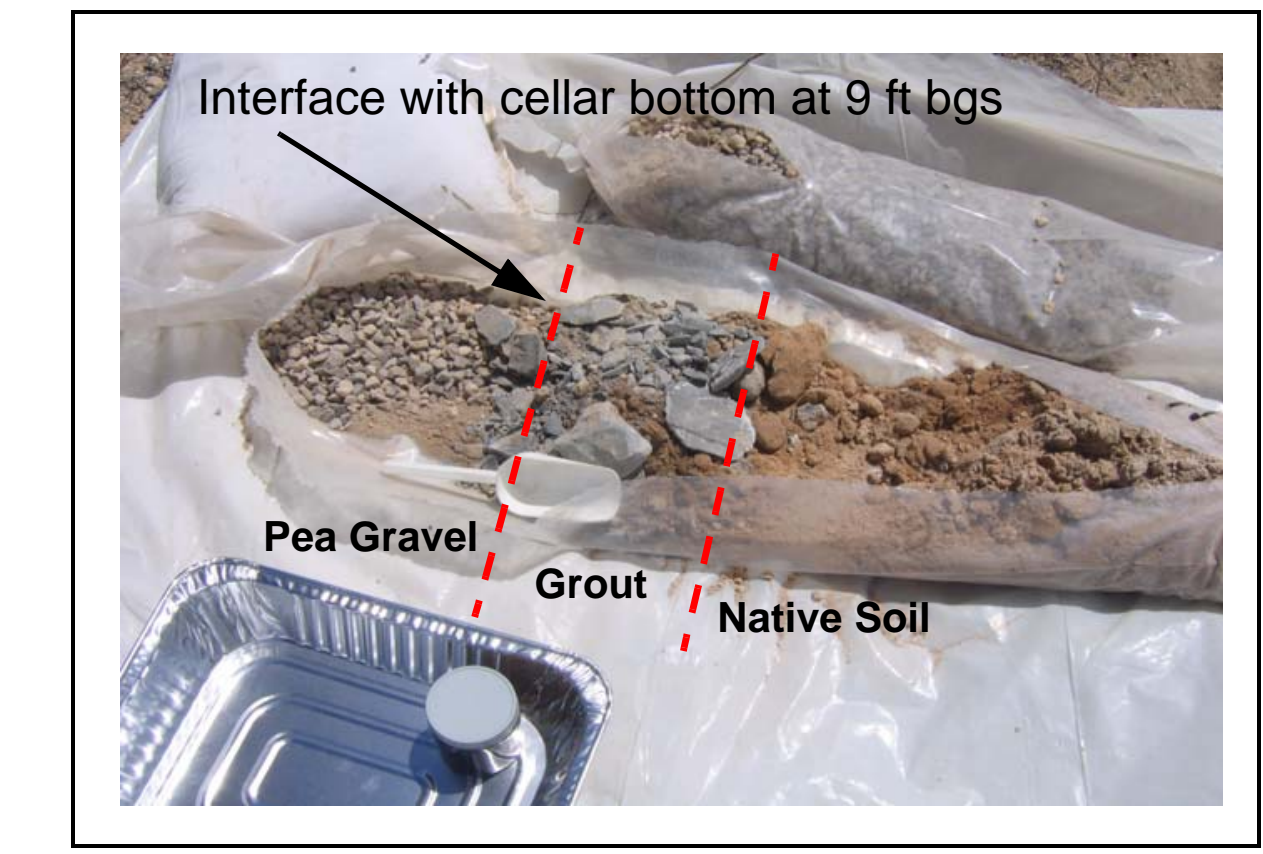

Figure D.5-2

Core Material Showing Interface with Cellar Bottom (Location C11) 


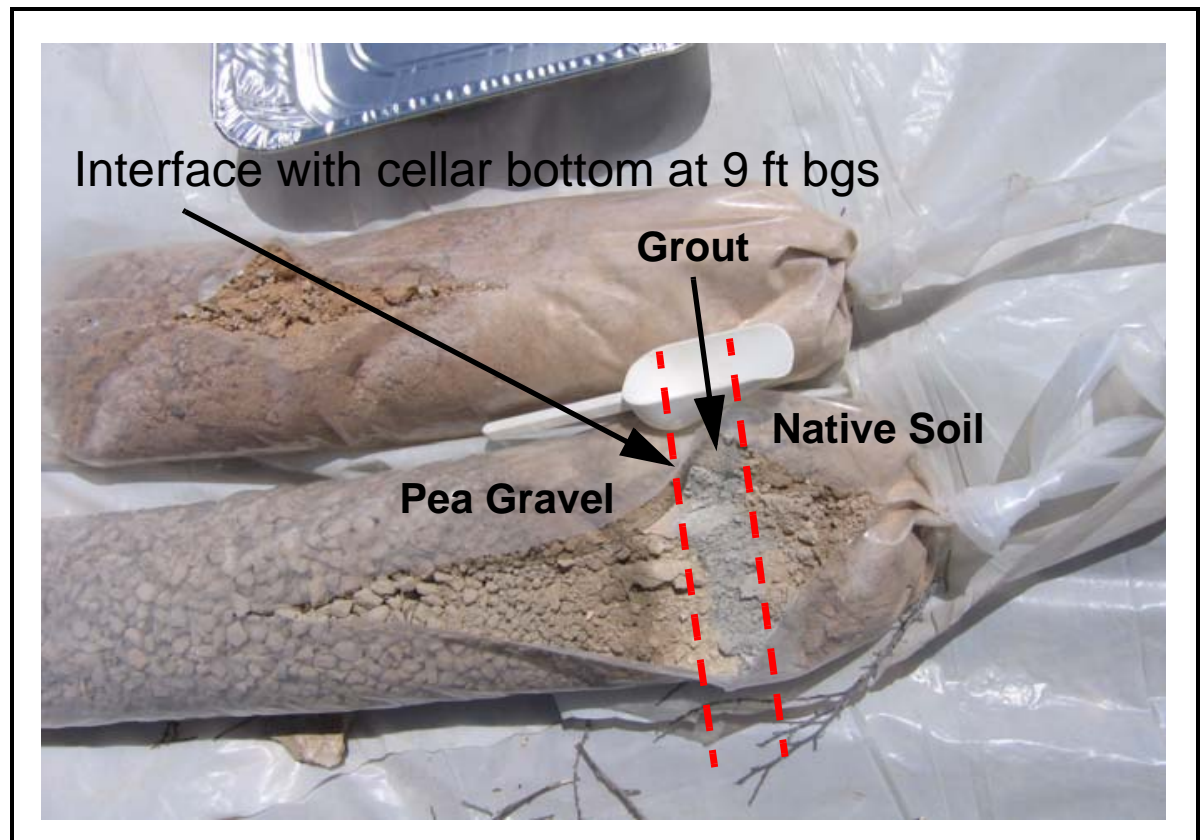

Figure D.5-3

Core Material Showing Interface with Cellar Bottom (Location C12)

\section{D.5.2 Investigation Results}

The following sections provide analytical results from the samples collected to complete investigation activities as outlined in the CAU 177 SAFER Plan (NNSA/NSO, 2006b). Investigation samples were analyzed for the SAFER-specified COPCs for cellars, which included VOCs, SVOCs, TPH-DRO and -GRO, RCRA metals, gamma-emitting radionuclides, isotopic U, isotopic Pu, and Sr-90; and mud pits, which included only the radiological analytes. Beryllium and PCBs were added parameters to the cellar suite, because these contaminants are a common concern at the NTS.

Table D.5-1 lists the sample-specific analytical suite for CAS 09-09-45. Analytical results from the soil samples with concentrations exceeding MDCs are summarized in the following sections.

For the judgmental samples at the cellar component of the CAS, an evaluation was conducted on all contaminants detected above MDCs by comparing individual concentration or activity results against the FALs to determine if a constituent is a COC. The FALs were established as the corresponding PAL concentrations or activities if the contaminant concentrations were below respective PALs.

For the probabilistic samples at the mud pit, any COPC that has a 95 percent UCL of the average concentration exceeding the FAL will result in that COPC being designated as a COC. As stipulated 
in the CAU 177 SAFER Plan, UCLs were calculated for a COPC only if it was detected in any sample within any CAS at a concentration equal to or exceeding the PAL (NNSA/NSO, 2006b). If COPCs were not detected in any mud pit sample at a concentration that exceeded the PAL, then it will be concluded that no COCs are present.

\section{D.5.2.1 Volatile Organic Compounds}

Analytical results for VOCs in soil samples collected from the cellar that were detected above MDCs are presented in Table D.5-2. No VOCs were detected at concentrations exceeding the respective PALs; therefore, the FALs were established as the corresponding PALs.

Table D.5-2

Soil Sample Results for Total VOCs Detected Above Minimum Detectable Concentrations at CAS 09-09-45, U-9bz PS \#1A Mud Pit (1) and Cellar

\begin{tabular}{|c|c|c|c|c|c|c|c|c|c|c|}
\hline \multirow[b]{2}{*}{ 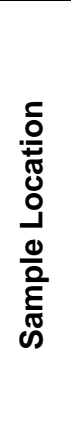 } & \multirow[b]{2}{*}{ 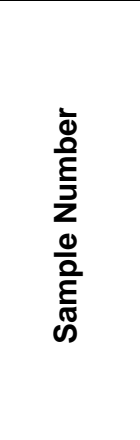 } & \multirow[b]{2}{*}{ 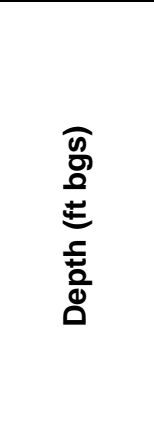 } & \multicolumn{8}{|c|}{ Contaminants of Potential Concern $(\mu \mathrm{g} / \mathrm{kg})$} \\
\hline & & & 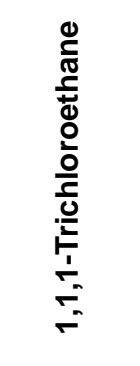 & 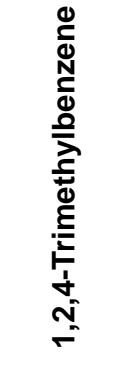 & 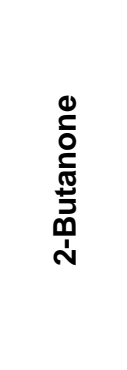 & 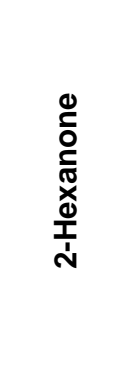 & 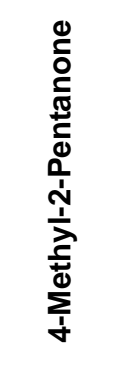 & 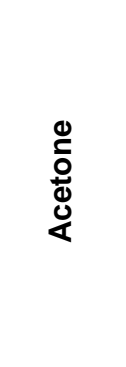 & $\begin{array}{l}\xi \\
\text { 흐 } \\
\frac{0}{0} \\
\text { 은 }\end{array}$ & 空 \\
\hline \multicolumn{3}{|c|}{ Final Action Levels ${ }^{a}$} & $\begin{array}{l}\text { ठे } \\
\text { Oे } \\
\text { N } \\
\text { - }\end{array}$ & $\begin{array}{l}\stackrel{0}{0} \\
\stackrel{-}{0} \\
\stackrel{-}{-}\end{array}$ & $\begin{array}{l}8 \\
0 \\
8 \\
0 \\
0 \\
0 \\
0\end{array}$ & $\begin{array}{l}\text { ¿ } \\
0 \\
8 \\
0 \\
0 \\
0\end{array}$ & 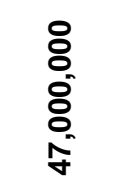 & $\begin{array}{l}8 \\
8 \\
8 \\
8 \\
\text { டे }\end{array}$ & $\stackrel{R}{\stackrel{9}{f}}$ & $\begin{array}{l}8 \\
8 \\
8 \\
8 \\
-1\end{array}$ \\
\hline \multicolumn{11}{|c|}{ Cellar Samples } \\
\hline C11 & $177 \mathrm{C001}$ & $8.0-9.0$ & $2.43(\mathrm{~J})$ & $0.36(\mathrm{~J})$ & $\overline{---}$ & 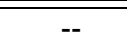 & $\overline{---}$ & $\overline{---}$ & $0.717(\mathrm{~J})$ & $0.259(\mathrm{~J})$ \\
\hline \multirow{2}{*}{ C12 } & $177 \mathrm{C003}$ & $8.0-9.0$ & $2.32(\mathrm{~J})$ & -- & $2.1(\mathrm{~J})$ & $\overline{--}$ & -- & $8.77(\mathrm{~J})$ & $0.723(\mathrm{~J})$ & -- \\
\hline & 177C004 & $9.5-10.5$ & $0.997(\mathrm{~J})$ & $\overline{--}$ & $47.1(\mathrm{~J})$ & $10.2(\mathrm{~J})$ & $3.56(\mathrm{~J})$ & $494(\mathrm{~J})$ & $0.395(\mathrm{~J})$ & -- \\
\hline
\end{tabular}

a'Based on U.S. Environmental Protection Agency, Region 9 Preliminary Remediation Goals (PRGs) (EPA, 2004).

$\mathrm{ft}$ bgs = Feet below ground surface $\mu \mathrm{g} / \mathrm{kg}=$ Micrograms per kilogram

-- = Not detected above minimum detectable concentrations.

$\mathrm{J}=$ Estimated value 


\section{D.5.2.2 Semivolatile Organic Compounds}

Analytical results for SVOCs in soil samples collected from the cellar that were detected above MDCs are presented in Table D.5-3. No SVOCs were detected at concentrations exceeding the respective PALs; therefore, the FALs were established as the corresponding PALs.

Table D.5-3

Soil Sample Results for Total SVOCs Detected Above Minimum Detectable Concentrations at CAS 09-09-45, U-9bz PS \#1A Mud Pit (1) and Cellar

\begin{tabular}{|c|c|c|c|c|}
\hline \multirow{2}{*}{$\begin{array}{l}\text { Sample } \\
\text { Location }\end{array}$} & \multirow{2}{*}{$\begin{array}{l}\text { Sample } \\
\text { Number }\end{array}$} & \multirow{2}{*}{$\begin{array}{l}\text { Depth } \\
\text { (ft bgs) }\end{array}$} & \multicolumn{2}{|c|}{ Contaminants of Potential Concern $(\mu \mathrm{g} / \mathrm{kg})$} \\
\hline & & & Bis(2-Ethylhexyl)Phthalate & Fluoranthene \\
\hline \multicolumn{3}{|c|}{ Final Action Levels ${ }^{a}$} & 120,000 & $22,000,000$ \\
\hline \multicolumn{5}{|c|}{ Cellar Samples } \\
\hline C11 & 177C002 & $9.5-10.5$ & -- & $41.4(\mathrm{~J})$ \\
\hline $\mathrm{C} 12$ & 177C004 & $9.5-10.5$ & $264(\mathrm{~J})$ & -- \\
\hline
\end{tabular}

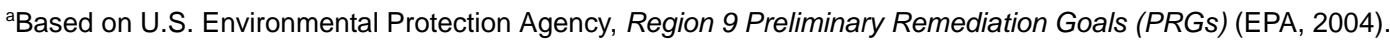

$\mathrm{ft}$ bgs $=$ Feet below ground surface $\mu \mathrm{g} / \mathrm{kg}=$ Micrograms per kilogram

$--=$ Not detected above minimum detectable concentrations.

$\mathrm{J}=$ Estimated value

\section{D.5.2.3 Total Petroleum Hydrocarbons}

The TPH-DRO analytical results for soil samples collected from the cellar that were detected above MDCs are presented in Table D.5-4. One subsurface sample (8 to $9 \mathrm{ft}$ bgs) collected at location C11 and one subsurface sample ( 9.5 to $10.5 \mathrm{ft}$ bgs) collected at location C12 exceeded the PAL of $100 \mathrm{mg} / \mathrm{kg}$ for TPH-DRO. The TPH-DRO was moved on to a Tier 2 evaluation and FALs were established for the hazardous constituents of TPH-DRO at the corresponding PAL concentrations. Concentrations of the hazardous constituents of TPH-DRO did not exceed FALs. Therefore, TPH-DRO is not considered a COC. Concentrations of TPH-GRO were not detected above the respective laboratory MDCs at this CAS.

\section{D.5.2.4 Polychlorinated Biphenyls}

Concentrations of PCBs were not detected above the respective laboratory MDCs at the cellar component of this CAS; therefore the FALs are established at the corresponding PALs. 
Table D.5-4

Soil Sample Results for TPH-DRO Detected Above Minimum Detectable Concentrations at CAS 09-09-45, U-9bz PS \#1A Mud Pit (1) and Cellar

\begin{tabular}{|c|c|c|c|}
\hline \multirow{2}{*}{$\begin{array}{l}\text { Sample } \\
\text { Location }\end{array}$} & \multirow{2}{*}{$\begin{array}{l}\text { Sample } \\
\text { Number }\end{array}$} & \multirow{2}{*}{$\begin{array}{l}\text { Depth } \\
\text { (ft bgs) }\end{array}$} & Contaminants of Potential Concern (mg/kg) \\
\hline & & & Diesel-Range Organics \\
\hline \multicolumn{3}{|c|}{ Preliminary Action Levels ${ }^{a}$} & 100 \\
\hline \multicolumn{4}{|c|}{ Cellar Samples } \\
\hline C11 & $177 \mathrm{C} 001$ & $8.0-9.0$ & $380(\mathrm{~J})$ \\
\hline \multirow{2}{*}{$\mathrm{C} 12$} & $177 \mathrm{C003}$ & $8.0-9.0$ & 80.7 \\
\hline & $177 \mathrm{C004}$ & $9.5-10.5$ & 103 \\
\hline
\end{tabular}

aBased on Nevada Administrative Code, "Contamination of Soil: Establishment of Action Levels" (NAC, 2006).

$\mathrm{ft}$ bgs = Feet below ground surface

$\mathrm{mg} / \mathrm{kg}=$ Milligrams per kilogram

$\mathrm{J}=$ Estimated value.

\section{D.5.2.5 RCRA Metals and Beryllium}

Analytical results for RCRA metals and beryllium in soil samples collected from the cellar that were detected above MDCs are presented in Table D.5-5. None of the metals were detected at concentrations exceeding the respective PALs; therefore, the FALs were established as corresponding PALs.

\section{D.5.2.6 Gamma-Emitting Radionuclides}

The analytical results for gamma-emitting radionuclides in soil samples from the mud pit and cellar that were detected above MDCs are presented in Table D.5-6. The radionuclide Eu-152 was detected at concentrations that exceeded the PAL $(5.7 \mathrm{pCi} / \mathrm{g})$ in 11 surface samples from 10 locations within the mud pit. However, the presence of Eu-152 is considered to be associated with the adjacent Soils Project CASs 09-99-01 and 09-23-14 and not a release from this CAS (Section D.5.3); therefore, the FALs were established at the PALs. 
Table D.5-5

Soil Sample Results for Metals Detected Above Minimum

Detectable Concentrations at CAS 09-09-45, U-9bz PS \#1A Mud Pit (1) and Cellar

\begin{tabular}{|c|c|c|c|c|c|c|c|c|c|c|}
\hline \multirow{2}{*}{ 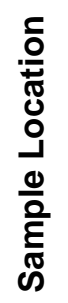 } & \multirow{2}{*}{ 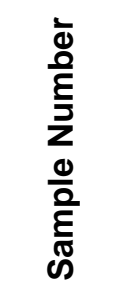 } & \multirow[b]{2}{*}{ 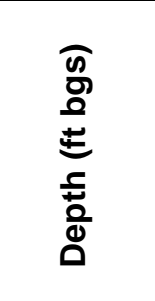 } & \multicolumn{8}{|c|}{ Contaminants of Potential Concern (mg/kg) } \\
\hline & & & $\begin{array}{l}\frac{0}{\frac{0}{d}} \\
\frac{\omega}{\alpha} \\
\frac{\omega}{4}\end{array}$ & 톨 & 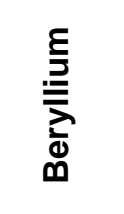 & $\frac{\underline{\xi}}{\bar{\Sigma}}$ & 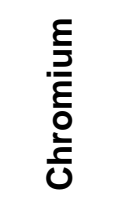 & ర్త్ర & 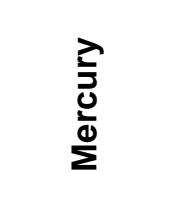 & $\frac{\bar{亠}}{\bar{\omega}}$ \\
\hline \multicolumn{3}{|c|}{ Final Action Levels } & $23^{a}$ & $67,000^{b}$ & $1,900^{b}$ & $450^{b}$ & $450^{b}$ & $800^{b}$ & $310^{b}$ & $5,100^{b}$ \\
\hline \multicolumn{11}{|c|}{ Cellar Samples } \\
\hline \multirow{2}{*}{ C11 } & 177C001 & $8.0-9.0$ & 5 & $242(\mathrm{~J}+)$ & 0.84 & 0.88 & $12(\mathrm{~J})$ & 136 & $0.029(\mathrm{~J}+)$ & 9 \\
\hline & $177 \mathrm{C002}$ & $9.5-10.5$ & 5.6 & $114(\mathrm{~J}+)$ & 0.67 & 0.21 & $7.7(\mathrm{~J})$ & 5.2 & $0.0088(\mathrm{~J}+)$ & 0.21 \\
\hline \multirow{2}{*}{ C12 } & $177 \mathrm{C003}$ & $8.0-9.0$ & 5.5 & $218(\mathrm{~J}+)$ & 0.63 & 0.55 & $10.5(\mathrm{~J})$ & 111 & $0.018(\mathrm{~J}+)$ & 0.27 \\
\hline & $177 \mathrm{C004}$ & $9.5-10.5$ & 5.9 & $121(\mathrm{~J}+)$ & 0.73 & 0.19 & $11.1(\mathrm{~J})$ & 18 & $0.015(\mathrm{~J}+)$ & -- \\
\hline
\end{tabular}

${ }^{a}$ Based on the background concentrations for metals. Background is considered the mean plus two times the standard deviation for sediment samples collected by the Nevada Bureau of Mines and Geology throughout the Nevada Test and Training Range (NBMG, 1998; Moore, 1999).

${ }^{\mathrm{b}}$ Based on U.S. Environmental Protection Agency, Region 9 Preliminary Remediation Goals (PRGs) (EPA, 2004).

$\mathrm{ft}$ bgs $=$ Feet below ground surface

$\mathrm{mg} / \mathrm{kg}=$ Milligrams per kilogram

$--=$ Not detected above minimum detectable concentrations.

$\mathrm{J}=$ Estimated value.

$\mathrm{J}+=$ The result is an estimated quantity, but may be biased high.

Table D.5-6

Soil Sample Results for Gamma-Emitting Radionuclides Detected Above Minimum Detectable Concentrations at CAS 09-09-45, U-9bz PS \#1A Mud Pit (1) and Cellar (Page 1 of 2)

\begin{tabular}{|c|c|c|c|c|c|c|c|c|c|c|c|}
\hline \multirow[b]{2}{*}{ 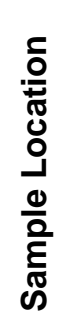 } & \multirow[b]{2}{*}{ 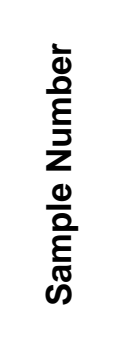 } & \multirow[b]{2}{*}{ 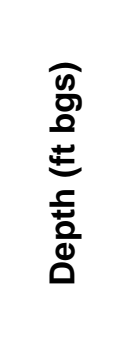 } & \multicolumn{9}{|c|}{ Contaminants of Potential Concern (pCi/g) } \\
\hline & & & 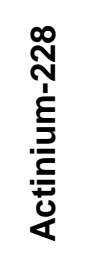 & 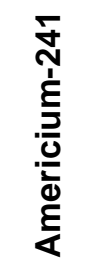 & 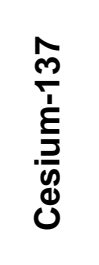 & $\begin{array}{l}8 \\
\stackrel{\varrho}{1} \\
\stackrel{\pi}{\pi} \\
\stackrel{0}{0}\end{array}$ & 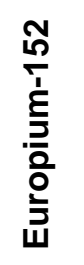 & 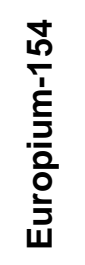 & 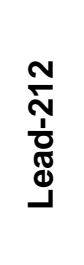 & 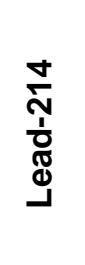 & 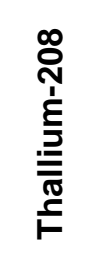 \\
\hline \multicolumn{3}{|c|}{ Final Action Levels } & $5^{\mathrm{a}}$ & $12.7^{b}$ & $12.2^{b}$ & $2.7^{\mathrm{b}}$ & $5.7^{\mathrm{b}}$ & $5.4^{b}$ & $5^{a}$ & $5^{a}$ & $5^{a}$ \\
\hline \multicolumn{12}{|c|}{ Mud Pit Samples } \\
\hline \multirow{2}{*}{ C01 } & 177C006 & $0.0-1.0$ & 1.91 & 0.582 & 1.94 & $\overline{---}$ & 10.3 & $\overline{---}$ & 1.92 & 1.47 & 0.606 \\
\hline & 177C007 & $0.0-1.0$ & 1.87 & -- & 1.71 & -- & 11.1 & -- & 1.95 & 1.16 & 0.651 \\
\hline
\end{tabular}


Table D.5-6 Soil Sample Results for Gamma-Emitting Radionuclides Detected Above Minimum
Detectable Concentrations at CAS 09-09-45, U-9bz PS \#1A Mud Pit (1) and Cellar (Page 2 of 2)

\begin{tabular}{|c|c|c|c|c|c|c|c|c|c|c|c|}
\hline \multirow[b]{2}{*}{ 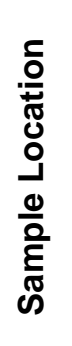 } & \multirow[b]{2}{*}{ 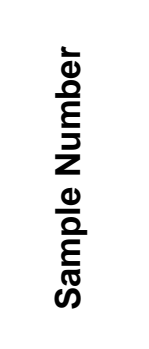 } & \multirow[b]{2}{*}{$\begin{array}{l}\tilde{n} \\
8 \\
0 \\
\pm \\
\frac{c}{5} \\
\frac{0}{0}\end{array}$} & \multicolumn{9}{|c|}{ Contaminants of Potential Concern (pCi/g) } \\
\hline & & & 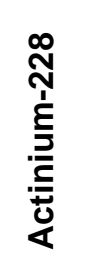 & 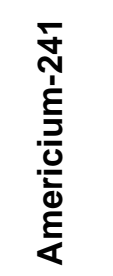 & 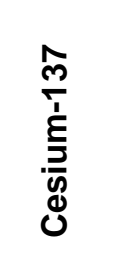 & 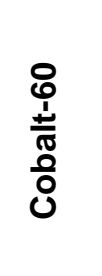 & 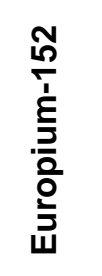 & 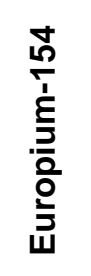 & 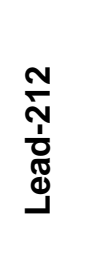 & 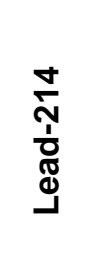 & 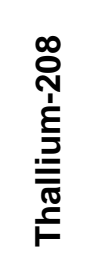 \\
\hline \multicolumn{3}{|c|}{ Final Action Levels } & $5^{a}$ & $12.7^{b}$ & $12.2^{b}$ & $2.7^{\mathrm{b}}$ & $5.7^{\mathrm{b}}$ & $5.4^{b}$ & $5^{a}$ & $5^{a}$ & $5^{a}$ \\
\hline \multicolumn{12}{|c|}{ Mud Pit Samples } \\
\hline $\mathrm{CO2}$ & $177 \mathrm{C005}$ & $0.0-1.0$ & 1.61 & -- & 0.921 & -- & 28.3 & 1.3 & 1.11 & 0.839 & 0.598 \\
\hline $\mathrm{CO3}$ & $177 C 009$ & $0.0-1.0$ & 1.75 & $\overline{--}$ & 1.72 & -- & 11.9 & -- & 1.86 & 1.09 & 0.513 \\
\hline $\mathrm{CO4}$ & $177 \mathrm{C008}$ & $0.0-1.0$ & 1.57 & $\overline{--}$ & 1.43 & -- & 17.1 & -- & 1.66 & 1.08 & 0.531 \\
\hline $\mathrm{C05}$ & $177 \mathrm{C010}$ & $0.0-1.0$ & -- & 0.7 & 1.28 & -- & 23.1 & -- & 1.7 & 0.904 & -- \\
\hline $\mathrm{C} 06$ & $177 \mathrm{C} 011$ & $0.0-1.0$ & 2.37 & 0.682 & 1.69 & -- & 12 & -- & 1.74 & 1.35 & 0.626 \\
\hline $\mathrm{CO7}$ & $177 \mathrm{C} 012$ & $0.0-1.0$ & 1.83 & -- & 1.46 & -- & 13.2 & -- & 1.79 & 1.2 & 0.498 \\
\hline $\mathrm{C08}$ & $177 \mathrm{C} 013$ & $0.0-1.0$ & 2.18 & 1.15 & 2.8 & 0.318 & 21.3 & -- & 1.76 & 1.44 & 0.581 \\
\hline $\mathrm{CO9}$ & $177 \mathrm{C} 014$ & $0.0-1.0$ & 2.21 & 2.04 & 3.7 & -- & 29.8 & 1.82 & 1.42 & 1.26 & 0.616 \\
\hline C10 & $177 \mathrm{C} 015$ & $0.0-1.0$ & 1.52 & 3.21 & 4.15 & 0.287 & 37.1 & 1.52 & 1.29 & 1.1 & 0.408 \\
\hline \multicolumn{12}{|c|}{ Cellar Samples } \\
\hline \multirow{2}{*}{ C11 } & $177 \mathrm{C001}$ & $8.0-9.0$ & 1.94 & 1.75 & $2.89(\mathrm{~J})$ & -- & 29.9 & 1.29 & 1.24 & 0.873 & -- \\
\hline & $177 \mathrm{C002}$ & $9.5-10.5$ & 1.37 & -- & -- & -- & 0.814 & -- & 1.14 & 1.03 & 0.341 \\
\hline \multirow{2}{*}{ C12 } & $177 \mathrm{C003}$ & $8.0-9.0$ & -- & 0.575 & $1.2(\mathrm{~J})$ & -- & 6.52 & -- & 1.18 & 0.929 & 0.449 \\
\hline & $177 \mathrm{C004}$ & $9.5-10.5$ & 1.04 & -- & -- & -- & 4.52 & -- & 1.07 & 1.03 & 0.351 \\
\hline
\end{tabular}

aTaken from the generic guidelines for residual concentrations of actinium-228, bismuth-214, lead-212, lead-214, thallium-208, and thorium-232, as found in Chapter IV of U.S. Department of Energy Order 5400.5, Change 2, Radiation Protection of the Public and Environment (DOE, 1993).

${ }^{\mathrm{b}}$ Taken from the construction, commercial, industrial land-use scenario in Table 2.1 of the National Council on Radiation Protection and Measurement Report No. 129, Recommended Screening Limits for Contaminated Surface Soil and Review Factors Relevant to Site-Specific Studies (NCRP, 1999). The values provided in this source document were scaled to a 25-millirem-per-year dose.

$\mathrm{ft}$ bgs $=$ Feet below ground surface $\mathrm{pCi} / \mathrm{g}=$ Picocuries per gram

$\mathrm{J}=$ Estimated value

-- = Not detected above minimum detectable concentrations. 
Two subsurface samples (177C001 from borehole C11 and 177C003 from borehole C12) collected at the interface (8 to $9 \mathrm{ft}$ bgs) with the cellar bottom had Eu-152 detected at concentrations that exceeded the PAL. The presence of Eu-152 is attributed to using the surrounding soils that are known to have elevated radioactivity as backfill material to fill the cellar, and is not considered to be a release from the CAS (Section D.5.3); therefore, Eu-152 is not a COC at the cellar component of this CAS and the FAL is established as the corresponding PAL.

\section{D.5.2.7 Plutonium, Strontium-90, and Uranium Isotopes}

The analytical results for isotopic Pu, isotopic Sr-90, and isotopic U in soil samples from the mud pit and cellar that were detected above MDCs are presented in Table D.5-7. No U or Sr-90 isotopes were detected in soil samples collected at the cellar at concentrations above the PALs; therefore, the FALs were established as the corresponding PALs.

Table D.5-7

Soil Sample Results for Isotopes Detected Above Minimum Detectable Concentrations at CAS 09-09-45, U-9bz PS \#1A Mud Pit (1) and Cellar (Page 1 of 2)

\begin{tabular}{|c|c|c|c|c|c|c|c|c|}
\hline \multirow[b]{2}{*}{$\begin{array}{l}\text { Sample } \\
\text { Location }\end{array}$} & \multirow[b]{2}{*}{$\begin{array}{l}\text { Sample } \\
\text { Number }\end{array}$} & \multirow[b]{2}{*}{$\begin{array}{c}\text { Depth } \\
\text { (ft bgs) }\end{array}$} & \multicolumn{6}{|c|}{ Contaminants of Potential Concern (pCi/g) } \\
\hline & & & 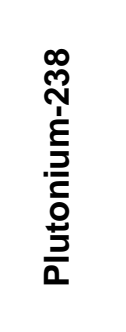 & 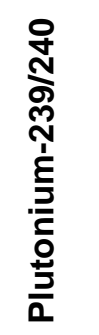 & 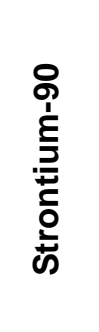 & 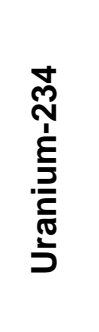 & 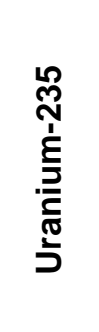 & 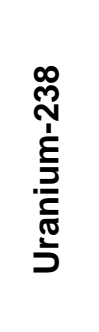 \\
\hline \multicolumn{3}{|c|}{ Final Action Levels ${ }^{a}$} & 13 & 12.7 & 838 & 143 & 17.6 & 105 \\
\hline \multicolumn{9}{|c|}{ Mud Pit Samples } \\
\hline \multirow{2}{*}{$\mathrm{C} 01$} & $177 \mathrm{C006}$ & $0.0-1.0$ & 0.0517 & 6.33 & 0.956 & 1.77 & 0.143 & 1.3 \\
\hline & $177 \mathrm{C007}$ & $0.0-1.0$ & -- & 4.9 & 0.583 & 1.17 & -- & 1.37 \\
\hline $\mathrm{CO2}$ & $177 \mathrm{C005}$ & $0.0-1.0$ & -- & 1.05 & 0.233 & 0.624 & -- & 0.924 \\
\hline $\mathrm{CO3}$ & $177 C 009$ & $0.0-1.0$ & $\overline{--}$ & 2.59 & -- & 1.26 & -- & 1.04 \\
\hline $\mathrm{CO4}$ & 177C008 & $0.0-1.0$ & -- & 2.66 & 0.76 & 1.28 & -- & 1.2 \\
\hline C05 & $177 \mathrm{C} 010$ & $0.0-1.0$ & $\overline{--}$ & 3.65 & 0.277 & 1.26 & $\overline{--}$ & 1.17 \\
\hline $\mathrm{C06}$ & 177C011 & $0.0-1.0$ & -- & 2.7 & 0.756 & 1.41 & -- & 1.43 \\
\hline $\mathrm{CO}$ & $177 \mathrm{C} 012$ & $0.0-1.0$ & 0.569 & 32.3 & 0.657 & 1.14 & $\overline{--}$ & 1.25 \\
\hline $\mathrm{C08}$ & $177 \mathrm{C} 013$ & $0.0-1.0$ & 0.194 & 14.9 & 0.636 & 1.85 & -- & 1.09 \\
\hline
\end{tabular}


Table D.5-7

Soil Sample Results for Isotopes Detected Above Minimum Detectable Concentrations at CAS 09-09-45, U-9bz PS \#1A Mud Pit (1) and Cellar (Page 2 of 2)

\begin{tabular}{|c|c|c|c|c|c|c|c|c|}
\hline \multirow[b]{2}{*}{$\begin{array}{c}\text { Sample } \\
\text { Location }\end{array}$} & \multirow[b]{2}{*}{$\begin{array}{l}\text { Sample } \\
\text { Number }\end{array}$} & \multirow[b]{2}{*}{$\begin{array}{l}\text { Depth } \\
\text { (ft bgs) }\end{array}$} & \multicolumn{6}{|c|}{ Contaminants of Potential Concern (pCi/g) } \\
\hline & & & 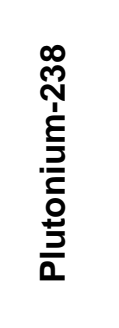 & 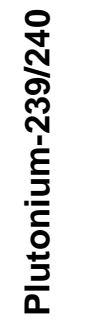 & 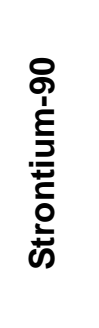 & 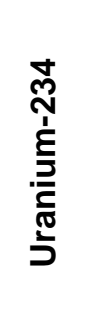 & 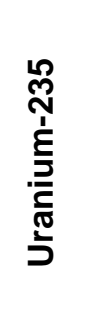 & 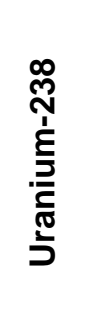 \\
\hline \multicolumn{3}{|c|}{ Final Action Levels ${ }^{a}$} & 13 & 12.7 & 838 & 143 & 17.6 & 105 \\
\hline \multicolumn{9}{|c|}{ Mud Pit Samples } \\
\hline $\mathrm{C09}$ & $177 \mathrm{C} 014$ & $0.0-1.0$ & 0.175 & 14.4 & 1 & 0.929 & -- & 0.849 \\
\hline C10 & $177 \mathrm{C} 015$ & $0.0-1.0$ & 0.182 & 23.1 & 1.45 & 1.23 & -- & 0.759 \\
\hline \multicolumn{9}{|c|}{ Cellar Samples } \\
\hline \multirow{2}{*}{ C11 } & 177C001 & $8.0-9.0$ & 0.0819 & 8.59 & 0.973 & 0.883 & 0.108 & 0.707 \\
\hline & $177 \mathrm{C002}$ & $9.5-10.5$ & -- & -- & -- & 1.04 & -- & 1.05 \\
\hline \multirow{2}{*}{ C12 } & $177 \mathrm{C} 003$ & $8.0-9.0$ & 0.0642 & 4.46 & 0.418 & 0.803 & -- & 0.974 \\
\hline & $177 \mathrm{C004}$ & $9.5-10.5$ & -- & 0.15 & - & 0.959 & -- & 0.773 \\
\hline
\end{tabular}

aTaken from the construction, commercial, industrial land-use scenario in Table 2.1 of the National Council on Radiation Protection and Measurement Report No. 129, Recommended Screening Limits for Contaminated Surface Soil and Review Factors Relevant to Site-Specific Studies (NCRP, 1999). The values provided in this source document were scaled to a 25-millirem-per-year dose.

$\mathrm{ft}$ bgs $=$ Feet below ground surface

$\mathrm{pCi} / \mathrm{g}=$ Picocuries per gram

-- = Not detected above minimum detectable concentrations.

Plutonium-239 was detected at concentrations that exceed the PAL (12.7 pCi/g) in four surface samples (177C012, 177C013, 177C014, 177C015) from four locations within the mud pit. However, the presence of Pu-239 is considered to be associated with the adjacent Soils Project CASs 09-99-01 and 09-23-14, not a release from this CAS (Section D.5.3); therefore, the FALs were established at the PALs. 


\section{D.5.3 Nature and Extent of Contamination}

To determine if the Eu-152 and $\mathrm{Pu}-239$ contamination was from a source other than a release from the CAS, the location of the site was overlain on a map that displays the results of a 1994 fly-over radiation survey (Figure D.4-2). The color-coded contours depict a plume of elevated radioactivity measured as man-made exposure rate (gamma ray) in $\mu \mathrm{R} / \mathrm{hr}$. This plume is associated with the B9a location and eight atmospheric nuclear tests, all conducted in adjacent locations and resulted in residual fission and soil activation products in the soil. The source of the radiological activity is attributed to the presence of trinity glass and other radioactivity that is dispersed throughout the area (DOE/NV, 2000). Corrective Action Site 09-09-45 is located near the center of the plume in the area of highest activity (80 to $240 \mu \mathrm{R} / \mathrm{hr}$ ) and is also located within a posted RMA boundary that has been established as a result of the eight atmospheric (balloon) tests conducted from June 1957 to October 1958 at the B9a location. The atmospheric releases associated with these tests are listed in the FFACO as CASs 09-99-01 and 09-23-14 and will be evaluated under the Soils Project CAU 105.

The results of a site-specific radiological land area survey (SNJV, 2006) at CAS 09-09-45

(Figure D.5-4) were then compared to identify areas of elevated radioactivity within the mud pit. The color-coded contours shown in Figure D.5-4 depict the radiological data in cps with the blue and green colors representing lower activities. Radiological activities at CAS 09-09-45 are lowest at the backfilled cellar and within the mud pit and become increasingly higher as distance increases from these features towards the surrounding native soil. This is expected because the mud pit and cellar represent areas where native soils were excavated during construction. Areas shown in dark orange and red, just beyond the mud pit and cellar boundaries, have elevated activities (1,230 to 1,350 cps) that are at least 10 times higher than the mean undisturbed background rate of 123 cps (measured outside of the posted RMA) (SNJV, 2006).

Based on the association of Eu-152 with atmospheric testing, the location of CAS 09-09-45 near the center of the radiological plume and proximal to the B-9a ground zero, and the relatively low activities at the cellar and within the mud pit in contrast to the elevated levels of radioactivity immediately outside of these features, the presence of Eu-152 and Pu-239 is assumed to be attributed to the background level of radioactivity known to be present in the area as defined by the B9a RMA and radiological plume. The Eu-152 detected at depth within the backfill material of the cellar is assumed to be attributed to use of the surrounding radioactive soils to backfill the cellar. Therefore, 
Eu-152 and Pu-239 contamination is not considered to be attributed to a release from CAS 09-09-45 (i.e., not considered a COC) and will be addressed under the evaluation of Soils Project CASs 09-99-01 and 09-23-14 in CAU 105.

\section{D.5.4 Revised Conceptual Site Model}

The CAU 177 SAFER Plan requirements were met at this CAS, and no revisions were necessary to the CSM. 


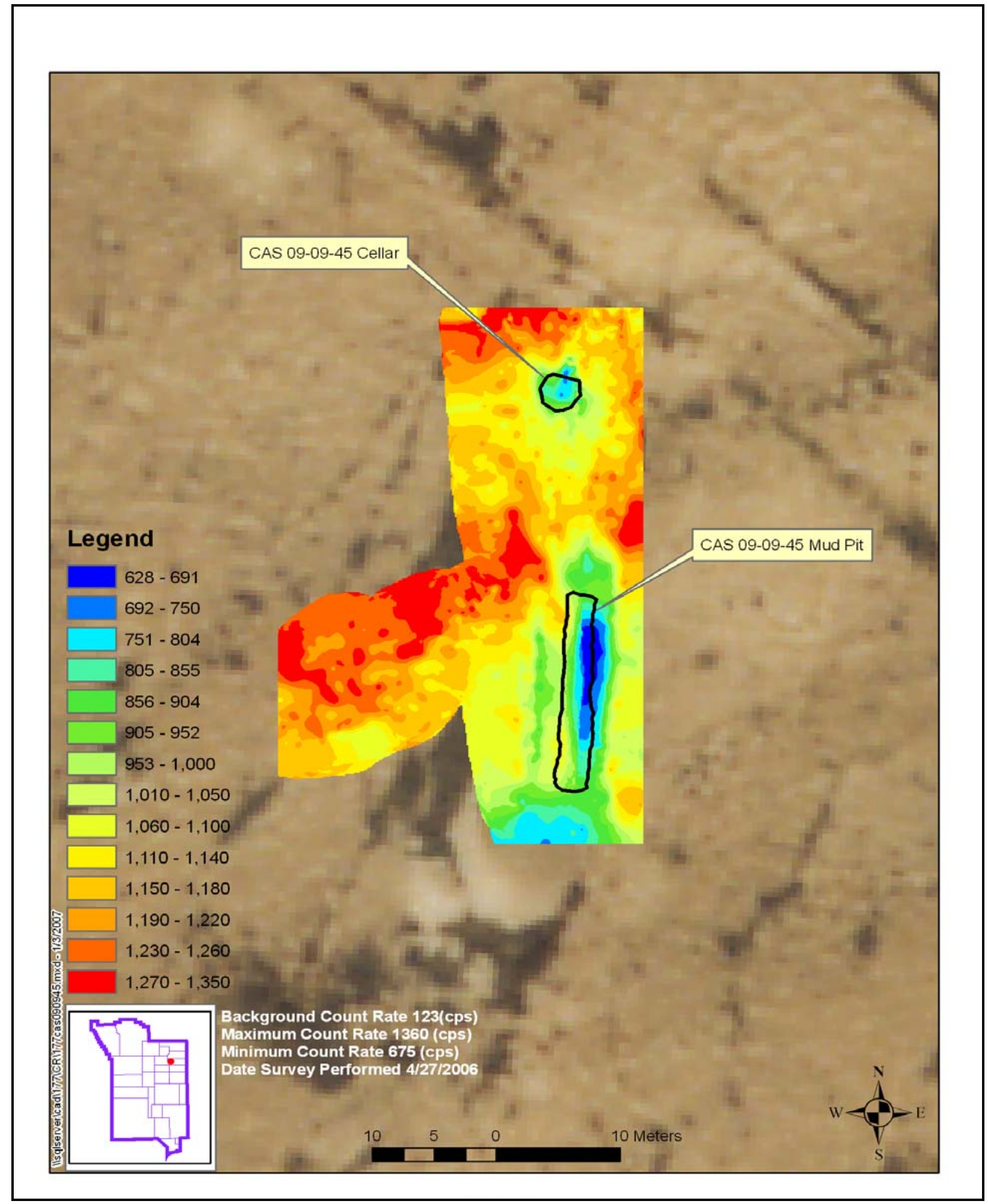

Figure D.5-4

CAS 09-09-45 Radiological Walkover Survey 


\section{D.6.0 CAS 09-23-05, Mud Pit and Cellar}

Corrective Action Site 09-23-05 is within a fenced URMA that is located on the east side of Old Mercury Highway in Area 9 (Figure 1-1), approximately $100 \mathrm{ft}$ west of the U-9ch crater. The CAS components identified for investigation include a backfilled earthen mud pit and a backfilled cellar. The boundaries of the backfilled mud pit were confirmed based on the presence of mud at a majority of the sample locations.

\section{D.6.1 Corrective Action Investigation}

Fifteen characterization samples were collected during investigation activities at CAS 09-23-05. Ten samples and one FD were collected at the mud pit and four samples were collected at the cellar. The sample IDs, locations, types, and analyses are listed in Table D.6-1. The specific CAI activities conducted to satisfy the CAU 177 SAFER Plan requirements at this CAS are described in the following sections.

\section{D.6.1.1 Field Screening}

Investigation samples were screened for total alpha and beta/gamma radiation. The FSRs were compared to FSLs and no exceedences were identified. Debris encountered during excavation at the backfilled mud pit did not show the presence of radioactivity.

\section{D.6.1.2 Visual Inspections}

No spills, staining, or other indications of potential contamination were identified during the inspection of CAS 09-23-05. The backfilled cellar was inspected to assess the orientation of exposed borehole casing for sample location selection and drilling purposes. During the inspection of the cellar it was noticed that the area had been disturbed since the last field visit to this CAS. An area (approximately $15 \mathrm{ft}$ in diameter) surrounding the borehole riser casing was now covered in a layer of pea-gravel; the cellar casing, which formerly was partially exposed, was not visible; and the riser casing, (cut off at $1 \mathrm{ft}$ above grade) was now filled with grout (Figures D.6-1 and D.6-2). A report from the Borehole Management Project indicates that the backfilled cellar was excavated to a depth where the top of the buried borehole casing was exposed (NSTec, 2004). The borehole casing was then extended with riser casing to above ground level, and grouted. Because these activities were 
conducted at a depth shallower than the base of the cellar, the soil sampled for this investigation is not believed to have been disturbed or impacted. All other site conditions were unchanged from previous field visits.

Table D.6-1

Samples Collected at CAS 09-23-05, Mud Pit and Cellar

\begin{tabular}{|c|c|c|c|c|c|}
\hline $\begin{array}{c}\text { Sample } \\
\text { Location }\end{array}$ & $\begin{array}{l}\text { Sample } \\
\text { Number }\end{array}$ & $\begin{array}{c}\text { Depth } \\
\text { (ft bgs) }\end{array}$ & Matrix & Purpose & Analyses \\
\hline \multicolumn{6}{|c|}{ Mud Pit Samples } \\
\hline D01 & 177D002A & $4.0-5.0$ & Soil & Environmental & Set 1 \\
\hline D02 & 177D001 & $3.5-4.5$ & Soil & Environmental & Set 1 \\
\hline D03 & 177D003A & $5.0-6.0$ & Soil & Environmental & Set 1 \\
\hline \multirow{2}{*}{ D04 } & 177D004A & $5.0-6.0$ & Soil & Environmental & Set 1 \\
\hline & 177D005A & $5.0-6.0$ & Soil & Field Duplicate of \#177D004A & Set 1 \\
\hline D05 & 177D006 & $5.0-6.0$ & Soil & Environmental & Set 1 \\
\hline D06 & 177D007 & $5.0-6.0$ & Soil & Environmental & Set 1 \\
\hline D07 & 177D008 & $5.0-6.0$ & Soil & Environmental & Set 1 \\
\hline D08 & 177D009 & $5.0-6.0$ & Soil & Environmental & Set 1 \\
\hline D09 & 177D010 & $5.0-6.0$ & Soil & Environmental & Set 1 \\
\hline D10 & 177D011 & $5.0-6.0$ & Soil & Environmental & Set 1 \\
\hline \multicolumn{6}{|c|}{ Cellar Samples } \\
\hline \multirow{2}{*}{ D11 } & 177D002 & $7.0-8.0$ & Soil & Environmental & Set 2 \\
\hline & 177D003 & $9.0-10.0$ & Soil & Environmental, Full Lab QC & Set 2 \\
\hline \multirow{2}{*}{ D12 } & 177D004 & $6.0-7.0$ & Soil & Environmental & Set 2 \\
\hline & 177D005 & $8.0-9.0$ & Soil & Environmental & Set 2 \\
\hline \multicolumn{6}{|c|}{ QC Samples } \\
\hline $\mathrm{N} / \mathrm{A}$ & 177D301 & $\mathrm{N} / \mathrm{A}$ & Water & Field Blank & Set 1 \\
\hline
\end{tabular}

Set 1 = Gamma Spectroscopy, Isotopic Uranium, Isotopic Plutonium, Strontium-90

Set 2 = VOCs, SVOCs, RCRA Metals, Beryllium, TPH-DRO, TPH-GRO, PCBs, Gamma Spectroscopy, Isotopic Uranium, Isotopic Plutonium, Strontium-90

DRO $=$ Diesel-range organics $\mathrm{ft}$ bgs $=$ Feet below ground surface $\mathrm{GRO}=$ Gasoline-range organics $\mathrm{N} / \mathrm{A}=$ Not applicable

$\mathrm{PCB}=$ Polychlorinated biphenyl
$\mathrm{QC}=$ Quality control

RCRA = Resource Conservation and Recovery Act

SVOC $=$ Semivolatile organic compound

$\mathrm{TPH}=$ Total petroleum hydrocarbons

VOC $=$ Volatile organic compound 


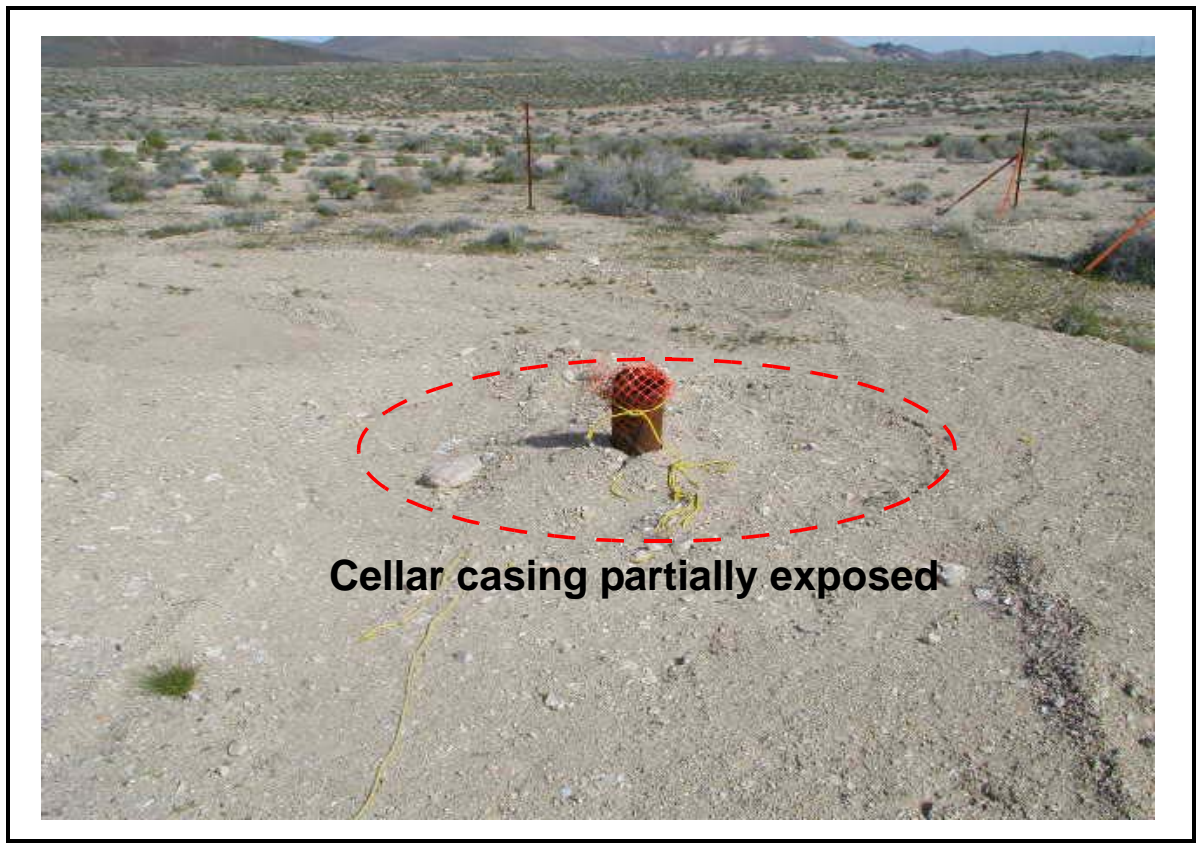

Figure D.6-1

Cellar Before Borehole Plugging Activities

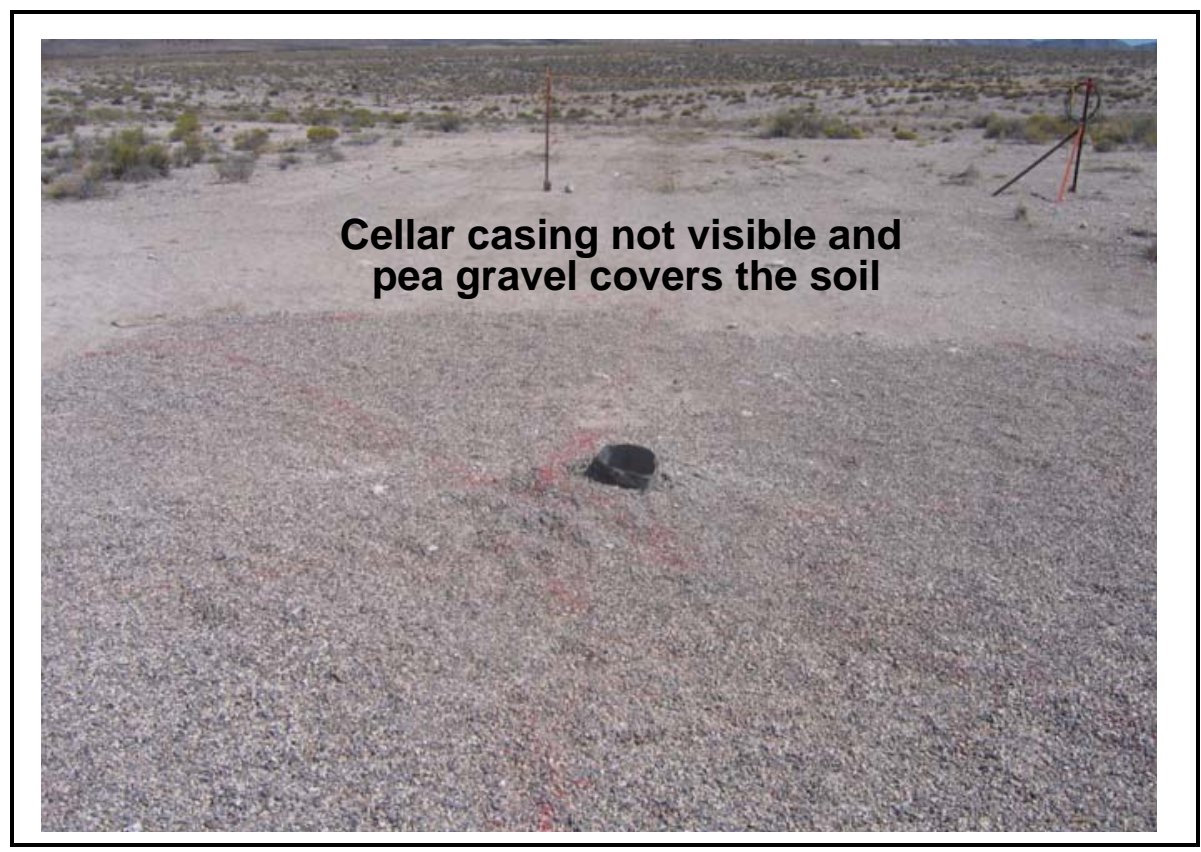

Figure D.6-2

Cellar After Borehole Plugging Activities 


\section{D.6.1.3 Sample Collection}

Decision I environmental sampling activities included the collection of random soil samples at the backfilled mud pit using a backhoe and biased surface and subsurface soil samples at the cellar (Figure D.6-3) using a sonic drill rig.

Eleven Decision I soil samples including 1 FD were collected from 10 locations (D01 through D10) within the estimated boundary of the mud pit. The trench and soils brought to the surface through backhoe excavation were monitored to identify the interface between backfill material and drilling mud/cuttings. An interface with mud/cuttings (Figures D.6-4 and D.6-5) and/or debris was consistently identified at 5 to $6 \mathrm{ft}$ bgs. Two locations, D01 and D02, originally encountered a resistant layer of potential native soil/caliche, indicating that these locations were outside of the mud pit boundary. These locations were moved approximately 1 to $2 \mathrm{ft}$ north to avoid the resistant interface. A similar resistant layer at $4 \mathrm{ft}$ bgs was encountered at the relocated D02, so a sample was collected at this depth. At D01 soil was excavated to $8 \mathrm{ft}$ bgs with no obvious mud interface identified, so a sample was collected at $4 \mathrm{ft}$ bgs beneath exposed debris.

Four Decision I environmental samples were collected at the cellar. One subsurface sample was collected from each borehole (locations D11 and D12), at the interface with the cellar bottom. Two deeper subsurface samples were collected from the same boreholes to obtain information regarding the vertical extent of potentially released contamination. Each borehole was drilled to a depth of $12 \mathrm{ft}$ bgs. Core material was monitored during drilling and the interface with the cellar bottom was identified at 7 to $8 \mathrm{ft}$ bgs, marked by a lithology change from backfilled soil to a potential grout layer (up to $1 \mathrm{ft}$ thick). The grout was underlain by moist fine sand with gravel, which is considered to represent native soil. The shallower subsurface samples were collected directly above the grout layer (7 to $8 \mathrm{ft}$ bgs, D11; 6 to $7 \mathrm{ft}$ bgs, D12), and the deeper subsurface samples were collected below the grout interface (9 to $10 \mathrm{ft}$ bgs, D11; 8 to $9 \mathrm{ft}$ bgs, D12). 


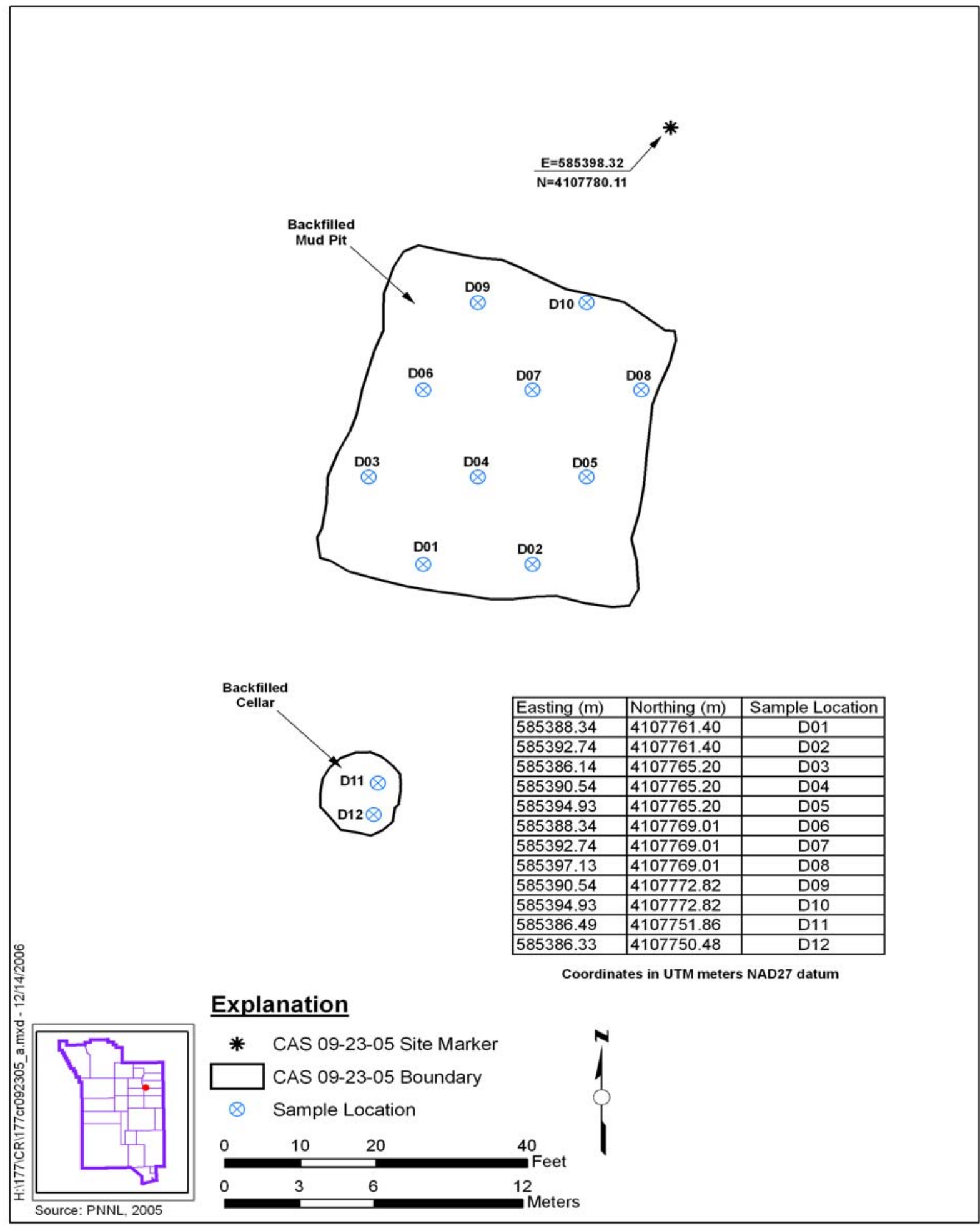

Figure D.6-3

CAS 09-23-05 Sample Location Map 


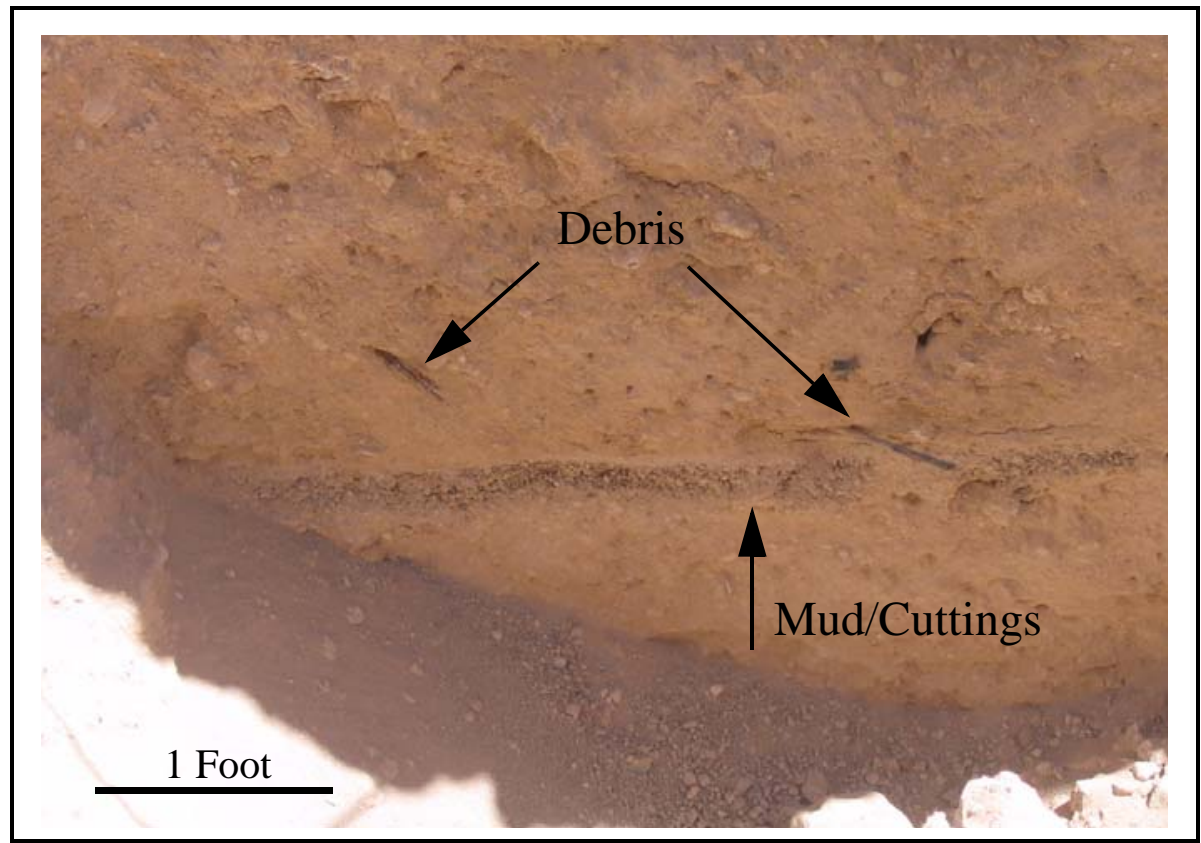

Figure D.6-4

Interface with Drilling Mud/Cuttings in Profile

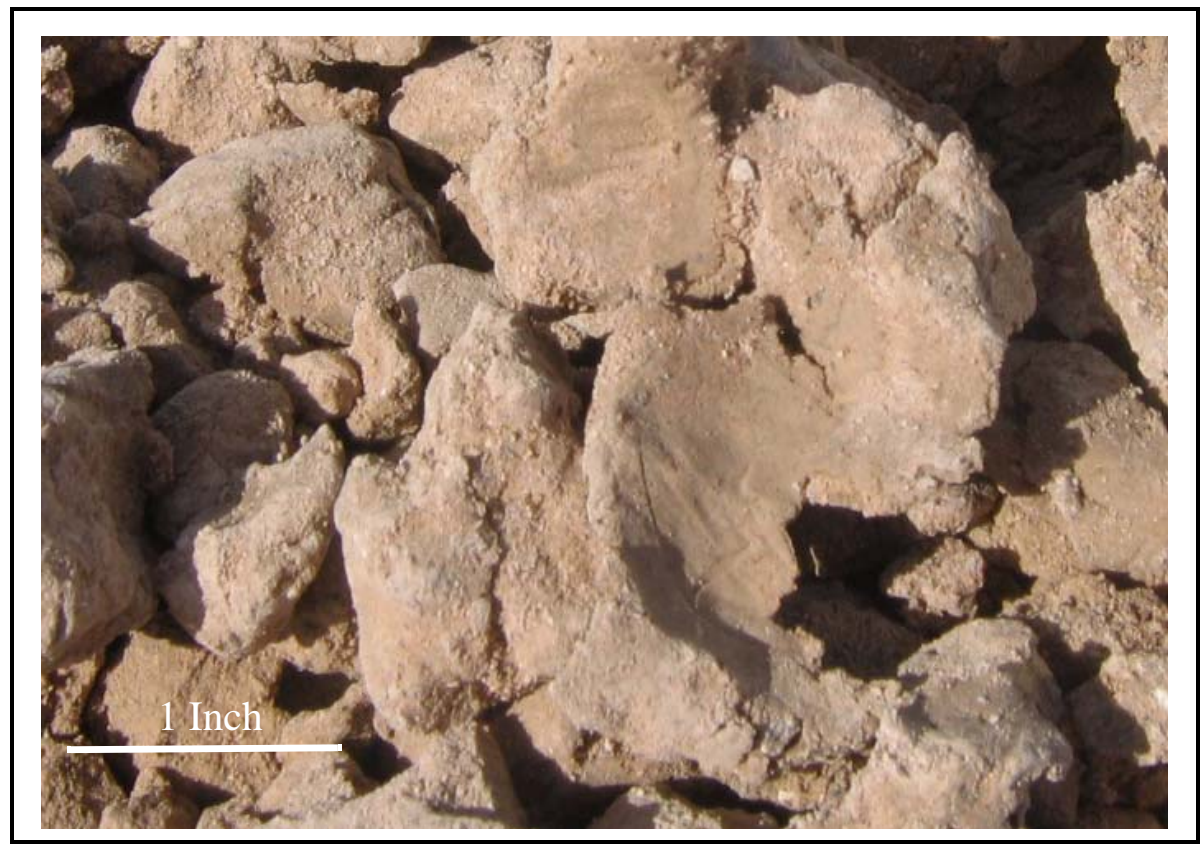

Figure D.6-5

Example of Soft Mud Sampled at CAS 09-23-05 Mud Pit 


\section{D.6.2 Investigation Results}

The following sections provide analytical results from the samples collected to complete investigation activities as outlined in the CAU 177 SAFER Plan (NNSA/NSO, 2006b). Investigation samples were analyzed for the SAFER-specified COPCs for cellars, which included VOCs, SVOCs, TPH-DRO and -GRO, RCRA metals, gamma-emitting radionuclides, isotopic $\mathrm{U}$, isotopic $\mathrm{Pu}$, and Sr-90; and mud pits, which included only the radiological analytes. Beryllium and PCBs were added parameters to the cellar suite, because these contaminants are a common concern at the NTS. Table D.6-1 lists the sample-specific analytical suite for CAS 09-23-05. Analytical results from the soil samples with concentrations exceeding MDCs are summarized in the following sections.

For the judgmental samples at the cellar component of the CAS, an evaluation was conducted on all contaminants detected above MDCs by comparing individual concentration or activity results against the FALs to determine if a constituent is a COC. The FALs were established as the corresponding PAL concentrations or activities if the contaminant concentrations were below respective PALs.

For the probabilistic samples at the mud pit, any COPC that has a 95 percent UCL of the average concentration exceeding the FAL will result in that COPC being designated as a COC. As stipulated in the CAU 177 SAFER Plan (NNSA/NSO, 2006b), UCLs were only calculated for a COPC if it was detected in any sample within any CAS at a concentration equal to or exceeding the PAL. If COPCs were not detected in any mud pit sample at a concentration that exceeded the PAL, then it will be concluded that no COCs are present.

\section{D.6.2.1 Volatile Organic Compounds}

Analytical results for VOCs in soil samples collected from the cellar that were detected above MDCs are presented in Table D.6-2. No VOCs were detected at concentrations exceeding the respective PALs; therefore the FALs were established as the corresponding PALs.

\section{D.6.2.2 Semivolatile Organic Compounds}

No SVOCs were detected above the respective laboratory MDCs in soil samples collected at the cellar component of this CAS; therefore the FALs are established at the corresponding PALs. 
Table D.6-2

Soil Sample Results for Total VOCs Detected Above Minimum Detectable Concentrations at CAS 09-23-05, Mud Pit and Cellar

\begin{tabular}{|c|c|c|c|c|c|}
\hline \multirow{2}{*}{$\begin{array}{l}\text { Sample } \\
\text { Location }\end{array}$} & \multirow{2}{*}{$\begin{array}{l}\text { Sample } \\
\text { Number }\end{array}$} & \multirow{2}{*}{$\begin{array}{l}\text { Depth } \\
\text { (ft bgs) }\end{array}$} & \multicolumn{3}{|c|}{ Contaminants of Potential Concern $(\mu \mathrm{g} / \mathrm{kg})$} \\
\hline & & & 2-Butanone & Acetone & Styrene \\
\hline \multicolumn{3}{|c|}{ Final Action Levels ${ }^{a}$} & $110,000,000$ & $54,000,000$ & $1,700,000$ \\
\hline \multicolumn{6}{|c|}{ Cellar Samples } \\
\hline 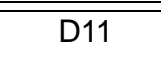 & 177D002 & $7.0-8.0$ & $3.1(\mathrm{~J})$ & $18.9(\mathrm{~J})$ & $0.503(\mathrm{~J})$ \\
\hline D12 & 177D005 & $8.0-9.0$ & -- & $2.96(\mathrm{~J})$ & -- \\
\hline
\end{tabular}

aBased on U.S. Environmental Protection Agency, Region 9 Preliminary Remediation Goals (PRGs) (EPA, 2004).

$\mathrm{ft}$ bgs $=$ Feet below ground surface

$\mu \mathrm{g} / \mathrm{kg}=$ Micrograms per kilogram

-- = Not detected above minimum detectable concentrations.

$\mathrm{J}=$ Estimated value.

\section{D.6.2.3 Total Petroleum Hydrocarbons}

The TPH-DRO analytical results for soil samples collected from the cellar that were detected above MDCs are presented in Table D.6-3. One subsurface interface sample (7 to $8 \mathrm{ft}$ bgs) collected at location D11 exceeded the PAL of $100 \mathrm{mg} / \mathrm{kg}$ for TPH-DRO. The TPH-DRO was moved on to a Tier 2 evaluation and FALs were established for the hazardous constituents of TPH-DRO at the corresponding PAL concentrations. Concentrations of the hazardous constituents of TPH-DRO did not exceed FALs; therefore, TPH-DRO is not considered a COC. Concentrations of TPH-GRO were not detected above the respective laboratory MDCs at this CAS.

\section{D.6.2.4 Polychlorinated Biphenyls}

Analytical results for soil sample 177D002 collected at 7.0 to $8.0 \mathrm{ft}$ bgs at the cellar of CAS 09-23-05 detected Aroclor 1260 and Aroclor 1268 above MDCs (2.04 and 1.4 micrograms per kilogram $[\mu \mathrm{g} / \mathrm{kg}]$, respectively; estimated values). The calculated total Aroclor for sample 177D002 (3.44 $\mu \mathrm{g} / \mathrm{kg}$ ) did not exceed the PAL (740 $\mu \mathrm{g} / \mathrm{kg}$ ); therefore, the FAL was established as the corresponding PAL. 
Table D.6-3

\section{Soil Sample Results for TPH-DRO Detected Above Minimum Reporting Limits at CAS 09-23-05, Mud Pit and Cellar}

\begin{tabular}{|c|c|c|c|}
\hline \multirow{2}{*}{$\begin{array}{l}\text { Sample } \\
\text { Location }\end{array}$} & \multirow{2}{*}{$\begin{array}{l}\text { Sample } \\
\text { Number }\end{array}$} & \multirow{2}{*}{$\begin{array}{l}\text { Depth } \\
\text { (ft bgs) }\end{array}$} & Contaminants of Potential Concern $(\mathrm{mg} / \mathrm{kg})$ \\
\hline & & & Diesel-Range Organics \\
\hline \multicolumn{3}{|c|}{ Preliminary Action Levels ${ }^{a}$} & 100 \\
\hline \multicolumn{4}{|c|}{ Cellar Samples } \\
\hline \multirow{2}{*}{ D11 } & 177D002 & $7.0-8.0$ & 104 \\
\hline & 177D003 & $9.0-10.0$ & 16.4 \\
\hline \multirow{2}{*}{ D12 } & 177D004 & $6.0-7.0$ & 24.6 \\
\hline & 177D005 & $8.0-9.0$ & 16.8 \\
\hline
\end{tabular}

aBased on Nevada Administrative Code, "Contamination of Soil: Establishment of Action Levels" (NAC, 2006).

$\mathrm{ft}$ bgs $=$ Feet below ground surface

$\mathrm{mg} / \mathrm{kg}=$ Milligrams per kilogram

\section{D.6.2.5 RCRA Metals and Beryllium}

Analytical results for RCRA metals and beryllium in soil samples collected from the cellar that were detected above MDCs are presented in Table D.6-4. None of the metals were detected at concentrations exceeding the respective PALs; therefore, the FALs were established as the corresponding PALs.

\section{D.6.2.6 Gamma-Emitting Radionuclides}

Analytical results for gamma-emitting radionuclides in soil samples from the mud pit and cellar that were detected above MDCs are presented in Table D.6-5. Because no gamma-emitting radionuclide COPCs were detected in any mud pit sample at a concentration equal to or exceeding the PAL, UCLs were not calculated for the mud pit component of this CAS, and it is determined that no COCs exist. Because no gamma-emitting radionuclide concentrations in cellar soil samples exceeded the respective PALs, the FALs were established as the corresponding PALs. 
Table D.6-4

Soil Sample Results for Metals Detected Above Minimum Detectable Concentrations at CAS 09-23-05, Mud Pit and Cellar

\begin{tabular}{|c|c|c|c|c|c|c|c|c|c|c|c|}
\hline \multirow{2}{*}{ 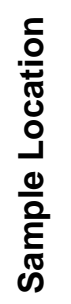 } & \multirow{2}{*}{ 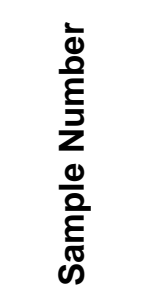 } & \multirow{2}{*}{ 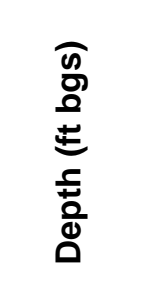 } & \multicolumn{9}{|c|}{ Contaminants of Potential Concern (mg/kg) } \\
\hline & & & $\begin{array}{l}\frac{U}{c} \\
\frac{d}{d} \\
\frac{U}{4}\end{array}$ & 占 & 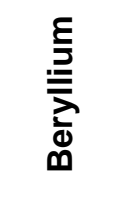 & 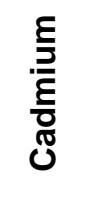 & 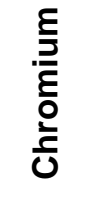 & ర్త్ర & 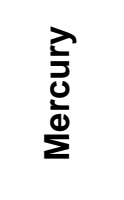 & 立 & 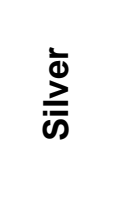 \\
\hline \multicolumn{3}{|c|}{ Final Action Levels } & $23^{a}$ & $67,000^{b}$ & $1,900^{b}$ & $450^{b}$ & $450^{b}$ & $800^{b}$ & $310^{b}$ & $5,100^{b}$ & $5,100^{b}$ \\
\hline \multicolumn{12}{|c|}{ Cellar Samples } \\
\hline \multirow{2}{*}{ D11 } & 177D002 & $7.0-8.0$ & 6.4 & 196 & 0.61 & 0.11 & 11.9 & 47.9 & 0.012 & 0.83 & $-\overline{-}$ \\
\hline & 177D003 & $9.0-10.0$ & 6 & 331 & 0.52 & 0.1 & 6.3 & 15.7 & 0.014 & -- & -- \\
\hline \multirow{2}{*}{ D12 } & 177D004 & $6.0-7.0$ & 2.9 & 354 & 0.41 & 0.13 & 5.1 & 10.3 & 0.016 & -- & 0.11 \\
\hline & 177D005 & $8.0-9.0$ & 2.2 & 65.4 & 0.3 & 0.11 & 2.8 & 4.7 & 0.0072 & -- & -- \\
\hline
\end{tabular}

aBased on the background concentrations for metals. Background is considered the mean plus two times the standard deviation for sediment samples collected by the Nevada Bureau of Mines and Geology throughout the Nevada Test and Training Range (NBMG, 1998; Moore, 1999).

${ }^{b}$ Based on U.S. Environmental Protection Agency, Region 9 Preliminary Remediation Goals (PRGs) (EPA, 2004)

$\mathrm{ft}$ bgs $=$ Feet below ground surface

$\mathrm{mg} / \mathrm{kg}=$ Milligrams per kilogram

$--=$ Not detected above minimum detectable concentrations.

Table D.6-5

Soil Sample Results for Gamma-Emitting Radionuclides Detected Above Minimum Detectable Concentrations at CAS 09-23-05, Mud Pit and Cellar (Page 1 of 2)

\begin{tabular}{|c|c|c|c|c|c|c|c|}
\hline \multirow{2}{*}{$\begin{array}{c}\text { Sample } \\
\text { Location }\end{array}$} & \multirow{2}{*}{$\begin{array}{l}\text { Sample } \\
\text { Number }\end{array}$} & \multirow{2}{*}{$\begin{array}{l}\text { Depth } \\
\text { (ft bgs) }\end{array}$} & \multicolumn{5}{|c|}{ Contaminants of Potential Concern (pCi/g) } \\
\hline & & & Actinium-228 & Cesium-137 & Lead-212 & Lead-214 & Thallium-208 \\
\hline \multicolumn{3}{|c|}{ Final Action Levels } & $5^{a}$ & $12.2^{b}$ & $5^{a}$ & $5^{a}$ & $5^{a}$ \\
\hline \multicolumn{8}{|c|}{ Mud Pit Samples } \\
\hline D01 & 177D002A & $4.0-5.0$ & 1.6 & -- & 1.42 & 1.06 & 0.514 \\
\hline D02 & 177D001 & $3.5-4.5$ & 1.11 & 0.338 & 1.58 & 1.15 & 0.566 \\
\hline D03 & 177D003A & $5.0-6.0$ & 1.81 & -- & 1.67 & 0.986 & 0.47 \\
\hline \multirow{2}{*}{ D04 } & 177D004A & $5.0-6.0$ & 1.5 & 0.175 & 1.24 & 0.944 & 0.42 \\
\hline & 177D005A & $5.0-6.0$ & 1.26 & -- & 1.36 & 0.885 & 0.433 \\
\hline D05 & 177D006 & $5.0-6.0$ & 1.76 & -- & 1.63 & 1.4 & 0.605 \\
\hline D06 & 177D007 & $5.0-6.0$ & 1.52 & -- & 1.69 & 1.28 & 0.513 \\
\hline D07 & 177D008 & $5.0-6.0$ & 1.96 & -- & 1.94 & 1.81 & 0.665 \\
\hline
\end{tabular}


Table D.6-5

Soil Sample Results for Gamma-Emitting Radionuclides Detected Above Minimum Detectable Concentrations at CAS 09-23-05, Mud Pit and Cellar (Page 2 of 2)

\begin{tabular}{|c|c|c|c|c|c|c|c|}
\hline \multirow{2}{*}{$\begin{array}{l}\text { Sample } \\
\text { Location }\end{array}$} & \multirow{2}{*}{$\begin{array}{l}\text { Sample } \\
\text { Number }\end{array}$} & \multirow{2}{*}{$\begin{array}{l}\text { Depth } \\
\text { (ft bgs) }\end{array}$} & \multicolumn{5}{|c|}{ Contaminants of Potential Concern (pCi/g) } \\
\hline & & & Actinium-228 & Cesium-137 & Lead-212 & Lead-214 & Thallium-208 \\
\hline \multicolumn{3}{|c|}{ Final Action Levels } & $5^{\mathrm{a}}$ & $12.2^{\mathrm{b}}$ & $5^{\mathrm{a}}$ & $5^{a}$ & $5^{a}$ \\
\hline \multicolumn{8}{|c|}{ Mud Pit Samples } \\
\hline D08 & 177D009 & $5.0-6.0$ & 2.01 & -- & 1.7 & 1.12 & 0.635 \\
\hline D09 & $177 \mathrm{D} 010$ & $5.0-6.0$ & 1.42 & -- & 1.58 & 1.25 & 0.534 \\
\hline D10 & 177D011 & $5.0-6.0$ & 2 & -- & 1.52 & 1.15 & 0.54 \\
\hline \multicolumn{8}{|c|}{ Cellar Samples } \\
\hline \multirow{2}{*}{ D11 } & 177D002 & $7.0-8.0$ & 1.47 & 0.334 & 1.5 & 1.09 & 0.512 \\
\hline & 177D003 & $9.0-10.0$ & 1.63 & -- & 1.5 & 1.02 & 0.338 \\
\hline \multirow{2}{*}{ D12 } & 177D004 & $6.0-7.0$ & 1.36 & 0.342 & 1.66 & 1.19 & 0.517 \\
\hline & 177D005 & $8.0-9.0$ & 1.09 & -- & 1.38 & 1.19 & 0.539 \\
\hline
\end{tabular}

aTaken from the generic guidelines for residual concentrations of actinium-228, bismuth-214, lead-212, lead-214, thallium-208, and thorium-232, as found in Chapter IV of U.S. Department of Energy Order 5400.5, Change 2, Radiation Protection of the Public and Environment (DOE, 1993).

${ }^{\mathrm{b}}$ Taken from the construction, commercial, industrial land-use scenario in Table 2.1 of the National Council on Radiation Protection and Measurement Report No. 129, Recommended Screening Limits for Contaminated Surface Soil and Review Factors Relevant to Site-Specific Studies (NCRP, 1999). The values provided in this source document were scaled to a 25-millirem-per-year dose.

$\mathrm{ft}$ bgs $=$ Feet below ground surface

$\mathrm{pCi} / \mathrm{g}=$ Picocuries per gram

-- = Not detected above minimum detectable concentrations.

\section{D.6.2.7 Plutonium, Strontium-90, and Uranium Isotopes}

Isotopic Pu and isotopic $\mathrm{U}$ analytical results for soil samples from the mud pit and cellar that were detected above MDCs are presented in Table D.6-6. Because no Pu, U, or Sr-90 isotope COPCs were detected in any mud pit sample at a concentration equal to or exceeding the PAL, UCLs were not calculated for the mud pit component of this CAS, and it is determined that no COCs exist. Because no cellar sample results for Sr-90, isotopic Pu, or isotopic $\mathrm{U}$ exceeded the respective PALs, the FALs were established as the corresponding PALs. 
Table D.6-6

Soil Sample Results for Isotopes Detected Above Minimum Detectable Concentrations at CAS 09-23-05, Mud Pit and Cellar

\begin{tabular}{|c|c|c|c|c|c|c|c|}
\hline \multirow[b]{2}{*}{$\begin{array}{l}\text { Sample } \\
\text { Location }\end{array}$} & \multirow[b]{2}{*}{$\begin{array}{l}\text { Sample } \\
\text { Number }\end{array}$} & \multirow[b]{2}{*}{$\begin{array}{l}\text { Depth } \\
\text { (ft bgs) }\end{array}$} & \multicolumn{5}{|c|}{ Contaminants of Potential Concern (pCi/g) } \\
\hline & & & 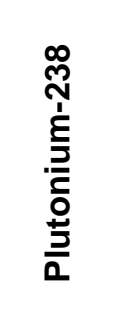 & 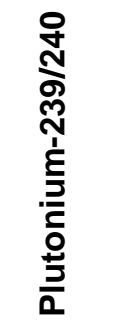 & 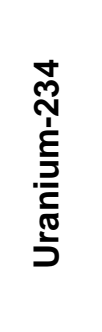 & 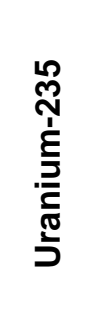 & 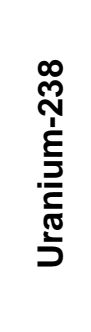 \\
\hline \multicolumn{3}{|c|}{ Final Action Levels ${ }^{a}$} & 13 & 12.7 & 143 & 17.6 & 105 \\
\hline \multicolumn{8}{|c|}{ Mud Pit Samples } \\
\hline D01 & 177D002A & $4.0-5.0$ & -- & -- & 0.865 & -- & 1 \\
\hline D02 & 177D001 & $3.5-4.5$ & -- & 0.114 & 1.08 & -- & 0.92 \\
\hline D03 & 177D003A & $5.0-6.0$ & -- & -- & 1.19 & -- & 0.892 \\
\hline \multirow{2}{*}{ D04 } & 177D004A & $5.0-6.0$ & 0.0486 & 0.122 & 0.874 & -- & 1.07 \\
\hline & 177D005A & $5.0-6.0$ & -- & -- & 0.98 & -- & 0.872 \\
\hline D05 & 177D006 & $5.0-6.0$ & -- & 0.0515 & 1.2 & 0.124 & 1.01 \\
\hline D06 & 177D007 & $5.0-6.0$ & -- & 0.143 & 1.07 & -- & 1.12 \\
\hline D07 & 177D008 & $5.0-6.0$ & -- & -- & 1.8 & 0.186 & 1.62 \\
\hline D08 & 177D009 & $5.0-6.0$ & -- & -- & 1.38 & 0.107 & 1.38 \\
\hline D09 & 177D010 & $5.0-6.0$ & -- & 0.0333 & 1.09 & 0.16 & 0.917 \\
\hline D10 & 177D011 & $5.0-6.0$ & -- & 0.134 & 0.922 & -- & 1.05 \\
\hline \multicolumn{8}{|c|}{ Cellar Samples } \\
\hline \multirow{2}{*}{ D11 } & 177D002 & $7.0-8.0$ & -- & 0.846 & 0.89 & -- & 0.835 \\
\hline & 177D003 & $9.0-10.0$ & -- & 0.102 & 0.907 & -- & 0.912 \\
\hline \multirow{2}{*}{$\mathrm{D} 12$} & 177D004 & $6.0-7.0$ & 0.165 & 4.49 & 0.851 & -- & 0.755 \\
\hline & 177D005 & $8.0-9.0$ & -- & -- & 0.874 & -- & 0.889 \\
\hline
\end{tabular}

aTaken from the construction, commercial, industrial land-use scenario in Table 2.1 of the National Council on Radiation Protection and Measurement Report No. 129, Recommended Screening Limits for Contaminated Surface Soil and Review Factors Relevant to Site-Specific Studies (NCRP, 1999). The values provided in this source document were scaled to a 25-millirem-per-year dose.

$\mathrm{ft}$ bgs $=$ Feet below ground surface

$\mathrm{pCi} / \mathrm{g}=$ Picocuries per gram

-- = Not detected above minimum detectable concentrations. 


\section{D.6.3 Nature and Extent of Contamination}

Based on the analytical results, no COCs were identified in the environmental soils samples collected at CAS 09-23-05.

\section{D.6.4 Revised Conceptual Site Model}

The CAU 177 SAFER Plan requirements were met at this CAS, and no revisions were necessary to the CSM. 


\section{D.7.0 CAS 09-23-08, Mud Pit and Cellar}

Corrective Action Site 09-23-08 is within a fenced URMA located in Area 9, approximately $100 \mathrm{ft}$ east of Old Mercury Highway (Figure 1-1). The CAS components identified for investigation include a backfilled mud pit and a backfilled cellar. No surface debris were identified at this CAS. The boundaries of the backfilled mud pit were confirmed based on the presence of mud at a majority of the sample locations.

\section{D.7.1 Corrective Action Investigation}

Thirteen characterization samples were collected during investigation activities at CAS 09-23-08. Ten samples and one FD were collected at the mud pit and two samples were collected at the cellar. The sample IDs, locations, types, and analyses are listed in Table D.7-1. The specific CAI activities conducted to satisfy the CAU 177 SAFER Plan requirements at this CAS are described in the following sections.

\section{D.7.1.1 Field Screening}

Investigation samples were screened for total alpha and beta/gamma radiation. The FSRs were compared to FSLs and samples from eight locations (E01, E02, E03, E04, E05, E06, E07, and E10) within the mud pit slightly exceeded the FSL for beta (3,608 dpm), which was attributed to naturally occurring radon in the soil. All other soil samples collected at this CAS were below background radiological FSLs for alpha and beta. Debris encountered during excavation at the backfilled mud pit did not show the presence of radioactivity.

\section{D.7.1.2 Visual Inspections}

No spills, staining, or other indications of potential contamination were identified during the inspection of CAS 09-23-08, and site conditions were unchanged from previous field visits. The backfilled cellar was inspected in order to select sample locations based on the estimated location of the cellar casing and expected orientation of potential buried borehole casing. 
Table D.7-1

Samples Collected at CAS 09-23-08, Mud Pit and Cellar

\begin{tabular}{|c|c|c|c|c|c|}
\hline $\begin{array}{l}\text { Sample } \\
\text { Location }\end{array}$ & $\begin{array}{l}\text { Sample } \\
\text { Number }\end{array}$ & $\begin{array}{l}\text { Depth } \\
\text { (ft bgs) }\end{array}$ & Matrix & Purpose & Analyses \\
\hline \multicolumn{6}{|c|}{ Mud Pit Samples } \\
\hline \multirow{2}{*}{ E01 } & 177E001 & $4.0-5.0$ & Soil & Environmental & Set 1 \\
\hline & 177E002 & $4.0-5.0$ & Soil & Field Duplicate of $\# 177 \mathrm{E} 001$ & Set 1 \\
\hline E02 & 177E003 & $3.0-4.0$ & Soil & Environmental, Full Lab QC & Set 1 \\
\hline E03 & 177E007 & $3.5-4.5$ & Soil & Environmental & Set 1 \\
\hline E04 & 177E006 & $4.0-5.0$ & Soil & Environmental & Set 1 \\
\hline E05 & 177E004 & $4.0-5.0$ & Soil & Environmental & Set 1 \\
\hline E06 & 177E009 & $4.0-5.0$ & Soil & Environmental & Set 1 \\
\hline E07 & 177E008 & $3.5-4.5$ & Soil & Environmental & Set 1 \\
\hline E08 & 177E005 & $4.0-5.0$ & Soil & Environmental & Set 1 \\
\hline E09 & 177E010 & $4.0-5.0$ & Soil & Environmental & Set 1 \\
\hline E10 & 177E011 & $4.0-5.0$ & Soil & Environmental & Set 1 \\
\hline \multicolumn{6}{|c|}{ Cellar Samples } \\
\hline E11 & 177E012 & $6.0-7.0$ & Soil & Environmental & Set 2 \\
\hline E12 & 177E013 & $6.0-7.0$ & Soil & Environmental & Set 2 \\
\hline \multicolumn{6}{|c|}{ QC Samples } \\
\hline N/A & 177E301 & $\mathrm{N} / \mathrm{A}$ & Water & Field Blank & Set 1 \\
\hline$N / A$ & 177Е302 & $\mathrm{N} / \mathrm{A}$ & Water & $\begin{array}{l}\text { Equipment Rinsate } \\
\text { (Backhoe Bucket) }\end{array}$ & Set 1 \\
\hline
\end{tabular}

Set 1 = Gamma Spectroscopy, Isotopic Uranium, Isotopic Plutonium, Strontium-90

Set 2 = VOCs, SVOCs, RCRA Metals, Beryllium, TPH-DRO, TPH-GRO, PCBs, Gamma Spectroscopy, Isotopic Uranium, Isotopic Plutonium, Strontium-90

DRO = Diesel-range organics

$\mathrm{ft}$ bgs = Feet below ground surface

$\mathrm{GRO}=$ Gasoline-range organics

N/A = Not applicable

$\mathrm{PCB}=$ Polychlorinated biphenyl
$\mathrm{QC}=$ Quality control

RCRA = Resource Conservation and Recovery Act

SVOC $=$ Semivolatile organic compound

$\mathrm{TPH}=$ Total petroleum hydrocarbons

VOC $=$ Volatile organic compound

\section{D.7.1.3 Sample Collection}

Decision I environmental sampling activities included the collection of random surface soil samples at the backfilled mud pit and biased subsurface soil samples at the backfilled cellar (Figure D.7-1). 


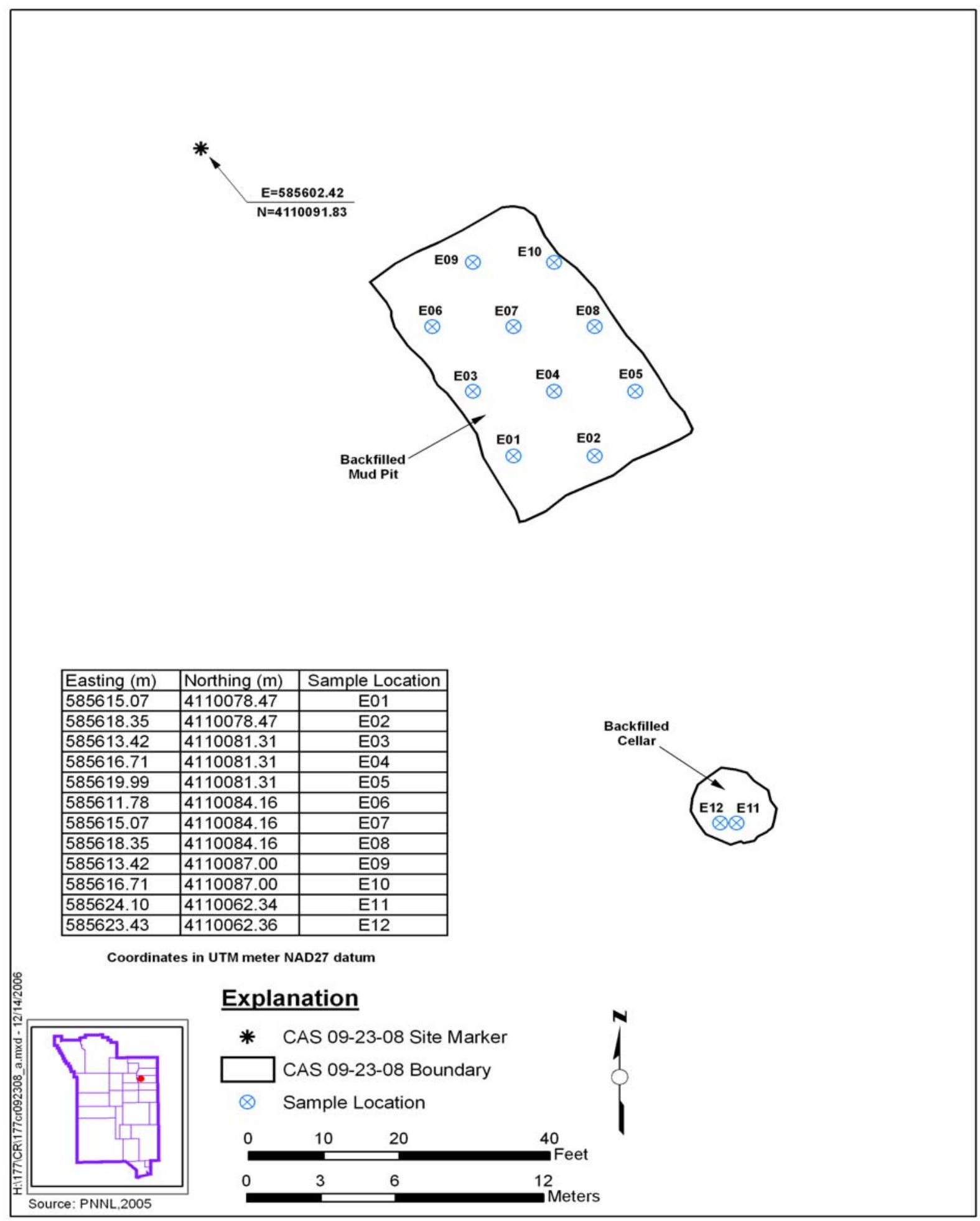

Figure D.7-1

CAS 09-23-08 Sample Location Map 
Eleven Decision I soil samples including 1 FD were collected from 10 locations (E01 through E10) within the estimated boundary of the mud pit to determine if drilling mud/cuttings released to the mud pit were contaminated. The trench walls and soils brought to the surface through backhoe excavation were monitored to identify the interface between backfill material and drilling mud/cuttings. An interface with mud/cuttings and/or debris was consistently identified at 3.5 to $5 \mathrm{ft}$ bgs at eight locations. No obvious interface or debris were identified at the two northernmost locations (E09 and E10) indicating that these points may be near the edge of the mud pit. Samples were therefore collected at the expected depth of the interface (4 to $5 \mathrm{ft}$ bgs) at these locations. Debris encountered during excavation included yellow rope, which was typically identified within backfill material directly above the interface with mud/cuttings.

Two subsurface Decision I environmental samples were collected at the cellar from each borehole (locations E11 and E12) at the backfill/cellar bottom interface. The first drilling attempt of borehole E11 encountered steel (suspected to be borehole casing), so the rig shifted $2 \mathrm{ft}$ south to the actual E11 location. Core material was monitored during drilling and the interface with the cellar bottom was identified at $7 \mathrm{ft}$ bgs, marked by a lithology change from backfilled soil to a layer of potential grout/concrete (at least $1.0 \mathrm{ft}$ thick). The presence of wood debris at the interface also supports the interpretation that the cellar bottom is located at $7 \mathrm{ft}$ bgs. Drilling was terminated at E11 and E12 at $8 \mathrm{ft}$ bgs to avoid creating a migration pathway through the grout/concrete, so deeper subsurface samples were not collected. The interface subsurface samples were collected at 6 to $7 \mathrm{ft}$ bgs, directly above the grout/concrete layer.

\section{D.7.2 Investigation Results}

The following sections provide analytical results from the samples collected to complete investigation activities as outlined in the CAU 177 SAFER Plan (NNSA/NSO, 2006b). Investigation samples were analyzed for the SAFER-specified COPCs for cellars, which included VOCs, SVOCs, TPH-DRO and -GRO, RCRA metals, gamma-emitting radionuclides, isotopic $\mathrm{U}$, isotopic $\mathrm{Pu}$, and Sr-90; and mud pits, which included only the radiological analytes. Beryllium and PCBs were added parameters to the cellar suite, because these contaminants are a common concern at the NTS. Table D.7-1 lists the sample-specific analytical suite for CAS 09-23-08. Analytical results from the soil samples with concentrations exceeding MDCs are summarized in the following sections. 
For the judgmental samples at the cellar component of the CAS, an evaluation was conducted on all contaminants detected above MDCs by comparing individual concentration or activity results against the FALs to determine if a constituent is a COC. The FALs were established as the corresponding PAL concentrations or activities if the contaminant concentrations were below their respective PALs.

For the probabilistic samples at the mud pit, any COPC that has a 95 percent UCL of the average concentration exceeding the FAL will result in that COPC being designated as a COC. As stipulated in the CAU 177 SAFER Plan, UCLs were only calculated for a COPC if it was detected in any sample within any CAS at a concentration equal to or exceeding the PAL (NNSA/NSO, 2006b). If COPCs were not detected in any mud pit sample at a concentration that exceeded the PAL, then it will be concluded that no COCs are present.

\section{D.7.2.1 Volatile Organic Compounds}

No VOCs were detected above the respective laboratory MDCs in soil samples collected at the cellar component of this CAS; therefore, the FALs are established at the corresponding PALs.

\section{D.7.2.2 Semivolatile Organic Compounds}

No SVOCs were detected above the respective laboratory MDCs in soil samples collected at the cellar component of this CAS; therefore, the FALs are established the corresponding PALs.

\section{D.7.2.3 Total Petroleum Hydrocarbons}

Analytical results for soil sample $177 \mathrm{E} 013$ collected at 6.0 to $7.0 \mathrm{ft}$ bgs at the cellar of this CAS detected TPH-DRO (7.67 mg/kg estimated value) above MDCs. Concentrations of TPH-DRO were not detected at concentrations exceeding the respective PAL (100 mg/kg); therefore, the FAL was established as the corresponding PAL. Concentrations of TPH-GRO were not detected above the respective laboratory MDCs at this CAS.

\section{D.7.2.4 Polychlorinated Biphenyls}

No PCBs were detected above the respective laboratory MDCs in soil samples collected at the cellar component of this CAS; therefore, the FALs are established at the corresponding PALs. 


\section{D.7.2.5 RCRA Metals and Beryllium}

Analytical results for RCRA metals and beryllium in soil samples collected from the cellar that were detected above MDCs are presented in Table D.7-2. None of the metals were detected at concentrations exceeding the respective PALs; therefore, the FALs were established as the corresponding PALs.

Table D.7-2

Soil Sample Results for Metals Detected Above Minimum Detectable Concentrations at CAS 09-23-08, Mud Pit and Cellar

\begin{tabular}{|c|c|c|c|c|c|c|c|c|c|c|c|}
\hline \multirow{2}{*}{ 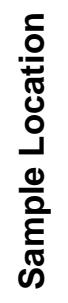 } & \multirow{2}{*}{ 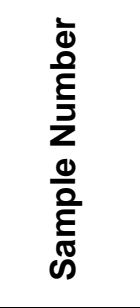 } & \multirow{2}{*}{ 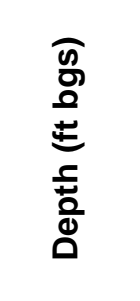 } & \multicolumn{9}{|c|}{ Contaminants of Potential Concern $(\mathrm{mg} / \mathrm{kg})$} \\
\hline & & & $\begin{array}{l}\frac{0}{C} \\
\frac{0}{d} \\
\frac{0}{2} \\
\frac{0}{<}\end{array}$ & 疍 & 竞 & 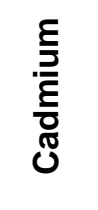 & 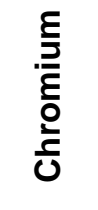 & 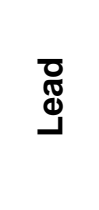 & 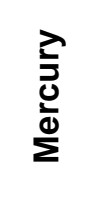 & $\frac{\xi}{\bar{D}}$ & $\frac{\bar{\Phi}}{\bar{\omega}}$ \\
\hline \multicolumn{3}{|c|}{ Final Action Levels } & $23^{a}$ & $67,000^{b}$ & $1,900^{b}$ & $450^{b}$ & $450^{b}$ & $800^{b}$ & $310^{b}$ & $5,100^{b}$ & $5,100^{b}$ \\
\hline \multicolumn{12}{|c|}{ Cellar Samples } \\
\hline E11 & $\overline{177 E 012}$ & $6.0-7.0$ & 4.5 & 130 & 0.55 & 0.11 & ב5.6 & 7.6 & 0.027 & 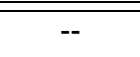 & 0.21 \\
\hline E12 & 177E013 & $6.0-7.0$ & 4.2 & 151 & 0.61 & -- & 6.5 & 9.1 & 0.021 & 0.67 & -- \\
\hline
\end{tabular}

${ }^{a} B a s e d$ on the background concentrations for metals. Background is considered the mean plus two times the standard deviation for sediment samples collected by the Nevada Bureau of Mines and Geology throughout the Nevada Test and Training Range (NBMG, 1998; Moore, 1999).

${ }^{\mathrm{b} B a s e d}$ on U.S. Environmental Protection Agency, Region 9 Preliminary Remediation Goals (PRGs) (EPA, 2004)

$\mathrm{ft}$ bgs $=$ Feet below ground surface

$\mathrm{mg} / \mathrm{kg}=$ Milligrams per kilogram

$--=$ Not detected above minimum detectable concentrations.

\section{D.7.2.6 Gamma-Emitting Radionuclides}

Analytical results for gamma-emitting radionuclides in soil samples from the mud pit and cellar that were detected above MDCs are presented in Table D.7-3. Because no gamma-emitting radionuclide COPCs were detected in any mud pit sample at a concentration equal to or exceeding the PAL, UCLs were not calculated for the mud pit component of this CAS and it is determined that no COCs exist. Because no gamma-emitting radionuclide concentrations in cellar soil samples exceeded the respective PALs, the FALs were established as the corresponding PALs. 
Table D.7-3

Soil Sample Results for Gamma-Emitting Radionuclides Detected Above Minimum Detectable Concentrations at CAS 09-23-08, Mud Pit and Cellar

\begin{tabular}{|c|c|c|c|c|c|c|c|c|c|}
\hline \multirow[b]{2}{*}{$\begin{array}{c}\text { Sample } \\
\text { Location }\end{array}$} & \multirow[b]{2}{*}{$\begin{array}{l}\text { Sample } \\
\text { Number }\end{array}$} & \multirow[b]{2}{*}{$\begin{array}{l}\text { Depth } \\
\text { (ft bgs) }\end{array}$} & \multicolumn{7}{|c|}{ Contaminants of Potential Concern (pCi/g) } \\
\hline & & & 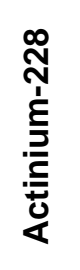 & 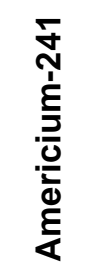 & 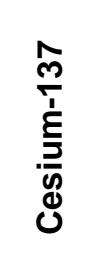 & 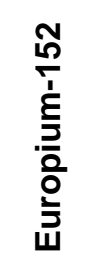 & 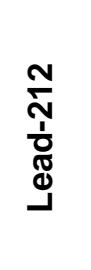 & 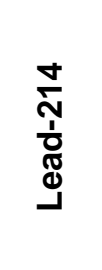 & 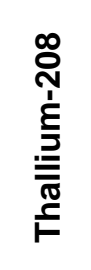 \\
\hline \multicolumn{3}{|c|}{ Final Action Levels } & $5^{a}$ & $12.7^{b}$ & $12.2^{b}$ & $5.7^{b}$ & $5^{a}$ & $5^{a}$ & $5^{a}$ \\
\hline \multicolumn{10}{|c|}{ Mud Pit Samples } \\
\hline \multirow{2}{*}{ E01 } & 177E001 & $4.0-5.0$ & 1.12 & -- & -- & 0.818 & 1.3 & 0.673 & 0.362 \\
\hline & 177E002 & $4.0-5.0$ & 1.33 & -- & -- & 1.05 & 1.18 & 0.884 & 0.454 \\
\hline E02 & 177E003 & $3.0-4.0$ & 1.3 & 0.328 & 0.536 & 2.74 & 1.16 & 0.837 & 0.404 \\
\hline E03 & 177E007 & $3.5-4.5$ & 1.85 & -- & 0.192 & 1.52 & 1.68 & 1.25 & 0.517 \\
\hline E04 & 177E006 & $4.0-5.0$ & 2.22 & -- & 0.182 & 1.62 & 1.95 & 1.23 & 0.61 \\
\hline E05 & 177E004 & $4.0-5.0$ & 2.21 & -- & -- & 1.84 & 1.69 & 1.07 & 0.619 \\
\hline E06 & 177E009 & $4.0-5.0$ & 1.84 & -- & -- & -- & 1.11 & 1.12 & 0.529 \\
\hline E07 & 177E008 & $3.5-4.5$ & 1.42 & -- & -- & -- & 1.48 & 1 & 0.368 \\
\hline E08 & 177E005 & $4.0-5.0$ & 1.16 & -- & -- & 2.26 & 1.02 & 0.762 & 0.384 \\
\hline E09 & 177E010 & $4.0-5.0$ & 1.88 & -- & -- & 0.612 & 1.65 & 1.08 & 0.485 \\
\hline E10 & 177E011 & $4.0-5.0$ & 1.61 & -- & -- & 1.32 & 1.5 & 0.944 & 0.451 \\
\hline \multicolumn{10}{|c|}{ Cellar Samples } \\
\hline E11 & 177E012 & $6.0-7.0$ & 1.31 & -- & 0.335 & 4.29 & 1.33 & 0.919 & 0.448 \\
\hline E12 & 177E013 & $6.0-7.0$ & 2.04 & 0.359 & -- & 4.45 & 1.31 & 0.932 & 0.449 \\
\hline
\end{tabular}

aTaken from the generic guidelines for residual concentrations of actinium-228, bismuth-214, lead-212, lead-214, thallium-208, and thorium-232, as found in Chapter IV of U.S. Department of Energy Order 5400.5, Change 2, Radiation Protection of the Public and Environment (DOE, 1993).

${ }^{\mathrm{b}}$ Taken from the construction, commercial, industrial land-use scenario in Table 2.1 of the National Council on Radiation Protection and Measurement Report No. 129, Recommended Screening Limits for Contaminated Surface Soil and Review Factors Relevant to Site-Specific Studies (NCRP, 1999). The values provided in this source document were scaled to a 25-millirem-per-year dose.

$\mathrm{ft}$ bgs $=$ Feet below ground surface $\mathrm{pCi} / \mathrm{g}=$ Picocuries per gram

$--=$ Not detected above minimum detectable concentrations.

\section{D.7.2.7 Plutonium, Strontium-90, and Uranium Isotopes}

Isotopic $\mathrm{Pu}$ and isotopic $\mathrm{U}$ analytical results for soil samples from the mud pit and cellar that were detected above MDCs are presented in Table D.7-4. Because no Pu, U, or Sr-90 isotope COPCs were 
detected in any mud pit sample at a concentration equal to or exceeding the PAL, UCLs were not calculated for the mud pit component of this CAS, and it is determined that no COCs exist. Because no Sr-90, isotopic Pu, or isotopic U concentrations exceeded the respective PALs, the FALs were established as the corresponding PALs.

Table D.7-4

Soil Sample Results for Isotopes Detected Above Minimum Detectable Concentrations at CAS 09-23-08, Mud Pit and Cellar

\begin{tabular}{|c|c|c|c|c|c|c|}
\hline \multirow[b]{2}{*}{$\begin{array}{c}\text { Sample } \\
\text { Location }\end{array}$} & \multirow[b]{2}{*}{$\begin{array}{l}\text { Sample } \\
\text { Number }\end{array}$} & \multirow[b]{2}{*}{$\begin{array}{l}\text { Depth } \\
\text { (ft bgs) }\end{array}$} & \multicolumn{4}{|c|}{ Contaminants of Potential Concern (pCi/g) } \\
\hline & & & 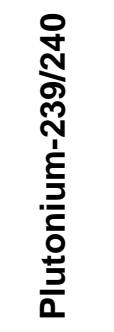 & 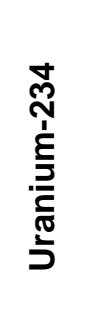 & 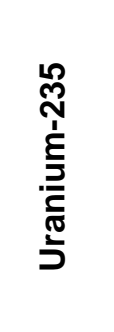 & 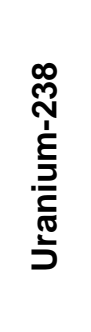 \\
\hline \multicolumn{3}{|c|}{ Final Action Levels ${ }^{a}$} & 12.7 & 143 & 17.6 & 105 \\
\hline \multicolumn{7}{|c|}{ Mud Pit Samples } \\
\hline \multirow{2}{*}{ E01 } & 177E001 & $4.0-5.0$ & -- & 0.811 & -- & 0.789 \\
\hline & 177E002 & $4.0-5.0$ & -- & 0.864 & $\overline{--}$ & 0.889 \\
\hline E02 & 177E003 & $3.0-4.0$ & 0.236 & 0.77 & -- & 0.775 \\
\hline E03 & 177E007 & $3.5-4.5$ & -- & 1.54 & -- & 1.9 \\
\hline E04 & 177E006 & $4.0-5.0$ & 0.0747 & 1.13 & 0.108 & 1.31 \\
\hline E05 & 177E004 & $4.0-5.0$ & 0.0792 & 1.13 & 0.0936 & 1.09 \\
\hline E06 & 177E009 & $4.0-5.0$ & -- & 0.985 & -- & 0.872 \\
\hline E07 & 177E008 & $3.5-4.5$ & -- & 1.05 & 0.0916 & 0.996 \\
\hline E08 & 177E005 & $4.0-5.0$ & -- & 0.802 & -- & 0.893 \\
\hline E09 & 177E010 & $4.0-5.0$ & -- & 1.2 & 0.0713 & 1.29 \\
\hline E10 & 177E011 & $4.0-5.0$ & -- & 1.14 & -- & 1.05 \\
\hline \multicolumn{7}{|c|}{ Cellar Samples } \\
\hline E11 & 177E012 & $6.0-7.0$ & 0.318 & 0.766 & -- & 0.699 \\
\hline E12 & 177E013 & $6.0-7.0$ & 0.773 & 0.591 & -- & 0.618 \\
\hline
\end{tabular}

${ }^{a}$ Taken from the construction, commercial, industrial land-use scenario in Table 2.1 of the National Council on Radiation Protection and Measurement Report No. 129, Recommended Screening Limits for Contaminated Surface Soil and Review Factors Relevant to Site-Specific Studies (NCRP, 1999). The values provided in this source document were scaled to a 25-millirem-per-year dose.

$\mathrm{ft}$ bgs $=$ Feet below ground surface

-- = Not detected above minimum detectable concentrations. 


\section{D.7.3 Nature and Extent of Contamination}

Based on the analytical results, no COCs were identified in the environmental soils samples collected at CAS 09-23-08.

\section{D.7.4 Revised Conceptual Site Model}

The CAU 177 SAFER Plan requirements were met at this CAS, and no revisions were necessary to the CSM. 


\section{D.8.0 CAS 09-23-09, U-9itsx20 PS \#1A Cellar}

Corrective Action Site 09-23-09 is within a fenced URMA that is located on the east side of Old Mercury Highway in Area 9 (Figure 1-1), northeast of the U-9itsx20 crater. The CAS components identified for investigation include a backfilled cellar.

\section{D.8.1 Corrective Action Investigation}

Three characterization samples including one FD were collected during investigation activities at the cellar of CAS 09-23-09. The sample IDs, locations, types, and analyses are listed in Table D.8-1. The specific CAI activities conducted to satisfy the CAU 177 SAFER Plan requirements at this CAS are described in the following sections.

Table D.8-1

Samples Collected at CAS 09-23-09, U-9itsx20 PS \#1A Cellar

\begin{tabular}{|c|c|c|c|c|c|}
\hline $\begin{array}{c}\text { Sample } \\
\text { Location }\end{array}$ & $\begin{array}{l}\text { Sample } \\
\text { Number }\end{array}$ & $\begin{array}{c}\text { Depth } \\
\text { (ft bgs) }\end{array}$ & Matrix & Purpose & Analyses \\
\hline \multicolumn{6}{|c|}{ Cellar Samples } \\
\hline \multirow{2}{*}{ F01 } & 177F001 & $6.0-7.0$ & Soil & Environmental & Set 2 \\
\hline & 177F002 & $6.0-7.0$ & Soil & Field Duplicate of \#177F001 & Set 2 \\
\hline F02 & 177F003 & $6.0-7.0$ & Soil & Environmental, Full Lab QC & Set 2 \\
\hline \multicolumn{6}{|c|}{ QC Samples } \\
\hline$\overline{\mathrm{N} / \mathrm{A}}$ & 177F301 & $\overline{N \mathrm{~N} / \mathrm{A}}$ & Water & Trip Blank & VOCs \\
\hline $\mathrm{N} / \mathrm{A}$ & 177F302 & $\mathrm{N} / \mathrm{A}$ & Water & Field Blank & Set 2 \\
\hline
\end{tabular}

Set 2 = VOCs, SVOCs, RCRA Metals, Beryllium, TPH-DRO, TPH-GRO, PCBs, Gamma Spectroscopy, Isotopic Uranium, Isotopic Plutonium, Strontium-90

DRO = Diesel-range organics $\mathrm{ft}$ bgs $=$ Feet below ground surface $\mathrm{GRO}=$ Gasoline-range organics N/A $=$ Not applicable

PCB $=$ Polychlorinated biphenyl
RCRA = Resource Conservation and Recovery Act SVOC $=$ Semivolatile organic compound $\mathrm{TPH}=$ Total petroleum hydrocarbons VOC $=$ Volatile organic compound

\section{D.8.1.1 Field Screening}

Investigation samples were screened for total alpha and beta/gamma radiation. The FSRs were compared to FSLs and no exceedences were identified. 


\section{D.8.1.2 Visual Inspections}

No spills, staining, or other indications of potential contamination were identified during the inspection of CAS 09-23-09 and site conditions were unchanged from previous field visits. The backfilled cellar was inspected in order to select sample locations based on the location of the exposed cellar casing and expected orientation of potential buried borehole casing.

\section{D.8.1.3 Sample Collection}

Decision I environmental sampling activities included the collection of biased soil samples at the cellar (Figure D.8-1) using a sonic drill rig. Three subsurface samples (including one FD) were collected from boreholes F01 and F02, directly above the interface with the cellar bottom. Borehole F01 was drilled to $7 \mathrm{ft}$ bgs and borehole F02 was drilled to $9 \mathrm{ft}$ bgs. Core material was monitored during drilling and the interface with the cellar bottom was identified at $7 \mathrm{ft}$ bgs, marked by a lithology change from backfilled soil to a layer of concrete (at least $2.0 \mathrm{ft}$ thick). Wood debris were also identified at the interface. Drilling was terminated at F02 at $9 \mathrm{ft}$ bgs to avoid creating a migration pathway through the concrete bottom; therefore, subsurface samples were not collected. The subsurface interface samples were collected directly above the interface at 6 to $7 \mathrm{ft}$ bgs.

\section{D.8.2 Investigation Results}

The following sections provide analytical results from the samples collected to complete investigation activities as outlined in the CAU 177 SAFER Plan (NNSA/NSO, 2006b). Investigation samples were analyzed for the SAFER-specified COPCs for cellars, which included VOCs, SVOCs, TPH-DRO and -GRO, RCRA metals, gamma-emitting radionuclides, isotopic $\mathrm{U}$, isotopic $\mathrm{Pu}$, and Sr-90. Beryllium and PCBs were added parameters because these contaminants are a common concern at the NTS. Table D.8-1 lists the sample-specific analytical suite for CAS 09-23-09. Analytical results from the soil samples with concentrations exceeding MDCs are summarized in the following sections.

An evaluation was conducted on all contaminants detected above MDCs by comparing individual concentration or activity results against the FALs to determine if a constituent is a COC. The FALs were established as the corresponding PAL concentrations or activities if the contaminant concentrations were below respective PALs. 


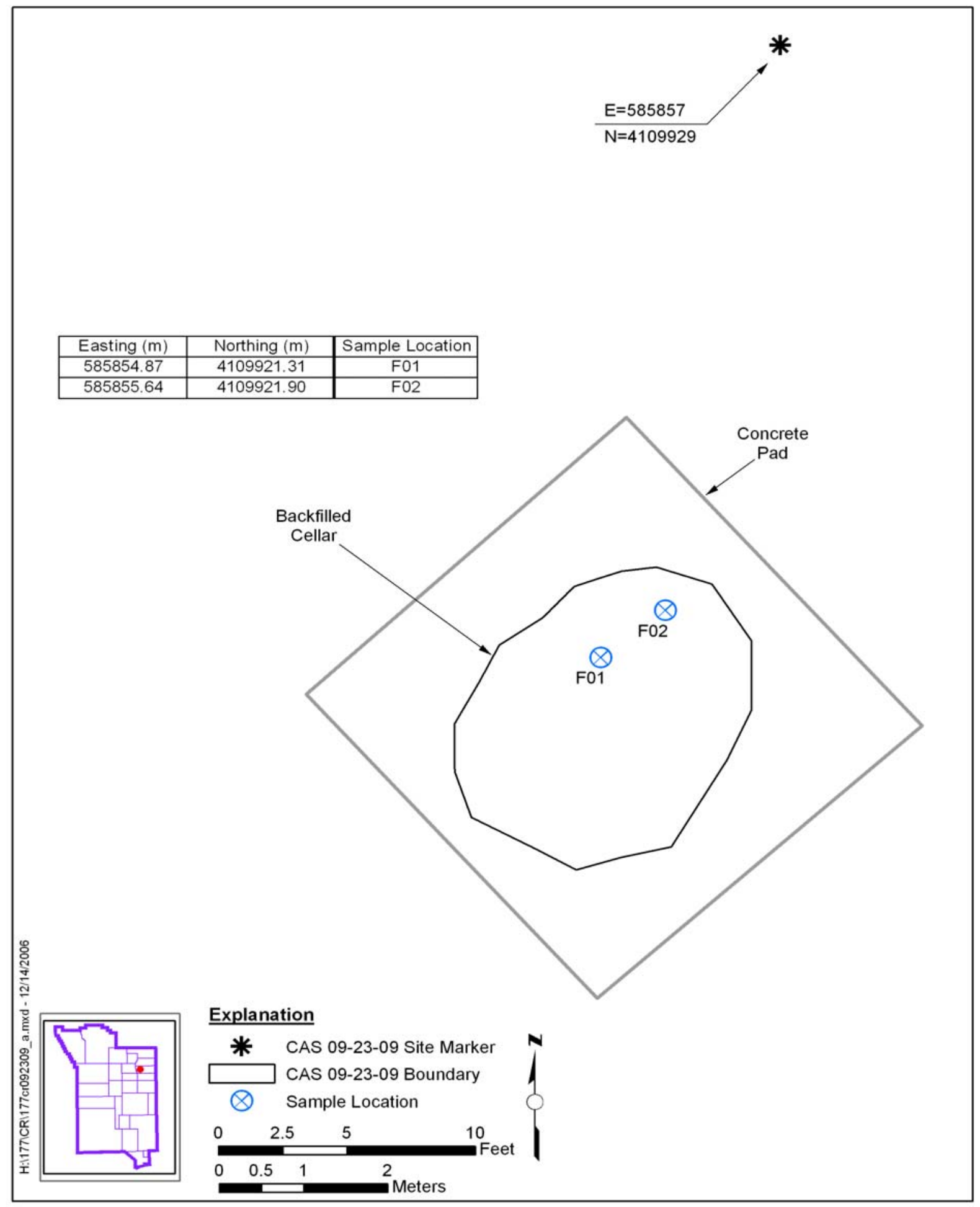

Figure D.8-1

CAS 09-23-09 Sample Location Map 


\section{D.8.2.1 Volatile Organic Compounds}

No VOCs were detected above the respective laboratory MDCs in soil samples collected at this CAS; therefore, the FALs are established at the corresponding PALs.

\section{D.8.2.2 Semivolatile Organic Compounds}

Analytical results from sample 177F002 collected at 6.0 to $7.0 \mathrm{ft}$ bgs detected bis (2-Ethylhexyl)phthalate (118 $\mu \mathrm{g} / \mathrm{kg}$, estimated value), fluoranthene (36.5 $\mu \mathrm{g} / \mathrm{kg}$, estimated value), phenantherene (15.9 $\mu \mathrm{g} / \mathrm{kg}$, estimated value), and pyrene (56.6 $\mu \mathrm{g} / \mathrm{kg}$, estimated value) above MDCs; however, no SVOCs were detected at concentrations exceeding the respective PALs. Therefore, the FALs were established as the corresponding PALs.

\section{D.8.2.3 Total Petroleum Hydrocarbons}

Analytical results for TPH-DRO in soil samples that were detected above MDCs are presented in Table D.8-2. Concentrations of TPH-DRO were not detected at concentrations exceeding the PAL; therefore, the FAL was established as the corresponding PAL. Concentrations of TPH-GRO were not detected above the respective laboratory MDCs at this CAS.

Table D.8-2

Soil Sample Results for TPH-DRO Detected Above Minimum Detectable Concentrations at CAS 09-23-09, U-9itsx20 PS \#1A Cellar

\begin{tabular}{||c|c|c|c|}
\hline \multirow{2}{*}{$\begin{array}{c}\text { Sample } \\
\text { Location }\end{array}$} & \multirow{2}{*}{$\begin{array}{c}\text { Sample } \\
\text { Number }\end{array}$} & $\begin{array}{c}\text { Depth } \\
\text { (ft bgs) }\end{array}$ & Contaminants of Potential Concern (mg/kg) \\
\cline { 3 - 4 } & & \multicolumn{2}{|c|}{ Diesel-Range Organics } \\
\hline \multicolumn{2}{|c|}{ Preliminary Action Levels ${ }^{\mathbf{a}}$} & $\mathbf{1 0 0}$ \\
\hline \hline \multicolumn{3}{|c|}{ Cellar Samples } \\
\hline \hline \multirow{2}{*}{ F01 } & $177 \mathrm{~F} 001$ & $6.0-7.0$ & $9.31(\mathrm{~J})$ \\
\cline { 2 - 4 } & $177 \mathrm{~F} 002$ & $6.0-7.0$ & 12.7 \\
\hline F02 & $177 \mathrm{~F} 003$ & $6.0-7.0$ & 26.4 \\
\hline
\end{tabular}

'Based on Nevada Administrative Code, "Contamination of Soil: Establishment of Action Levels" (NAC, 2006).

$\mathrm{ft}$ bgs $=$ Feet below ground surface $\mathrm{mg} / \mathrm{kg}=$ Milligrams per kilogram $\mathrm{J}=$ Estimate value. 


\section{D.8.2.4 Polychlorinated Biphenyls}

Analytical results for soil sample 177F003 collected at 6.0 to $7.0 \mathrm{ft}$ bgs at the cellar detected Aroclor 1254 (1.8 $\mu \mathrm{g} / \mathrm{kg}$; estimated value) above MDCs. No PCB concentrations exceed the PAL (740 $\mu \mathrm{g} / \mathrm{kg}$ ), therefore, the FALs were established as the corresponding PALs.

\section{D.8.2.5 RCRA Metals and Beryllium}

Analytical results for RCRA metals and beryllium in soil samples that were detected above MDCs are presented in Table D.8-3. None of the metals were detected at concentrations exceeding the respective PALs; therefore, the FALs were established as the corresponding PALs.

Table D.8-3

Soil Sample Results for Metals Detected Above Minimum Detectable Concentrations at CAS 09-23-09, U-9itsx20 PS \#1A Cellar

\begin{tabular}{|c|c|c|c|c|c|c|c|c|c|c|c|}
\hline \multirow{2}{*}{ 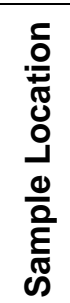 } & \multirow{2}{*}{ 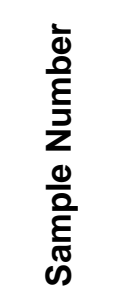 } & \multirow{2}{*}{ 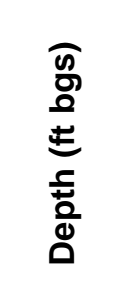 } & \multicolumn{9}{|c|}{ Contaminants of Potential Concern $(\mathrm{mg} / \mathrm{kg})$} \\
\hline & & & 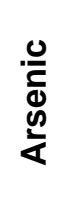 & 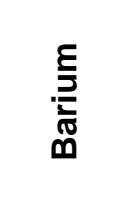 & 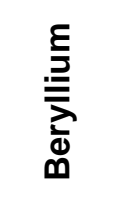 & 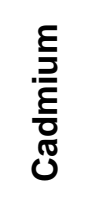 & 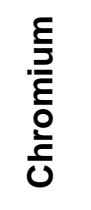 & శ్తు & 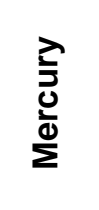 & 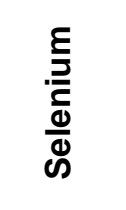 & $\frac{\grave{D}}{\bar{\omega}}$ \\
\hline \multicolumn{3}{|c|}{ Final Action Levels } & $23^{a}$ & $67,000^{b}$ & $1,900^{b}$ & $450^{b}$ & $450^{b}$ & $800^{b}$ & $310^{b}$ & $5,100^{b}$ & $5,100^{b}$ \\
\hline \multicolumn{12}{|c|}{ Cellar Samples } \\
\hline \multirow{2}{*}{ F01 } & 177F001 & $6.0-7.0$ & 4.5 & 131 & 0.45 & 0.1 & 5.7 & 8.3 & 0.03 & -- & 0.21 \\
\hline & 177F002 & $6.0-7.0$ & 4.9 & 132 & 0.51 & 0.12 & 6 & 10.5 & 0.025 & 0.8 & 1.3 \\
\hline $\mathrm{F} 02$ & 177F003 & $6.0-7.0$ & 7 & 181 & 0.51 & 0.17 & 7.2 & 119 & 0.045 & 0.82 & -- \\
\hline
\end{tabular}

a Based on the background concentrations for metals. Background is considered the mean plus two times the standard deviation for sediment samples collected by the Nevada Bureau of Mines and Geology throughout the Nevada Test and Training Range (NBMG, 1998; Moore, 1999).

based on U.S. Environmental Protection Agency, Region 9 Preliminary Remediation Goals (PRGs) (EPA, 2004)

$\mathrm{ft}$ bgs $=$ Feet below ground surface

$\mathrm{mg} / \mathrm{kg}=$ Milligrams per kilogram

-- = Not detected above minimum detectable concentrations.

\section{D.8.2.6 Gamma-Emitting Radionuclides}

Analytical results for gamma-emitting radionuclides in soil samples that were detected above MDCs are presented in Table D.8-4. No gamma-emitting radionuclide concentrations exceeded the respective PALs; therefore, the FALs were established as the corresponding PALs. 
Table D.8-4

Soil Sample Results for Gamma-Emitting Radionuclides Detected Above Minimum Detectable Concentrations at CAS 09-23-09, U-9itsx20 PS \#1A Cellar

\begin{tabular}{|c|c|c|c|c|c|c|c|c|c|}
\hline \multirow[b]{2}{*}{$\begin{array}{l}\text { Sample } \\
\text { Location }\end{array}$} & \multirow[b]{2}{*}{$\begin{array}{l}\text { Sample } \\
\text { Number }\end{array}$} & \multirow[b]{2}{*}{$\begin{array}{l}\text { Depth } \\
\text { (ft bgs) }\end{array}$} & \multicolumn{7}{|c|}{ Contaminants of Potential Concern (pCi/g) } \\
\hline & & & 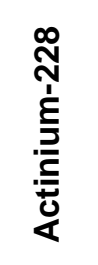 & 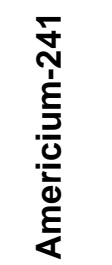 & 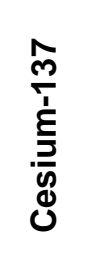 & 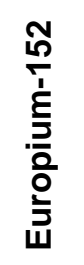 & 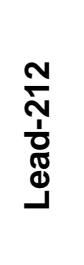 & 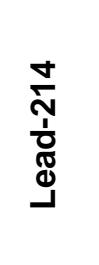 & 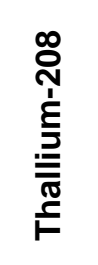 \\
\hline \multicolumn{3}{|c|}{ Final Action Levels } & $5^{a}$ & $12.7^{b}$ & $12.2^{\mathrm{b}}$ & $5.7^{\mathrm{b}}$ & $5^{\mathrm{a}}$ & $5^{a}$ & $5^{a}$ \\
\hline \multicolumn{10}{|c|}{ Cellar Samples } \\
\hline \multirow{2}{*}{ F01 } & 177F001 & $6.0-7.0$ & 1.15 & 1.85 & 0.671 & 1.31 & 1.37 & 0.799 & 0.453 \\
\hline & 177F002 & $6.0-7.0$ & 0.958 & 0.935 & 0.376 & 1.29 & 1.2 & 0.886 & 0.37 \\
\hline F02 & 177F003 & $6.0-7.0$ & 1.33 & 2.9 & 1.42 & 2.01 & 1.37 & 1.07 & 0.377 \\
\hline
\end{tabular}

${ }^{a}$ Taken from the generic guidelines for residual concentrations of actinium-228, bismuth-214, lead-212, lead-214, thallium-208, and thorium-232, as found in Chapter IV of U.S. Department of Energy Order 5400.5, Change 2, Radiation Protection of the Public and Environment (DOE, 1993).

${ }^{\mathrm{b}}$ Taken from the construction, commercial, industrial land-use scenario in Table 2.1 of the National Council on Radiation Protection and Measurement Report No. 129, Recommended Screening Limits for Contaminated Surface Soil and Review Factors Relevant to Site-Specific Studies (NCRP, 1999). The values provided in this source document were scaled to a 25-millirem-per-year dose.

$\mathrm{ft}$ bgs $=$ Feet below ground surface

$\mathrm{pCi} / \mathrm{g}=$ Picocuries per gram

\section{D.8.2.7 Plutonium, Strontium-90, and Uranium Isotopes}

Isotopic $\mathrm{Pu}$ and isotopic $\mathrm{U}$ analytical results for soil samples that were detected above MDCs are presented in Table D.8-5. Concentrations of Sr-90 did not exceed the respective laboratory MDCs and no isotopic Pu or U concentrations exceeded the respective PALs; therefore, the FALs were established as the corresponding PALs.

\section{D.8.3 Nature and Extent of Contamination}

Based on the analytical results, no COCs were identified in the environmental soils samples collected at CAS 09-23-09. 
Table D.8-5

Soil Sample Results for Isotopes Detected Above Minimum Detectable Concentrations at CAS 09-23-09, U-9itsx20 PS \#1A Cellar

\begin{tabular}{|c|c|c|c|c|c|c|c|}
\hline \multirow[b]{2}{*}{$\begin{array}{c}\text { Sample } \\
\text { Location }\end{array}$} & \multirow[b]{2}{*}{$\begin{array}{l}\text { Sample } \\
\text { Number }\end{array}$} & \multirow[b]{2}{*}{$\begin{array}{l}\text { Depth } \\
\text { (ft bgs) }\end{array}$} & \multicolumn{5}{|c|}{ Contaminants of Potential Concern (pCi/g) } \\
\hline & & & 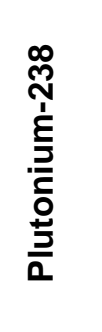 & 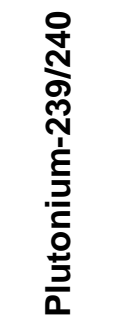 & 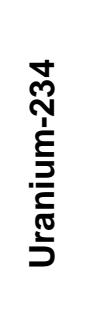 & 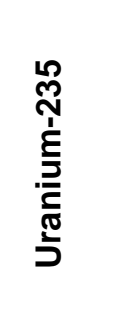 & 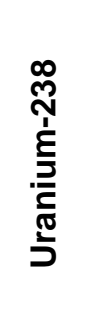 \\
\hline \multicolumn{3}{|c|}{ Final Action Levels ${ }^{a}$} & 13 & 12.7 & 143 & 17.6 & 105 \\
\hline \multicolumn{8}{|c|}{ Cellar Samples } \\
\hline \multirow{2}{*}{ F01 } & 177F001 & $6.0-7.0$ & -- & 2.12 & 0.695 & 0.0768 & 0.556 \\
\hline & 177F002 & $6.0-7.0$ & -- & 10.5 & 0.64 & -- & 0.733 \\
\hline F02 & 177F003 & $6.0-7.0$ & 0.169 & $6.19(\mathrm{~J})$ & 0.768 & -- & 0.577 \\
\hline
\end{tabular}

aTaken from the construction, commercial, industrial land-use scenario in Table 2.1 of the National Council on Radiation Protection and Measurement Report No. 129, Recommended Screening Limits for Contaminated Surface Soil and Review Factors Relevant to Site-Specific Studies (NCRP, 1999). The values provided in this source document were scaled to a 25-millirem-per-year dose.

$\mathrm{ft}$ bgs = Feet below ground surface

$\mathrm{pCi} / \mathrm{g}=$ Picocuries per gram

-- = Not detected above minimum detectable concentrations.

\section{D.8.4 Revised Conceptual Site Model}

The CAU 177 SAFER Plan requirements were met at this CAS, and no revisions were necessary to the CSM. 


\section{D.9.0 CAS 10-23-02, Mud Pit and Cellar}

Corrective Action Site 10-23-02 is within a fenced URMA located in Area 8 (Figure 1-1), north of the U-10am3 crater. The CAS components identified for investigation include an open earthen mud pit and two backfilled cellars (“north” cellar and “west” cellar).

\section{D.9.1 Corrective Action Investigation}

Fifteen characterization samples were collected during investigation activities at CAS 10-23-02. Ten samples and one FD were collected at the mud pit and four samples were collected at the cellars. The sample IDs, locations, types, and analyses are listed in Table D.9-1. The specific CAI activities conducted to satisfy the CAU 177 SAFER Plan requirements at this CAS are described in the following sections.

Table D.9-1

Samples Collected at CAS 10-23-02, Mud Pit and Cellar (Page 1 of 2)

\begin{tabular}{|c|c|c|c|c|c|}
\hline $\begin{array}{l}\text { Sample } \\
\text { Location }\end{array}$ & $\begin{array}{l}\text { Sample } \\
\text { Number }\end{array}$ & $\begin{array}{c}\text { Depth } \\
\text { (ft bgs) }\end{array}$ & Matrix & Purpose & Analyses \\
\hline \multicolumn{6}{|c|}{ Mud Pit Samples } \\
\hline$\overline{\mathrm{G} \text { G01 }}$ & 177G001 & $0.0-1.0$ & Soil & Environmental & Set 1 \\
\hline \multirow{2}{*}{ G02 } & $177 \mathrm{G} 002$ & $0.0-1.0$ & Soil & Environmental & Set 1 \\
\hline & $177 G 003$ & $0.0-1.0$ & Soil & Field Duplicate of \#177G002 & Set 1 \\
\hline G03 & $177 G 004$ & $0.0-1.0$ & Soil & Environmental & Set 1 \\
\hline G04 & $177 G 005$ & $0.0-1.0$ & Soil & Environmental & Set 1 \\
\hline G05 & $177 \mathrm{G} 006$ & $0.0-1.0$ & Soil & Environmental, Full Lab QC & Set 1 \\
\hline G06 & $177 \mathrm{G} 007$ & $0.0-1.0$ & Soil & Environmental & Set 1 \\
\hline G07 & $177 \mathrm{G} 008$ & $0.0-1.0$ & Soil & Environmental & Set 1 \\
\hline G08 & 177G009 & $0.0-1.0$ & Soil & Environmental & Set 1 \\
\hline G09 & $177 \mathrm{G} 010$ & $0.0-1.0$ & Soil & Environmental & Set 1 \\
\hline G10 & $177 \mathrm{G} 011$ & $0.0-1.0$ & Soil & Environmental & Set 1 \\
\hline \multicolumn{6}{|c|}{ Cellar Samples } \\
\hline G11 & $177 \mathrm{G} 012$ & $7.0-8.0$ & Soil & Environmental & Set 2 \\
\hline G12 & $177 \mathrm{G} 013$ & $7.0-8.0$ & Soil & Environmental & Set 2 \\
\hline G13 & $177 \mathrm{G} 014$ & $7.0-8.0$ & Soil & Environmental & Set 2 \\
\hline G14 & $177 \mathrm{G} 015$ & $7.0-8.0$ & Soil & Environmental & Set 2 \\
\hline
\end{tabular}


Table D.9-1

Samples Collected at CAS 10-23-02, Mud Pit and Cellar

(Page 2 of 2)

\begin{tabular}{|c|c|c|c|c|c||}
\hline $\begin{array}{c}\text { Sample } \\
\text { Location }\end{array}$ & $\begin{array}{c}\text { Sample } \\
\text { Number }\end{array}$ & $\begin{array}{c}\text { Depth } \\
\text { (ft bgs) }\end{array}$ & Matrix & Purpose & Analyses \\
\hline \hline \multicolumn{7}{|c|}{ QC Samples } & Set 2 \\
\hline \hline N/A & $177 G 301$ & N/A & Water & Field Blank & VOCs \\
\hline N/A & $177 G 302$ & N/A & Water & Trip Blank & VOnk \\
\hline
\end{tabular}

Set 1 = Gamma Spectroscopy, Isotopic Uranium, Isotopic Plutonium, Strontium-90

Set 2 = VOCs, SVOCs, RCRA Metals, Beryllium, TPH-DRO, TPH-GRO, PCBs, Gamma Spectroscopy, Isotopic Uranium, Isotopic Plutonium, Strontium-90

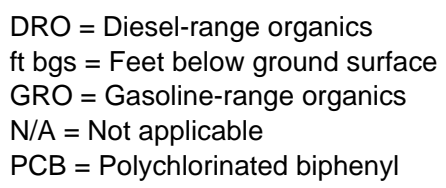

\section{D.9.1.1 Field Screening}

Investigation samples were screened for total alpha and beta/gamma radiation. The FSRs were compared to FSLs and no exceedences were identified.

\section{D.9.1.2 Visual Inspections}

No spills, staining, disturbances of soil, or other indications of potential contamination were identified during the inspection of CAS 10-23-02 and site conditions were unchanged from previous field visits. The backfilled cellars were inspected to identify exposures of the cellar casing for sample location selection and drilling purposes.

\section{D.9.1.3 Sample Collection}

Decision I environmental sampling activities included the collection of random surface samples at the open mud pit and biased subsurface soil samples at the two backfilled cellars (Figure D.9-1).

Eleven Decision I surface samples including 1 FD were collected from 10 locations (G01 through G10) within the mud pit. The mud pit boundary of this CAS was re-established and new sample locations were generated using the VSP model because several original locations were in the mud pit berms. Soil collected consisted primarily of coarse sand with well to poorly sorted angular small gravel, which may be interpreted as drill cuttings. No mud was identified. 


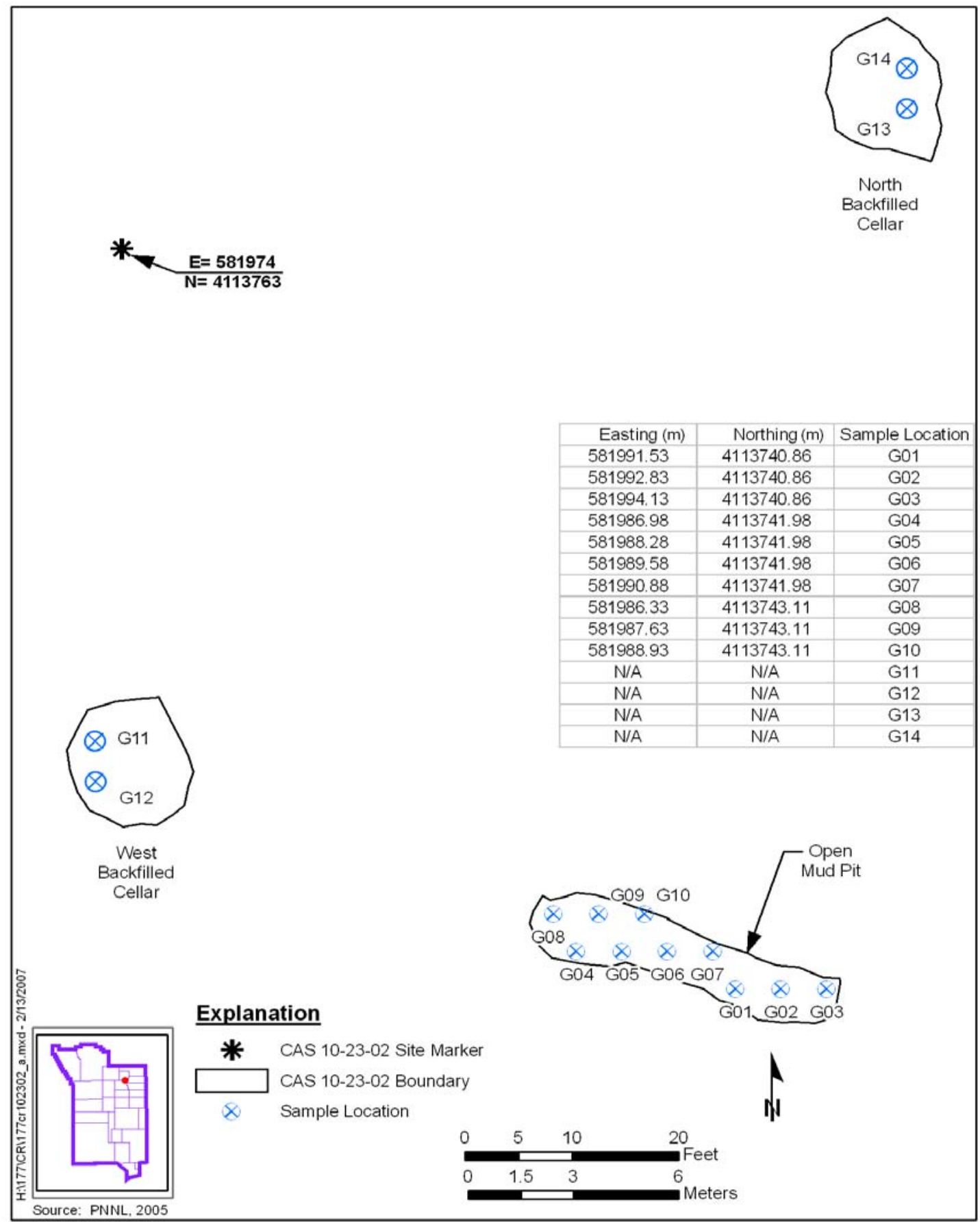

Figure D.9-1

CAS 10-23-02 Sample Location Map 
Two subsurface Decision I environmental samples were collected at the "west” cellar from each borehole (locations G11 and G12) to determine if there was a release to the cellar floor before backfilling. Drilling refusal due to contact with buried steel (suspected to be borehole casing) occurred during the first and second attempts of borehole G12, so the rig shifted $2 \mathrm{ft}$ east to the actual G12 location. Core material was monitored during drilling and the interface with the cellar bottom was identified at $8 \mathrm{ft}$ bgs, marked by a lithology change from backfilled soil to a layer of potential concrete. The presence of plastic and insulation debris and small animal bones at the interface also supports the interpretation that the cellar bottom is located at $8 \mathrm{ft}$ bgs. Drilling was terminated at G11 and G12 at $8 \mathrm{ft}$ bgs to avoid creating a migration pathway through the concrete; therefore, no deeper subsurface samples were collected. The interface subsurface samples were collected at 6 to $7 \mathrm{ft}$ bgs, directly above the concrete layer.

Two subsurface Decision I environmental samples were collected at the "north” cellar from each borehole (locations G13 and G14). Similar to the "west" cellar, the interface with the cellar bottom was identified at $8 \mathrm{ft}$ bgs, marked by a lithology change from backfilled soil to a layer of potential concrete. Plastic debris was also identified at the interface at G14. Drilling was terminated at G13 and G14 at $8 \mathrm{ft}$ bgs to avoid creating a migration pathway through the concrete; therefore, no deeper subsurface samples were collected. The interface subsurface samples were collected at 6 to $7 \mathrm{ft}$ bgs, directly above the concrete layer.

\section{D.9.2 Investigation Results}

The following sections provide analytical results from the samples collected to complete investigation activities as outlined in the CAU 177 SAFER Plan (NNSA/NSO, 2006b). Investigation samples were analyzed for the SAFER-specified COPCs for cellars, which included VOCs, SVOCs, TPH-DRO and -GRO, RCRA metals, gamma-emitting radionuclides, isotopic $\mathrm{U}$, isotopic $\mathrm{Pu}$, and Sr-90; and mud pits, which included only the radiological analytes. Beryllium and PCBs were added parameters to the cellar suite, because these contaminants are a common concern at the NTS. Table D.9-1 lists the sample-specific analytical suite for CAS 10-23-02. Analytical results from the soil samples with concentrations exceeding MDCs are summarized in the following sections.

For the judgmental samples at the cellar components of the CAS, an evaluation was conducted on all contaminants detected above MDCs by comparing individual concentration or activity results against 
the FALs to determine if a constituent is a COC. The FALs were established as the corresponding PAL concentrations or activities if the contaminant concentrations were below respective PALs.

For the probabilistic samples at the mud pit, any COPC that has a 95 percent UCL of the average concentration exceeding the FAL will result in that COPC being designated as a COC. As stipulated in the CAU 177 SAFER Plan (NNSA/NSO, 2006b), UCLs were only calculated for a COPC if it was detected in any sample within any CAS at a concentration equal to or exceeding the PAL. If COPCs were not detected in any mud pit sample at a concentration that exceeded the PAL, then it will be concluded that no COCs are present.

\section{D.9.2.1 Volatile Organic Compounds}

Analytical results for VOCs in soil samples collected from the cellars that were detected above MDCs are presented in Table D.9-2. No VOCs were detected at concentrations exceeding the respective PALs; therefore, the FALs were established as the corresponding PALs.

Table D.9-2

Soil Sample Results for Total VOCs Detected Above Minimum Detectable Concentrations at CAS 10-23-02, Mud Pit and Cellar

(Page 1 of 2)

\begin{tabular}{|c|c|c|c|c|c|c|c|c|}
\hline \multirow[b]{2}{*}{ 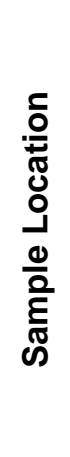 } & \multirow[b]{2}{*}{ 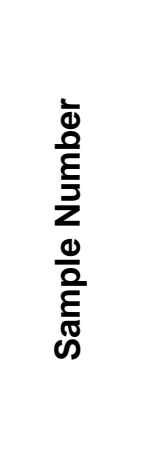 } & \multirow[b]{2}{*}{ 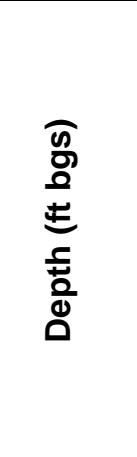 } & \multicolumn{6}{|c|}{ Contaminants of Potential Concern $(\mu \mathrm{g} / \mathrm{kg})$} \\
\hline & & & 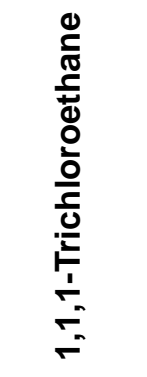 & 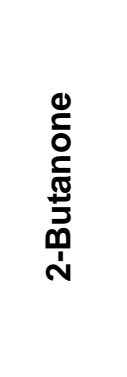 & 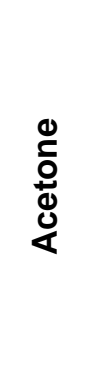 & $\begin{array}{l}\text { 튼 } \\
\text { 음 } \\
\frac{0}{0} \\
\frac{0}{0}\end{array}$ & 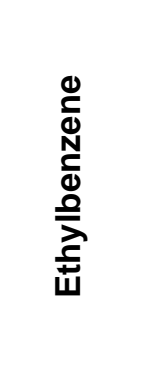 & 离 \\
\hline \multicolumn{3}{|c|}{ Final Action Levels ${ }^{a}$} & 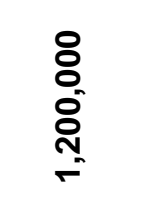 & $\begin{array}{l}8 \\
8 \\
8 \\
8 \\
8 \\
0 \\
0 \\
-1\end{array}$ & $\begin{array}{l}8 \\
8 \\
8 \\
8 \\
0 \\
0 \\
0\end{array}$ & $\stackrel{?}{\stackrel{f}{f}}$ & 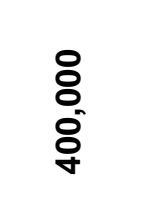 & $\begin{array}{l}8 \\
8 \\
8 \\
8 \\
-1\end{array}$ \\
\hline \multicolumn{9}{|c|}{ Cellar Samples } \\
\hline "G11 & $177 \mathrm{G} 012$ & $7.0-8.0$ & $0.649(\mathrm{~J})$ & $3.92(\mathrm{~J})$ & 53.7 & $0.395(\mathrm{~J})$ & $0.264(\mathrm{~J})$ & $0.305(\mathrm{~J})$ \\
\hline G13 & $177 G 014$ & $7.0-8.0$ & $0.343(\mathrm{~J})$ & -- & -- & $0.29(\mathrm{~J})$ & -- & -- \\
\hline
\end{tabular}


Table D.9-2

Soil Sample Results for Total VOCs Detected Above Minimum Detectable Concentrations at CAS 10-23-02, Mud Pit and Cellar (Page 2 of 2)

\begin{tabular}{|c|c|c|c|c|c|c|c|c|}
\hline \multirow[b]{2}{*}{ 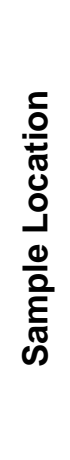 } & \multirow[b]{2}{*}{ 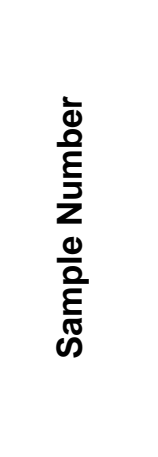 } & \multirow[b]{2}{*}{ 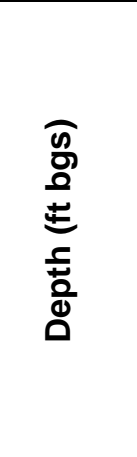 } & \multicolumn{6}{|c|}{ Contaminants of Potential Concern $(\mu \mathrm{g} / \mathrm{kg})$} \\
\hline & & & 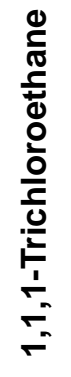 & 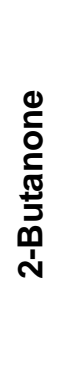 & $\begin{array}{l}\stackrel{0}{0} \\
\stackrel{0}{0} \\
\stackrel{0}{0}\end{array}$ & $\begin{array}{l}\text { ह } \\
\text { o } \\
\frac{0}{0} \\
\frac{0}{0} \\
\frac{c}{U}\end{array}$ & 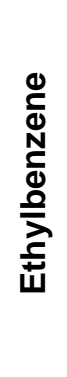 & 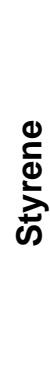 \\
\hline \multicolumn{3}{|c|}{ Final Action Levels ${ }^{a}$} & 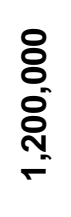 & $\begin{array}{l}8 \\
8 \\
8 \\
8 \\
8 \\
0 \\
\text { - } \\
7\end{array}$ & $\begin{array}{l}8 \\
8 \\
8 \\
8 \\
8 \\
\text { டे }\end{array}$ & $\stackrel{P}{f}$ & $\begin{array}{l}\text { ঃ } \\
80 \\
8 \\
+\end{array}$ & $\begin{array}{l}8 \\
8 \\
8 \\
8 \\
\end{array}$ \\
\hline \multicolumn{9}{|c|}{ Cellar Samples } \\
\hline G14 & $177 G 015$ & $7.0-8.0$ & -- & -- & -- & $0.221(\mathrm{~J})$ & -- & -- \\
\hline
\end{tabular}

aBased on U.S. Environmental Protection Agency, Region 9 Preliminary Remediation Goals (PRGs) (EPA, 2004).

$\mathrm{ft}$ bgs = Feet below ground surface $\mu \mathrm{g} / \mathrm{kg}=$ Micrograms per kilogram

$--=$ Not detected above minimum detectable concentrations.

$\mathrm{J}=$ Estimated value

\section{D.9.2.2 Semivolatile Organic Compounds}

No SVOCs were detected above the respective laboratory MDCs in soil samples collected at cellars of this CAS; therefore, the FALs are established at the corresponding PALs.

\section{D.9.2.3 Total Petroleum Hydrocarbons}

The TPH-DRO analytical results for soil samples collected from the cellars that were detected above MDCs are presented in Table D.9-3. One subsurface sample (7 to $8 \mathrm{ft}$ bgs) collected at location G11 exceeded the PAL of $100 \mathrm{mg} / \mathrm{kg}$ for TPH-DRO. The TPH-DRO was moved on to a Tier 2 evaluation and FALs were established for the hazardous constituents of TPH-DRO at the corresponding PAL concentrations. Concentrations of the hazardous constituents of TPH-DRO did not exceed FALs; therefore, TPH-DRO is not considered a COC. Concentrations of TPH-GRO were not detected above the respective laboratory MDCs at this CAS. 
Table D.9-3

Soil Sample Results for TPH-DRO Detected Above Minimum Detectable Concentrations at CAS 10-23-02, Mud Pit and Cellar

\begin{tabular}{|c|c|c|c|}
\hline \multirow{2}{*}{$\begin{array}{l}\text { Sample } \\
\text { Location }\end{array}$} & \multirow{2}{*}{$\begin{array}{l}\text { Sample } \\
\text { Number }\end{array}$} & \multirow{2}{*}{$\begin{array}{l}\text { Depth } \\
\text { (ft bgs) }\end{array}$} & Contaminants of Potential Concern (mg/kg) \\
\hline & & & Diesel-Range Organics \\
\hline \multicolumn{3}{|c|}{ Preliminary Action Levels ${ }^{a}$} & 100 \\
\hline \multicolumn{4}{|c|}{ Cellar Samples } \\
\hline 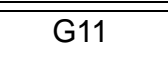 & 17 177G012 & $7.0-8.0$ & 205 \\
\hline G12 & $177 \mathrm{G} 013$ & $7.0-8.0$ & 18.1 \\
\hline G13 & $177 G 014$ & $7.0-8.0$ & $7.76(\mathrm{~J})$ \\
\hline G14 & 177G015 & $7.0-8.0$ & 18.1 \\
\hline
\end{tabular}

aBased on Nevada Administrative Code, "Contamination of Soil: Establishment of Action Levels" (NAC, 2006).

$\mathrm{ft}$ bgs $=$ Feet below ground surface $\mathrm{mg} / \mathrm{kg}=$ Milligrams per kilogram $\mathrm{J}=$ Estimated value.

\section{D.9.2.4 Polychlorinated Biphenyls}

Analytical results for PCBs in soil samples collected from the cellars that were detected above MDCs are presented in Table D.9-4. Aroclor 1254 was detected at concentrations that exceed the PAL (740 $\mu \mathrm{g} / \mathrm{kg})$ in a subsurface soil sample (177G012; 7 to $8 \mathrm{ft}$ bgs) collected at borehole location G11 from the west cellar. Aroclor 1254 was moved to a Tier 2 evaluation in which it was determined that reasonable points of exposure do not exist at this location (see Section H.1.10). As Aroclor 1254 does not exceed PALs at reasonable points of exposure within CAS 10-23-02, the FALs were established at the PAL concentrations.

\section{D.9.2.5 RCRA Metals and Beryllium}

Analytical results for RCRA metals and beryllium in soil samples collected from the cellars that were detected above MDCs are presented in Table D.9-5. None of the metals were detected at concentrations exceeding the respective PALs; therefore, the FALs were established as the corresponding PALs. 
Table D.9-4

Soil Sample Results for PCBs Detected Above Minimum

Detectable Concentrations at CAS 10-23-02, Mud Pit and Cellar

\begin{tabular}{|c|c|c|c|}
\hline \multirow{2}{*}{$\begin{array}{c}\text { Sample } \\
\text { Location }\end{array}$} & $\begin{array}{c}\text { Sample } \\
\text { Number }\end{array}$ & $\begin{array}{c}\text { Depth } \\
\text { (ft bgs) }\end{array}$ & Contaminants of Potential Concern $(\mu \mathrm{g} / \mathrm{kg})$ \\
\cline { 3 - 4 } & & Aroclor 1254 \\
\hline \hline \multicolumn{3}{|c|}{ Final Action Levels ${ }^{\mathrm{a}}$} & $\mathbf{7 4 0}$ \\
\hline \hline \multicolumn{3}{|c|}{ Cellar Samples } \\
\hline $\mathrm{G} 11$ & $177 \mathrm{G} 012$ & $7.0-8.0$ & $\mathbf{1 , 2 3 0}$ \\
\hline $\mathrm{G} 12$ & $177 \mathrm{G} 013$ & $7.0-8.0$ & $19.4(\mathrm{~J})$ \\
\hline $\mathrm{G} 13$ & $177 \mathrm{G} 014$ & $7.0-8.0$ & $22.6(\mathrm{~J})$ \\
\hline
\end{tabular}

${ }^{\text {a} B a s e d ~ o n ~ U . S . ~ E n v i r o n m e n t a l ~ P r o t e c t i o n ~ A g e n c y, ~ R e g i o n ~} 9$ Preliminary Remediation Goals (PRGs) (EPA, 2004)

$\mathrm{ft}$ bgs $=$ Feet below ground surface

$\mu \mathrm{g} / \mathrm{kg}=$ Micrograms per kilogram

$\mathrm{J}=$ Estimated value.

Table D.9-5

Soil Sample Results for Metals Detected Above Minimum Detectable Concentrations at CAS 10-23-02, Mud Pit and Cellar

\begin{tabular}{|c|c|c|c|c|c|c|c|c|c|c|c|}
\hline \multirow{2}{*}{ 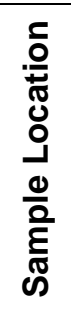 } & \multirow{2}{*}{ 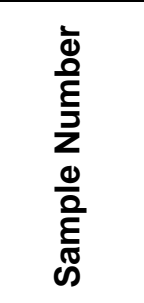 } & \multirow{2}{*}{$\begin{array}{l}\bar{n} \\
0 \\
0 \\
\pm \\
\pm \\
5 \\
0 \\
0 \\
0\end{array}$} & \multicolumn{9}{|c|}{ Contaminants of Potential Concern (mg/kg) } \\
\hline & & & $\begin{array}{l}\frac{0}{c} \\
\frac{\omega}{d} \\
\frac{\omega}{\alpha}\end{array}$ & 立 & 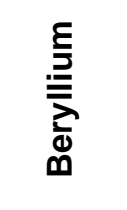 & 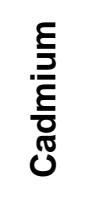 & 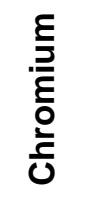 & ב্] & 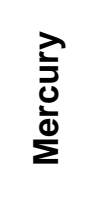 & $\frac{\grave{\Phi}}{\bar{\omega}}$ & 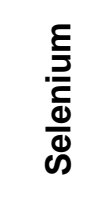 \\
\hline \multicolumn{3}{|c|}{ Final Action Levels } & $23^{a}$ & $67,000^{b}$ & $1,900^{b}$ & $450^{b}$ & $450^{b}$ & $800^{b}$ & $310^{b}$ & $5,100^{b}$ & $5,100^{b}$ \\
\hline \multicolumn{12}{|c|}{ Cellar Samples } \\
\hline G11 & $177 \mathrm{G} 012$ & $7.0-8.0$ & 17.6 & 220 & 0.78 & 0.3 & 17 & $38.5(\mathrm{~J})$ & 0.026 & 3.4 & 0.83 \\
\hline G12 & $177 \mathrm{G} 013$ & $7.0-8.0$ & 10.8 & 157 & 0.97 & 0.1 & 16.1 & $14(\mathrm{~J})$ & 0.027 & -- & 1.1 \\
\hline G13 & $177 \mathrm{G} 014$ & $7.0-8.0$ & 7.4 & 238 & 0.9 & 0.11 & 11.5 & $13.1(\mathrm{~J})$ & 0.034 & 0.21 & 1.1 \\
\hline G14 & $177 \mathrm{G} 015$ & $7.0-8.0$ & 10 & 249 & 0.99 & 0.22 & 15.2 & $17(\mathrm{~J})$ & 0.043 & 0.19 & 0.95 \\
\hline
\end{tabular}

aBased on the background concentrations for metals. Background is considered the mean plus two times the standard deviation for sediment samples collected by the Nevada Bureau of Mines and Geology throughout the Nevada Test and Training Range (NBMG, 1998; Moore, 1999).

${ }^{\mathrm{b} B a s e d}$ on U.S. Environmental Protection Agency, Region 9 Preliminary Remediation Goals (PRGs) (EPA, 2004)

$\mathrm{ft}$ bgs = Feet below ground surface

$\mathrm{mg} / \mathrm{kg}=$ Milligrams per kilogram

$--=$ Not detected above minimum detectable concentrations.

$\mathrm{J}=$ Estimated value. 


\section{D.9.2.6 Gamma-Emitting Radionuclides}

Analytical results for gamma-emitting radionuclides in soil samples from the mud pit and cellars that were detected above MDCs are presented in Table D.9-6. Because no gamma-emitting radionuclide COPCs were detected in any mud pit sample at a concentration equal to or exceeding the PAL, UCLs were not calculated for the mud pit component of this CAS and it is determined that no COCs exist. Because no gamma-emitting radionuclide concentrations exceeded the respective PALs in cellar samples, the FALs were established as the corresponding PALs.

\section{D.9.2.7 Plutonium, Strontium-90, and Uranium Isotopes}

Isotopic Pu and isotopic U and Sr-90 analytical results for soil samples from the mud pit and cellars that were detected above MDCs are presented in Table D.9-6. Because no Pu, U, or Sr-90 isotope COPCs were detected in any mud pit sample at a concentration equal to or exceeding the PAL, UCLs were not calculated for the mud pit component of this CAS, and it is determined that no COCs exist. Because none of the isotopic concentrations in cellar samples exceed the respective PALs, the FALs were established as the corresponding PALs.

\section{D.9.3 Nature and Extent of Contamination}

Based on the analytical results, no COCs were identified in the environmental soils samples collected at CAS 10-23-02.

\section{D.9.4 Revised Conceptual Site Model}

The CAU 177 SAFER Plan requirements were met at this CAS, and no revisions were necessary to the CSM. 
Table D.9-6

Soil Sample Results for Gamma-Emitting Radionuclides Detected Above Minimum Detectable Concentrations at CAS 10-23-02, Mud Pit and Cellar

\begin{tabular}{|c|c|c|c|c|c|c|c|c|}
\hline \multirow[b]{2}{*}{ 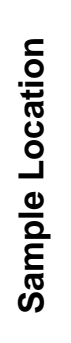 } & \multirow[b]{2}{*}{ 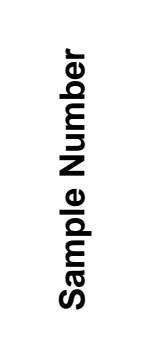 } & \multirow[b]{2}{*}{ 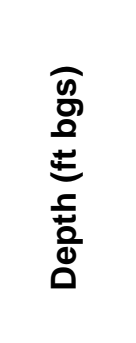 } & \multicolumn{6}{|c|}{ Contaminants of Potential Concern (pCi/g) } \\
\hline & & & 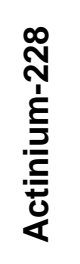 & 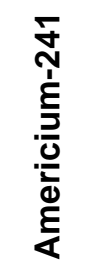 & 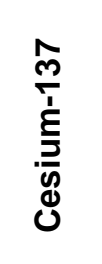 & $\begin{array}{l}\text { ㄱ. } \\
\text { N } \\
\frac{1}{0} \\
\mathbb{d} \\
\end{array}$ & 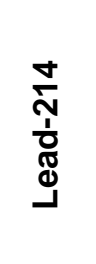 & 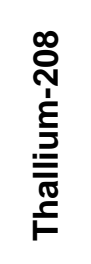 \\
\hline \multicolumn{3}{|c|}{ Final Action Levels } & $5^{a}$ & $12.7^{\mathrm{b}}$ & $12.2^{b}$ & $5^{a}$ & $5^{a}$ & $5^{a}$ \\
\hline \multicolumn{9}{|c|}{ Mud Pit Samples } \\
\hline G01 & 177G001 & $0.0-1.0$ & 1.16 & -- & 0.601 & 1.26 & 1.2 & 0.412 \\
\hline \multirow{2}{*}{ G02 } & $177 \mathrm{G} 002$ & $0.0-1.0$ & 1.27 & -- & 0.637 & 1.17 & 1.04 & 0.36 \\
\hline & $177 \mathrm{G} 003$ & $0.0-1.0$ & 1.34 & -- & 0.716 & 1.2 & 1.04 & 0.267 \\
\hline G03 & $177 \mathrm{G} 004$ & $0.0-1.0$ & -- & -- & - & 0.735 & 0.907 & 0.25 \\
\hline G04 & 177G005 & $0.0-1.0$ & 1.51 & -- & 1.85 & 1.55 & 1.13 & 0.512 \\
\hline G05 & 177G006 & $0.0-1.0$ & 1.67 & -- & 1.44 & 1.4 & 1.01 & 0.493 \\
\hline G06 & 177G007 & $0.0-1.0$ & 1.93 & -- & 2.68 & 1.66 & 1.23 & 0.673 \\
\hline G07 & 177G008 & $0.0-1.0$ & 1.23 & -- & 0.32 & 1.03 & 1.11 & 0.302 \\
\hline G08 & 177G009 & $0.0-1.0$ & 1.11 & -- & -- & 1.1 & 0.869 & 0.316 \\
\hline G09 & $177 G 010$ & $0.0-1.0$ & 1.43 & -- & 0.734 & 1.5 & 0.863 & 0.376 \\
\hline G10 & $177 G 011$ & $0.0-1.0$ & 1.77 & -- & 3.74 & 1.36 & 1.17 & 0.519 \\
\hline \multicolumn{9}{|c|}{ Cellar Samples } \\
\hline G11 & $177 G 012$ & $7.0-8.0$ & 1.28 & -- & 1.41 & 1.29 & 1.08 & 0.271 \\
\hline G12 & $177 \mathrm{G} 013$ & $7.0-8.0$ & 1.64 & 0.33 & 2.34 & 1.1 & 1.05 & 0.552 \\
\hline G13 & $177 \mathrm{G} 014$ & $7.0-8.0$ & 1.58 & 0.474 & 3.33 & 1.14 & 0.936 & 0.389 \\
\hline G14 & $177 \mathrm{G} 015$ & $7.0-8.0$ & 1.71 & -- & 2.44 & 1.34 & 0.903 & 0.429 \\
\hline
\end{tabular}

aTaken from the generic guidelines for residual concentrations of actinium-228, bismuth-214, lead-212, lead-214, thallium-208, and thorium-232, as found in Chapter IV of U.S. Department of Energy Order 5400.5, Change 2, Radiation Protection of the Public and Environment (DOE, 1993).

${ }^{\mathrm{b}}$ Taken from the construction, commercial, industrial land-use scenario in Table 2.1 of the National Council on Radiation Protection and Measurement Report No. 129, Recommended Screening Limits for Contaminated Surface Soil and Review Factors Relevant to Site-Specific Studies (NCRP, 1999). The values provided in this source document were scaled to a 25-millirem-per-year dose.

$\mathrm{ft}$ bgs $=$ Feet below ground surface $\mathrm{pCi} / \mathrm{g}=$ Picocuries per gram

-- = Not detected above minimum detectable concentrations 
Table D.9-7

Soil Sample Results for Isotopes Detected Above Minimum Detectable Concentrations at CAS 10-23-02, Mud Pit and Cellar

\begin{tabular}{|c|c|c|c|c|c|c|c|}
\hline \multirow[b]{2}{*}{ 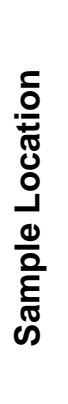 } & \multirow[b]{2}{*}{ 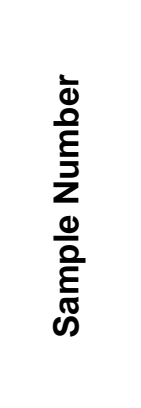 } & \multirow[b]{2}{*}{ 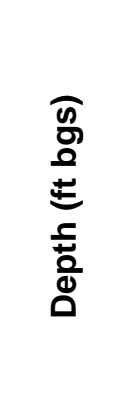 } & \multicolumn{5}{|c|}{ Contaminants of Potential Concern (pCi/g) } \\
\hline & & & 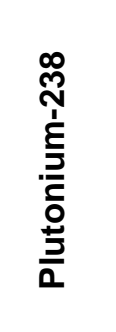 & 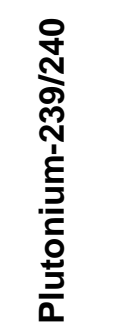 & 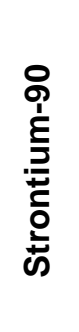 & 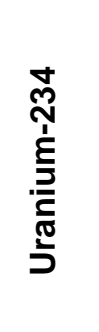 & 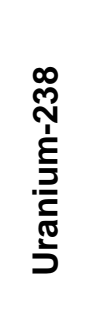 \\
\hline \multicolumn{3}{|c|}{ Final Action Levels ${ }^{a}$} & 13 & 12.7 & 838 & 143 & 105 \\
\hline \multicolumn{8}{|c|}{ Mud Pit Samples } \\
\hline G01 & $177 \mathrm{G} 001$ & $0.0-1.0$ & -- & -- & -- & 1.11 & 1.07 \\
\hline \multirow{2}{*}{ G02 } & $177 \mathrm{G} 002$ & $0.0-1.0$ & 1.94 & 5.11 & -- & 0.954 & 1.25 \\
\hline & $177 \mathrm{G} 003$ & $0.0-1.0$ & -- & 0.273 & -- & 1.15 & 1.14 \\
\hline G03 & $177 \mathrm{G} 004$ & $0.0-1.0$ & -- & 0.0911 & -- & 1 & 0.809 \\
\hline G04 & $177 \mathrm{G} 005$ & $0.0-1.0$ & 1.96 & 4.93 & -- & 0.793 & 0.862 \\
\hline G05 & $177 \mathrm{G} 006$ & $0.0-1.0$ & -- & 0.0695 & -- & 0.85 & 0.971 \\
\hline G06 & $177 \mathrm{G} 007$ & $0.0-1.0$ & -- & 0.111 & -- & 1.09 & 1.08 \\
\hline G07 & $177 \mathrm{G} 008$ & $0.0-1.0$ & -- & 0.0995 & -- & 0.818 & 1.01 \\
\hline G08 & $177 G 009$ & $0.0-1.0$ & -- & 0.099 & -- & 1 & 1.07 \\
\hline G09 & $177 \mathrm{G} 010$ & $0.0-1.0$ & 2.43 & 6.44 & -- & 0.798 & 0.802 \\
\hline G10 & $177 G 011$ & $0.0-1.0$ & -- & 0.456 & 0.47 & 0.978 & 0.949 \\
\hline \multicolumn{8}{|c|}{ Cellar Samples } \\
\hline G11 & $177 G 012$ & $7.0-8.0$ & -- & 0.36 & -- & 0.934 & 1.06 \\
\hline G12 & $177 \mathrm{G} 013$ & $7.0-8.0$ & 0.0999 & 0.476 & -- & 0.839 & 0.812 \\
\hline G13 & $177 G 014$ & $7.0-8.0$ & 0.0961 & 1.15 & -- & 0.882 & 0.976 \\
\hline G14 & $177 G 015$ & $7.0-8.0$ & 0.107 & 0.984 & -- & 0.956 & 0.91 \\
\hline
\end{tabular}

aTaken from the construction, commercial, industrial land-use scenario in Table 2.1 of the National Council on Radiation Protection and Measurement Report No. 129, Recommended Screening Limits for Contaminated Surface Soil and Review Factors Relevant to Site-Specific Studies (NCRP, 1999). The values provided in this source document were scaled to a 25-millirem-per-year dose.

$\mathrm{ft}$ bgs $=$ Feet below ground surface

$\mathrm{pCi} / \mathrm{g}=$ Picocuries per gram

-- = Not detected above minimum detectable concentrations. 


\section{D.10.0 CAS 10-23-03, Mud Pit and Cellar}

Corrective Action Site 10-23-03 is within a fenced URMA located in Area 8 (Figure 1-1), north of the U-10am1 crater. The CAS components identified for investigation include an open mud pit and a backfilled cellar.

\section{D.10.1 Corrective Action Investigation}

Fifteen characterization samples were collected during investigation activities at CAS 10-23-03. Ten samples and one FD were collected at the mud pit and four samples were collected at the cellar. The sample IDs, locations, types, and analyses are listed in Table D.10-1. The specific CAI activities conducted to satisfy the CAU 177 SAFER Plan requirements at this CAS are described in the following sections.

Table D.10-1

Samples Collected at CAS 10-23-03, Mud Pit and Cellar (Page 1 of 2)

\begin{tabular}{|c|c|c|c|c|c|}
\hline $\begin{array}{l}\text { Sample } \\
\text { Location }\end{array}$ & $\begin{array}{l}\text { Sample } \\
\text { Number }\end{array}$ & $\begin{array}{l}\text { Depth } \\
\text { (ft bgs) }\end{array}$ & Matrix & Purpose & Analyses \\
\hline \multicolumn{6}{|c|}{ Mud Pit Samples } \\
\hline $\mathrm{H} 01$ & $177 \mathrm{H003}$ & $0.0-1.0$ & Soil & Environmental & Set 1 \\
\hline $\mathrm{HO2}$ & $177 \mathrm{H004}$ & $0.0-1.0$ & Soil & Environmental & Set 1 \\
\hline $\mathrm{HO3}$ & $177 \mathrm{H} 005$ & $0.0-1.0$ & Soil & Environmental & Set 1 \\
\hline $\mathrm{HO4}$ & $177 \mathrm{H007}$ & $0.0-1.0$ & Soil & Environmental & Set 1 \\
\hline $\mathrm{H} 05$ & $177 \mathrm{H} 006$ & $0.0-1.0$ & Soil & Environmental & Set 1 \\
\hline \multirow{2}{*}{$\mathrm{H} 06$} & $177 \mathrm{H} 008$ & $0.0-1.0$ & Soil & Environmental & Set 1 \\
\hline & $177 \mathrm{H009}$ & $0.0-1.0$ & Soil & Field Duplicate of \#177H008 & Set 1 \\
\hline $\mathrm{H} 07$ & $177 \mathrm{H} 010$ & $0.0-1.0$ & Soil & Environmental & Set 1 \\
\hline $\mathrm{H} 08$ & $177 \mathrm{H} 013$ & $0.0-1.0$ & Soil & Environmental & Set 1 \\
\hline H09 & $177 \mathrm{H} 014$ & $0.0-1.0$ & Soil & Environmental & Set 1 \\
\hline $\mathrm{H} 10$ & $177 \mathrm{H} 015$ & $0.0-1.0$ & Soil & Environmental & Set 1 \\
\hline \multicolumn{6}{|c|}{ Cellar Samples } \\
\hline \multirow{2}{*}{$\mathrm{H} 11$} & $177 \mathrm{H} 001$ & $11.0-12.0$ & Soil & Environmental & Set 2 \\
\hline & $177 \mathrm{H002}$ & $13.0-14.0$ & Soil & Environmental & Set 2 \\
\hline \multirow{2}{*}{$\mathrm{H} 12$} & $177 \mathrm{H} 011$ & $11.0-12.0$ & Soil & Environmental, Full Lab QC & Set 2 \\
\hline & $177 \mathrm{H} 012$ & $13.0-14.0$ & Soil & Environmental & Set 2 \\
\hline
\end{tabular}


Table D.10-1

\section{Samples Collected at CAS 10-23-03, Mud Pit and Cellar}

(Page 2 of 2)

\begin{tabular}{|c|c|c|c|c|c||}
\hline $\begin{array}{c}\text { Sample } \\
\text { Location }\end{array}$ & $\begin{array}{c}\text { Sample } \\
\text { Number }\end{array}$ & $\begin{array}{c}\text { Depth } \\
\text { (ft bgs) }\end{array}$ & Matrix & Purpose & Analyses \\
\hline \hline \multicolumn{7}{|c||}{ QC Samples } \\
\hline \hline N/A & $177 \mathrm{H} 301$ & N/A & Water & Trip Blank & VOCs \\
\hline N/A & $177 \mathrm{H} 302$ & N/A & Water & Field Blank & Set 2 \\
\hline
\end{tabular}

Set 1 = Gamma Spectroscopy, Isotopic Uranium, Isotopic Plutonium, Strontium-90

Set 2 = VOCs, SVOCs, RCRA Metals, Beryllium, TPH-DRO, TPH-GRO, PCBs, Gamma Spectroscopy, Isotopic Uranium, Isotopic Plutonium, Strontium-90

DRO = Diesel-range organics

$\mathrm{ft}$ bgs $=$ Feet below ground surface

$\mathrm{GRO}=$ Gasoline-range organics

N/A = Not applicable

$\mathrm{PCB}=$ Polychlorinated biphenyl
$\mathrm{QC}=$ Quality control

$\mathrm{RCRA}=$ Resource Conservation and Recovery Act

SVOC $=$ Semivolatile organic compound

$\mathrm{TPH}=$ Total petroleum hydrocarbons

VOC $=$ Volatile organic compound

\section{D.10.1.1 Field Screening}

Investigation samples were screened for total alpha and beta/gamma radiation. The FSRs were compared to FSLs and no exceedences were identified.

\section{D.10.1.2 Visual Inspections}

No spills, staining, disturbances of soil, or other indications of potential contamination were identified during the inspection of CAS 10-23-03 and site conditions were unchanged from previous field visits. The backfilled cellar was inspected to identify exposures of the cellar casing and to assess the orientation of exposed borehole riser casing for sample location selection and drilling purposes.

\section{D.10.1.3 Sample Collection}

Decision I environmental sampling activities included the collection of random surface samples at the open mud pit and biased subsurface soil samples at the cellar (Figure D.10-1). Eleven Decision I surface samples including 1 FD were collected from 10 locations (H01 through H10) within the mud pit. Two sample locations (H01 and H03) were staked on the mud pit berm. A green-gray mud was collected from H05, located at the center of the mud pit. All other samples consisted of sand with moderately to poorly sorted gravel, which may be interpreted as drill cuttings. 


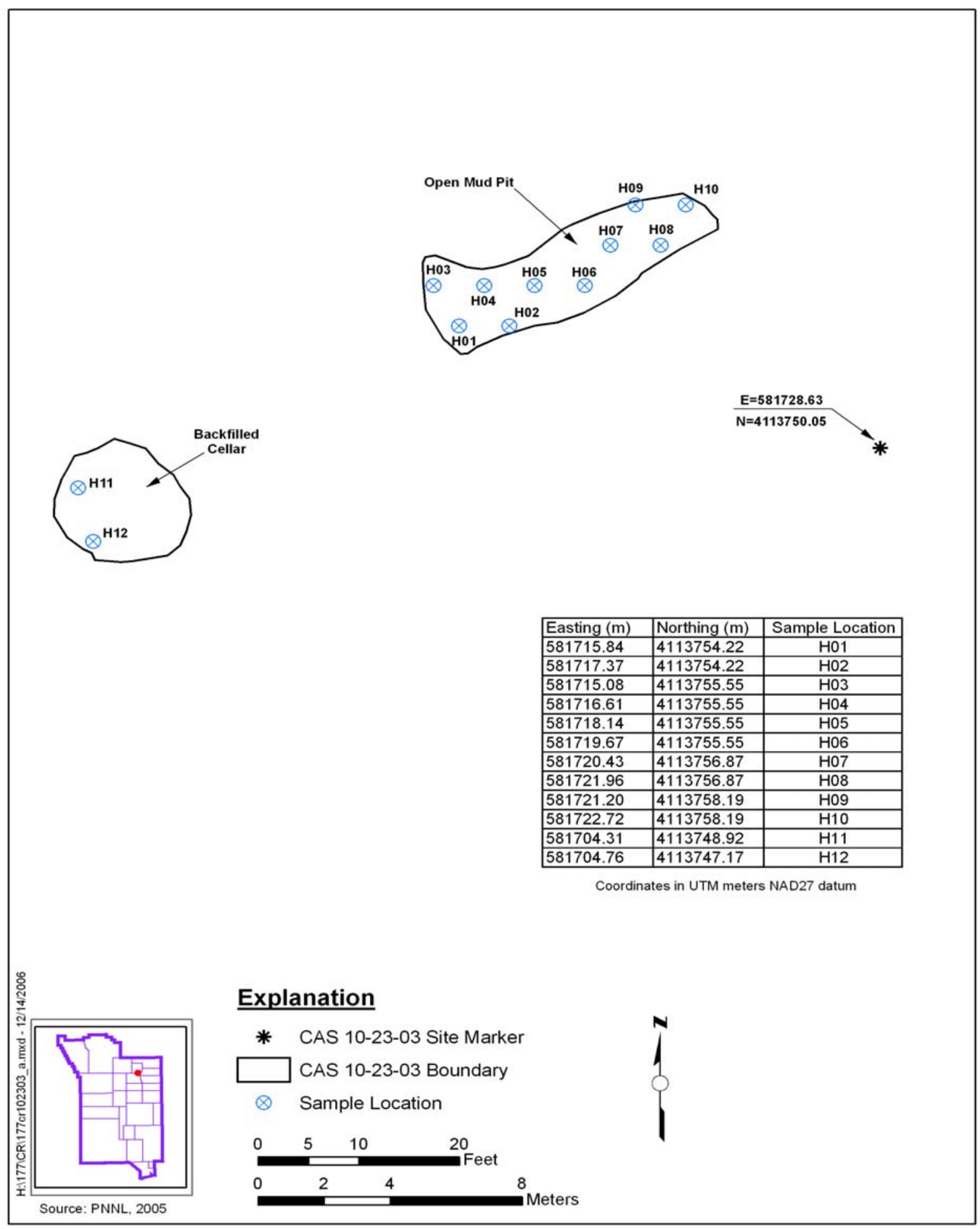

Figure D.10-1

CAS 10-23-03 Sample Location Map 
Four Decision I environmental samples were collected at the cellar. One subsurface sample was collected from each borehole (H11 and H12) at the interface with the cellar bottom. Two deeper subsurface samples were collected from the same boreholes to obtain information regarding the vertical extent of potentially released contamination. Each borehole was drilled to a depth of $14 \mathrm{ft}$ bgs. Drilling refusal due to contact with buried metal debris occurred during the first attempt of borehole H12, so the rig shifted $2 \mathrm{ft}$ north to the reported H12 location. Core material was monitored during drilling and the interface with the cellar bottom was identified at $12 \mathrm{ft}$ bgs, marked by a lithology change from backfilled soil to a thin layer (less than $0.5 \mathrm{ft}$ thick) of gray silt suspected to represent grout. Plastic debris identified at the interface of $\mathrm{H} 11$ also supports the interpretation that this boundary represents the cellar bottom. The shallower subsurface samples were collected directly above the grout layer at 11 to $12 \mathrm{ft}$ bgs and the deeper subsurface samples were collected below the interface at 13 to $14 \mathrm{ft}$ bgs.

\section{D.10.2 Investigation Results}

The following sections provide analytical results from the samples collected to complete investigation activities as outlined in the CAU 177 SAFER Plan (NNSA/NSO, 2006b). Investigation samples were analyzed for the SAFER-specified COPCs for cellars, which included VOCs, SVOCs, TPH-DRO and -GRO, RCRA metals, gamma-emitting radionuclides, isotopic $\mathrm{U}$, isotopic Pu, and Sr-90; and mud pits, which included only the radiological analytes. Beryllium and PCBs were added parameters to the cellar suite, because these contaminants are a common concern at the NTS.

Table D.10-1 lists the sample-specific analytical suite for CAS 10-23-03. Analytical results from the soil samples with concentrations exceeding MDCs are summarized in the following sections.

For the judgmental samples at the cellar component of the CAS, an evaluation was conducted on all contaminants detected above MDCs by comparing individual concentration or activity results against the FALs to determine if a constituent is a COC. The FALs were established as the corresponding PAL concentrations or activities if the contaminant concentrations were below respective PALs.

For the probabilistic samples at the mud pit, any COPC that has a 95 percent UCL of the average concentration exceeding the FAL will result in that COPC being designated as a COC. As stipulated in the CAU 177 SAFER Plan (NNSA/NSO, 2006b), UCLs were only calculated for a COPC if it was detected in any sample within any CAS at a concentration equal to or exceeding the PAL. If COPCs 
were not detected in any mud pit sample at a concentration that exceeded the PAL, then it will be concluded that no COCs are present.

\section{D.10.2.1 Volatile Organic Compounds}

No VOCs were detected above the respective laboratory MDCs in soil samples collected at the cellar component of this CAS; therefore, the FALs are established at the corresponding PALs.

\section{D.10.2.2 Semivolatile Organic Compounds}

Analytical results from cellar sample $177 \mathrm{H} 001$ collected at 11.0 to $12.0 \mathrm{ft}$ bgs detected bis (2-Ethylhexyl)phthalate (588 $\mu \mathrm{g} / \mathrm{kg})$, butylbenzylphthalate (70.5 $\mu \mathrm{g} / \mathrm{kg}$, estimated value), and di-n-butylphthalate (74.9 $\mu \mathrm{g} / \mathrm{kg}$, estimated value) above MDCs; however, no SVOCs were detected at concentrations exceeding the respective PALs. Therefore, the FALs were established as the corresponding PALs.

\section{D.10.2.3 Total Petroleum Hydrocarbons}

Analytical results for TPH-DRO in soil samples collected from the cellar that were detected above MDCs are presented in Table D.10-2. Concentrations of TPH-DRO were not detected at concentrations exceeding the respective PAL; therefore, the FAL was established at the corresponding PAL. Concentrations of TPH-GRO were not detected above the respective laboratory MDCs at this CAS.

\section{D.10.2.4 Polychlorinated Biphenyls}

Analytical results for soil sample $177 \mathrm{H} 001$ collected at 11.0 to $12.0 \mathrm{ft}$ bgs at the cellar detected Aroclor 1260 (1.6 $\mu \mathrm{g} / \mathrm{kg}$; estimated value) above MDCs. No PCB concentrations exceed the PAL (740 $\mu \mathrm{g} / \mathrm{kg}$ ), therefore, the FALs were established as the corresponding PALs.

\section{D.10.2.5 RCRA Metals and Beryllium}

Analytical results for RCRA metals and beryllium in soil samples collected from the cellar that were detected above MDCs are presented in Table D.10-3. None of the metals were detected at concentrations exceeding the respective PALs; therefore, the FALs were established as the corresponding PALs. 
Table D.10-2

Soil Sample Results for TPH-DRO Detected Above Minimum Detectable Concentrations at CAS 10-23-03, Mud Pit and Cellar

\begin{tabular}{|c|c|c|c|}
\hline \multirow{2}{*}{$\begin{array}{c}\text { Sample } \\
\text { Location }\end{array}$} & \multirow{2}{*}{$\begin{array}{c}\text { Sample } \\
\text { Number }\end{array}$} & $\begin{array}{c}\text { Depth } \\
\text { (ft bgs) }\end{array}$ & Contaminants of Potential Concern (mg/kg) \\
\cline { 3 - 4 } & & & Diesel-Range Organics \\
\hline \multicolumn{2}{|c|}{ Preliminary Action Levels } \\
\end{tabular}

aBased on Nevada Administrative Code, "Contamination of Soil: Establishment of Action Levels" (NAC, 2006).

$\mathrm{ft}$ bgs $=$ Feet below ground surface

$\mathrm{mg} / \mathrm{kg}=$ Milligrams per kilogram

$\mathrm{J}=$ Estimated value

Table D.10-3

Soil Sample Results for Metals Detected Above Minimum Detectable Concentrations at CAS 10-23-03, Mud Pit and Cellar

\begin{tabular}{|c|c|c|c|c|c|c|c|c|c|c|}
\hline \multirow[b]{2}{*}{$\begin{array}{c}\text { Sample } \\
\text { Location }\end{array}$} & \multirow[b]{2}{*}{$\begin{array}{l}\text { Sample } \\
\text { Number }\end{array}$} & \multirow[b]{2}{*}{$\begin{array}{l}\text { Depth } \\
\text { (ft bgs) }\end{array}$} & \multicolumn{8}{|c|}{ Contaminants of Potential Concern (mg/kg) } \\
\hline & & & 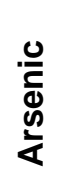 & 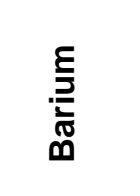 & 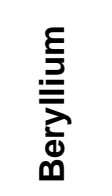 & 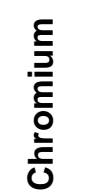 & శ్త & 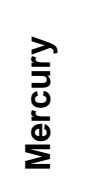 & $\begin{array}{l}\frac{\xi}{D} \\
\frac{\bar{D}}{d} \\
\frac{D}{d}\end{array}$ & 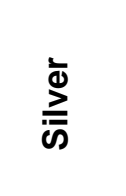 \\
\hline \multicolumn{3}{|c|}{ Final Action Levels } & $23^{\mathrm{a}}$ & $67,000^{b}$ & $1,900^{b}$ & $450^{b}$ & $800^{b}$ & $310^{b}$ & $5,100^{b}$ & $5,100^{b}$ \\
\hline \multicolumn{11}{|c|}{ Cellar Samples } \\
\hline \multirow{2}{*}{$\mathrm{H} 11$} & $177 \mathrm{H} 001$ & $11.0-12.0$ & 13 & 157 & 0.86 & 11.3 & 62 & 0.038 & $\begin{array}{l}-- \\
-\end{array}$ & 0.14 \\
\hline & $177 \mathrm{H} 002$ & $13.0-14.0$ & 3.2 & 92.1 & 0.69 & 5.8 & 5.4 & 0.025 & 0.89 & 0.22 \\
\hline \multirow{2}{*}{$\mathrm{H} 12$} & $177 \mathrm{H} 011$ & $11.0-12.0$ & 7.3 & 161 & 0.96 & 9.2 & 20.6 & 0.032 & 1.2 & -- \\
\hline & $177 \mathrm{H} 012$ & $13.0-14.0$ & 3.1 & 68.1 & 0.51 & 5.9 & 3.5 & 0.053 & 0.75 & -- \\
\hline
\end{tabular}

${ }^{a}$ Based on the background concentrations for metals. Background is considered the mean plus two times the standard deviation for sediment samples collected by the Nevada Bureau of Mines and Geology throughout the Nevada Test and Training Range (NBMG, 1998; Moore, 1999).

bBased on U.S. Environmental Protection Agency, Region 9 Preliminary Remediation Goals (PRGs) (EPA, 2004).

$\mathrm{ft}$ bgs $=$ Feet below ground surface

$\mathrm{mg} / \mathrm{kg}=$ Milligrams per kilogram

$--=$ Not detected above minimum detectable concentrations 


\section{D.10.2.6 Gamma-Emitting Radionuclides}

Analytical results for gamma-emitting radionuclides in soil samples from the mud pit and cellar that were detected above MDCs are presented in Table D.10-4. Because no gamma-emitting radionuclide COPCs were detected in any mud pit sample at a concentration equal to or exceeding the PAL, UCLs were not calculated for the mud pit component of this CAS, and it is determined that no COCs exist. Because no gamma-emitting radionuclide concentrations in cellar samples exceeded the respective PALs, the FALs were established as the corresponding PALs.

\section{D.10.2.7 Plutonium, Strontium-90, and Uranium Isotopes}

Isotopic Pu and isotopic $\mathrm{U}$ analytical results for soil samples from the mud pit and cellar that were detected above MDCs are presented in Table D.10-5. Because no Pu, U, or Sr-90 isotope COPCs were detected in any mud pit sample at a concentration equal to or exceeding the PAL, UCLs were not calculated for the mud pit component of this CAS, and it is determined that no COCs exist. Because no Sr-90, isotopic Pu, or isotopic U concentrations exceeded the respective PALs, the FALs were established as the corresponding PALs.

\section{D.10.3 Nature and Extent of Contamination}

Based on the analytical results, no COCs were identified in the environmental soils samples collected at CAS 10-23-03.

\section{D.10.4 Revised Conceptual Site Model}

The CAU 177 SAFER Plan requirements were met at this CAS, and no revisions were necessary to the CSM. 
Table D.10-4

Soil Sample Results for Gamma-Emitting Radionuclides Detected Above Minimum Detectable Concentrations at CAS 10-23-03, Mud Pit and Cellar

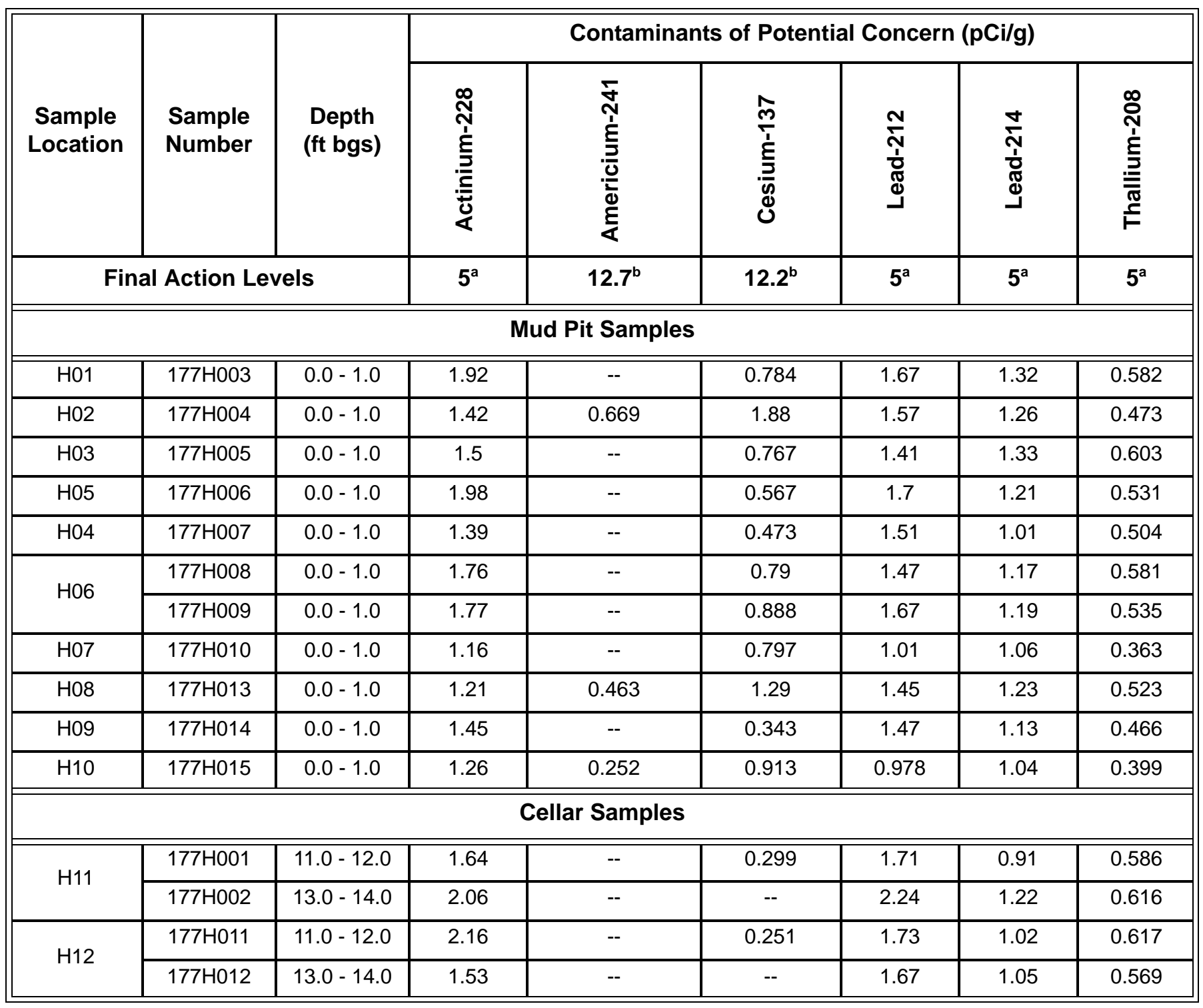

${ }^{a}$ Taken from the generic guidelines for residual concentrations of actinium-228, bismuth-214, lead-212, lead-214, thallium-208, and thorium-232, as found in Chapter IV of U.S. Department of Energy Order 5400.5, Change 2, Radiation Protection of the Public and Environment (DOE, 1993).

${ }^{\mathrm{b}}$ Taken from the construction, commercial, industrial land-use scenario in Table 2.1 of the National Council on Radiation Protection and Measurement Report No. 129, Recommended Screening Limits for Contaminated Surface Soil and Review Factors Relevant to Site-Specific Studies (NCRP, 1999). The values provided in this source document were scaled to a 25-millirem-per-year dose.

$\mathrm{ft}$ bgs $=$ Feet below ground surface

$\mathrm{pCi} / \mathrm{g}=$ Picocuries per gram

-- = Not detected above minimum detectable concentrations 
Table D.10-5

Soil Sample Results for Isotopes Detected Above Minimum Detectable Concentrations at CAS 10-23-03, Mud Pit and Cellar

\begin{tabular}{|c|c|c|c|c|c|c|}
\hline \multirow[b]{2}{*}{$\begin{array}{l}\text { Sample } \\
\text { Location }\end{array}$} & \multirow[b]{2}{*}{$\begin{array}{l}\text { Sample } \\
\text { Number }\end{array}$} & \multirow[b]{2}{*}{$\begin{array}{c}\text { Depth } \\
\text { (ft bgs) }\end{array}$} & \multicolumn{4}{|c|}{ Contaminants of Potential Concern (pCi/g) } \\
\hline & & & 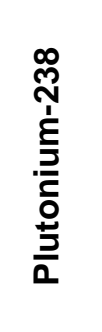 & 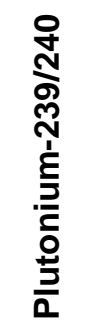 & 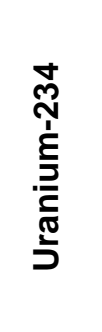 & 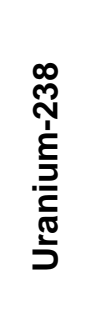 \\
\hline \multicolumn{3}{|c|}{ Final Action Levels ${ }^{a}$} & 13 & 12.7 & 143 & 105 \\
\hline \multicolumn{7}{|c|}{ Mud Pit Samples } \\
\hline $\mathrm{HO1}$ & $177 \mathrm{H003}$ & $0.0-1.0$ & 0.218 & 0.539 & 0.743 & 0.949 \\
\hline $\mathrm{H} 02$ & $177 \mathrm{H} 004$ & $0.0-1.0$ & -- & 0.175 & 0.921 & 0.925 \\
\hline $\mathrm{HO3}$ & $177 \mathrm{H} 005$ & $0.0-1.0$ & -- & 0.431 & 0.983 & 1.02 \\
\hline $\mathrm{H} 05$ & $177 \mathrm{H} 006$ & $0.0-1.0$ & -- & 0.172 & 0.821 & 0.706 \\
\hline $\mathrm{H} 04$ & $177 \mathrm{H} 007$ & $0.0-1.0$ & -- & 0.116 & 0.931 & 1.08 \\
\hline \multirow{2}{*}{$\mathrm{H} 06$} & $177 \mathrm{H} 008$ & $0.0-1.0$ & -- & 0.323 & 0.951 & 1 \\
\hline & $177 \mathrm{H} 009$ & $0.0-1.0$ & -- & 0.227 & 0.951 & 1.07 \\
\hline $\mathrm{HO}$ & $177 \mathrm{H} 010$ & $0.0-1.0$ & 0.182 & 0.836 & 0.957 & 0.965 \\
\hline $\mathrm{H} 08$ & $177 \mathrm{H} 013$ & $0.0-1.0$ & -- & 0.134 & 0.816 & 0.867 \\
\hline $\mathrm{HO9}$ & $177 \mathrm{H} 014$ & $0.0-1.0$ & -- & -- & 0.809 & 0.658 \\
\hline $\mathrm{H} 10$ & $177 \mathrm{H} 015$ & $0.0-1.0$ & -- & 0.135 & 0.717 & 0.838 \\
\hline \multicolumn{7}{|c|}{ Cellar Samples } \\
\hline \multirow{2}{*}{$\mathrm{H} 11$} & $177 \mathrm{H} 001$ & $11.0-12.0$ & -- & -- & 0.968 & 1.08 \\
\hline & $177 \mathrm{H} 002$ & $13.0-14.0$ & -- & -- & 0.641 & 0.595 \\
\hline \multirow{2}{*}{$\mathrm{H} 12$} & $177 \mathrm{H} 011$ & $11.0-12.0$ & -- & -- & 1.12 & 1.16 \\
\hline & $177 \mathrm{H} 012$ & $13.0-14.0$ & -- & -- & 1.11 & 0.956 \\
\hline
\end{tabular}

aTaken from the construction, commercial, industrial land-use scenario in Table 2.1 of the National Council on Radiation Protection and Measurement Report No. 129, Recommended Screening Limits for Contaminated Surface Soil and Review Factors Relevant to Site-Specific Studies (NCRP, 1999). The values provided in this source document were scaled to a 25-millirem-per-year dose.

$\mathrm{ft}$ bgs $=$ Feet below ground surface

$\mathrm{pCi} / \mathrm{g}=$ Picocuries per gram

-- = Not detected above minimum detectable concentrations. 


\section{D.11.0 CAS 19-23-01, Mud Pit and Cellar}

Corrective Action Site 19-23-01 is located in Area 19 (Figure 1-1), northeast of the U-19ys crater. The CAS components identified for investigation include a backfilled mud pit (not fenced or posted) and a backfilled cellar, which is located in a fenced URMA and has a single Controlled Area posting at the east side.

\section{D.11.1 Corrective Action Investigation}

Fifteen characterization samples were collected during investigation activities at CAS 19-23-01. Ten samples and one FD were collected at the mud pit, and four samples were collected at the cellar. The sample IDs, locations, types, and analyses are listed in Table D.11-1. The specific CAI activities conducted to satisfy the CAU 177 SAFER Plan requirements at this CAS are described in the following sections.

Table D.11-1

Samples Collected at CAS 19-23-01, Mud Pit and Cellar (Page 1 of 2)

\begin{tabular}{|c|c|c|c|c|c|}
\hline $\begin{array}{l}\text { Sample } \\
\text { Location }\end{array}$ & $\begin{array}{l}\text { Sample } \\
\text { Number }\end{array}$ & $\begin{array}{l}\text { Depth } \\
\text { (ft bgs) }\end{array}$ & Matrix & Purpose & Analyses \\
\hline \multicolumn{6}{|c|}{ Mud Pit Samples } \\
\hline 101 & 1771006 & 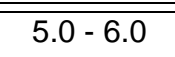 & 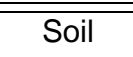 & Environmental & Set 1 \\
\hline 102 & 1771005 & $4.0-5.0$ & Soil & Environmental, Full Lab QC & Set 1 \\
\hline 103 & $177 \mid 011$ & $4.0-5.0$ & Soil & Environmental & Set 1 \\
\hline \multirow{2}{*}{104} & 1771003 & $3.0-4.0$ & Soil & Environmental & Set 1 \\
\hline & 1771004 & $3.0-4.0$ & Soil & Field Duplicate of \#1771003 & Set 1 \\
\hline 105 & 1771010 & $5.5-6.5$ & Soil & Environmental & Set 1 \\
\hline 106 & 1771002 & $3.0-4.0$ & Soil & Environmental & Set 1 \\
\hline 107 & 1771009 & $5.0-6.0$ & Soil & Environmental & Set 1 \\
\hline 108 & $177 \mid 001$ & $3.0-4.0$ & Soil & Environmental & Set 1 \\
\hline 109 & 1771008 & $5.0-6.0$ & Soil & Environmental & Set 1 \\
\hline 110 & 1771007 & $2.0-3.0$ & Soil & Environmental & Set 1 \\
\hline \multicolumn{6}{|c|}{ Cellar Samples } \\
\hline \multirow{2}{*}{111} & 1777012 & "12.0-13.0 & 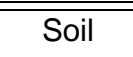 & Environmental & 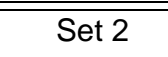 \\
\hline & 1771013 & $14.0-15.0$ & Soil & Environmental & Set 2 \\
\hline
\end{tabular}


Table D.11-1

Samples Collected at CAS 19-23-01, Mud Pit and Cellar

(Page 2 of 2)

\begin{tabular}{|c|c|c|c|c|c|}
\hline $\begin{array}{c}\text { Sample } \\
\text { Location }\end{array}$ & $\begin{array}{l}\text { Sample } \\
\text { Number }\end{array}$ & $\begin{array}{l}\text { Depth } \\
\text { (ft bgs) }\end{array}$ & Matrix & Purpose & Analyses \\
\hline \multirow{2}{*}{112} & 1771014 & $11.0-12.0$ & Soil & Environmental & Set 2 \\
\hline & $177 \mid 015$ & $12.0-13.0$ & Soil & Environmental & Set 2 \\
\hline \multicolumn{6}{|c|}{ QC Samples } \\
\hline N/A & $177 \mid 301$ & N/A & Water & Field Blank & Set 1 \\
\hline N/A & $177 \mid 302$ & $\mathrm{~N} / \mathrm{A}$ & Water & Trip Blank & VOCs \\
\hline
\end{tabular}

Set 1 = Gamma Spectroscopy, Isotopic Uranium, Isotopic Plutonium, Strontium-90

Set 2 = VOCs, SVOCs, RCRA Metals, Beryllium, TPH-DRO, TPH-GRO, PCBs, Gamma Spectroscopy, Isotopic Uranium, Isotopic Plutonium, Strontium-90

DRO = Diesel-range organics

$\mathrm{ft}$ bgs $=$ Feet below ground surface

GRO = Gasoline-range organics

N/A = Not applicable

$\mathrm{PCB}=$ Polychlorinated biphenyl
$\mathrm{QC}=$ Quality control

RCRA = Resource Conservation and Recovery Act

SVOC $=$ Semivolatile organic compound

$\mathrm{TPH}=$ Total petroleum hydrocarbons

VOC $=$ Volatile organic compound

\section{D.11.1.1 Field Screening}

Investigation samples were screened for total alpha and beta/gamma radiation. The FSRs were compared to FSLs and no exceedences were identified.

\section{D.11.1.2 Visual Inspections}

No spills, staining, disturbances of soil, or other indications of potential contamination were identified during the inspection of CAS 19-23-01 and site conditions were unchanged from previous field visits. The backfilled cellar was inspected to identify exposures of the cellar casing and to assess the orientation of potential buried borehole casing for sample location selection and drilling purposes.

\section{D.11.1.3 Sample Collection}

Decision I environmental sampling activities included the collection of random samples at the backfilled mud pit using a backhoe and biased samples at the cellar (Figure D.11-1) using a sonic drill rig. 


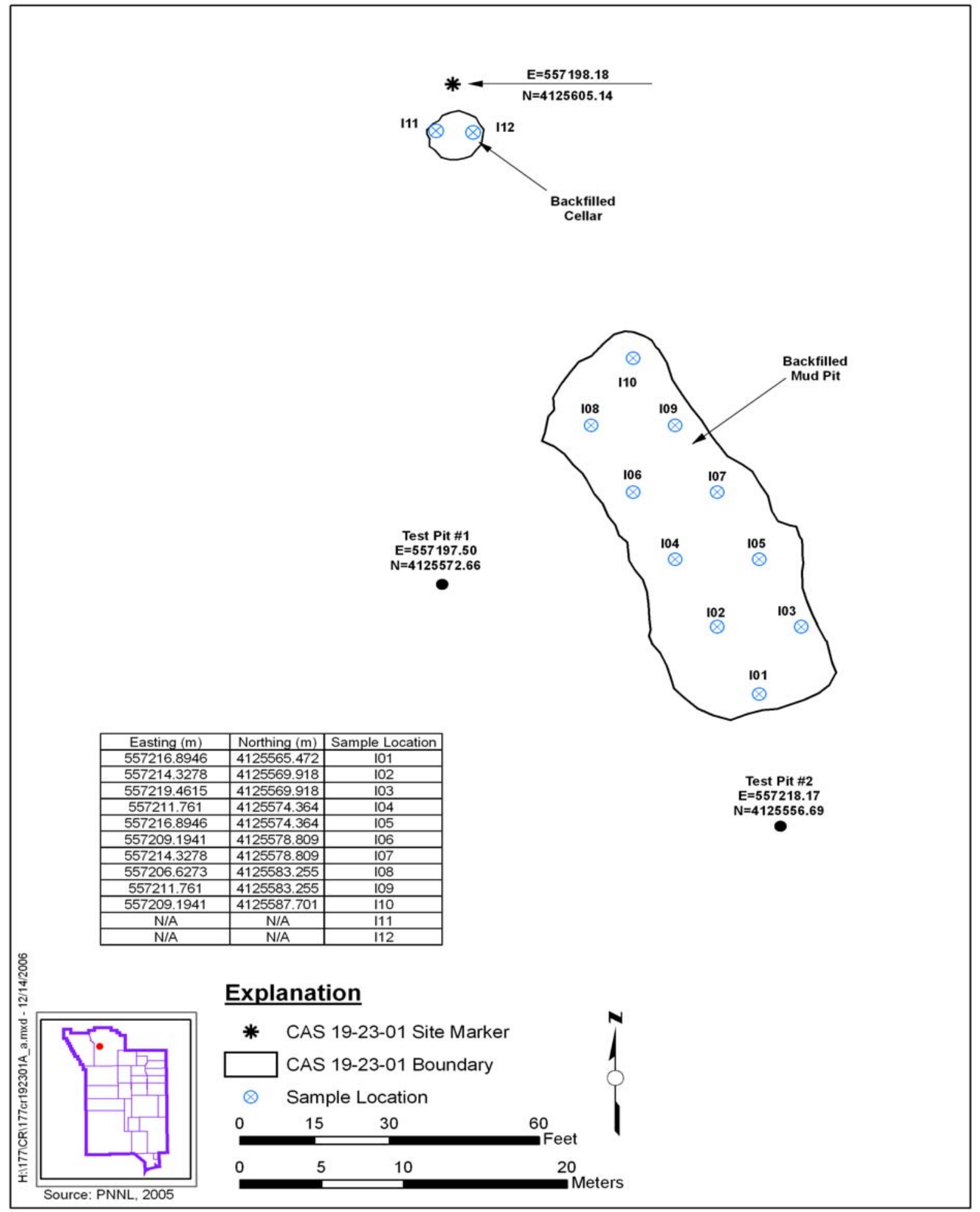

Figure D.11-1

CAS 19-23-01 Sample Location Map 
Because the boundaries of the backfilled mud pit were obscure, three potential mud pit perimeters (Layouts A, B, and C) were investigated before staking sample locations. Two potholes were excavated to determine which perimeter best represented the mud pit. Caliche/native soil was encountered at approximately $2.5 \mathrm{ft}$ bgs at Test Pit \#1 (Figure D.11-1), which was excavated at the edge of the largest perimeter (Layout C); and at Test Pit \#2 (Figure D.11-1), which was excavated at the edge of the second largest perimeter (Layout B). Layout A (Figure D.11-1) was chosen to represent the mud pit because the two test locations encountered native soil at a shallow depth and did not show any evidence of an interface with drilling mud/cuttings. Layout $\mathrm{A}$ is represented at the ground surface by a dirt mound that extends approximately 2.0 to $3.0 \mathrm{ft}$ above grade.

Eleven Decision I samples including 1 FD were collected from 10 locations (I01 through I10) within the estimated perimeter of the mud pit. The trench walls and soils brought to the surface through backhoe excavation were monitored to identify the interface between backfill material and drilling mud/cuttings. The depth to the interface ranged from approximately 3 to $6 \mathrm{ft}$ bgs. This variation can be attributed to the original excavation/construction of the mud pit and to the placement of sample locations (e.g., near the center or walls/berms of the mud pit). Soil collected consisted mostly of a gray silty-sand that ranged from poorly consolidated to moderately consolidated (or clumpy) and often exhibited layering. The soil collected is suspected to represent drill cuttings. Debris (e.g., t-posts, wood, wire/cables, rope) was encountered at several locations just above the identified interface.

Four Decision I environmental samples were collected at the cellar. One subsurface sample was collected from each borehole (I11 and I12) at the interface with the cellar bottom. These locations were determined based on the expected orientation of the borehole casing, which is expected to trend west-southwest towards the associated U-19ys ground zero. Two deeper subsurface samples were collected from the same boreholes to obtain information regarding the vertical extent of potentially released contamination. Each borehole was drilled to a depth of $15 \mathrm{ft}$ bgs. Core material was monitored during drilling and the interface with the cellar bottom was identified at 12 to $13 \mathrm{ft}$ bgs, marked by a lithology change from backfilled soil to a layer (several inches thick) of potential grout. Abundant plant material identified above the interface at location I12 also supports the interpretation that this boundary represents the cellar bottom. The shallower subsurface samples were collected 
directly above the grout layer (12 to $13 \mathrm{ft}$ bgs at I11 and 11 to $12 \mathrm{ft}$ bgs at I12), and the deeper subsurface samples were collected below the interface (14 to $15 \mathrm{ft}$ bgs at I11; 12 to $13 \mathrm{ft}$ bgs at I12).

\section{D.11.2 Investigation Results}

The following sections provide analytical results from the samples collected to complete investigation activities as outlined in the CAU 177 SAFER Plan (NNSA/NSO, 2006b). Investigation samples were analyzed for the SAFER-specified COPCs for cellars, which included VOCs, SVOCs, TPH-DRO and -GRO, RCRA metals, gamma-emitting radionuclides, isotopic U, isotopic Pu, and Sr-90; and mud pits, which included only the radiological analytes. Beryllium and PCBs were added parameters to the cellar suite, because these contaminants are a common concern at the NTS.

Table D.11-1 lists the sample-specific analytical suite for CAS 19-23-01. Analytical results from the soil samples with concentrations exceeding MDCs are summarized in the following sections.

For the judgmental samples at the cellar component of the CAS, an evaluation was conducted on all contaminants detected above MDCs by comparing individual concentration or activity results against the FALs to determine if a constituent is a COC. The FALs were established as the corresponding PAL concentrations or activities if the contaminant concentrations were below their respective PALs.

For the probabilistic samples at the mud pit, any COPC that has a 95 percent UCL of the average concentration exceeding the FAL will result in that COPC being designated as a COC. As stipulated in the CAU 177 SAFER Plan, UCLs were only calculated for a COPC if it was detected in any sample within any CAS at a concentration equal to or exceeding the PAL (NNSA/NSO, 2006b). If COPCs were not detected in any mud pit sample, at a concentration that exceeded the PAL, then it will be concluded that no COCs are present.

\section{D.11.2.1 Volatile Organic Compounds}

Analytical results for VOCs in soil samples collected from the cellar that were detected above MDCs are presented in Table D.11-2. No VOCs were detected at concentrations exceeding the respective PALs; therefore, the FALs were established as the corresponding PALs. 
Table D.11-2

Soil Sample Results for Total VOCs Detected Above Minimum Detectable Concentrations at CAS 19-23-01, Mud Pit and Cellar

\begin{tabular}{|c|c|c|c|c|c|c|c|}
\hline \multirow[b]{2}{*}{$\begin{array}{c}\text { Sample } \\
\text { Location }\end{array}$} & \multirow[b]{2}{*}{$\begin{array}{l}\text { Sample } \\
\text { Number }\end{array}$} & \multirow[b]{2}{*}{$\begin{array}{l}\text { Depth } \\
\text { (ft bgs) }\end{array}$} & \multicolumn{5}{|c|}{ Contaminants of Potential Concern $(\mu \mathrm{g} / \mathrm{kg})$} \\
\hline & & & 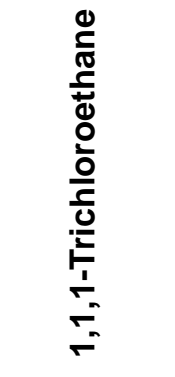 & 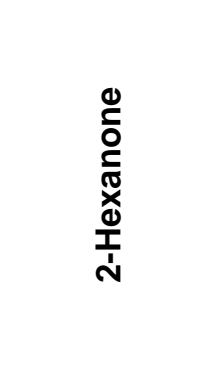 & 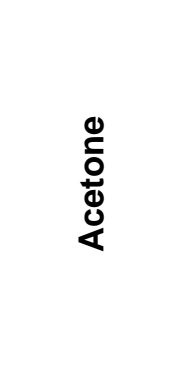 & $\begin{array}{l}\text { 튼 } \\
\frac{0}{0} \\
\frac{0}{0} \\
\frac{c}{U}\end{array}$ & 离 \\
\hline \multicolumn{3}{|c|}{ Final Action Levels ${ }^{a}$} & $1,200,000$ & $110,000,000$ & $54,000,000$ & 470 & $1,700,000$ \\
\hline \multicolumn{8}{|c|}{ Cellar Samples } \\
\hline \multirow{2}{*}{111} & 1771012 & $12.0-13.0$ & $0.342(\mathrm{~J})$ & 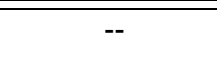 & $8.05(\mathrm{~J})$ & 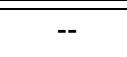 & $0.541(\mathrm{~J})$ \\
\hline & $177 \mid 013$ & $14.0-15.0$ & -- & $10.3(\mathrm{~J})$ & $2.82(\mathrm{~J})$ & -- & $0.513(\mathrm{~J})$ \\
\hline 112 & 1771015 & $12.0-13.0$ & -- & -- & -- & $0.27(\mathrm{~J})$ & -- \\
\hline
\end{tabular}

a'Based on U.S. Environmental Protection Agency, Region 9 Preliminary Remediation Goals (PRGs) (EPA, 2004).

$\mathrm{ft}$ bgs $=$ Feet below ground surface $\mu \mathrm{g} / \mathrm{kg}=$ Milligrams per kilogram

$--=$ Not detected above minimum detectable concentrations.

$\mathrm{J}=$ Estimated value.

\section{D.11.2.2 Semivolatile Organic Compounds}

Analytical results from sample $177 \mathrm{I} 012$ collected at 12.0 to $13.0 \mathrm{ft}$ bgs detected bis(2-Ethylhexyl)phthalate (363 $\mu \mathrm{g} / \mathrm{kg})$, di-n-butylphthalate (68.1 $\mu \mathrm{g} / \mathrm{kg}$, estimated value), fluoranthene (75.1 $\mu \mathrm{g} / \mathrm{kg}$, estimated value), phenantherene (32.6 $\mu \mathrm{g} / \mathrm{kg}$, estimated value), and pyrene (200 $\mu \mathrm{g} / \mathrm{kg}$, estimated value) above MDCs; however, no SVOCs were detected at concentrations exceeding the respective PALs. Therefore, the FALs were established as the corresponding PALs.

\section{D.11.2.3 Total Petroleum Hydrocarbons}

The TPH-DRO analytical results for soil samples collected from the cellar that were detected above MDCs are presented in Table D.11-3. One interface subsurface sample (12 to $13 \mathrm{ft}$ bgs) and one deeper subsurface sample (14 to $15 \mathrm{ft}$ bgs) collected at location I11 exceeded the PAL of $100 \mathrm{mg} / \mathrm{kg}$ for TPH-DRO. The TPH-DRO was moved on to a Tier 2 evaluation and FALs were established for the hazardous constituents of TPH-DRO at the corresponding PAL concentrations. Concentrations of 
Table D.11-3

Soil Sample Results for TPH-DRO Detected Above Minimum Detectable Concentrations at CAS 19-23-01, Mud Pit and Cellar

\begin{tabular}{|c|c|c|c|}
\hline \multirow{2}{*}{$\begin{array}{l}\text { Sample } \\
\text { Location }\end{array}$} & \multirow{2}{*}{$\begin{array}{l}\text { Sample } \\
\text { Number }\end{array}$} & \multirow{2}{*}{$\begin{array}{l}\text { Depth } \\
\text { (ft bgs) }\end{array}$} & Contaminants of Potential Concern ( $\mathrm{mg} / \mathrm{kg})$ \\
\hline & & & Diesel-Range Organics \\
\hline \multicolumn{3}{|c|}{ Preliminary Action Levels ${ }^{a}$} & 100 \\
\hline \multicolumn{4}{|c|}{ Cellar Samples } \\
\hline \multirow{2}{*}{ I11 } & 1771012 & $12.0-13.0$ & 382 \\
\hline & 1771013 & $14.0-15.0$ & 163 \\
\hline \multirow{2}{*}{112} & 1771014 & $11.0-12.0$ & 43 \\
\hline & $177 \mid 015$ & $12.0-13.0$ & 20.8 \\
\hline
\end{tabular}

aBased on Nevada Administrative Code, "Contamination of Soil: Establishment of Action Levels" (NAC, 2006).

$\mathrm{ft}$ bgs $=$ Feet below ground surface

$\mathrm{mg} / \mathrm{kg}=$ Milligrams per kilogram

the hazardous constituents of TPH-DRO did not exceed FALs; therefore, TPH-DRO is not considered a COC.

\section{D.11.2.4 Polychlorinated Biphenyls}

Analytical results for soil sample $177 \mathrm{I} 015$ collected at 12.0 to $13.0 \mathrm{ft}$ bgs at the cellar detected Aroclor 1254 and Aroclor 1260 (13.6 and $9.1 \mu \mathrm{g} / \mathrm{kg}$, respectively, estimated values) above MDCs. The calculated total Aroclor for sample 177I015 (22.7 $\mu \mathrm{g} / \mathrm{kg})$ did not exceed the PAL (740 $\mu \mathrm{g} / \mathrm{kg})$; therefore, the FAL was established as the corresponding PAL.

\section{D.11.2.5 RCRA Metals and Beryllium}

Analytical results for RCRA metals and beryllium in soil samples collected from the cellar that were detected above MDCs are presented in Table D.11-4. None of the metals were detected at concentrations exceeding the respective PALs; therefore, the FALs were established as the corresponding PALs. 
Table D.11-4

Soil Sample Results for Metals Detected Above Minimum Detectable Concentrations at CAS 19-23-01, Mud Pit and Cellar

\begin{tabular}{|c|c|c|c|c|c|c|c|c|c|c|}
\hline \multirow{2}{*}{ 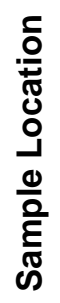 } & \multirow{2}{*}{ 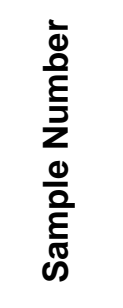 } & \multirow{2}{*}{ 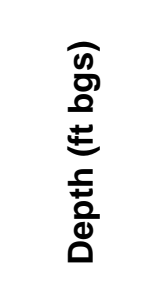 } & \multicolumn{8}{|c|}{ Contaminants of Potential Concern $(\mathrm{mg} / \mathrm{kg})$} \\
\hline & & & 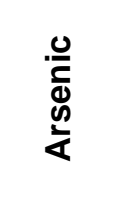 & 歺 & 芷 & 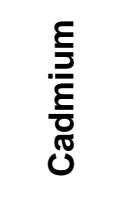 & 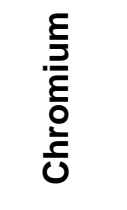 & శ్త్ర & 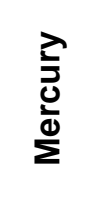 & $\frac{\bar{\Phi}}{\bar{\omega}}$ \\
\hline \multicolumn{3}{|c|}{ Final Action Levels } & $23^{a}$ & $67,000^{b}$ & $1,900^{b}$ & $450^{b}$ & $450^{b}$ & $800^{b}$ & $310^{b}$ & $5,100^{b}$ \\
\hline \multicolumn{11}{|c|}{ Cellar Samples } \\
\hline \multirow{2}{*}{ I11 } & 1771012 & $12.0-13.0$ & 3.8 & 83.9 & 0.57 & 0.24 & 8.5 & 15.2 & 0.033 & 0.14 \\
\hline & 1771013 & $14.0-15.0$ & 4.2 & 108 & 0.69 & 0.17 & 6.1 & 8.7 & 0.03 & -- \\
\hline \multirow{2}{*}{112} & 1771014 & $11.0-12.0$ & 3 & 74.3 & 0.48 & 0.12 & 5.8 & 7.7 & 0.026 & 0.62 \\
\hline & 1771015 & $12.0-13.0$ & $6.3(\mathrm{~J}-)$ & 176 & 0.97 (J-) & $0.2(\mathrm{~J}-)$ & 8.7 (J-) & $9.3(\mathrm{~J}-)$ & 0.033 & $0.34(\mathrm{~J}-)$ \\
\hline
\end{tabular}

aBased on the background concentrations for metals. Background is considered the mean plus two times the standard deviation for sediment samples collected by the Nevada Bureau of Mines and Geology throughout the Nevada Test and Training Range (NBMG, 1998; Moore, 1999).

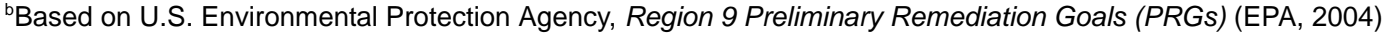

$\mathrm{ft}$ bgs $=$ Feet below ground surface

$\mathrm{mg} / \mathrm{kg}=$ Milligrams per kilogram

$--=$ Not detected above minimum detectable concentrations

$\mathrm{J}-=$ The result is an estimated quantity, but may be biased low.

\section{D.11.2.6 Gamma-Emitting Radionuclides}

Analytical results for gamma-emitting radionuclides in soil samples from the mud pit and cellar that were detected above MDCs are presented in Table D.11-5. Because no gamma-emitting radionuclide COPCs were detected in any mud pit sample at a concentration equal to or exceeding the PAL, UCLs were not calculated for the mud pit component of this CAS and it is determined that no COCs exist. Because no gamma-emitting radionuclide concentrations in cellar samples exceeded the respective PALs, the FALs were established as the corresponding PALs.

\section{D.11.2.7 Plutonium, Strontium-90, and Uranium Isotopes}

Isotopic $U$ analytical results for soil samples from the mud pit and cellar that were detected above MDCs are presented in Table D.11-6. Because no Pu, U, or Sr-90 isotope COPCs were detected in any mud pit sample at a concentration equal to or exceeding the PAL, UCLs were not calculated for the mud pit component of this CAS, and it is determined that no COCs exist. Because no Sr-90, 
Table D.11-5

Soil Sample Results for Gamma-Emitting Radionuclides Detected Above Minimum Detectable Concentrations at CAS 19-23-01, Mud Pit and Cellar

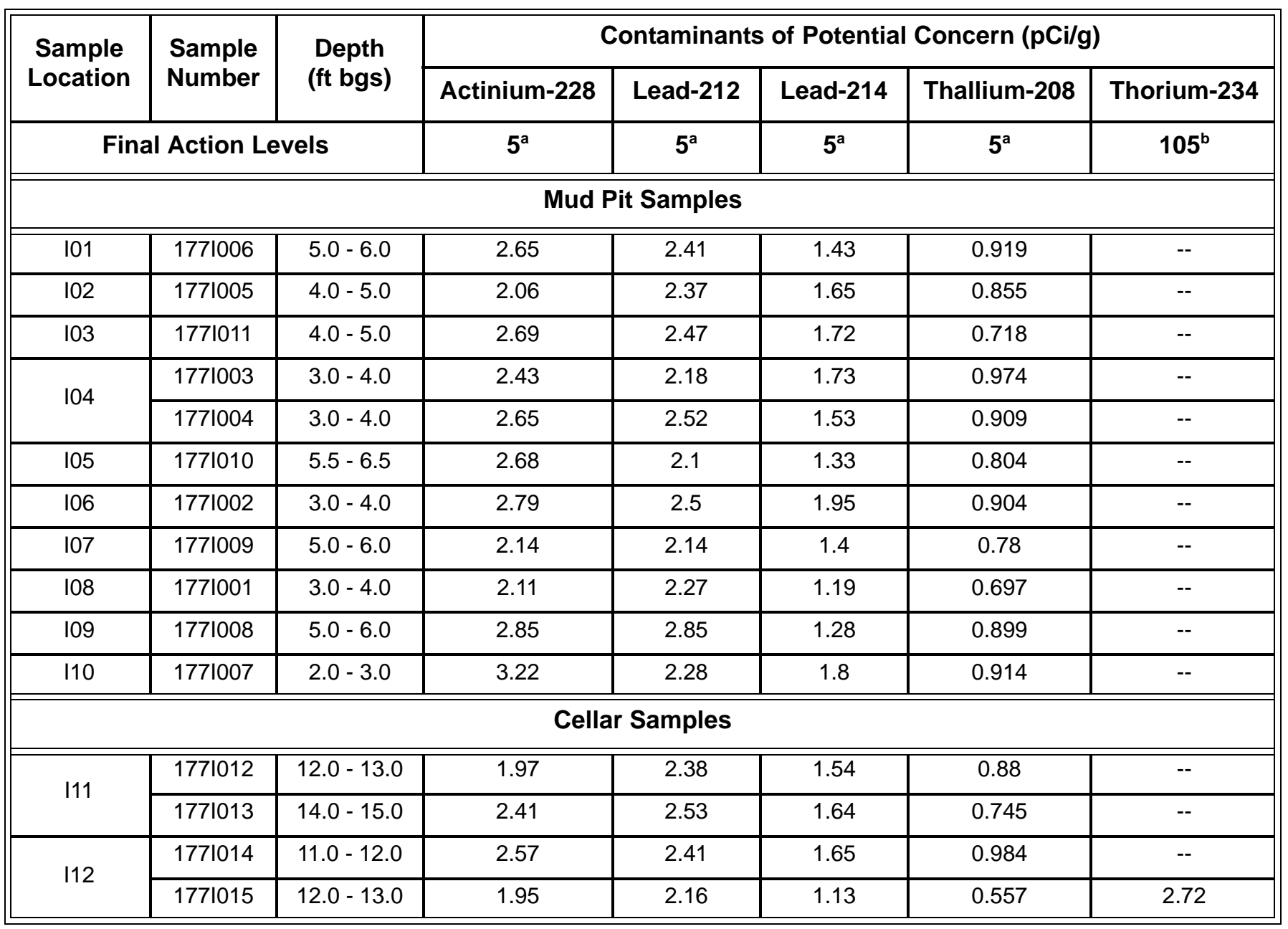

${ }^{a}$ Taken from the generic guidelines for residual concentrations of actinium-228, bismuth-214, lead-212, lead-214, thallium-208, and thorium-232, as found in Chapter IV of U.S. Department of Energy Order 5400.5, Change 2, Radiation Protection of the Public and Environment (DOE, 1993).

${ }^{\mathrm{b}}$ Taken from the construction, commercial, industrial land-use scenario in Table 2.1 of the National Council on Radiation Protection and Measurement Report No. 129, Recommended Screening Limits for Contaminated Surface Soil and Review Factors Relevant to Site-Specific Studies (NCRP, 1999). The values provided in this source document were scaled to a 25-millirem-per-year dose.

$\mathrm{ft}$ bgs $=$ Feet below ground surface

$\mathrm{pCi} / \mathrm{g}=$ Picocuries per gram

-- = Not detected above minimum detectable concentrations

isotopic Pu, or isotopic $\mathrm{U}$ concentrations exceeded the respective PALs, the FALs were established as the corresponding PALs. 
Table D.11-6

Soil Sample Results for Isotopic Uranium Detected Above Minimum Detectable Concentration at CAS 19-23-01, Mud Pit and Cellar

\begin{tabular}{|c|c|c|c|c|c|}
\hline \multirow{2}{*}{$\begin{array}{l}\text { Sample } \\
\text { Location }\end{array}$} & \multirow{2}{*}{$\begin{array}{l}\text { Sample } \\
\text { Number }\end{array}$} & \multirow{2}{*}{$\begin{array}{l}\text { Depth } \\
\text { (ft bgs) }\end{array}$} & \multicolumn{3}{|c|}{ Contaminants of Potential Concern (pCi/g) } \\
\hline & & & Uranium-234 & Uranium-235 & Uranium-238 \\
\hline \multicolumn{3}{|c|}{ Final Action Levels ${ }^{a}$} & 143 & 17.6 & 105 \\
\hline \multicolumn{6}{|c|}{ Mud Pit Samples } \\
\hline 101 & 1771006 & $5.0-6.0$ & 1.34 & -- & 1.24 \\
\hline 102 & 1771005 & $4.0-5.0$ & 1.49 & -- & 1.5 \\
\hline 103 & $177 \mid 011$ & $4.0-5.0$ & 1.66 & -- & 2.15 \\
\hline \multirow{2}{*}{104} & 1771003 & $3.0-4.0$ & 1.59 & -- & 1.64 \\
\hline & 1771004 & $3.0-4.0$ & 1.5 & -- & 1.69 \\
\hline 105 & 1771010 & $5.5-6.5$ & 1.29 & -- & 1.39 \\
\hline 106 & 1771002 & $3.0-4.0$ & 1.48 & -- & 1.5 \\
\hline 107 & 1771009 & $5.0-6.0$ & 1.47 & -- & 1.27 \\
\hline 108 & 1771001 & $3.0-4.0$ & 1.38 & -- & 1.66 \\
\hline 109 & 1771008 & $5.0-6.0$ & 1.1 & & 1.01 \\
\hline 110 & 1771007 & $2.0-3.0$ & 1.15 & -- & 1.34 \\
\hline \multicolumn{6}{|c|}{ Cellar Samples } \\
\hline \multirow{2}{*}{ I11 } & 1771012 & $12.0-13.0$ & 1.43 & -- & 1.33 \\
\hline & 1771013 & $14.0-15.0$ & 1.39 & 0.0987 & 1.45 \\
\hline \multirow{2}{*}{112} & 1771014 & $11.0-12.0$ & 1.21 & 0.0949 & 1.14 \\
\hline & 1771015 & $12.0-13.0$ & 1.21 & 0.0612 & 1.21 \\
\hline
\end{tabular}

${ }^{a}$ Taken from the construction, commercial, industrial land-use scenario in Table 2.1 of the National Council on Radiation Protection and Measurement Report No. 129, Recommended Screening Limits for Contaminated Surface Soil and Review Factors Relevant to Site-Specific Studies (NCRP, 1999). The values provided in this source document were scaled to a 25-millirem-per-year dose.

$\mathrm{ft}$ bgs $=$ Feet below ground surface

$\mathrm{pCi} / \mathrm{g}=$ Picocuries per gram

$--=$ Not detected above minimum detectable concentrations

\section{D.11.3 Nature and Extent of Contamination}

Based on the analytical results, no COCs were identified in the environmental soils samples collected at CAS 19-23-01. 


\section{D.11.4 Revised Conceptual Site Model}

The CAU 177 SAFER Plan requirements were met at this CAS, and no revisions were necessary to the CSM. 


\section{D.12.0 CAS 19-23-02, Cellar and Waste Storage Area}

Corrective Action Site 19-23-02 is located in Area 19 (Figure 1-1), several hundred feet northeast of CAS 19-23-01. The CAS components identified for investigation include a backfilled cellar that is not fenced or posted. The location of the cellar is marked by a steel pole at its center, but it is difficult to see due to the vegetation cover. The area immediately surrounding the steel pole is slightly subsided indicating that the cellar casing may have been removed. There is no debris present at this CAS.

\section{D.12.1 Corrective Action Investigation}

Five characterization samples including one FD were collected at the cellar during investigation activities at CAS 19-23-02. The sample IDs, locations, types, and analyses are listed in Table D.12-1. The specific CAI activities conducted to satisfy the CAU 177 SAFER Plan requirements at this CAS are described in the following sections.

Table D.12-1

Samples Collected at CAS 19-23-02, Cellar and Waste Storage Area

\begin{tabular}{|c|c|c|c|c|c|}
\hline $\begin{array}{l}\text { Sample } \\
\text { Location }\end{array}$ & $\begin{array}{l}\text { Sample } \\
\text { Number }\end{array}$ & $\begin{array}{c}\text { Depth } \\
\text { (ft bgs) }\end{array}$ & Matrix & Purpose & Analyses \\
\hline \multicolumn{6}{|c|}{ Cellar Samples } \\
\hline \multirow{2}{*}{ J01 } & $177 \mathrm{J001}$ & $12.0-13.0$ & Soil & Environmental & Set 2 \\
\hline & $177 \mathrm{~J} 002$ & $14.0-15.0$ & Soil & Environmental, Full Lab QC & Set 2 \\
\hline \multirow{3}{*}{$\mathrm{J} 02$} & $177 \mathrm{~J} 003$ & $12.0-13.0$ & Soil & Environmental & Set 2 \\
\hline & $177 \mathrm{~J} 004$ & $14.0-15.0$ & Soil & Environmental & Set 2 \\
\hline & $177 \mathrm{J005}$ & $14.0-15.0$ & Soil & Field Duplicate of \#177J004 & Set 2 \\
\hline
\end{tabular}

Set 2 = VOCs, SVOCs, RCRA Metals, Beryllium, TPH-DRO, TPH-GRO, PCBs, Gamma Spectroscopy, Isotopic Uranium, Isotopic Plutonium, Strontium-90

DRO = Diesel-range organics $\mathrm{ft}$ bgs = Feet below ground surface GRO = Gasoline-range organics $\mathrm{PCB}=$ Polychlorinated biphenyl $\mathrm{QC}=$ Quality control
RCRA = Resource Conservation and Recovery Act SVOC = Semivolatile organic compound $\mathrm{TPH}=$ Total petroleum hydrocarbons VOC $=$ Volatile organic compound 


\section{D.12.1.1 Field Screening}

Investigation samples were screened for total alpha and beta/gamma radiation. The FSRs were compared to FSLs and no exceedences were identified.

\section{D.12.1.2 Visual Inspections}

No spills, staining, or other indications of potential contamination were identified during the inspection of CAS 19-23-02 and site conditions were unchanged from previous field visits. The backfilled cellar was inspected to select sample locations, which are based on the expected orientation of potential buried borehole casing.

\section{D.12.1.3 Sample Collection}

Decision I environmental sampling activities included the collection of biased soil samples at the cellar (Figure D.12-1) using a sonic drill rig.

Five Decision I environmental samples were collected at the cellar from borehole locations J01 and J02, drilled within the southwest and southeast quadrants of the cellar, respectively. These locations were determined based on the expected orientation of the borehole casing, which is expected to trend due south towards the associated U-19ay ground zero. Two subsurface samples were collected from $\mathrm{J} 01$ and J02 to determine if there was a release to the cellar floor before backfilling. Three deeper subsurface samples (including one FD) were collected to obtain information regarding the vertical extent of potentially released contamination. Each borehole was drilled to $15 \mathrm{ft}$ bgs. Core material was monitored during drilling and the interface with the cellar bottom was identified at $12 \mathrm{ft}$ bgs, marked by a lithology change from pea gravel (backfill) to a fine brown sand that extended to at least $15 \mathrm{ft}$ bgs. String/rope debris identified at the interface of J01 also supports the interpretation that this boundary represents the cellar bottom. The shallower subsurface samples were collected from the fine sand at 12 to $13 \mathrm{ft}$ bgs, directly below the pea gravel interface, and the deeper subsurface samples were collected at 14 to $15 \mathrm{ft}$ bgs.

\section{D.12.2 Investigation Results}

The following sections provide analytical results from the samples collected to complete investigation activities as outlined in the CAU 177 SAFER Plan (NNSA/NSO, 2006b). Investigation 


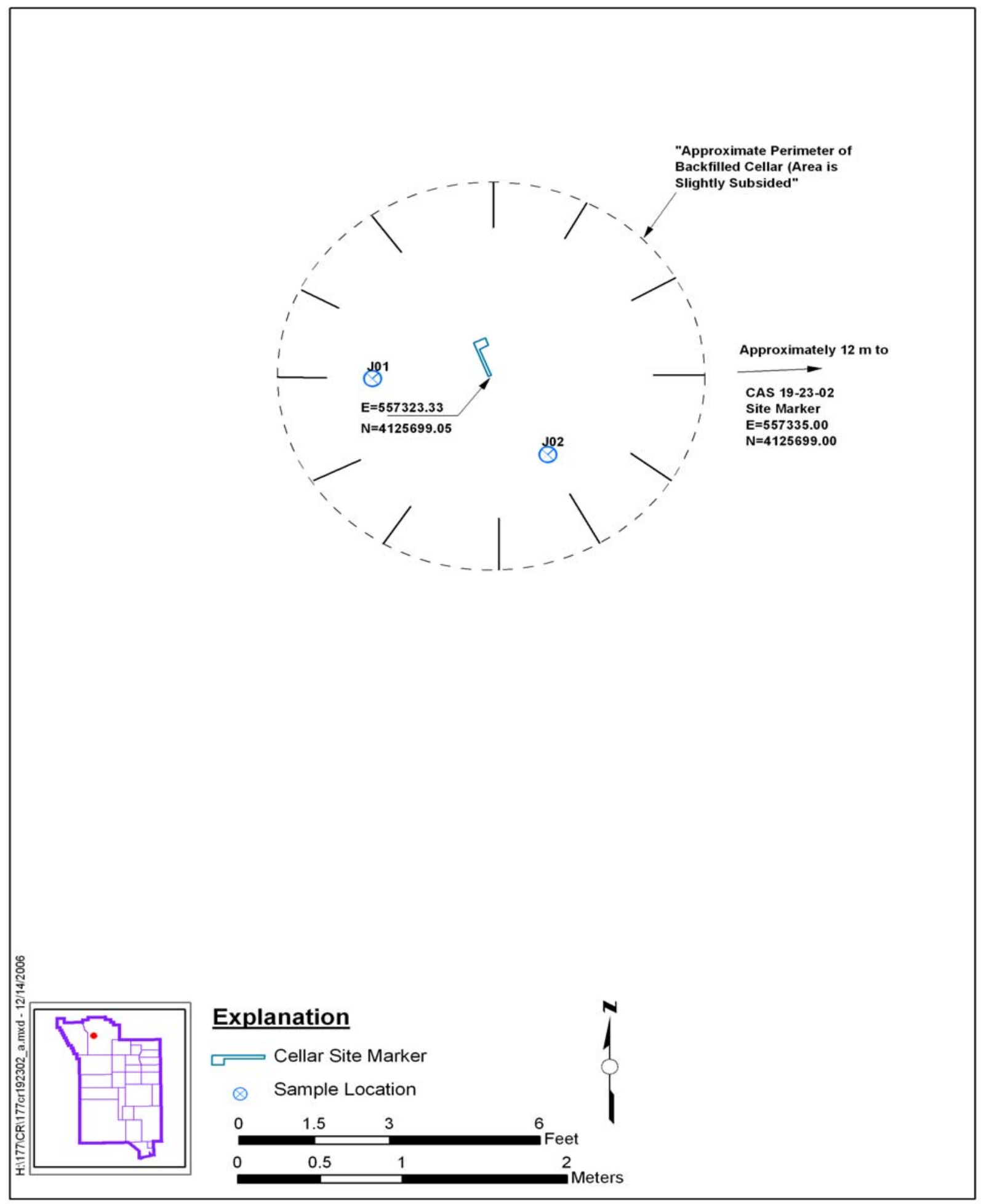

Figure D.12-1

CAS 19-23-02 Sample Location Map 
samples were analyzed for the SAFER-specified COPCs for cellars, which included VOCs, SVOCs, TPH-DRO and -GRO, RCRA metals, gamma-emitting radionuclides, isotopic U, isotopic $\mathrm{Pu}$, and Sr-90. Beryllium and PCBs were added parameters, because these contaminants are a common concern at the NTS. Table D.12-1 lists the sample-specific analytical suite for CAS 19-23-02.

Analytical results from the soil samples with concentrations exceeding MDCs are summarized in the following sections.

For the judgmental samples at the cellar, an evaluation was conducted on all contaminants detected above MDCs by comparing individual concentration or activity results against the FALs to determine if a constituent is a COC. The FALs were established as the corresponding PAL concentrations or activities if the contaminant concentrations were below respective PALs.

\section{D.12.2.1 Volatile Organic Compounds}

Analytical results for VOCs in soil samples collected from the cellar that were detected above MDCs are presented in Table D.12-2. No VOCs were detected at concentrations exceeding the respective PALs; therefore, the FALs were established at the corresponding PALs.

Table D.12-2

Soil Sample Results for Total VOCs Detected Above Minimum Detectable Concentrations at CAS 19-23-02, Cellar and Waste Storage Area

\begin{tabular}{||c|c|c|c|c|}
\hline \multirow{2}{*}{$\begin{array}{c}\text { Sample } \\
\text { Location }\end{array}$} & \multirow{2}{*}{$\begin{array}{c}\text { Sample } \\
\text { Number }\end{array}$} & \multirow{2}{*}{$\begin{array}{c}\text { Depth } \\
\text { fft bgs) }\end{array}$} & \multicolumn{2}{|c|}{ Contaminants of Potential Concern $(\mu \mathrm{g} / \mathrm{kg})$} \\
\cline { 3 - 5 } & & Acetone & Chloroform \\
\hline \multicolumn{6}{|c|}{ Final Action Levels ${ }^{\mathbf{a}}$} & $\mathbf{5 4 , 0 0 0 , 0 0 0}$ & $\mathbf{4 7 0}$ \\
\hline \hline \multicolumn{5}{|c|}{ Cellar Samples } \\
\hline \hline \multirow{2}{*}{$\mathrm{J} 02$} & $177 \mathrm{~J} 003$ & $12.0-13.0$ & $5.62(\mathrm{~J})$ & $0.261(\mathrm{~J})$ \\
\cline { 3 - 5 } & $177 \mathrm{~J} 004$ & $14.0-15.0$ & -- & -- \\
\hline
\end{tabular}

aBased on U.S. Environmental Protection Agency, Region 9 Preliminary Remediation Goals (PRGs) (EPA, 2004).

$\mathrm{ft}$ bgs $=$ Feet below ground surface

$\mu \mathrm{g} / \mathrm{kg}=$ Micrograms per kilogram

-- = Not detected above minimum detectable concentrations

$\mathrm{J}=$ Estimated value 


\section{D.12.2.2 Semivolatile Organic Compounds}

Analytical results for SVOCs in soil samples collected from the cellar that were detected above MDCs are presented in Table D.12-3. No SVOCs were detected at concentrations exceeding the respective PALs; therefore, the FALs were established as the corresponding PALs.

Table D.12-3

Soil Sample Results for Total SVOCs Detected Above Minimum Detectable Concentrations at CAS 19-23-02, Cellar and Waste Storage Area

\begin{tabular}{|c|c|c|c|c|}
\hline \multirow{2}{*}{$\begin{array}{c}\text { Sample } \\
\text { Location }\end{array}$} & \multirow{2}{*}{$\begin{array}{c}\text { Sample } \\
\text { Number }\end{array}$} & \multirow{2}{*}{$\begin{array}{l}\text { Depth } \\
\text { (ft bgs) }\end{array}$} & \multicolumn{2}{|c|}{ Contaminants of Potential Concern $(\mu \mathrm{g} / \mathrm{kg})$} \\
\hline & & & Bis(2-Ethylhexyl)Phthalate & Fluoranthene \\
\hline \multicolumn{3}{|c|}{ Final Action Levels ${ }^{a}$} & 120,000 & $22,000,000$ \\
\hline \multicolumn{5}{|c|}{ Cellar Samples } \\
\hline J01 & $177 \mathrm{~J} 002$ & $14.0-15.0$ & $301(\mathrm{~J})$ & $41.5(\mathrm{~J})$ \\
\hline $\mathrm{J} 02$ & 177J003 & $12.0-13.0$ & $109(\mathrm{~J})$ & -- \\
\hline
\end{tabular}

aBased on U.S. Environmental Protection Agency, Region 9 Preliminary Remediation Goals (PRGs) (EPA, 2004).

$\mathrm{ft}$ bgs = Feet below ground surface $\mu \mathrm{g} / \mathrm{kg}=$ Milligrams per kilogram

$--=$ Not detected above minimum detectable concentrations.

$\mathrm{J}=$ Estimated value.

\section{D.12.2.3 Total Petroleum Hydrocarbons}

Analytical results for TPH-DRO in soil samples collected from the cellar that were detected above MDCs are presented in Table D.12-4. Concentrations of TPH-DRO were not detected at concentrations exceeding the respective PAL; therefore, the FAL was established at the corresponding PAL concentration. Concentrations of TPH-GRO were not detected above the respective laboratory MDCs at this CAS.

\section{D.12.2.4 Polychlorinated Biphenyls}

Analytical results for soil sample $177 \mathrm{~J} 001$ collected at 12.0 to $13.0 \mathrm{ft}$ bgs at the cellar detected Aroclor 1254 and Aroclor 1260 (3.5 and $2.9 \mu \mathrm{g} / \mathrm{kg}$, respectively, estimated values) above MDCs. The calculated total Aroclor for sample 177J001 (6.4 $\mu \mathrm{g} / \mathrm{kg})$ did not exceed the PAL (740 $\mu \mathrm{g} / \mathrm{kg})$; therefore, the FAL was established as the corresponding PAL. 
Table D.12-4

Soil Sample Results for TPH-DRO Detected Above Minimum Detectable Concentrations at CAS 19-23-02, Cellar and Waste Storage Area

\begin{tabular}{|c|c|c|c|}
\hline \multirow{2}{*}{$\begin{array}{l}\text { Sample } \\
\text { Location }\end{array}$} & \multirow{2}{*}{$\begin{array}{l}\text { Sample } \\
\text { Number }\end{array}$} & \multirow{2}{*}{$\begin{array}{l}\text { Depth } \\
\text { (ft bgs) }\end{array}$} & Contaminants of Potential Concern (mg/kg) \\
\hline & & & Diesel-Range Organics \\
\hline \multicolumn{3}{|c|}{ Preliminary Action Levels ${ }^{a}$} & 100 \\
\hline \multicolumn{4}{|c|}{ Cellar Samples } \\
\hline \multirow{2}{*}{ J01 } & $177 \mathrm{~J} 001$ & $12.0-13.0$ & $4.44(\mathrm{~J})$ \\
\hline & $177 \mathrm{J002}$ & $14.0-15.0$ & $5.06(\mathrm{~J})$ \\
\hline \multirow{3}{*}{ J02 } & $177 \mathrm{J003}$ & $12.0-13.0$ & $8.63(\mathrm{~J})$ \\
\hline & $177 \mathrm{~J} 004$ & $14.0-15.0$ & $1.69(\mathrm{~J})$ \\
\hline & $177 \mathrm{~J} 005$ & $14.0-15.0$ & 12.9 \\
\hline
\end{tabular}

aBased on Nevada Administrative Code, "Contamination of Soil: Establishment of Action Levels" (NAC, 2006).

$\mathrm{ft}$ bgs $=$ Feet below ground surface $\mathrm{mg} / \mathrm{kg}=$ Milligrams per kilogram

$\mathrm{J}=$ Estimated value

\section{D.12.2.5 RCRA Metals and Beryllium}

Analytical results for RCRA metals and beryllium in soil samples collected from the cellar that were detected above MDCs are presented in Table D.12-5. None of the metals were detected at concentrations exceeding the respective PALs; therefore, the FALs were established as the corresponding PALs.

\section{D.12.2.6 Gamma-Emitting Radionuclides}

Analytical results for gamma-emitting radionuclides in soil samples collected from the cellar, that were detected above MDCs, are presented in Table D.12-6. No gamma-emitting radionuclide concentrations exceeded the respective PALs; therefore, the FALs were established as the corresponding PALs. 
Table D.12-5

Soil Sample Results for Metals Detected Above Minimum Detectable Concentrations at CAS 19-23-02, Cellar and Waste Storage Area

\begin{tabular}{|c|c|c|c|c|c|c|c|c|c|c|c|}
\hline \multirow{2}{*}{ 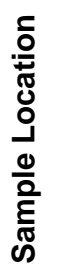 } & \multirow{2}{*}{ 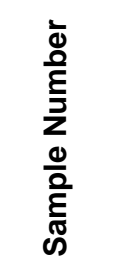 } & \multirow{2}{*}{ 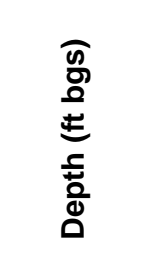 } & \multicolumn{9}{|c|}{ Contaminants of Potential Concern (mg/kg) } \\
\hline & & & $\begin{array}{l}\frac{0}{c} \\
\frac{0}{d} \\
\frac{\omega}{\alpha}\end{array}$ & 卢 & $\frac{\underline{\varepsilon}}{\stackrel{\underline{\Xi}}{\bar{\lambda}}}$ & $\frac{\mathfrak{E}}{\mathfrak{D}}$ & 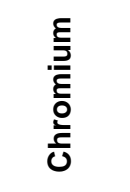 & శ్ర్త & $\begin{array}{l}\frac{\lambda}{J} \\
\frac{0}{d} \\
\sum\end{array}$ & 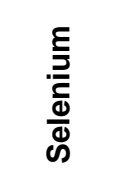 & $\frac{\grave{\Xi}}{\bar{c}}$ \\
\hline \multicolumn{3}{|c|}{ Final Action Levels } & $23^{a}$ & $67,000^{b}$ & $1,900^{b}$ & $450^{b}$ & $450^{b}$ & $800^{b}$ & $310^{b}$ & $5,100^{b}$ & $5,100^{b}$ \\
\hline \multicolumn{12}{|c|}{ Cellar Samples } \\
\hline \multirow{2}{*}{ J01 } & $177 \mathrm{J001}$ & $12.0-13.0$ & $4.9(\mathrm{~J}-)$ & 343 & $0.83(\mathrm{~J}-)$ & $0.37(\mathrm{~J}-)$ & $5.6(\mathrm{~J}-)$ & $8.1(\mathrm{~J}-)$ & 0.024 & $0.85(\mathrm{~J}-)$ & $7.7(\mathrm{~J}-)$ \\
\hline & $177 \mathrm{J002}$ & $14.0-15.0$ & $6(\mathrm{~J}-)$ & 214 & $1.1(\mathrm{~J}-)$ & $0.22(\mathrm{~J}-)$ & $9.8(\mathrm{~J}-)$ & $11.1(\mathrm{~J}-)$ & 0.032 & -- & $0.81(\mathrm{~J}-)$ \\
\hline \multirow{3}{*}{ J02 } & $177 \mathrm{~J} 003$ & $12.0-13.0$ & $6.8(\mathrm{~J}-)$ & 368 & $0.91(\mathrm{~J}-)$ & $0.23(\mathrm{~J}-)$ & $5.8(\mathrm{~J}-)$ & $20.4(\mathrm{~J}-)$ & 0.021 & -- & $0.44(\mathrm{~J}-)$ \\
\hline & $177 \mathrm{~J} 004$ & $14.0-15.0$ & $6.4(\mathrm{~J}-)$ & 178 & $1.2(\mathrm{~J}-)$ & $0.26(\mathrm{~J}-)$ & $10.8(\mathrm{~J}-)$ & $13.1(\mathrm{~J}-)$ & 0.02 & $\overline{--}$ & $0.29(\mathrm{~J}-)$ \\
\hline & 177J005 & $14.0-15.0$ & $5.5(\mathrm{~J}-)$ & 159 & $1.1(\mathrm{~J}-)$ & $0.24(\mathrm{~J}-)$ & $10.4(\mathrm{~J}-)$ & $11.1(\mathrm{~J}-)$ & 0.023 & -- & $0.34(\mathrm{~J}-)$ \\
\hline
\end{tabular}

aBased on the background concentrations for metals. Background is considered the mean plus two times the standard deviation for sediment samples collected by the Nevada Bureau of Mines and Geology throughout the Nevada Test and Training Range (NBMG, 1998; Moore, 1999).

${ }^{\mathrm{b}}$ Based on U.S. Environmental Protection Agency, Region 9 Preliminary Remediation Goals (PRGs) (EPA, 2004)

$\mathrm{ft}$ bgs = Feet below ground surface

$\mathrm{mg} / \mathrm{kg}=$ Milligrams per kilogram

$--=$ Not detected above minimum detectable concentrations.

$\mathrm{J}-=$ The result is an estimated quantity, but may be biased low.

Table D.12-6

Soil Sample Results for Gamma-Emitting Radionuclides Detected Above Minimum Detectable Concentrations at CAS 19-23-02, Cellar and Waste Storage Area (Page 1 of 2)

\begin{tabular}{|c|c|c|c|c|c|c|c|}
\hline \multirow[b]{2}{*}{$\begin{array}{c}\text { Sample } \\
\text { Location }\end{array}$} & \multirow[b]{2}{*}{$\begin{array}{l}\text { Sample } \\
\text { Number }\end{array}$} & \multirow[b]{2}{*}{$\begin{array}{l}\text { Depth } \\
\text { (ft bgs) }\end{array}$} & \multicolumn{5}{|c|}{ Contaminants of Potential Concern (pCi/g) } \\
\hline & & & 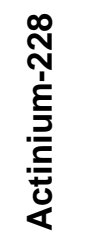 & 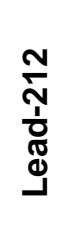 & 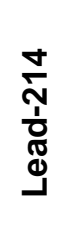 & 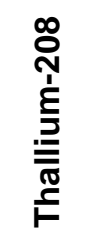 & 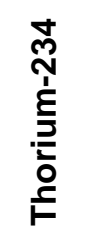 \\
\hline \multicolumn{3}{|c|}{ Final Action Levels } & $5^{a}$ & $5^{a}$ & $5^{\mathrm{a}}$ & $5^{\mathrm{a}}$ & $105^{b}$ \\
\hline \multicolumn{8}{|c|}{ Cellar Samples } \\
\hline \multicolumn{8}{|c|}{ Cellar Samples } \\
\hline \multirow{2}{*}{ J01 } & $177 \mathrm{~J} 001$ & $12.0-13.0$ & 1.33 & 1.55 & 1.11 & 0.415 & 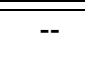 \\
\hline & $177 \mathrm{~J} 002$ & $14.0-15.0$ & 2.05 & 2.45 & 1.51 & 0.939 & 2.91 \\
\hline
\end{tabular}


Table D.12-6

Soil Sample Results for Gamma-Emitting Radionuclides Detected Above
Minimum Detectable Concentrations at CAS 19-23-02, Cellar and Waste Storage Area (Page 2 of 2)

\begin{tabular}{|c|c|c|c|c|c|c|c|}
\hline \multirow[b]{2}{*}{$\begin{array}{l}\text { Sample } \\
\text { Location }\end{array}$} & \multirow[b]{2}{*}{$\begin{array}{l}\text { Sample } \\
\text { Number }\end{array}$} & \multirow[b]{2}{*}{$\begin{array}{l}\text { Depth } \\
\text { (ft bgs) }\end{array}$} & \multicolumn{5}{|c|}{ Contaminants of Potential Concern (pCi/g) } \\
\hline & & & 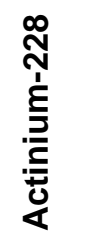 & 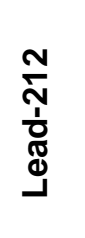 & 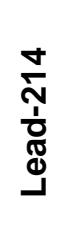 & 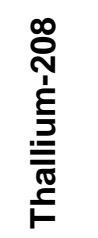 & 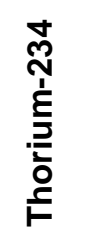 \\
\hline \multicolumn{3}{|c|}{ Final Action Levels } & $5^{a}$ & $5^{a}$ & $5^{a}$ & $5^{a}$ & $105^{b}$ \\
\hline \multicolumn{8}{|c|}{ Cellar Samples } \\
\hline \multirow{3}{*}{ J02 } & $177 \mathrm{~J} 003$ & $12.0-13.0$ & 2 & 1.65 & 1.12 & 0.69 & -- \\
\hline & $177 \mathrm{~J} 004$ & $14.0-15.0$ & 2.27 & 2.25 & 1.72 & 0.759 & -- \\
\hline & $177 \mathrm{J005}$ & $14.0-15.0$ & 2.23 & 2.38 & 1.43 & 0.693 & -- \\
\hline
\end{tabular}

aTaken from the generic guidelines for residual concentrations of actinium-228, bismuth-214, lead-212, lead-214, thallium-208, and thorium-232, as found in Chapter IV of U.S. Department of Energy Order 5400.5, Change 2, Radiation Protection of the Public and Environment (DOE, 1993).

${ }^{\mathrm{b}}$ Taken from the construction, commercial, industrial land-use scenario in Table 2.1 of the National Council on Radiation Protection and Measurement Report No. 129, Recommended Screening Limits for Contaminated Surface Soil and Review Factors Relevant to Site-Specific Studies (NCRP, 1999). The values provided in this source document were scaled to a 25-millirem-per-year dose.

$\mathrm{ft}$ bgs $=$ Feet below ground surface

$\mathrm{pCi} / \mathrm{g}=$ Picocuries per gram

-- = Not detected above minimum detectable concentrations.

\section{D.12.2.7 Plutonium, Strontium-90, and Uranium Isotopes}

Isotopic $\mathrm{U}$ analytical results for soil samples collected from the cellar that were detected above MDCs are presented in Table D.12-7. Concentrations of isotopic Pu and Sr-90 did not exceed the respective laboratory MDCs, and no isotopic U concentrations exceeded the respective PALs; therefore, the FALs were established as the corresponding PALs.

\section{D.12.3 Nature and Extent of Contamination}

Based on the analytical results, no COCs were identified in the environmental soils samples collected at CAS 19-23-02. 
Table D.12-7

Soil Sample Results for Isotopic Uranium Detected Above Minimum Detectable Concentrations at CAS 19-23-02, Cellar and Waste Storage Area

\begin{tabular}{|c|c|c|c|c|c|}
\hline \multirow{2}{*}{$\begin{array}{c}\text { Sample } \\
\text { Location }\end{array}$} & \multirow{2}{*}{$\begin{array}{l}\text { Sample } \\
\text { Number }\end{array}$} & \multirow{2}{*}{$\begin{array}{l}\text { Depth } \\
\text { (ft bgs) }\end{array}$} & \multicolumn{3}{|c|}{ Contaminants of Potential Concern (pCi/g) } \\
\hline & & & Uranium-234 & Uranium-235 & Uranium-238 \\
\hline \multicolumn{3}{|c|}{ Final Action Levels ${ }^{a}$} & 143 & 17.6 & 105 \\
\hline \multicolumn{6}{|c|}{ Cellar Samples } \\
\hline \multirow{2}{*}{ J01 } & $177 \mathrm{~J} 001$ & $12.0-13.0$ & 0.943 & 0.0576 & 0.992 \\
\hline & $177 \mathrm{~J} 002$ & $14.0-15.0$ & 1.22 & 0.0994 & 1.46 \\
\hline \multirow{3}{*}{$\mathrm{J} 02$} & $177 \mathrm{~J} 003$ & $12.0-13.0$ & 1.15 & 0.0478 & 1.14 \\
\hline & $177 \mathrm{~J} 004$ & $14.0-15.0$ & 1.3 & 0.0595 & 1.24 \\
\hline & $177 \mathrm{~J} 005$ & $14.0-15.0$ & 1.22 & 0.0844 & 1.34 \\
\hline
\end{tabular}

aTaken from the construction, commercial, industrial land-use scenario in Table 2.1 of the National Council on Radiation Protection and Measurement Report No. 129, Recommended Screening Limits for Contaminated Surface Soil and Review Factors Relevant to Site-Specific Studies (NCRP, 1999). The values provided in this source document were scaled to a 25-millirem-per-year dose.

$\mathrm{ft}$ bgs $=$ Feet below ground surface

$\mathrm{pCi} / \mathrm{g}=$ Picocuries per gram

\section{D.12.4 Revised Conceptual Site Model}

The CAU 177 SAFER Plan requirements were met at this CAS, and no revisions were necessary to the CSM. 


\section{D.13.0 CAS 19-23-03, Cellar with Casing}

Corrective Action Site 19-23-03 is located within a fenced URMA off of Dead Horse Flats Road in Area 19 (Figure 1-1). The CAS components identified for investigation include an open cellar.

\section{D.13.1 Corrective Action Investigation}

Three characterization samples including one FD were collected during investigation activities at CAS 19-23-03. The sample IDs, locations, types, and analyses are listed in Table D.13-1. The specific CAI activities conducted to satisfy the CAU 177 SAFER Plan requirements at this CAS are described in the following sections.

Table D.13-1

Samples Collected at CAS 19-23-03, Cellar with Casing

\begin{tabular}{|c|c|c|c|c|c|}
\hline $\begin{array}{c}\text { Sample } \\
\text { Location }\end{array}$ & $\begin{array}{l}\text { Sample } \\
\text { Number }\end{array}$ & $\begin{array}{c}\text { Depth } \\
\text { (ft bgs) }\end{array}$ & Matrix & Purpose & Analyses \\
\hline \multicolumn{6}{|c|}{ Cellar Samples } \\
\hline \multirow{2}{*}{ K01 } & $177 \mathrm{~K} 001$ & $0.0-0.25$ & 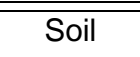 & Environmental & 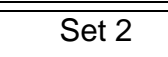 \\
\hline & $177 \mathrm{~K} 002$ & $0.0-0.25$ & Soil & Field Duplicate of \#177K001 & Set 2 \\
\hline K02 & $177 \mathrm{~K} 003$ & $0.0-0.25$ & Soil & Environmental, Full Lab QC & Set 2 \\
\hline \multicolumn{6}{|c|}{ QC Samples } \\
\hline $\bar{N} / \mathrm{A}$ & 177K301 & N/A & Water & Trip Blank & VOCs \\
\hline
\end{tabular}

Set 2 = VOCs, SVOCs, RCRA Metals, Beryllium, TPH-DRO, TPH-GRO, PCBs, Gamma Spectroscopy, Isotopic Uranium, Isotopic Plutonium, Strontium-90

DRO = Diesel-range organics $\mathrm{ft}$ bgs $=$ Feet below ground surface $\mathrm{GRO}=$ Gasoline-range organics $\mathrm{N} / \mathrm{A}=$ Not applicable

$\mathrm{PCB}=$ Polychlorinated biphenyl

\author{
$\mathrm{QC}=$ Quality control \\ RCRA = Resource Conservation and Recovery Act \\ SVOC $=$ Semivolatile organic compound \\ $\mathrm{TPH}=$ Total petroleum hydrocarbons \\ VOC $=$ Volatile organic compound
}

\section{D.13.1.1 Field Screening}

Investigation samples were screened for total alpha and beta/gamma radiation. The FSRs were compared to FSLs and no exceedences were identified. Soil and debris (miscellaneous wood, plastic, paper, and metal) at the surface of the cellar floor were screened for radioactivity, to ensure worker health and safety, and to guide selection of sample locations; however, no elevated readings were detected. 


\section{D.13.1.2 Visual Inspections}

No spills, staining, disturbances of soil, or other indications of potential contamination were identified during the inspection of CAS 19-23-03 and site conditions were unchanged from previous field visits. No visible biasing factors were identified at the cellar floor that would guide selection of sample locations. Instead, two sample locations were equally spaced on the most accessible side of the cellar floor.

\section{D.13.1.3 Sample Collection}

Decision I environmental sampling activities included the collection of biased soil samples at the cellar (Figure D.13-1) using a scoop and trowel.

Three Decision I environmental samples including one FD were collected from locations K01 and K02 to determine if there was a release to the cellar floor. These locations were equally spaced on the most accessible side of the cellar floor as no obvious biasing factors were identified. The surface samples were collected at 0.0 to $0.25 \mathrm{ft}$ bgs and consisted of coarse sand. The sample collected at location K02 additionally contained clumps of moist sand with slight orange staining/discoloration, possibly from a piece of corroded metal debris. Subsurface samples were not collected due to the presence of a concrete bottom 4 in. beneath the surface soil.

\section{D.13.2 Investigation Results}

The following sections provide analytical results from the samples collected to complete investigation activities as outlined in the CAU 177 SAFER Plan (NNSA/NSO, 2006b). Investigation samples were analyzed for the SAFER-specified COPCs for cellars, which included VOCs, SVOCs, TPH-DRO and -GRO, RCRA metals, gamma-emitting radionuclides, isotopic $\mathrm{U}$, isotopic $\mathrm{Pu}$, and Sr-90. Beryllium and PCBs were added parameters, because these contaminants are a common concern at the NTS. Table D.13-1 lists the sample-specific analytical suite for CAS 19-23-03. Analytical results from the soil samples with concentrations exceeding MDCs are summarized in the following sections.

For the judgmental samples at the cellar, an evaluation was conducted on all contaminants detected above MDCs by comparing individual concentration or activity results against the FALs to determine 


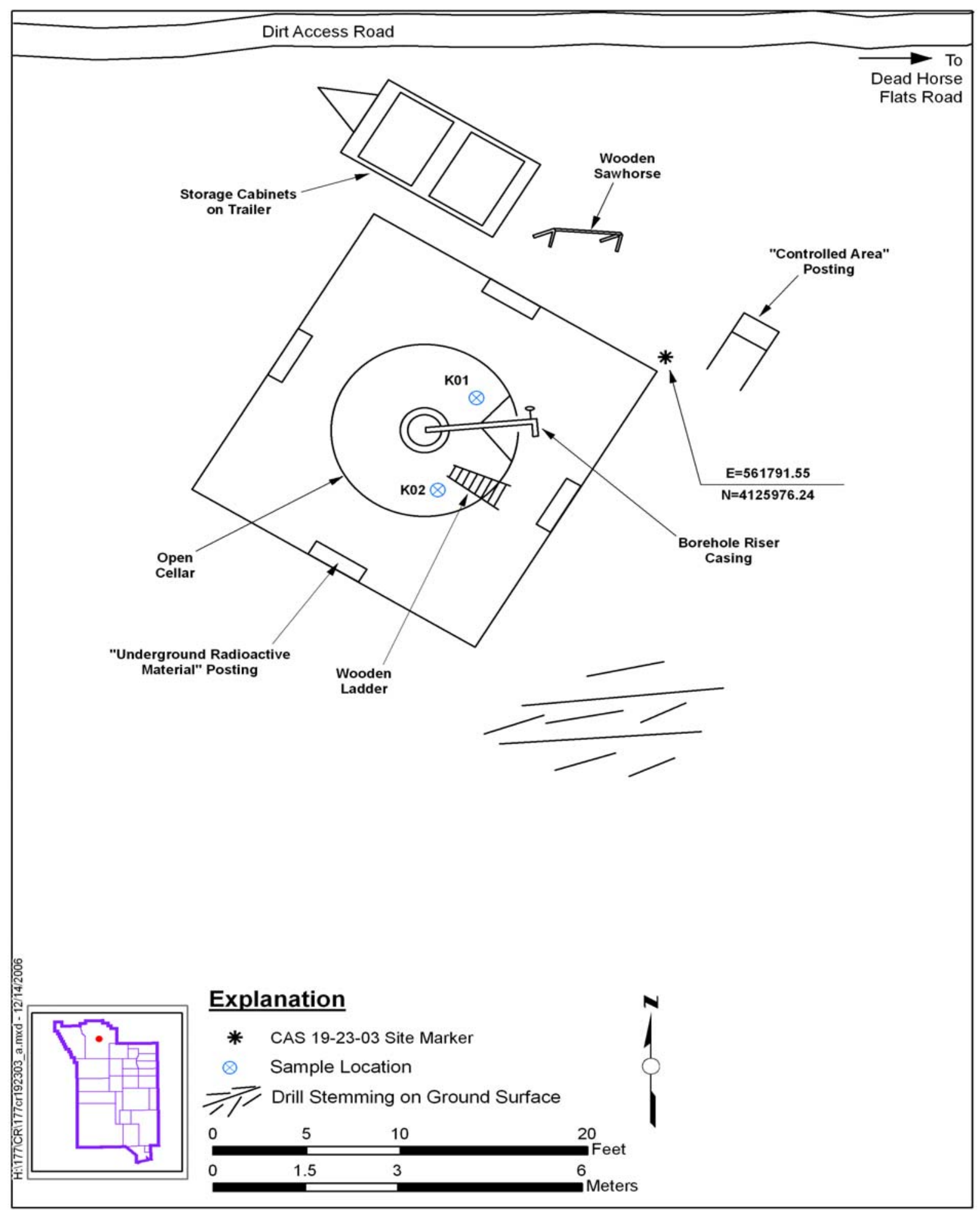

Figure D.13-1

CAS 19-23-03 Sample Location Map 
if a constituent is a COC. The FALs were established as the corresponding PALs concentrations or activities if the contaminant concentrations were below their respective PALs.

\section{D.13.2.1 Volatile Organic Compounds}

Analytical results for VOCs in soil samples collected from the cellar that were detected above MDCs are presented in Table D.13-2. No VOCs were detected at concentrations exceeding the respective PALs; therefore, the FALs were established as the corresponding PALs.

Table D.13-2

Soil Sample Results for Total VOCs Detected Above Minimum Detectable Concentrations at CAS 19-23-03, Cellar with Casing

\begin{tabular}{|c|c|c|c||}
\hline \multirow{2}{*}{$\begin{array}{c}\text { Sample } \\
\text { Location }\end{array}$} & \multirow{2}{*}{$\begin{array}{c}\text { Sample } \\
\text { Number }\end{array}$} & $\begin{array}{c}\text { Depth } \\
\text { (ft bgs) }\end{array}$ & Contaminants of Potential Concern $(\mu \mathbf{g} / \mathbf{k g})$ \\
\cline { 3 - 4 } & & $\mathbf{1 , 1 , 1 - T r i c h l o r o e t h a n e ~}$ \\
\hline \multicolumn{3}{|c|}{ Final Action Levels ${ }^{\mathbf{a}}$} & $\mathbf{1 , 2 0 0 , 0 0 0}$ \\
\hline \hline \multicolumn{3}{|c|}{ Cellar Samples } \\
\hline \hline \multirow{2}{*}{ K01 } & $177 \mathrm{~K} 001$ & $0.0-0.25$ & $1.78(\mathrm{~J})$ \\
\cline { 2 - 4 } & $177 \mathrm{~K} 002$ & $0.0-0.25$ & $1.67(\mathrm{~J})$ \\
\hline K02 & $177 \mathrm{~K} 003$ & $0.0-0.25$ & $3.34(\mathrm{~J})$ \\
\hline
\end{tabular}

${ }^{a}$ Based on U.S. Environmental Protection Agency, Region 9 Preliminary Remediation Goals (PRGs) (EPA, 2004).

$\mathrm{ft}$ bgs $=$ Feet below ground surface $\mu \mathrm{g} / \mathrm{kg}=$ Micrograms per kilogram $\mathrm{J}=$ Estimated value

\section{D.13.2.2 Semivolatile Organic Compounds}

No SVOCs were detected above the respective laboratory MDCs in soil samples collected at this CAS; therefore, the FALs are established at the corresponding PALs.

\section{D.13.2.3 Total Petroleum Hydrocarbons}

The TPH-DRO analytical results for soil samples collected from the cellar that were detected above MDCs are presented in Table D.13-3. Two surface samples ( 0 to $0.25 \mathrm{ft}$ bgs) collected at location K01 and one surface sample ( 0 to $0.25 \mathrm{ft}$ bgs) collected at location K02 exceeded the PAL of $100 \mathrm{mg} / \mathrm{kg}$ for TPH-DRO. The TPH-DRO was moved onto a Tier 2 evaluation and FALs were established for the hazardous constituents of TPH-DRO at the corresponding PAL concentrations. 
Table D.13-3

Soil Sample Results for TPH-DRO Detected Above Minimum Detectable Concentrations at CAS 19-23-03, Cellar with Casing

\begin{tabular}{|c|c|c|c|}
\hline \multirow{2}{*}{$\begin{array}{c}\text { Sample } \\
\text { Location }\end{array}$} & \multirow{2}{*}{$\begin{array}{l}\text { Sample } \\
\text { Number }\end{array}$} & \multirow{2}{*}{$\begin{array}{l}\text { Depth } \\
\text { (ft bgs) }\end{array}$} & Contaminants of Potential Concern (mg/kg) \\
\hline & & & Diesel-Range Organics \\
\hline \multicolumn{3}{|c|}{ Preliminary Action Levels ${ }^{a}$} & 100 \\
\hline \multicolumn{4}{|c|}{ Cellar Samples } \\
\hline \multirow{2}{*}{ K01 } & $177 \mathrm{~K} 001$ & $0.0-0.25$ & 1,820 \\
\hline & $177 \mathrm{~K} 002$ & $0.0-0.25$ & 2,220 \\
\hline K02 & $177 \mathrm{~K} 003$ & $0.0-0.25$ & 1,470 \\
\hline
\end{tabular}

aBased on Nevada Administrative Code, "Contamination of Soil: Establishment of Action Levels" (NAC, 2006).

$\mathrm{ft}$ bgs $=$ Feet below ground surface

$\mathrm{mg} / \mathrm{kg}=$ Milligrams per kilogram

Concentrations of the hazardous constituents of TPH-DRO did not exceed FALs; therefore, TPH-DRO is not considered a COC. Concentrations of TPH-GRO were not detected above the respective laboratory MDCs at this CAS.

\section{D.13.2.4 Polychlorinated Biphenyls}

Analytical results for soil sample $177 \mathrm{~K} 001$ collected at 0 to $0.25 \mathrm{ft}$ bgs at the cellar detected Aroclor 1242 (21.7 $\mu \mathrm{g} / \mathrm{kg}$; estimated value) above MDCs. No PCB concentrations exceed the PALs (740 $\mu \mathrm{g} / \mathrm{kg}$ ); therefore, the FALs were established as the corresponding PALs.

\section{D.13.2.5 RCRA Metals and Beryllium}

Analytical results for RCRA metals and beryllium in soil samples collected from the cellar that were detected above MDCs are presented in Table D.13-4. None of the metals were detected at concentrations exceeding the respective PALs; therefore, the FALs were established as the corresponding PALs. 
Table D.13-4

Soil Sample Results for Metals Detected Above Minimum Detectable Concentrations at CAS 19-23-03, Cellar with Casing

\begin{tabular}{|c|c|c|c|c|c|c|c|c|c|}
\hline \multirow[b]{2}{*}{$\begin{array}{l}\text { Sample } \\
\text { Location }\end{array}$} & \multirow[b]{2}{*}{$\begin{array}{l}\text { Sample } \\
\text { Number }\end{array}$} & \multirow[b]{2}{*}{$\begin{array}{l}\text { Depth } \\
\text { (ft bgs) }\end{array}$} & \multicolumn{7}{|c|}{ Contaminants of Potential Concern (mg/kg) } \\
\hline & & & 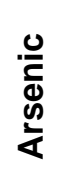 & 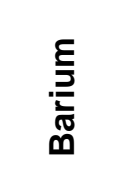 & & 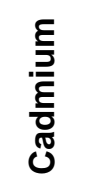 & 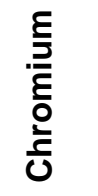 & 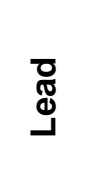 & 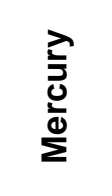 \\
\hline \multicolumn{3}{|c|}{ Final Action Levels } & $23^{a}$ & $67,000^{b}$ & $1,900^{b}$ & $450^{b}$ & $450^{b}$ & $800^{b}$ & $310^{\mathrm{b}}$ \\
\hline \multicolumn{10}{|c|}{ Cellar Samples } \\
\hline \multirow{2}{*}{ K01 } & $177 \mathrm{~K} 001$ & $0.0-0.25$ & 1.9 & 231 & 0.38 & 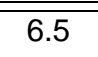 & 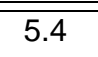 & 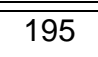 & 0.0091 \\
\hline & $177 \mathrm{~K} 002$ & $0.0-0.25$ & 2 & 178 & 0.32 & 6.5 & 5 & 223 & 0.011 \\
\hline K02 & 177K003 & $0.0-0.25$ & 2.1 & 276 & 0.38 & 1 & 5 & 130 & 0.0083 \\
\hline
\end{tabular}

${ }^{a}$ Based on the background concentrations for metals. Background is considered the mean plus two times the standard deviation for sediment samples collected by the Nevada Bureau of Mines and Geology throughout the Nevada Test and Training Range (NBMG, 1998; Moore, 1999).

${ }^{\mathrm{b} B a s e d}$ on U.S. Environmental Protection Agency, Region 9 Preliminary Remediation Goals (PRGs) (EPA, 2004)

$\mathrm{ft}$ bgs $=$ Feet below ground surface

$\mu \mathrm{g} / \mathrm{kg}=$ Milligrams per kilogram

-- = Not detected above minimum detectable concentrations.

\section{D.13.2.6 Gamma-Emitting Radionuclides}

Analytical results for gamma-emitting radionuclides in soil samples collected from the cellar that were detected above MDCs are presented in Table D.13-5. No gamma-emitting radionuclide concentrations exceeded the respective PALs; therefore, the FALs were established as the corresponding PALs.

\section{D.13.2.7 Plutonium, Strontium-90, and Uranium Isotopes}

Isotopic Pu and isotopic $\mathrm{U}$ analytical results for soil samples collected from the cellar that were detected above MDCs are presented in Table D.13-6. Concentrations of Sr-90 did not exceed the respective laboratory MDCs and no isotopic Pu or $\mathrm{U}$ concentrations exceeded the respective PALs; therefore, the FALs were established as the corresponding PALs. 
Table D.13-5

Soil Sample Results for Gamma-Emitting Radionuclides Detected Above Minimum Detectable Concentrations at CAS 19-23-03, Cellar with Casing

\begin{tabular}{|c|c|c|c|c|c|c|}
\hline \multirow{2}{*}{$\begin{array}{l}\text { Sample } \\
\text { Location }\end{array}$} & \multirow{2}{*}{$\begin{array}{l}\text { Sample } \\
\text { Number }\end{array}$} & \multirow{2}{*}{$\begin{array}{c}\text { Depth } \\
\text { (ft bgs) }\end{array}$} & \multicolumn{4}{|c|}{ Contaminants of Potential Concern (pCi/g) } \\
\hline & & & Actinium-228 & Lead-212 & Lead-214 & Thallium-208 \\
\hline \multicolumn{3}{|c|}{ Final Action Levels ${ }^{a}$} & 5 & 5 & 5 & 5 \\
\hline \multicolumn{7}{|c|}{ Cellar Samples } \\
\hline \multirow{2}{*}{ K01 } & $177 \mathrm{~K} 001$ & $0.0-0.25$ & 2.2 & 2.4 & 1.33 & 0.688 \\
\hline & 177K002 & $0.0-0.25$ & 2.23 & 2.19 & 1.41 & 0.737 \\
\hline K02 & $177 \mathrm{~K} 003$ & $0.0-0.25$ & 2.08 & 2.2 & 1.26 & 0.617 \\
\hline
\end{tabular}

${ }^{a}$ Taken from the generic guidelines for residual concentrations of actinium-228, bismuth-214, lead-212, lead-214, thallium-208, and thorium-232, as found in Chapter IV of U.S. Department of Energy Order 5400.5, Change 2, Radiation Protection of the Public and Environment (DOE, 1993).

$\mathrm{ft}$ bgs $=$ Feet below ground surface

$\mathrm{pCi} / \mathrm{g}=$ Picocuries per gram

Table D.13-6

Soil Sample Results for Isotopes Detected Above Minimum Detectable Concentrations at CAS 19-23-03, Cellar with Casing

\begin{tabular}{|c|c|c|c|c|c|c|}
\hline \multirow{2}{*}{$\begin{array}{l}\text { Sample } \\
\text { Location }\end{array}$} & \multirow{2}{*}{$\begin{array}{l}\text { Sample } \\
\text { Number }\end{array}$} & \multirow{2}{*}{$\begin{array}{c}\text { Depth } \\
\text { (ft bgs) }\end{array}$} & \multicolumn{4}{|c|}{ Contaminants of Potential Concern (pCi/g) } \\
\hline & & & Plutonium-239/240 & Uranium-234 & Uranium-235 & Uranium-238 \\
\hline \multicolumn{3}{|c|}{ Final Action Levels ${ }^{a}$} & 12.7 & 143 & 17.6 & 105 \\
\hline \multicolumn{7}{|c|}{ Cellar Samples } \\
\hline \multirow{2}{*}{ K01 } & $177 \mathrm{~K} 001$ & $0.0-0.25$ & -- & 1.32 & -- & 1.35 \\
\hline & $177 \mathrm{~K} 002$ & $0.0-0.25$ & 0.0649 & 1.24 & -- & 1.46 \\
\hline $\mathrm{K} 02$ & $177 \mathrm{~K} 003$ & $0.0-0.25$ & -- & 1.23 & 0.134 & 1.42 \\
\hline
\end{tabular}

aTaken from the construction, commercial, industrial land-use scenario in Table 2.1 of the National Council on Radiation Protection and Measurement Report No. 129, Recommended Screening Limits for Contaminated Surface Soil and Review Factors Relevant to Site-Specific Studies (NCRP, 1999). The values provided in this source document were scaled to a 25-millirem-per-year dose.

$\mathrm{ft}$ bgs $=$ Feet below ground surface

$\mathrm{pCi} / \mathrm{g}=$ Picocuries per gram

-- = Not detected above minimum detectable concentrations.

\section{D.13.3 Nature and Extent of Contamination}

Based on the analytical results, no COCs were identified in the environmental soils samples collected at CAS 19-23-03. 


\section{D.13.4 Revised Conceptual Site Model}

The CAU 177 SAFER Plan requirements were met at this CAS, and no revisions were necessary to the CSM. 


\section{D.14.0 CAS 20-23-07, Cellar}

Corrective Action Site 20-23-07 is approximately $1 \mathrm{mi}$ past Area 20 Camp off of the east side of Pahute Mesa Road in Area 20 (Figure 1-1). The CAS component identified for investigation includes an open cellar, surrounded by orange construction fencing. The floor of the cellar is covered with approximately 4 in. of soil and contains borehole casing that has been cut off at approximately $2 \mathrm{ft}$ above grade.

\section{D.14.1 Corrective Action Investigation}

Three characterization samples including one FD were collected during investigation activities at CAS 20-23-07. The sample IDs, locations, types, and analyses are listed in Table D.14-1. The specific CAI activities conducted to satisfy the CAU 177 SAFER Plan requirements at this CAS are described in the following sections.

Table D.14-1

Samples Collected at CAS 20-23-07, Cellar

\begin{tabular}{|c|c|c|c|c|c|}
\hline $\begin{array}{l}\text { Sample } \\
\text { Location }\end{array}$ & $\begin{array}{l}\text { Sample } \\
\text { Number }\end{array}$ & $\begin{array}{c}\text { Depth } \\
\text { (ft bgs) }\end{array}$ & Matrix & Purpose & Analyses \\
\hline \multicolumn{6}{|c|}{ Cellar Samples } \\
\hline \multirow{2}{*}{ L01 } & 177L001 & $0.0-0.25$ & Soil & Environmental & Set 2 \\
\hline & 177L002 & $0.0-0.25$ & Soil & Field Duplicate of \#177L001 & Set 2 \\
\hline L02 & 177L003 & $0.0-0.25$ & Soil & Environmental, Full Lab QC & Set 2 \\
\hline \multicolumn{6}{|c|}{ QC Samples } \\
\hline $\bar{N} / \mathrm{A}$ & 177L301 & $\overline{\mathrm{N} / \mathrm{A}}$ & Water & Trip Blank & VOCs \\
\hline $\mathrm{N} / \mathrm{A}$ & 177L302 & $N / A$ & Water & Field Blank & Set 2 \\
\hline
\end{tabular}

Set 2 = VOCs, SVOCs, RCRA Metals, Beryllium, TPH-DRO, TPH-GRO, PCBs, Gamma Spectroscopy, Isotopic Uranium, Isotopic Plutonium, Strontium-90

DRO = Diesel-range organics $\mathrm{ft}$ bgs $=$ Feet below ground surface $\mathrm{GRO}=$ Gasoline-range organics $\mathrm{N} / \mathrm{A}=$ Not applicable

$\mathrm{PCB}=$ Polychlorinated biphenyl
$\mathrm{QC}=$ Quality control RCRA = Resource Conservation and Recovery Act SVOC $=$ Semivolatile organic compound $\mathrm{TPH}=$ Total petroleum hydrocarbons $\mathrm{VOC}=$ Volatile organic compound 


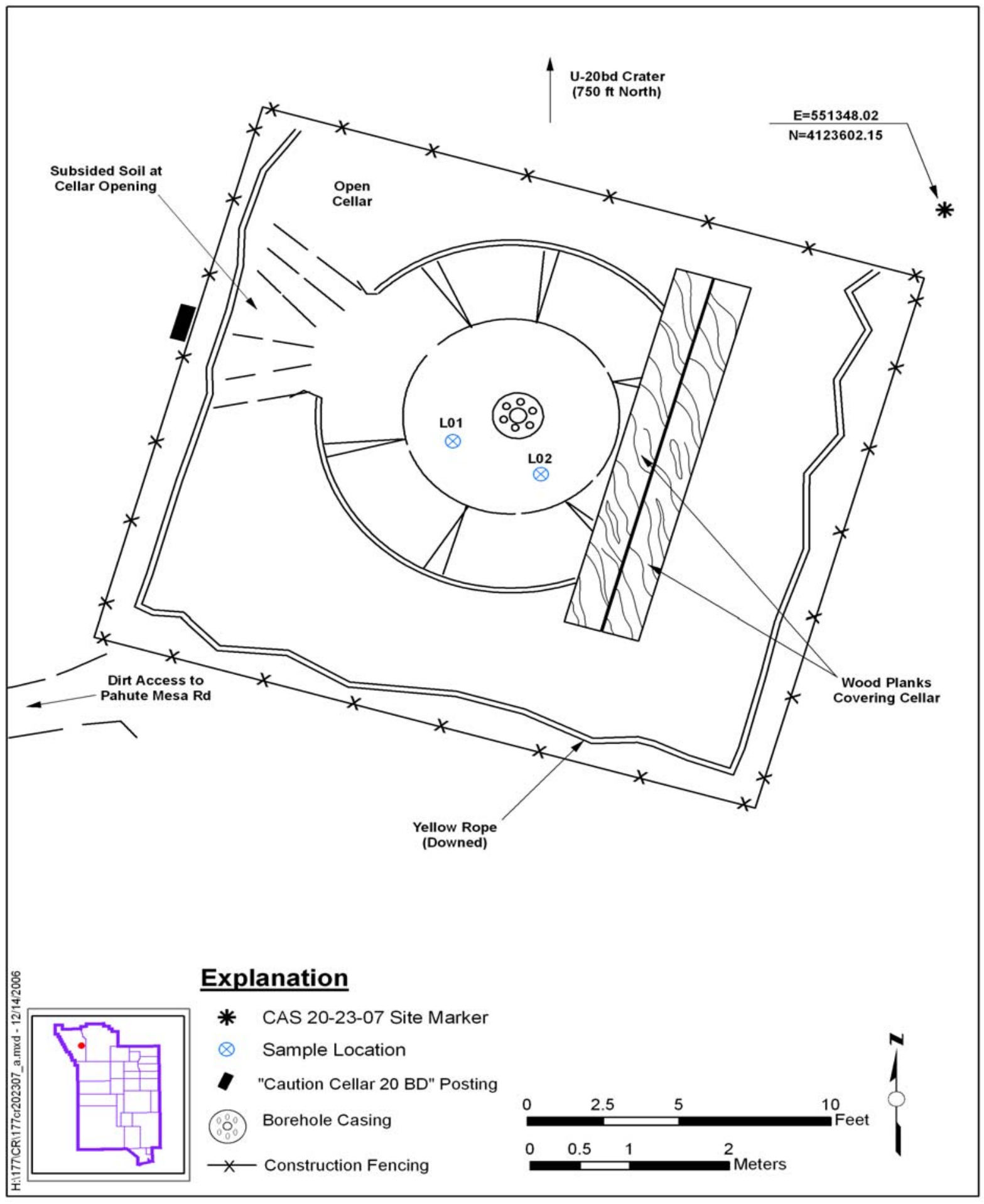

Figure D.14-1

CAS 20-23-07 Sample Location Map 


\section{D.14.1.1 Field Screening}

Investigation samples were screened for total alpha and beta/gamma radiation. The FSRs were compared to FSLs and no exceedences were identified. Soil and debris (miscellaneous wood, plastic, paper, and metal) at the surface of the cellar floor were screened for radioactivity for protection of worker health and safety and to guide selection of sample locations. During this survey, an area of elevated beta radioactivity of approximately 22,000 dpm (six times background FSL of 3,641 dpm, beta) was identified at the southeast quadrant of the cellar floor. This area of elevated radioactivity was used as a biasing factor for selection of sample location L02. Because soil collected at location L02 did not exceed radiological FSLs, it is likely that the elevated beta levels identified at the surface may have been sourced from debris that was not captured in the collected soil. Sample location L01 was placed in the southwest quadrant, equally spaced from L02 as no other biasing factors were identified.

\section{D.14.1.2 Visual Inspections}

No spills, staining, disturbances of soil, or other indications of potential contamination were identified during the inspection of CAS 20-23-07, and site conditions were unchanged from previous field visits. No visible biasing factors were identified at the cellar floor that would guide selection of sample locations.

\section{D.14.1.3 Sample Collection}

Decision I environmental sampling activities included the collection of biased soil samples at the cellar (Figure D.14-1) using a scoop and trowel.

Three Decision I environmental samples including one FD were collected from locations L01 and L02 to determine if there was a release to the cellar floor. The surface samples were collected at 0.0 to $0.25 \mathrm{ft}$ bgs and consisted of fine to medium sand with abundant grout chips, plant roots, and possible plastic and rubber debris. Subsurface samples were not collected due to the presence of a concrete bottom 4 in. beneath the surface soil. 


\section{D.14.2 Investigation Results}

The following sections provide analytical results from the samples collected to complete investigation activities as outlined in the CAU 177 SAFER Plan (NNSA/NSO, 2006b). Investigation samples were analyzed for the SAFER-specified COPCs for cellars which included: VOCs, SVOCs, TPH-DRO and -GRO, RCRA metals, gamma-emitting radionuclides, isotopic $\mathrm{U}$, isotopic $\mathrm{Pu}$, and Sr-90. Beryllium and PCBs were added parameters, because these contaminants are a common concern at the NTS. Table D.14-1 lists the sample-specific analytical suite for CAS 20-23-07. Analytical results from the soil samples with concentrations exceeding MDCs are summarized in the following sections.

For the judgmental samples at the cellar, an evaluation was conducted on all contaminants detected above MDCs by comparing individual concentration or activity results against the FALs to determine if a constituent is a COC. The FALs were established as the corresponding PAL concentrations or activities if the contaminant concentrations were below their respective PALs.

\section{D.14.2.1 Volatile Organic Compounds}

Analytical results for VOCs in soil samples collected from the cellar that were detected above MDCs are presented in Table D.14-2. No VOCs were detected at concentrations exceeding the respective PALs; therefore, the FALs were established as the corresponding PALs.

\section{D.14.2.2 Semivolatile Organic Compounds}

Analytical results for soil sample 177L001 collected at 0 to $0.25 \mathrm{ft}$ bgs at the cellar detected bis(2-Ethylhexyl)Phthalate (1,800 $\mu \mathrm{g} / \mathrm{kg}$, estimated value) above MDCs. No SVOCs were detected at concentrations exceeding the respective PALs; therefore, the FALs were established as the corresponding PALs.

\section{D.14.2.3 Total Petroleum Hydrocarbons}

The TPH-DRO analytical results for soil samples collected from the cellar that were detected above MDCs are presented in Table D.14-3. Two surface samples (0 to $0.25 \mathrm{ft}$ bgs, includes one FD) collected at location L01 and one surface sample ( 0 to $0.25 \mathrm{ft}$ bgs) collected at location L02 exceeded the PAL of $100 \mathrm{mg} / \mathrm{kg}$ for TPH-DRO. The TPH-DRO was moved on to a Tier 2 evaluation and FALs 
Table D.14-2

Soil Sample Results for Total VOCs Detected Above Minimum Detectable Concentrations at CAS 20-23-07, Cellar

\begin{tabular}{|c|c|c|c|c|}
\hline \multirow{2}{*}{$\begin{array}{c}\text { Sample } \\
\text { Location }\end{array}$} & \multirow{2}{*}{$\begin{array}{l}\text { Sample } \\
\text { Number }\end{array}$} & \multirow{2}{*}{$\begin{array}{l}\text { Depth } \\
\text { (ft bgs) }\end{array}$} & \multicolumn{2}{|c|}{ Contaminants of Potential Concern $(\mu \mathrm{g} / \mathrm{kg})$} \\
\hline & & & 1,1,1-Trichloroethane & Toluene \\
\hline \multicolumn{3}{|c|}{ Final Action Levels ${ }^{a}$} & $1,200,000$ & 520,000 \\
\hline \multicolumn{5}{|c|}{ Cellar Samples } \\
\hline \multirow{2}{*}{ L01 } & 177L001 & $0.0-0.25$ & $3.39(\mathrm{~J})$ & $0.606(\mathrm{~J})$ \\
\hline & 177L002 & $0.0-0.25$ & $2.55(\mathrm{~J})$ & $0.34(\mathrm{~J})$ \\
\hline L02 & 177L003 & $0.0-0.25$ & $3.22(\mathrm{~J})$ & $0.554(\mathrm{~J})$ \\
\hline
\end{tabular}

a'Based on U.S. Environmental Protection Agency, Region 9 Preliminary Remediation Goals (PRGs) (EPA, 2004).

$\mathrm{ft}$ bgs $=$ Feet below ground surface

$\mu \mathrm{g} / \mathrm{kg}=$ Micrograms per kilogram

$\mathrm{J}=$ Estimated value.

were established for the hazardous constituents of TPH-DRO at the corresponding PAL concentrations. Concentrations of the hazardous constituents of TPH-DRO did not exceed FALs; therefore, TPH-DRO is not considered a COC. Concentrations of TPH-GRO were not detected above the respective laboratory MDCs at this CAS.

Table D.14-3

Soil Sample Results for TPH-DRO Detected Above Minimum Detectable Concentrations at CAS 20-23-07, Cellar

\begin{tabular}{|c|c|c|c||}
\hline \multirow{2}{*}{$\begin{array}{c}\text { Sample } \\
\text { Location }\end{array}$} & \multirow{2}{*}{$\begin{array}{c}\text { Sample } \\
\text { Number }\end{array}$} & $\begin{array}{c}\text { Depth } \\
\text { (ft bgs) }\end{array}$ & Contaminants of Potential Concern (mg/kg) \\
\cline { 3 - 4 } & & \multicolumn{2}{|c|}{ Diesel-Range Organics } \\
\hline \multicolumn{2}{|c|}{ Preliminary Action Levels } & Cellar Samples \\
\hline \hline \multicolumn{2}{|c|}{} & $\mathbf{4 , 0 5 0}$ \\
\hline \hline \multirow{2}{*}{ L01 } & $177 L 001$ & $0.0-0.25$ & $\mathbf{3 , 5 3 0}$ \\
\cline { 2 - 4 } & $177 \mathrm{~L} 002$ & $0.0-0.25$ & $\mathbf{2 , 9 8 0}$ \\
\hline L02 & $177 L 003$ & $0.0-0.25$ & \\
\hline
\end{tabular}

aBased on Nevada Administrative Code, "Contamination of Soil: Establishment of Action Levels" (NAC, 2006).

$\mathrm{ft}$ bgs = Feet below ground surface $\mathrm{mg} / \mathrm{kg}=$ Milligrams per kilogram 


\section{D.14.2.4 Polychlorinated Biphenyls}

Analytical results for soil sample 177L003 collected at 0.0 to $0.25 \mathrm{ft}$ bgs at the cellar detected Aroclor 1242, Aroclor 1254, and Aroclor 1268 (48.9, 26.5, and $22.3 \mu \mathrm{g} / \mathrm{kg}$, respectively; estimated values) above MDCs. The calculated total Aroclor for sample 177L003 (97.7 $\mu \mathrm{g} / \mathrm{kg})$ did not exceed the PAL (740 $\mu \mathrm{g} / \mathrm{kg}$ ); therefore, the FAL was established as the corresponding PAL.

\section{D.14.2.5 RCRA Metals and Beryllium}

Analytical results for RCRA metals and beryllium in soil samples collected from the cellar that were detected above MDCs are presented in Table D.14-4. None of the metals were detected at concentrations exceeding the respective PALs; therefore, the FALs were established as the corresponding PALs.

Table D.14-4

Soil Sample Results for Metals Detected Above Minimum Detectable Concentrations at CAS 20-23-07, Cellar

\begin{tabular}{|c|c|c|c|c|c|c|c|c|c|c|}
\hline \multirow[b]{2}{*}{$\begin{array}{c}\text { Sample } \\
\text { Location }\end{array}$} & \multirow[b]{2}{*}{$\begin{array}{l}\text { Sample } \\
\text { Number }\end{array}$} & \multirow[b]{2}{*}{$\begin{array}{l}\text { Depth } \\
\text { (ft bgs) }\end{array}$} & \multicolumn{8}{|c|}{ Contaminants of Potential Concern (mg/kg) } \\
\hline & & & 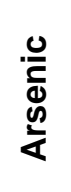 & 疍 & 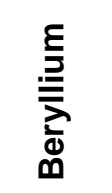 & 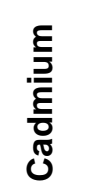 & 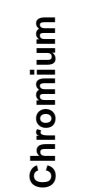 & శ్ర్త & 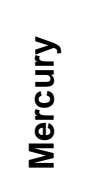 & $\frac{\bar{亠}}{\bar{\omega}}$ \\
\hline \multicolumn{3}{|c|}{ Final Action Levels } & $23^{a}$ & $67,000^{b}$ & $1,900^{b}$ & $450^{b}$ & $450^{b}$ & $800^{b}$ & $310^{b}$ & $5,100^{b}$ \\
\hline \multicolumn{11}{|c|}{ Cellar Samples } \\
\hline \multirow{2}{*}{ L01 } & 177L001 & $0.0-0.25$ & 4.7 & 167 & 0.48 & 1.5 & 13.1 & 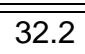 & 0.016 & 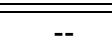 \\
\hline & 177L002 & $0.0-0.25$ & 5.6 & 219 & 0.59 & 1.8 & 16.4 & 38.7 & 0.013 & 0.12 \\
\hline L02 & 177L003 & $0.0-0.25$ & 4.2 & 142 & 0.46 & 1.4 & 12.1 & 39.4 & 0.014 & -- \\
\hline
\end{tabular}

aBased on the background concentrations for metals. Background is considered the mean plus two times the standard deviation for sediment samples collected by the Nevada Bureau of Mines and Geology throughout the Nevada Test and Training Range (NBMG, 1998; Moore, 1999). bBased on U.S. Environmental Protection Agency, Region 9 Preliminary Remediation Goals (PRGs) (EPA, 2004) 


\section{D.14.2.6 Gamma-Emitting Radionuclides}

Analytical results for gamma-emitting radionuclides in soil samples collected from the cellar that were detected above MDCs are presented in Table D.14-5. No gamma-emitting radionuclide concentrations exceeded the respective PALs; therefore, the FALs were established as the corresponding PALs.

Table D.14-5

Soil Sample Results for Gamma-Emitting Radionuclides Detected Above Minimum Detectable Concentrations at CAS 20-23-07, Cellar

\begin{tabular}{|c|c|c|c|c|c|c|c|}
\hline \multirow[b]{2}{*}{$\begin{array}{l}\text { Sample } \\
\text { Location }\end{array}$} & \multirow[b]{2}{*}{$\begin{array}{l}\text { Sample } \\
\text { Number }\end{array}$} & \multirow[b]{2}{*}{$\begin{array}{l}\text { Depth } \\
\text { (ft bgs) }\end{array}$} & \multicolumn{5}{|c|}{ Contaminants of Potential Concern (pCi/g) } \\
\hline & & & 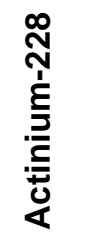 & 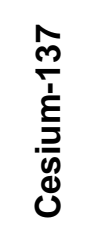 & 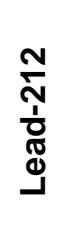 & 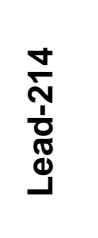 & 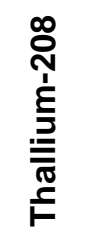 \\
\hline \multicolumn{3}{|c|}{ Final Action Levels } & $5^{a}$ & $12.2^{\mathrm{b}}$ & $5^{a}$ & $5^{a}$ & $5^{a}$ \\
\hline \multicolumn{8}{|c|}{ Cellar Samples } \\
\hline \multirow{2}{*}{ L01 } & 177L001 & $0.0-0.25$ & 1.52 & 0.534 & 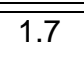 & 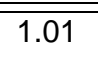 & 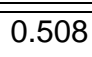 \\
\hline & 177L002 & $0.0-0.25$ & 1.63 & 0.673 & 1.66 & 1.08 & 0.443 \\
\hline L02 & 177L003 & $0.0-0.25$ & 1.65 & 0.291 & 1.71 & 0.846 & 0.639 \\
\hline
\end{tabular}

Taken from the generic guidelines for residual concentrations of actinium-228, bismuth-214, lead-212, lead-214, thallium-208, and thorium-232, as found in Chapter IV of U.S. Department of Energy Order 5400.5, Change 2, Radiation Protection of the Public and Environment (DOE, 1993).

${ }^{\mathrm{b}}$ Taken from the construction, commercial, industrial land-use scenario in Table 2.1 of the National Council on Radiation Protection and Measurement Report No. 129, Recommended Screening Limits for Contaminated Surface Soil and Review Factors Relevant to Site-Specific Studies (NCRP, 1999). The values provided in this source document were scaled to a 25-millirem-per-year dose.

$\mathrm{ft}$ bgs $=$ Feet below ground surface

$\mathrm{pCi} / \mathrm{g}=$ Picocuries per gram

\section{D.14.2.7 Plutonium, Strontium-90, and Uranium Isotopes}

Isotopic $\mathrm{U}$ analytical results for soil samples collected from the cellar that were detected above MDCs are presented in Table D.14-6. Concentrations of isotopic Pu and Sr-90 did not exceed the respective laboratory MDCs and no isotopic $U$ concentrations exceeded the respective PALs; therefore, the FALs were established as the corresponding PALs. 
Table D.14-6

Soil Sample Results for Isotopic Uranium Detected Above Minimum Detectable Concentrations at CAS 20-23-07, Cellar

\begin{tabular}{|c|c|c|c|c|}
\hline \multirow{2}{*}{$\begin{array}{l}\text { Sample } \\
\text { Location }\end{array}$} & \multirow{2}{*}{$\begin{array}{c}\text { Sample } \\
\text { Number }\end{array}$} & \multirow{2}{*}{$\begin{array}{l}\text { Depth } \\
\text { (ft bgs) }\end{array}$} & \multicolumn{2}{|c|}{ Contaminants of Potential Concern (pCi/g) } \\
\hline & & & Uranium-234 & Uranium-238 \\
\hline \multicolumn{3}{|c|}{ Final Action Levels ${ }^{a}$} & 143 & 105 \\
\hline \multicolumn{5}{|c|}{ Cellar Samples } \\
\hline \multirow{2}{*}{ L01 } & 177L001 & $0.0-0.25$ & 1.05 & 1.06 \\
\hline & 177L002 & $0.0-0.25$ & 0.871 & 0.913 \\
\hline L02 & 177L003 & $0.0-0.25$ & 0.917 & 0.793 \\
\hline
\end{tabular}

aTaken from the construction, commercial, industrial land-use scenario in Table 2.1 of the National Council on Radiation Protection and Measurement Report No. 129, Recommended Screening Limits for Contaminated Surface Soil and Review Factors Relevant to Site-Specific Studies (NCRP, 1999). The values provided in this source document were scaled to a 25-millirem-per-year dose.

$\mathrm{ft}$ bgs $=$ Feet below ground surface $\mathrm{pCi} / \mathrm{g}=$ Picocuries per gram

\section{D.14.3 Nature and Extent of Contamination}

Based on the analytical results, no COCs were identified in the environmental soils samples collected at CAS 20-23-07.

\section{D.14.4 Revised Conceptual Site Model}

The CAU 177 SAFER Plan requirements were met at this CAS, and no revisions were necessary to the CSM. 


\section{D.15.0 Waste Disposition}

The following sections address IDW generated during the CAU 177 field investigation. Investigation activities did not require waste characterization samples to be collected and non-IDW waste streams were not generated.

\section{D.15.1 Investigation-Derived Waste}

During CAU 177 the field investigation activities, IDW was generated. The waste streams generated include disposable PPE, disposable sampling equipment, and decontamination rinse water. Investigation-derived waste was segregated to the greatest extent possible, and waste minimization techniques were effectively integrated into the field activities to reduce the amount of waste generated. Controls were in place to minimize the use of hazardous materials and the unnecessary generation of hazardous and/or mixed waste. Decontamination activities were planned and executed in a manner that minimized the volume of rinsate generated to amounts that did not require management.

There were no drums of waste (hazardous or non-hazardous) generated during the field investigation and none of the five areas designated for HWAAs were established.

\section{D.15.2 Waste Streams}

During the investigation, IDW generated was segregated into the following waste streams:

- Disposable PPE and sampling equipment

- Decontamination rinsate

Disposable PPE and sampling equipment waste was inspected for gross contamination and radioactivity, managed as sanitary IDW, and disposed of in a designated sanitary industrial waste bin at Building 23-153 and allocated for NTS industrial waste landfill disposal. Although decontamination rinsate was generated, the small volumes evaporated before the rinsate could be transferred for containment or sampled. Office waste and lunch trash was disposed of in designated sanitary waste bins allocated for NTS sanitary landfill disposal. 


\section{D.16.0 Quality Assurance}

This section contains a summary of QA/QC measures implemented during the sampling and analysis activities conducted in support of the CAU 177 CAI. The following sections discuss the data validation process, QC samples, and nonconformances. A detailed evaluation of the DQIs is presented in Section 4.1.

Laboratory analyses were conducted for samples used in the decision-making process to provide a quantitative measurement of any COPCs present. Rigorous QA/QC was implemented for all laboratory samples including documentation, verification and validation of analytical results, and affirmation of DQI requirements related to laboratory analysis. Detailed information regarding the QA program is contained in the Industrial Sites QAPP (NNSA/NV, 2002).

\section{D.16.1 Data Validation}

Data validation was performed in accordance with the Industrial Sites QAPP and approved protocols and procedures. All laboratory data from samples collected and analyzed for CAU 177 were evaluated for data quality in a tiered process and are presented in Sections D.16.1.1 through D.16.1.3. Data were reviewed to ensure that samples were appropriately processed and analyzed, and the results were evaluated using validation criteria. Documentation of the data qualifications resulting from these reviews is retained in project files as a hard copy and electronic media.

One hundred percent of the data analyzed as part of this investigation were subjected to Tier 1 and Tier 2 evaluations. A Tier 3 evaluation was performed on approximately 5 percent of the data analyzed.

\section{D.16.1.1 Tier 1 Evaluation}

Tier 1 evaluation for chemical and radiochemical analysis examines, but is not limited to:

- Sample count/type consistent with chain of custody.

- Analysis count/type consistent with chain of custody.

- Correct sample matrix.

- Significant problems stated in cover letter or case narrative.

- Completeness of certificates of analysis. 
- Completeness of Contract Laboratory Program (CLP) or CLP-like packages.

- Completeness of signatures, dates, and times on chain of custody.

- Condition-upon-receipt variance form included.

- Requested analyses performed on all samples.

- Date received/analyzed given for each sample.

- Correct concentration units indicated.

- Electronic data transfer supplied.

- Results reported for field and laboratory QC samples.

- Whether or not the deliverable met the overall objectives of the project.

\section{D.16.1.2 Tier 2 Evaluation}

Tier 2 evaluation for chemical analysis examines, but is not limited to:

- Correct detection limits achieved.

- Sample, preparation, and analysis dates for each sample.

- Holding time criteria met.

- Quality control batch association for each sample.

- Cooler temperature upon receipt.

- Sample $\mathrm{pH}$ for aqueous samples, as required.

- Detection limits properly adjusted for dilution, as required.

- Blank contamination evaluated and applied to sample results/qualifiers.

- Matrix spike matrix spike duplicate (MSD) percent recoveries (\%R) and RPDs evaluated and qualifiers applied to laboratory results, as necessary.

- Field duplicate RPDs evaluated using professional judgment and qualifiers applied to laboratory results, as necessary.

- Laboratory duplicate RPDs evaluated and qualifiers applied to laboratory results, as necessary.

- Surrogate \%R evaluated and qualifiers applied to laboratory results, as necessary.

- Laboratory control sample (LCS) \%R evaluated and qualifiers applied to laboratory results, as necessary.

- Initial and continuing calibration evaluated and qualifiers applied to laboratory results, as necessary.

- Internal standard evaluation.

- Mass spectrometer tuning criteria.

- Organic compound quantitation. 
- Inductively coupled plasma interference check sample evaluation.

- Graphite furnace atomic absorption QC.

- Inductively coupled plasma serial dilution effects.

- Recalculation of 10 percent of laboratory results from raw data.

Tier 2 evaluation for radiochemical analysis examines, but is not limited to:

- Correct detection limits achieved.

- Blank contamination evaluated and, if significant, qualifiers are applied to sample results.

- Certificate of Analysis consistent with data package documentation.

- Quality control sample results (duplicates, LCSs, laboratory blanks) evaluated and used to determine laboratory result qualifiers.

- Sample results, uncertainty, and MDC evaluated.

- Detector system calibrated with National Institute for Standards and Technology (NIST)traceable sources.

- Calibration sources preparation documented, demonstrated proper preparation and appropriateness for sample matrix, emission energies, and concentrations.

- Detector system response to daily or weekly background and calibration checks for peak energy, peak centroid, peak full-width half-maximum, and peak efficiency, depending on the detection system.

- Tracers NIST-traceable, appropriate for the analysis performed, and recoveries that meet QC requirements.

- Documentation of all QC sample preparation complete and properly performed.

- Spectra lines, photon emissions, particle energies, peak, and background peak areas support the identified radionuclide and its concentration.

\section{D.16.1.3 Tier 3 Evaluation}

The Tier 3 review is an independent examination of the Tier 2 evaluation. A Tier 3 review of 5 percent of the sample analytical data was performed by TLI Solutions, of Lakewood, Colorado.

Tier 2 and Tier 3 results were compared and no differences were noted; therefore, there were no changes to the data qualifications. This review included the following additional evaluations:

\section{Chemical:}

- Recalculation of all laboratory results from raw data. 


\section{Radioanalytical:}

- QC sample results (e.g., calibration source concentration, \%R, and RPD) verified.

- Radionuclides and concentration validated as appropriate considering decay schemes, half-lives, process knowledge, and history of the facility and site.

- Each identified line in spectra verified against emission libraries and calibration results.

- Independent identification of spectra lines, area under the peaks, and quantification of radionuclide concentration in a random number of sample results.

\section{D.16.2 Field Quality Control Samples}

Field QC samples consisted of eight trip blanks, two equipment rinsate blanks, nine field blanks, one source blanks, twelve full lab QCs, and twelve FDs collected and submitted for analysis by the laboratory analytical methods shown in Table D.2-2. The QC samples, except for full lab QCs, were assigned individual sample numbers and sent to the laboratory "blind."

Review of the field blank analytical data resulted in three samples being qualified for field blank contamination of toluene. Field blanks, source blanks, and equipment rinsates were analyzed for the applicable parameters listed in Table D.2-2 and trip blanks were analyzed for VOCs only.

During the CAI, 12 FDs were sent as blind samples to the laboratory to be analyzed for the investigation parameters listed in Table D.2-2. For these samples, the duplicate results precision (i.e., RPDs between the environmental sample results and corresponding FD sample results) were evaluated.

\section{D.16.2.1 Laboratory Quality Control Samples}

Analysis of preparation QC blanks were performed on each sample delivery group (SDG) for inorganics. Analysis for surrogate spikes and method blanks (MBs) were performed on each SDG for organics only. Initial and continuing calibration and LCSs were performed for each SDG. The results of these analyses were used to qualify associated environmental sample results. Documentation of data qualifications resulting from the application of these guidelines is retained in project files as both hard copy and electronic media.

The laboratory included a preparation, LCS, and a laboratory duplicate sample with each batch of field samples analyzed for radionuclides. 


\section{D.16.3 Field Nonconformances}

There were no field nonconformances identified for the CAI.

\section{D.16.4 Laboratory Nonconformances}

Laboratory nonconformances are generally due to inconsistencies in the analytical instrumentation operation, sample preparations, extractions, missed holding times, and fluctuations in internal standard and calibration results. Thirty-two nonconformances were issued by the laboratories that may or may not have resulted in qualifying data. These laboratory nonconformances have been accounted for and resolved during the data qualification process. 


\section{D.17.0 Summary}

CAS 08-23-01, Mud Pit and Cellar; CAS 09-23-05, Mud Pit and Cellar; CAS 19-23-01 Mud Pit and Cellar; CAS 19-23-03, Cellar with Casing; CAS 20-23-07, Cellar

Total petroleum hydrocarbons were detected above the PAL in soil collected from the cellars of these CASs; however, the Tier 2 evaluation determined that none of the hazardous constituents of diesel were detected above PALs, therefore, TPH-DRO is not a COC for these CASs. No COCs were identified at these CASs, and the analytical data support no further action.

\section{CAS 09-09-41, Unknown \#3 Mud Pit/Disposal Area and CAS 09-09-45, U-9bz PS \#1A}

\section{Mud Pit (1) and Cellar}

The Eu-152 detected in concentrations above the PAL in soils samples collected at CASs 09-09-41 and 09-09-45 and the Pu-239 detected above the PAL at the mud pit of CAS 09-09-45 are not considered to be COCs. Their presence is assumed to be sourced from the adjacent Soils Project CASs 09-99-01 and 09-23-14, which consist of soils that contain elevated radioactivity and not from a release associated with these CASs. The analytical data obtained as a result of the investigation of these CASs, along with the radiological data presented in Sections D.4.3 and D.5.3, support no further action for this CAS. No COCs were identified at these CASs.

\section{CAS 10-23-02, Mud Pit and Cellar}

Total petroleum hydrocarbons were detected above the PAL in soil collected from the "west" cellar; however, the Tier 2 evaluation determined that none of the hazardous constituents of diesel were detected above PALs, so TPH-DRO is not a COC. Aroclor 1254 was detected above the PAL in a soil sample collected at the "west" cellar but did not exceed the Tier 2 RBCA criteria of being present at a reasonable point of exposure; therefore, it is not considered a COC. No COCs were identified at this CAS and the analytical data support no further action for this CAS. Justification that Aroclor 1254 is not present at a reasonable point of exposure includes the following:

- Aroclor 1254 contamination is at depth and covered by $8 \mathrm{ft}$ of backfilled soil. A receptor would only be exposed to contamination if the buried soils were to be excavated.

- Migration of contaminants is limited laterally by the presence of a metal corrugated metal casing 
- Migration of contaminants is limited vertically by the presence of a concrete cellar bottom.

- The presence of a borehole will prevent future use of the cellar component of the CAS and serves in part as a use restriction. According to the Borehole Management Project, the borehole (U-10am \#3 PS \#1A) associated with the west cellar is on the current list for plugback candidates; however, no plugback work has been scheduled (Gustafson, 2006). Because plugback activities would only involve excavating soil to the depth of the riser casing (typically 3 to $4 \mathrm{ft}$ above the cellar floor), the soil interval sampled as part of this investigation is not expected to be disturbed; therefore, there is little potential for future exposure. To assure that the soil containing Aroclor 1254 will not be disturbed, the Borehole Management Project will be informed of the results of the investigation at CAS 10-23-02.

- The CAS is currently located within a fenced area that is posted as an URMA. 


\section{D.18.0 References}

ASTM, see American Society for Testing and Materials.

American Society for Testing and Materials. 2000a. Standard Test Method for Radiochemical Determination of Plutonium in Soil by Alpha Spectroscopy, C 1001-2000. Philadelphia, PA.

American Society for Testing and Materials. 2000b. Standard Test Method for Strontium-90 in Water, D 5811-2000. Philadelphia, PA.

American Society for Testing and Materials. 2002a. Standard Test Method for Isotopic Uranium in Water by Radiochemistry, D 3972-2002. Philadelphia, PA.

American Society for Testing and Materials. 2002b. Standard Test Method for Plutonium in Water, D 3865-02. Philadelphia, PA.

American Society for Testing and Materials. 2002c. Standard Test Method for Radiochemical Determination of Uranium Isotopes in Soil by Alpha Spectroscopy, E 1000-2000. Philadelphia, PA.

DOE, see U.S. Department of Energy.

DOE/NV, see U.S. Department of Energy, Nevada Operations Office.

EPA, see U.S. Environmental Protection Agency.

FFACO, see Federal Facility Agreement and Consent Order.

Federal Facility Agreement and Consent Order. 1996 (as amended). Agreed to by the State of Nevada, the U.S. Department of Energy, and the U.S. Department of Defense.

Gustafson, D., National Security Technologies, LLC. 2006. Email to N. Nastanski (SNJV) concerning CAU 177 Boreholes, 6 February. Las Vegas, NV.

Moore, J., Science Applications International Corporation. 1999. Memorandum to M. Todd (SAIC), “Background Concentrations for NTS and TTR Soil Samples,” 3 February. Las Vegas, NV.

NAC, see Nevada Administrative Code.

NBMG, see Nevada Bureau of Mines and Geology

NCRP, see National Council on Radiation Protection and Measurements. 
NNSA/NV, see U.S. Department of Energy, National Nuclear Security Administration Nevada Operations Office.

NNSA/NSO, see U.S. Department of Energy, National Nuclear Security Administration Nevada Site Office.

NSTec, see National Security Technologies, LLC.

National Council on Radiation Protection and Measurements. 1999. Recommended Screening Limits for Contaminated Surface Soil and Review of Factors Relevant to Site-Specific Studies, Report No. 129. Bethesda, MD.

National Security Technologies, LLC. 2004. Bechtel Nevada Daily Rig Operations Log. December. Las Vegas, NV.

Nevada Administrative Code. 2006. NAC 445A.2272, “Contamination of Soil: Establishment of Action Levels.” Carson City, NV.

Nevada Bureau of Mines and Geology. 1998. Mineral and Energy Resource Assessment of the Nellis Air Force Range, Open-File Report 98-1. Reno, NV.

PNNL, see Pacific Northwest National Laboratory.

Pacific Northwest National Laboratory. 2005. Visual Sample Plan, Version 4.0, User’s Guide, PNNL-14002. Richland, WA.

SNJV, see Stoller-Navarro Joint Venture.

Snelling-Young, J.K., Stoller-Navarro Joint Venture. 2006. Memorandum to S.L. Alderson, et. al, entitled, “New Default Stoller-Navarro Joint Venture (SNJV) Isotopic Gamma Library,”5 July. Las Vegas, NV.

Stoller-Navarro Joint Venture. 2006. Radiological Land Area Surveys for CAU 177. Las Vegas, NV.

U.S. Department of Energy. 1993. Radiation Protection of the Public and the Environment, DOE Order 5400.5, Change 2. Washington, DC.

U.S. Department of Energy, National Nuclear Security Administration Nevada Operations Office. 2002. Industrial Sites Quality Assurance Project Plan, Nevada Test Site, Nevada, Rev. 3, DOE/NV--372. Las Vegas, NV.

U.S. Department of Energy, National Nuclear Security Administration Nevada Site Office. 2004. NV/YMP Radiological Control Manual, DOE/NV/11718--079. Las Vegas, NV. 
U.S. Department of Energy, National Nuclear Security Administration Nevada Site Office. 2006a. Industrial Sites Project Establishment of Final Action Levels. February. Las Vegas, NV.

U.S. Department of Energy, National Nuclear Security Administration Nevada Site Office. 2006b. Streamlined Approach for Environmental Restoration Plan for Corrective Action Unit 177: Mud Pits and Cellars, Nevada Test Site, Nevada, DOE/NV--1126, Rev. 0. Las Vegas, NV.

U.S. Department of Energy, Nevada Operations Office. 2000. Nevada Test Site Contaminated Land Areas Report, Volume 1, DOE/NV/11718-481-Vol 1. December. Las Vegas, NV.

U.S. Environmental Protection Agency. 1996. Test Methods for Evaluating Solid Waste, Physical/Chemical Methods, SW-846, 3rd Edition, CD-ROM PB97-501928GEI. Washington, DC.

U.S. Environmental Protection Agency. 2004 (as revised). Region 9 Preliminary Remediation Goals (PRGs). As accessed at www.epa.gov/region09/waste/sfund/prg/htm on 15 November 2006.

U.S. Environmental Protection Agency. 2006. Data Quality Objectives Process for Hazardous Waste Site Investigations, EPA QA/G-4HW, EPA/600/R-00/007. Washington, DC: Office of Environmental Information. 


\section{Appendix E}

\section{Waste Disposition Documentation}




\section{E.1.0 Waste Disposition Documentation}

This section does not apply to CAU 177. 


\section{Appendix F}

\section{Modifications to the Post-Closure Plan}




\section{F.1.0 Modifications to the Post-Closure Plan}

This section does not apply to CAU 177. 


\section{Appendix G}

\section{Use Restrictions}




\section{G.1.0 Closure Activity Summary}

The appendix does not apply to CAU 177. 


\section{Appendix $\mathrm{H}$}

\section{Risk Evaluation}




\section{H.1.0 Introduction}

The RBCA process used to establish FALs is described in the Industrial Sites Project Establishment of Final Action Levels (NNSA/NSO, 2006a). This process conforms with NAC Section 445A.227, which lists the requirements for sites with soil contamination (NAC, 2006a). For the evaluation of corrective actions, NAC Section 445A.22705 (NAC, 2006b) requires the use of ASTM Method E 1739-95 (ASTM, 1995) to "conduct an evaluation of the site, based on the risk it poses to public health and the environment, to determine the necessary remediation standards (i.e., FALs) or to establish that corrective action is not necessary.”

The evaluation of the need for corrective action will include the potential for wastes that are present at a site to cause the future contamination of site environmental media if the wastes were to be released.

This section contains documentation of the RBCA process used to establish FALs described in the Industrial Sites Project Establishment of Final Action Levels (NNSA/NSO, 2006a). This process defines three tiers (or levels) to establish FALs used to evaluate DQO decisions:

- $\quad$ Tier 1 - Sample results from source areas (highest concentrations) compared to risk-based screening levels (RBSLs) (i.e., PALs) based on generic (non-site-specific) conditions.

- $\quad$ Tier 2 - Sample results from exposure points compared to SSTLs calculated using site-specific inputs and Tier 1 formulas.

- $\quad$ Tier 3 - Sample results from exposure points compared to SSTLs and points of compliance calculated using chemical fate/transport and probabilistic modeling.

The risk-based corrective action decision process stipulated in the Industrial Sites Project Establishment of Final Action Levels (NNSA/NSO, 2006a) is summarized in Figure H.1-1.

\section{H.1.1 A. Scenario}

Corrective Action Unit 177, Mud Pits and Cellars, consists of the following 12 inactive sites within Areas 8, 9, 19, and 20 of the NTS:

- 08-23-01, Mud Pit and Cellar

- 09-09-41, Unknown \#3 Mud Pit/Disposal Area 


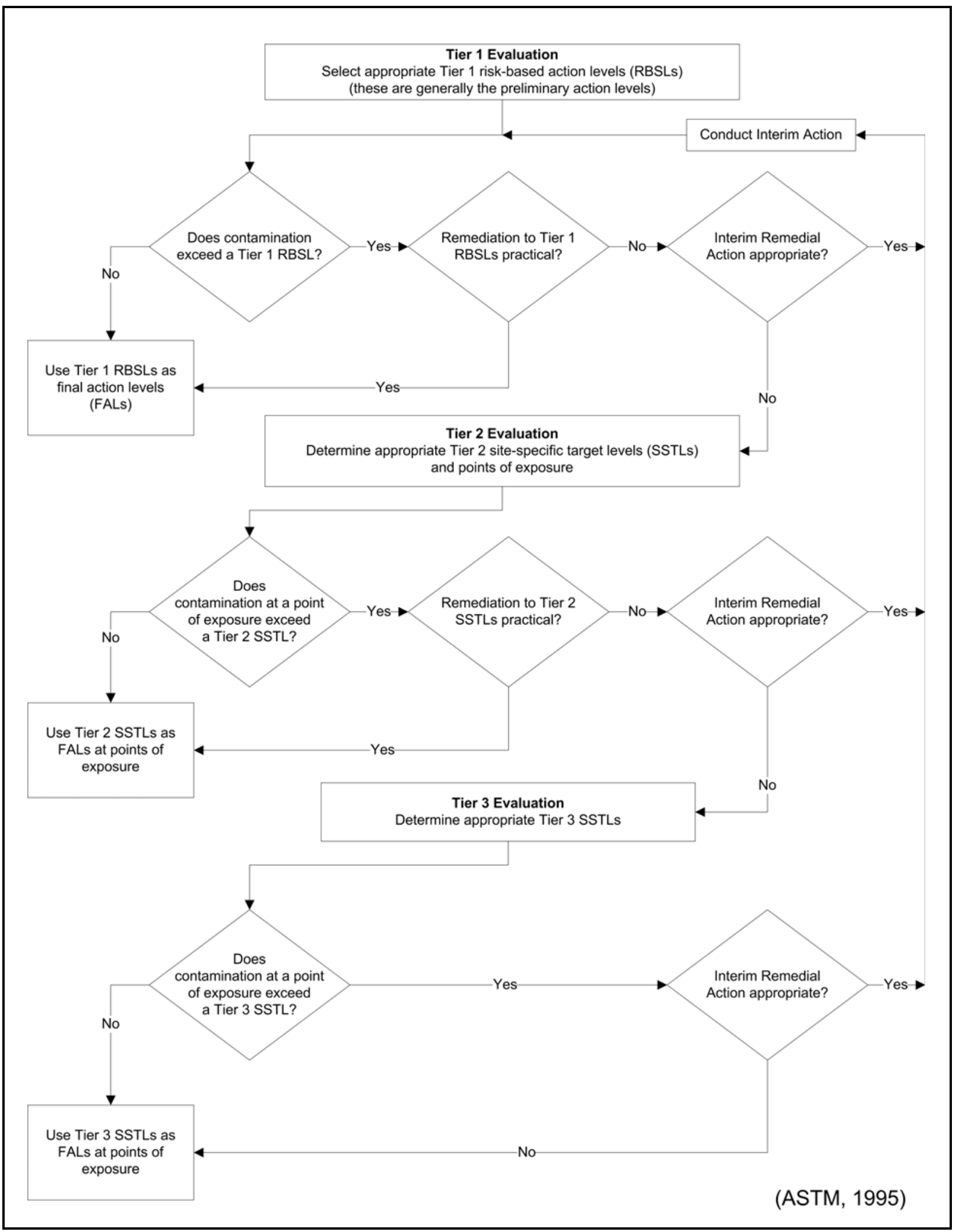

Figure H.1-1

Risk-Based Corrective Action Decision Process 
- 09-09-45, U-9bz PS \#1A Mud Pit (1) and Cellar

- 09-23-05, Mud Pit and Cellar

- 09-23-08, Mud Pit and Cellar

- 09-23-09, U-9itsx20 PS \#1A Cellar

- 10-23-02, Mud Pit and Cellar

- 10-23-03, Mud Pit and Cellar

- 19-23-01, Mud Pit and Cellar

- 19-23-02, Cellar and Waste Storage Area

- 19-23-03, Cellar with Casing

- 20-23-07, Cellar

All 12 CASs consist of mud pits and/or cellars constructed and used during drilling activities conducted at the NTS in support of underground nuclear weapons testing. In particular, the mud pits and cellars of 11 CASs were constructed as part of post-test drilling activities, and most are located within URMAs. It is speculated that the URMAs were posted based on process knowledge that the mud pits and cellars were associated with the post-test borehole that extended into the underground area potentially affect by the associated nuclear test. The rationale for posting the area may have been that the borehole allowed for a pathway to media that was potentially radioactive. The borehole casing that remains in cellars are under the control of the Borehole Management Project. The mud pit of CAS 09-09-41 is a disposal-type mud pit and the only one in this CAU that is not associated with a borehole.

\section{H.1.2 B. Site Assessment}

The investigation involved sampling at the mud pits and cellars to assess their potential to cause present and future harm to human health and the environment. The analytical results support no further action as the closure option for all CAU 177 CASs. Four CASs (09-23-08, 09-23-09, 10-23-03, and 19-23-02) had no COPC concentrations in soil samples that were detected above the respective PALs. No unexpected conditions or other indicators of contamination were encountered during the CAI.The maximum concentration of contaminants identified at each CAS are presented in Table H.1-1. 
Table H.1-1

Maximum Reported Value for Tier 1 Comparison

(Page 1 of 3)

\begin{tabular}{|c|c|c|c|c|c|c|c|c|c|c|c|c|c|}
\hline \multirow[b]{2}{*}{ Parameter } & \multirow[b]{2}{*}{ Units } & \multicolumn{12}{|c|}{ Maximum Reported Value } \\
\hline & & 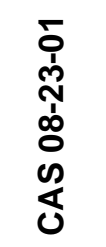 & 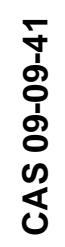 & 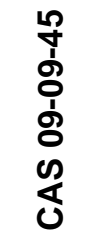 & 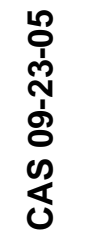 & 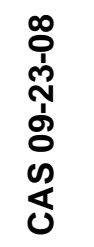 & 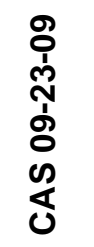 & 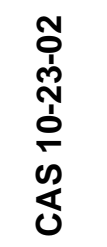 & 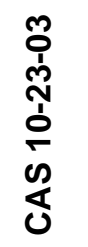 & 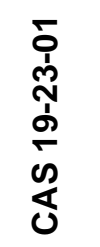 & 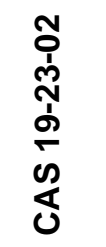 & 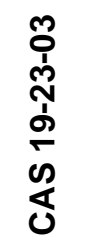 & 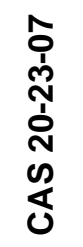 \\
\hline 1,1,1-Trichloroethane & $\mathrm{mg} / \mathrm{kg}$ & 0.856 & 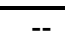 & 2.43 & 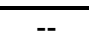 & 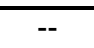 & 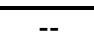 & 0.649 & $\overline{-1-}$ & 0.342 & 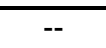 & 3.34 & 3.39 \\
\hline 1,2,4-Trimethylbenzene & $\mathrm{mg} / \mathrm{kg}$ & -- & -- & 0.36 & -- & -- & -- & & -- & -- & -- & -- & -- \\
\hline 2-Butanone & $\mathrm{mg} / \mathrm{kg}$ & 1.9 & -- & 47.1 & 3.1 & -- & -- & 3.92 & -- & -- & -- & -- & -- \\
\hline 2-Hexanone & $\mathrm{mg} / \mathrm{kg}$ & -- & -- & 10.2 & -- & -- & -- & -- & -- & 10.3 & -- & -- & -- \\
\hline 4-Methyl-2-Pentanone & $\mathrm{mg} / \mathrm{kg}$ & -- & -- & 3.56 & -- & -- & -- & -- & -- & -- & -- & -- & -- \\
\hline Acetone & $\mathrm{mg} / \mathrm{kg}$ & 5.26 & -- & 494 & 18.9 & -- & -- & 53.7 & -- & 8.05 & 5.62 & -- & -- \\
\hline Total PCBs ${ }^{a}$ & $\mathrm{mg} / \mathrm{kg}$ & 1.86 & -- & -- & 3.44 & -- & 1.8 & 1230 & 1.6 & 22.7 & 6.4 & 21.7 & 97.7 \\
\hline Arsenic & $\mathrm{mg} / \mathrm{kg}$ & 13.7 & -- & 5.9 & 6.4 & 4.5 & 7 & 17.6 & 13 & 6.3 & 6.8 & 2.1 & 5.6 \\
\hline Barium & $\mathrm{mg} / \mathrm{kg}$ & 675 & -- & 242 & 354 & 151 & 181 & 249 & 161 & 176 & 368 & 276 & 219 \\
\hline Beryllium & $\mathrm{mg} / \mathrm{kg}$ & 1.3 & -- & 0.84 & 0.61 & 0.61 & 0.51 & 0.99 & 0.96 & 0.97 & 1.2 & 0.38 & 0.59 \\
\hline Bis(2-Ethylhexyl)Phthalate & $\mathrm{mg} / \mathrm{kg}$ & 101 & -- & 221 & -- & -- & 118 & -- & 588 & 363 & 301 & -- & 1800 \\
\hline Butylbenzylphthalate & $\mathrm{mg} / \mathrm{kg}$ & -- & -- & -- & -- & -- & -- & -- & 70.5 & -- & -- & -- & -- \\
\hline Cadmium & $\mathrm{mg} / \mathrm{kg}$ & 0.32 & -- & 0.88 & 0.13 & 0.11 & 0.17 & 0.3 & -- & 0.24 & 0.37 & 6.5 & 1.8 \\
\hline Chlorform & $\mathrm{mg} / \mathrm{kg}$ & 0.42 & -- & 0.723 & -- & -- & -- & 0.395 & -- & 0.27 & 0.261 & -- & -- \\
\hline Chromium & $\mathrm{mg} / \mathrm{kg}$ & 19.7 & -- & 11.1 & -- & 6.5 & 7.2 & 16.1 & 11.3 & 8.7 & 10.8 & 5.4 & 16.4 \\
\hline Diesel-Range Organics & $\mathrm{mg} / \mathrm{kg}$ & 153 & -- & 380 & 104 & 7.67 & 26.4 & 205 & 20.2 & 382 & 12.9 & 2220 & 4050 \\
\hline Di-N-Butylphthalate & $\mathrm{mg} / \mathrm{kg}$ & -- & -- & -- & -- & -- & -- & -- & 74.9 & 68.1 & -- & -- & -- \\
\hline Ethylbenzene & $\mathrm{mg} / \mathrm{kg}$ & -- & -- & -- & -- & -- & -- & 0.264 & -- & -- & -- & -- & -- \\
\hline
\end{tabular}


Table H.1-1

Maximum Reported Value for Tier 1 Comparison

(Page 2 of 3 )

\begin{tabular}{|c|c|c|c|c|c|c|c|c|c|c|c|c|c|}
\hline \multirow[b]{2}{*}{ Parameter } & \multirow[b]{2}{*}{ Units } & \multicolumn{12}{|c|}{ Maximum Reported Value } \\
\hline & & 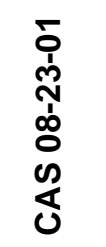 & 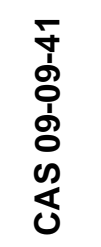 & 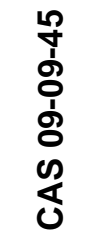 & 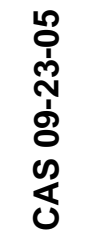 & 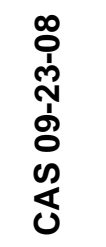 & 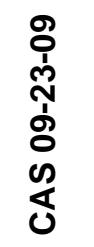 & 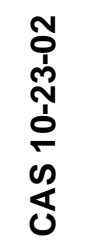 & 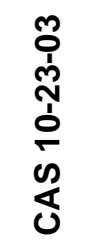 & 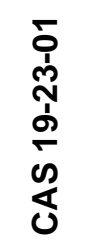 & 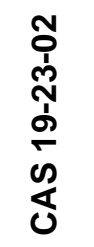 & 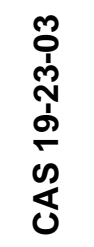 & 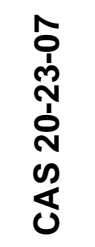 \\
\hline Fluoranthene & $\overline{\mathrm{mg} / \mathrm{kg}}$ & 39.4 & $\overline{---}$ & 41.4 & 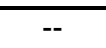 & $\overline{-1-}$ & 36.5 & 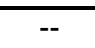 & $\overline{-1-}$ & 75.1 & 41.5 & 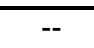 & $\overline{---}$ \\
\hline Lead & $\mathrm{mg} / \mathrm{kg}$ & 381 & -- & 136 & 47.9 & 9.1 & 10.5 & 38.5 & 62 & 15.2 & 20.4 & 223 & 39.4 \\
\hline Mercury & $\mathrm{mg} / \mathrm{kg}$ & 0.066 & -- & 0.029 & 0.016 & 0.027 & 0.045 & 0.043 & 0.053 & 0.033 & 0.032 & 0.011 & 0.016 \\
\hline Phenanthrene & $\mathrm{mg} / \mathrm{kg}$ & -- & -- & -- & -- & -- & 15.9 & -- & -- & 32.6 & -- & -- & -- \\
\hline Pyrene & $\mathrm{mg} / \mathrm{kg}$ & -- & -- & -- & -- & -- & 56.6 & -- & -- & 200 & -- & -- & -- \\
\hline Selenium & $\mathrm{mg} / \mathrm{kg}$ & 1.4 & -- & -- & 0.83 & 0.67 & 0.82 & 1.1 & 1.2 & -- & 0.85 & -- & -- \\
\hline Silver & $\mathrm{mg} / \mathrm{kg}$ & 0.24 & -- & 9 & 0.11 & 0.21 & 1.3 & 3.4 & 0.22 & 0.62 & 7.7 & -- & 0.12 \\
\hline Styrene & $\mathrm{mg} / \mathrm{kg}$ & 0.412 & -- & 0.259 & 0.503 & -- & -- & 0.305 & -- & 0.541 & -- & -- & -- \\
\hline Actinium-228 & $\mathrm{pCi} / \mathrm{g}$ & 1.73 & 1.61 & 2.37 & 2.01 & 2.22 & 1.33 & 1.93 & 2.16 & 2.85 & 2.27 & 2.23 & 1.65 \\
\hline Americium-241 & $\mathrm{pCi} / \mathrm{g}$ & -- & 0.609 & 3.21 & -- & 0.359 & 2.9 & 0.474 & 0.669 & -- & -- & -- & -- \\
\hline Cesium-137 & $\mathrm{pCi} / \mathrm{g}$ & 1.49 & 0.781 & 4.15 & 0.342 & 0.536 & 1.42 & 3.74 & 1.88 & -- & -- & -- & 0.673 \\
\hline Cobalt-60 & $\mathrm{pCi} / \mathrm{g}$ & -- & 0.635 & 0.318 & -- & -- & -- & -- & -- & -- & -- & -- & -- \\
\hline
\end{tabular}


Table H.1-1

Maximum Reported Value for Tier 1 Comparison

(Page 3 of 3 )

\begin{tabular}{|c|c|c|c|c|c|c|c|c|c|c|c|c|c|}
\hline \multirow[b]{2}{*}{ Parameter } & \multirow[b]{2}{*}{ Units } & \multicolumn{12}{|c|}{ Maximum Reported Value } \\
\hline & & 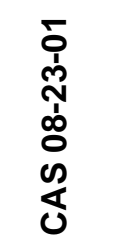 & 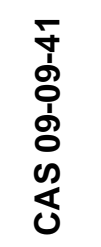 & 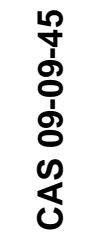 & 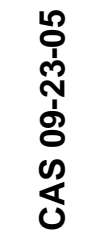 & 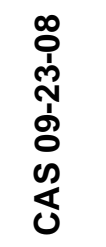 & 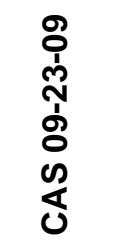 & 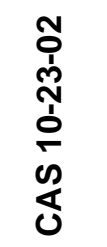 & 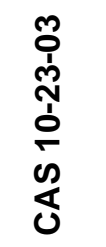 & 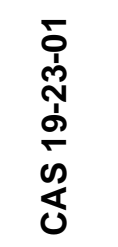 & 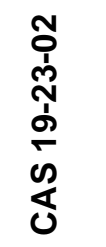 & 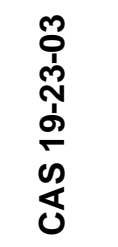 & 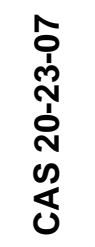 \\
\hline Europium-152 & $\overline{\mathrm{pCi} / \mathrm{g}}$ & $\overline{---}$ & 53.1 & 37.1 & $\overline{---}$ & 4.45 & 2.01 & $\overline{---}$ & $\overline{---}$ & $\overline{---}$ & $\overline{---}$ & $\overline{---}$ & $\overline{---}$ \\
\hline Europium-154 & $\mathrm{pCi} / \mathrm{g}$ & -- & 1.81 & 1.82 & -- & -- & -- & -- & -- & -- & -- & -- & -- \\
\hline Lead-212 & $\mathrm{pCi} / \mathrm{g}$ & 1.81 & 1.49 & 1.95 & 1.94 & 1.95 & 1.37 & 1.66 & 2.24 & 2.85 & 2.45 & 2.4 & 1.71 \\
\hline Lead-214 & $\mathrm{pCi} / \mathrm{g}$ & 1.23 & 1.05 & 1.47 & 1.81 & 1.25 & 1.07 & 1.23 & 1.33 & 1.95 & 1.72 & 1.41 & 1.08 \\
\hline Plutonium-238 & $\mathrm{pCi} / \mathrm{g}$ & -- & -- & 0.569 & 0.165 & -- & 0.169 & 2.43 & 0.218 & -- & -- & -- & -- \\
\hline Plutonium-239/240 & $\mathrm{pCi} / \mathrm{g}$ & 0.0935 & 1.25 & 32.3 & 4.49 & 0.773 & 10.5 & 6.44 & 0.836 & $\begin{array}{l}- \\
-\end{array}$ & -- & 0.0649 & -- \\
\hline Strontium-90 & $\mathrm{pCi} / \mathrm{g}$ & -- & 0.677 & 1.45 & -- & -- & -- & 0.47 & -- & -- & -- & -- & -- \\
\hline Thallium-208 & $\mathrm{pCi} / \mathrm{g}$ & 0.652 & 0.548 & 0.651 & 0.665 & 0.619 & 0.453 & 0.673 & 0.617 & 0.984 & 0.939 & 0.737 & 0.639 \\
\hline Uranium-233/234 & $\mathrm{pCi} / \mathrm{g}$ & 1.08 & 1.09 & 1.77 & 1.8 & 1.54 & 0.768 & 1.15 & 1.12 & 1.66 & 1.22 & 1.32 & 1.05 \\
\hline Uranium-235/236 & $\mathrm{pCi} / \mathrm{g}$ & 0.116 & -- & 0.143 & 0.186 & 0.108 & 0.0768 & -- & -- & 0.0987 & -- & 0.134 & -- \\
\hline Uranium-238 & $\mathrm{pCi} / \mathrm{g}$ & 1.12 & 1 & 1.43 & 1.62 & 1.9 & 0.733 & 1.25 & 1.16 & 2.15 & 1.46 & 1.46 & 1.06 \\
\hline
\end{tabular}

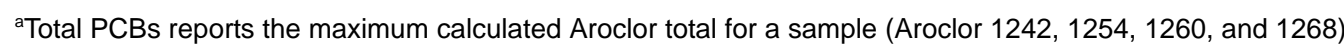

$\mathrm{mg} / \mathrm{kg}=$ Milligrams per kilogram

$\mathrm{PCB}=$ Polychlorinated biphenyl

$\mathrm{pCi} / \mathrm{g}=$ Picocuries per gram

$\mu \mathrm{g} / \mathrm{kg}=$ Micrograms per kilogram

-- = Not detected above preliminary action levels 


\section{H.1.3 C. Site Classification and Initial Response Action}

The four major site classifications listed in Table 3 of the ASTM Standard are: (1) immediate threat to human health, safety, and the environment; (2) short-term (0 to 2 years) threat to human health, safety, and the environment; (3) long-term (greater than 2 years) threat to human health, safety, or the environment; and (4) no demonstrated long-term threats. Based on the results of the CAI, no CASs present an immediate threat to human health, safety, and the environment; therefore, no interim response actions are necessary at these sites. All 12 CASs are determined to be Classification 4 sites as defined by ASTM Method E 1739-95 (ASTM, 1995) and pose no demonstrated near- or long-term threats.

\section{H.1.4 D. Development of Tier 1 Look-Up Table of RBSLS}

Tier 1 action levels have been defined as the PALs established during the DQO process. The PALs are a tabulation of chemical-specific (but not site-specific) screening levels based on the type of media (soil) and potential exposure scenarios (industrial). These are very conservative estimates of risk, are preliminary in nature, and are used as action levels for site screening purposes. Although the PALs are not intended to be used as FALs, a FAL may be defined as the Tier 1 action level (i.e., PAL) value if individual contaminant analytical results are below the corresponding Tier 1 action level value. The FAL may also be established as the Tier 1 action level value if individual contaminant analytical results exceed the corresponding Tier 1 action level value and implementing a corrective action based on the FAL level is practical. The PALs are defined as:

- EPA Region 9 Risk-Based PRGs for Industrial Soils (2004).

- Background concentrations for RCRA metals will be evaluated when natural background exceeds the PAL, as is often the case with arsenic. Background is considered the mean plus two times the standard deviation based on data published in Mineral and Energy Resource Assessment of the Nellis Air Force Range (NBMG, 1998; Moore, 1999). 
- TPH concentrations above the action level of $100 \mathrm{mg} / \mathrm{kg}$ per NAC 445A.2272 (NAC, 2006c).

- For COPCs without established preliminary remediation goals (PRGs), a protocol similar to EPA Region 9 will be used to establish an action level; otherwise, an established PRG from another EPA region may be chosen.

- The PALs for material, equipment, and structures with residual surface contamination are the allowable total residual surface contamination values for unrestricted release of material and equipment listed in the DOE Order 5400.5 (DOE, 1993), which is also Table 4-2 of the NV/YMP RadCon Manual (NNSA/NSO, 2004).

- The PALs for radioactive contaminants are based on the NCRP Report No. 129 recommended screening limits for construction, commercial, industrial land-use scenarios (NCRP, 1999) scaled to 25-millirem-per-year dose constraint (Appenzeller-Wing, 2004) and the generic guidelines for residual concentration of radionuclides in DOE Order 5400.5 (DOE, 1993).

The PALs were developed based on an industrial scenario. Because the CAU 177 CASs are not assigned work stations and are considered to be in occasional use areas, the use of industrial reuse based PALs is conservative. The Tier 1 lookup table is defined as the PAL concentrations or activities defined in the CAU 177 SAFER Plan (NNSA/NSO, 2006b).

\section{H.1.5 E. Exposure Pathway Evaluation}

The DQOs stated that site workers would only be exposed to COCs through oral ingestion, inhalation, external radiation, or dermal contact (absorption) due to exposure to potentially contaminated media (i.e., soil) at the CASs. The limited migration of contaminants, elapsed time since the suspected releases, and depth to groundwater supports the selection and evaluation that surface and shallow subsurface contact with soil are the only complete exposure pathways.

\section{H.1.6 F. Comparison of Site Conditions with Tier 1 RBSLs}

All analytical results of contaminants associated with releases from CAU 177 were below their corresponding Tier 1 action levels (i.e., PALs) except those listed in Table H.1-2. Corrective Action Sites 09-23-08, 09-23-09, 09-09-41, 10-23-03, and 19-23-02 had no contaminants associated with releases from CAU 177 detected above PALs. 
Table H.1-2

COPCs Detected Above PALs at CAU 177

\begin{tabular}{|c|c|c|}
\hline Corrective Action Site & TPH-DRO & Aroclor 1254 \\
\hline \hline $08-23-01$ & $\mathrm{X}$ & -- \\
\hline $09-09-45$ & $\mathrm{X}$ & -- \\
\hline $09-23-05$ & $\mathrm{X}$ & -- \\
\hline $10-23-02$ & $\mathrm{X}$ & $\mathrm{X}$ \\
\hline $19-23-01$ & $\mathrm{X}$ & -- \\
\hline $19-23-03$ & $\mathrm{X}$ & -- \\
\hline $20-23-07$ & $\mathrm{X}$ & -- \\
\hline
\end{tabular}

COPC = Contaminant of potential concern

DRO = Diesel-range organics

$\mathrm{PAL}=$ Preliminary action level

$\mathrm{TPH}=$ Total petroleum hydrocarbons

$--=$ COPC not detected above PAL

$\mathrm{X}=\mathrm{COPC}$ detected above PAL

\section{H.1.7 G. Evaluation of Tier 1 Results}

For all contaminants at all CASs not listed in Table H.1-2, the FALs were established as the Tier 1 RBSLs. It was determined that no further action is required for these contaminants at these CASs. The NNSA/NSO determined that remediation of the remaining contaminants listed in Table H.1-2 was not practical; therefore, a Tier 2 SSTL will be calculated for TPH-DRO and Aroclor 1254.

\section{H.1.8 H. Tier 1 Remedial Action Evaluation}

It was determined that remediation of TPH-DRO and PCB contamination at the CASs identified in Table H.1-2 to Tier 1 action levels is not practical; therefore, these constituents were moved to a Tier 2 evaluation to establish a SSTL.

\section{H.1.9 I. Tier 2 Evaluation}

No additional data were needed to complete a Tier 2 evaluation. 


\section{H.1.10 J. Development of Tier 2 Table of SSTLS}

\section{Evaluation of TPH-DRO SSTLS}

Method E1739-95 stipulates that risk evaluations for TPH-DRO contamination be calculated and evaluated based on the risk posed by the potentially hazardous constituents of TPH-DRO.

Section 6.4.3 (“Use of Total Petroleum Hydrocarbon Measurements”) of ASTM Method E 1739-95 states: “TPHs should not be used for risk assessment because the general measure of TPH-DRO provides insufficient information about the amounts of individual chemical(s) of concern present” (see also Sections X1.5.4 and X1.42 of Method E1739-95 in ASTM, 1995). Therefore, the individual potentially hazardous constituents in TPH-DRO were compared to corresponding Tier 2 SSTLs to evaluate the need for corrective action at each CAS with TPH-DRO listed in Table H.1-2. For CAU 177, the Tier 2 SSTLs for the potentially hazardous constituents in TPH-DRO were established at the corresponding Tier 1 (i.e., PAL) concentrations.

\section{Evaluation of PCB SSTLS}

Aroclor 1254 detected in a soil sample at the "west" cellar of CAS 10-23-02 did not exceed the Tier 2 RBCA criteria of being present a reasonable point of exposure (NNSA/NSO, 2006a). Therefore, it is not considered to be a COC. Justification that Aroclor 1254 is not present at a reasonable point of exposure includes the following:

- Aroclor 1254 contamination is at depth and covered by $8 \mathrm{ft}$ of backfilled soil. A receptor would only be exposed to contamination if the buried soils were to be excavated, which is not expected.

- Migration of contaminants is limited laterally by the presence of a metal corrugated metal casing.

- Migration of contaminants is limited vertically by the presence of a concrete cellar bottom.

- The presence of a borehole within the cellar will prevent future use of the cellar component of the CAS and serves in part as a use restriction.

- According to the Borehole Management Project, the borehole (U-10am \#3 PS \#1A) associated with the west cellar is on the current list for plugback candidates; however, no plugback work has been scheduled (Gustafson, 2006). Because plugback activities would only involve excavating soil to the depth of the riser casing (typically 3 to $4 \mathrm{ft}$ above the cellar floor), the soil interval sampled as part of this investigation is not expected to be disturbed; therefore, there is little potential for future exposure. To ensure that the soil containing Aroclor 1254 
will not be disturbed, the Borehole Management Project will be informed of the results of the investigation at CAS 10-23-02.

- The CAS is currently located within a fenced area that is posted as an URMA.

\section{H.1.11 K. Comparison of Site Conditions with Tier 2 Table SSTLS}

None of the hazardous constituents of diesel were detected at any CAS at concentrations that exceeded the established Tier 2 SSTLs and the Aroclor 1254 detected at CAS 10-23-02 did not exceed the Tier 2 RBCA criteria of being present as a reasonable point of exposure.

\section{H.1.12 L. Tier 2 Remedial Action Evaluation}

Based on the Tier 2 evaluation of the TPH-DRO hazardous constituents, the TPH-DRO does not pose an unacceptable risk to human health and the environment. Therefore, no further action concerning TPH-DRO is required at the CASs within CAU 177. Based on the Tier 2 evaluation of Aroclor 1254 at CAS 10-23-03, it was determined that there is no exceedance at reasonable points of exposure (NNSA/NSO, 2006a); therefore, the PCB does not pose an unacceptable risk to human health and the environment, and no further action is required at this CAS.

As all contaminant FALs were established as Tier 1 or Tier 2 action levels, a Tier 3 evaluation was not necessary. 


\section{H.2.0 Recommendations}

As all of the site contaminant concentrations in soils from the analysis of CAU 177 samples were less than the corresponding FALs at all locations, it was determined that these sites do not pose a significant risk to human health or the environment and, therefore, do not warrant corrective actions.

The Eu-152 contamination detected at CASs 09-09-41 and 09-09-45 and the Pu-239 contamination detected at CAS 09-09-45 are not associated with a release from these CASs. This contamination will be further evaluated by the Soils Project CASs 09-99-01 and 09-23-14 in CAU 105. 


\section{H.3.0 References}

ASTM, see American Society for Testing and Materials.

American Society for Testing and Materials. 1995. Standard Guide for Risk-Based Corrective Action Applied at Petroleum Release Sites, Method E 1739-95 (Reapproved 2002). Philadelphia, PA.

Appenzeller-Wing, J., U.S. Department of Energy, National Nuclear Security Administration Nevada Site Office. 2004. Letter to T.A. Maize (NDEP) entitled, "Submittal of Proposed Radiological Preliminary Action Levels (PALs) for the Industrial Sites Project,” 15 January. Las Vegas, NV.

DOE, see U.S. Department of Energy.

EPA, see U.S. Environmental Protection Agency.

Gustafson, D., National Security Technologies, LLC. 2006. Email to N. Nastanski (SNJV) concerning CAU 177 Boreholes, 6 February. Las Vegas, NV.

Moore, J., Science Applications International Corporation. 1999. Memorandum to M. Todd (SAIC), “Background Concentrations for NTS and TTR Soil Samples,” 3 February. Las Vegas, NV.

NAC, see Nevada Administrative Code

NBMG, see Nevada Bureau of Mines and Geology.

NCRP, see National Council on Radiation Protection and Measurements.

National Council on Radiation Protection and Measurements. 1999. Recommended Screening Limits for Contaminated Surface Soil and Review of Factors Relevant to Site-Specific Studies, NCRP Report No. 129. Bethesda, MD.

Nevada Administrative Code. 2006a. NAC 445A.227, “Contamination of Soil: Order by Director for Corrective Action; Factors To Be Considered in Determining Whether Corrective Action Required.” Carson City, NV.

Nevada Administrative Code. 2006b. NAC 445A.22705, “Contamination of Soil: Evaluation of Site by Owner or Operator; Review of Evaluation by Division.” Carson City, NV.

Nevada Administrative Code. 2006c. NAC 445A.2272, “Contamination of Soil: Establishment of Action Levels.” Carson City, NV.

Nevada Bureau of Mines and Geology. 1998. Mineral and Energy Resource Assessment of the Nellis Air Force Range, Open-File Report 98-1. Reno, NV. 
U.S. Department of Energy. 1993. Radiation Protection of the Public and the Environment, DOE Order 5400.5, Change 2. Washington, DC.

U.S. Department of Energy, National Nuclear Security Administration Nevada Site Office. 2004. NV/YMP Radiological Control Manual, DOE/NV/11718--079. Las Vegas, NV.

U.S. Department of Energy, National Nuclear Security Administration Nevada Site Office. 2006a. Industrial Sites Project Establishment of Final Action Levels. February. Las Vegas, NV.

U.S. Department of Energy, National Nuclear Security Administration Nevada Site Office. 2006b. Streamlined Approach for Environmental Restoration (SAFER) Plan for Corrective Action Unit 177: Mud Pits and Cellars, Nevada Test Site, Nevada, Rev. 0, DOE/NV--1126.

Las Vegas, NV.

U.S. Environmental Protection Agency. 2004. Region 9 Preliminary Remediation Goals (PRGs). As accessed at http://www.epa.gov/region09/waste/sfund/prg/index.htm 15 November 2006. 


\title{
Appendix I
}

\section{Nevada Division of Environmental Protection Comments}

\author{
(1 Page)
}




\section{NEVADA ENVIRONMENTAL RESTORATION PROJECT DOCUMENT REVIEW SHEET}

\begin{tabular}{|c|c|}
\hline $\begin{array}{ll}\text { 1. Document Title/Number: } & \text { Draft Closure Report for Corrective Action Unit 177: Mud Pits and } \\
& \text { Cellars, Nevada }\end{array}$ & 2. Document Date: $\quad 02 / 07 / 2007$ \\
\hline 3. Revision Number: 0 & 4. Originator/Organization: Stoller-Navarro \\
\hline 5. Responsible NNSA/NV ERP Project Manager: Peter Sanders & 6. Date Comments Due: 02/05/2007 \\
\hline 7. Review Criteria: Full & \\
\hline 8. Reviewer/Organization/Phone No: John Wong, NDEP, 486-2850 & 9. Reviewer's Signature: \\
\hline
\end{tabular}

\begin{tabular}{|c|c|c|c|c|}
\hline $\begin{array}{l}\text { 10. Comment } \\
\text { Number/Location }\end{array}$ & 11. Type* & 12. Comment & 13. Comment Response & $\begin{array}{c}14 . \\
\text { Accept }\end{array}$ \\
\hline 1.) & & $\begin{array}{l}\text { NDEP reviewed the Draft Closure Report for Corrective } \\
\text { Action Unit 177: Mud Pits and Cellars, and had no } \\
\text { comments to this document. }\end{array}$ & & \\
\hline
\end{tabular}




\section{Library Distribution List}

\section{$\underline{\text { Copies }}$}

U.S. Department of Energy

National Nuclear Security Administration

Nevada Site Office

Technical Library

P.O. Box 98518, M/S 505

Las Vegas, NV 89193-8518

U.S. Department of Energy

Office of Scientific and Technical Information

P.O. Box 62

Oak Ridge, TN 37831-0062

Southern Nevada Public Reading Facility

c/o Nuclear Testing Archive

P.O. Box 98521, M/S 400

Las Vegas, NV 89193-8521

Manager, Northern Nevada FFACO

Public Reading Facility

c/o Nevada State Library \& Archives

100 N Stewart Street

Carson City, NV 89701-4285
1 (Uncontrolled, electronic copy)

1 (Uncontrolled, electronic copy)

2 (Uncontrolled, electronic copies)

1 (Uncontrolled, electronic copy) 